\title{
MAGNESIUM ALLOY STRIP PRODUCED BY A MELT-CONDITIONED TWIN ROLL CASTING PROCESS
}

A Thesis submitted to Brunel University for the Degree of DOCTOR OF PHILOSOPHY

BY

\section{IMAN BAYANDORIAN}

Brunel Centre for Advanced Solidification Technology (BCAST)

School of Engineering and Design

Brunel University

Uxbridge

UB8 3PH

United Kingdom

MARCH 2010 


\section{ABSTRACT}

Twin roll casting (TRC) offers a promising route for the economic production of $\mathrm{Mg}$ sheet, but unfortunately, it produces strip with coarse and non-uniform microstructures and severe centre line segregation. Recently, a novel magnesium strip casting process termed melt conditioned twin roll casting (MC-TRC) was developed that, compared with the conventional TRC process, emphasizes solidification control at the casting stage rather than hot rolling. This was achieved by melt conditioning under intensive forced convection prior to twin roll casting resulting in enhanced heterogeneous nucleation followed by equiaxed growth. In this study the development of TRC and MC-TRC processes and a microstructural comparison of the MC-TRC Mg-alloy strip with that of conventional TRC strip, have been investigated. Emphasis has been focused on the solidification behaviour of the intensively sheared liquid metal, and on the mechanisms for microstructural refinement and compositional uniformity in the MCTRC process. The results of the process development indicate that the MC-TRC process reduces considerably or eliminates defects such as the centre line segregation, voids and cracks at or near the strip surface that are always present in conventional TRC strip.

The newly-designed homogenization treatment investigated for TRC and MC-TRC magnesium alloy strips was based on microstructural evolution obtained during heat treatment. The results of the MC-TRC strips showed a much faster recrystallization rate with finer recrystallized grains, which are due to more homogeneous and a finer grain size of the as-cast MC-TRC strips compared with the as-cast TRC strips.

During down-stream processing, the effects of MC-TRC process on microstructural evolution of hot-rolled magnesium strips have been understood thoroughly by accurate control of the hot-rolling procedure during each step of strip thickness reduction. This study indicates that the MC-TRC strip requires fewer rolling steps when compared to TRC strip, thus offering reduced processing cost and carbon footprint. Mechanical properties at room temperature of MC-TRC as-cast and rolled sheets are much improved when compared with the conventional TRC as-cast and rolled sheets which can result in a higher quality of final components. The mechanical properties at elevated temperature shows for the first time that the higher elongation and lower yield strength of MC-TRC as-cast strips at a temperature close to its optimised hot-rolling temperature results in better ability for rolling and higher ductility of MC-TRC Mg strip compared with the TRC Mg strip. 


\section{LIST OF PUBLICATIONS}

1. I. Bayandorian, Z. Bian, M. Xia, H. Zhang, G.M. Scamans, Z. Fan, “Magnesium Alloy Strip Produced by Melt Conditioned Twin Roll Casting (MCTRC) Process", in: TMS 2009 Annual Meeting \& Exhibition, San Francisco, California, USA, February 15-19, 2009, p. 363-368.

2. I. Bayandorian, M. Xia, R. Keyte, G.M. Scamans, Z. Fan:, "Microstructure and Mechanical Properties of Melt Conditioned Twin Roll Cast AZ31 Alloy Strip”, in: $8^{\text {th }}$ International Conference on Magnesium Alloys and their Applications, Weimar, Germany, 26-29 Oct, 2009, in press.

3. Z. Bian, I. Bayandorian and Z. Fan, "Extremely Fine and Uniform Microstructure of Magnesium AZ91D Alloy Sheets Produced by Melt Conditioned Twin Roll Casting", Materials Science and Technology, 2009, 280, p. 599-606.

4. Z. Bian, I. Bayandorian, H.W. Zhang, and Z. Fan, "Twin Roll Casting and Melt Conditioned Twin-roll Casting of Magnesium", Solid State Phenomena, 2008, 141-143, p.195-200.

5. H.W. Zhang, L.J. Cao, Z. Bian, I. Bayandorian, Z. Fan, "Melt Conditioned Twin Roll Casting (MC-TRC) process for wrought Aluminium alloy strips", in: Aluminium Alloys: their physical and mechanical properties, Ed. J. Hirsch et al., 2008, p. 421-426.

6. Z. Fan, M. Xia, H. Zhang, G. Liu, J.B. Patel, Z. Bian, I. Bayandorian, Y. Wang, H.T. Li, and G.M. Scamans, "Melt Conditioning by Advanced Shear Technology (MCAST) for Refining Solidification Microstructures", International Journal of Cast Metals Research, 2009, 22, p. 103-107. 
7. I. Bayandorian, H. Men, M. Xia, G.M. Scamans, Z. Fan, "Magnesium alloy strip produced by melt conditioned twin roll casting (MC-TRC) process", to be submitted to Acta Materialia, 2010.

8. I. Bayandorian, M. Xia, R. Keyte, G.M. Scamans, Z. Fan; “Microstructural evolution and mechanical properties of melt conditioned twin roll cast magnesium alloys strips during down-stream processing", to be submitted to Acta Materialia, 2010. 


\section{ACKNOWLEDGEMENTS}

My thanks and appreciation go to my supervisor, Prof. Zhongyun Fan for helping me with my work with patience throughout the time it took me to complete my research, whose encouragement, guidance and support from the initial to the final level enabled me to develop an understanding of the project.

I would like to show my gratitude to Dr. Hari Babu Nadendla, Prof. Brian Ralph, Mr. Richard Keyte, Prof. Geoff Scamans, Prof. John Hunt, Dr. Hua Men and Dr. Phil Bradbury for their supportive guidance in conducting the research work, preparing this thesis and for many inspiring discussions.

I wish to thank colleagues who have supported me especially Dr. Mingxu Xia, Dr. Kumar Sundaram, Dr. Yubo Zuo, Dr. Huawei Zhang, Mr. Stephen Cook, Mr. Peter Lloyd and Mr. Carmelo Nunez for their assistance and technical knowledge throughout the project that immensely helped in conducting the experimental work.

I owe my deepest gratitude to, EPSRC for financial support to conduct this research work, Brunel Centre for Advanced Solidification Technology (BCAST) and Innoval Technology Limited for all the infrastructural support, Imperial College of London for their materials processing facilities and the Experimental Techniques Centre (ETC) Brunel for providing their services in electron microscopy analysis.

Lastly, I offer my regards and blessings to those who made this thesis possible such as my wife and my family who gave me the moral support I required during the completion of the project. 


\section{CONTENTS}

\section{ABSTRACT}

LIST OF PUBLICATIONS

ACKNOWLEDGMENTS

\section{CHAPTER 1 INTRODUCTION}

1.1. Background.

1.2. Objectives of the present study and investigation methodology. 4

\section{CHAPTER 2 LITERTATURE REVIEW}

2.1. Metallurgy of light metals - Magnesium alloys.......................... 6

2.1.1. Magnesium and magnesium alloy............................... 6

2.1.2. Microstructure of $\mathrm{Mg}-\mathrm{Al}$ alloys................................. 8

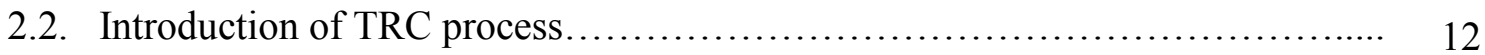

2.2.1. Moving mould casters........................................ 12

2.2.2. Current status of the strip casting of magnesium alloys.................. 14

2.3. Principles of the TRC process....................................... 17

2.3.1. Influence of casting parameters on strip characteristics................. 20

2.3.2. Mechanical behavior of the mushy zone............................ 23

2.3.2.1. Rheological behavior....................................... 23

2.3.2.2. Deformation behavior........................................ 24 
2.4. Cast strip quality.................................................. 27

2.5. As-cast microstructure and properties of TRC strip....................... 31

2.5.1. General solidification of metals................................. 31

2.5.2. General features of magnesium alloy strip-cast microstructures.......... 34

2.6. Down-stream processing of magnesium alloy strip......................... 37

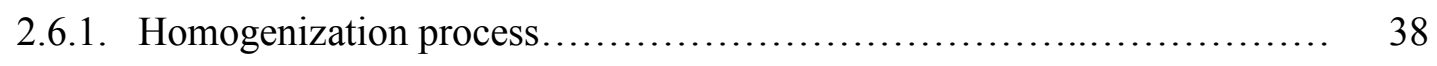

2.6.2. Hot rolling process........................................... 38

2.6.3. Annealing process............................................ 42

2.7. Technologies for production of grain-refined feedstock.................... 44

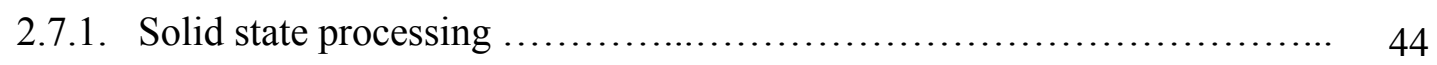

2.7.2. Liquid state processing ....................................... 47

2.7.3. Mechanisms for grain refinement under forced convection .............. 51

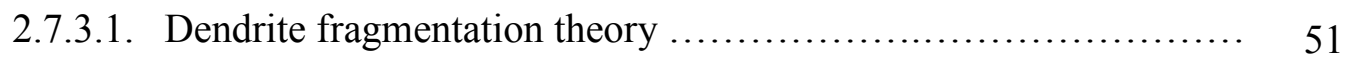

2.7.3.2. Dendrite remelting theory ................................ 52

2.7.3.3. Enhanced heterogeneous nucleation and growth controlled theory.. 52

\section{CHAPTER 3 EXPERIMENTAL PROCEDURES}

3.1. Materials preparation................................................... 55

3.1.1. Chemical composition analysis................................ 56

3.2. Strip-Casting processes......................................... 57

3.2.1. The Brunel University twin roll caster............................ 57

3.2.2. Melt conditioned twin roll casting (MC-TRC) process.................. 61

3.2.2.1. MCAST machine........................................... 62

3.2.3. Major casting parameters.................................... 67

3.3. Down-stream processing.............................................. 69

3.3.1. Homogenization treatment..................................... 69

3.3.2. Rolling and annealing processes............................... 69

3.4. Microstructure characterization...................................... 71

3.4.1. Metallographic sample preparation.............................. 71

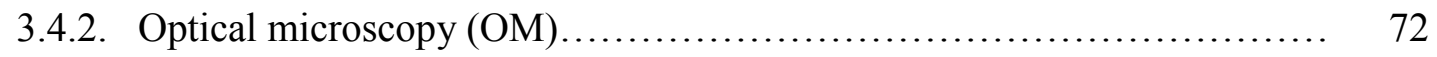


3.4.3. Scanning electron microscopy (SEM) .......................... 74

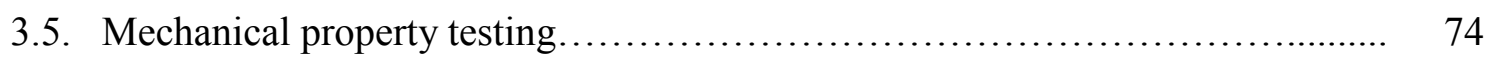

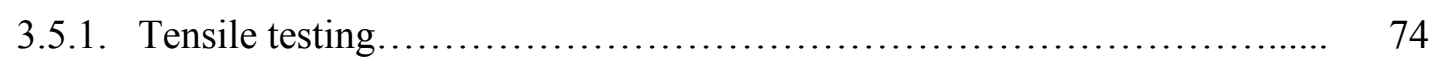

3.5.2. Vickers hardness measurements............................... 77

\section{CHAPTER 4 RESULTS-1}

4.1. Optimization of the TRC process.................................... 78

4.1.1. Pouring temperature......................................... 78

4.1.2. Casting speed................................................ 83

4.1.3. Tip setback ............................................... 86

4.1.4. Roll gap.................................................... 90

4.1.5. The selected processing parameters............................... 95

4.2. Optimization of the melt conditioned twin roll casting (MC-TRC) ............ 97

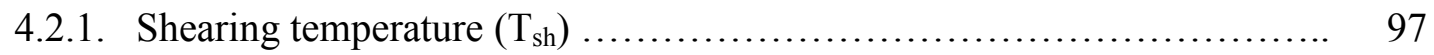

4.2.2. Shearing speed and shearing time................................ 101

4.2.3. Effect of tip setback............................................ 103

4.2.4. The selected processing parameters............................. 105

4.3. Comparison of microstructure and hardness between TRC and MC-TRC Mgalloy strips.................................................... 106

4.3.1. AZ91D Mg-alloy ............................................. 106

4.3.2. AZ31 Mg-alloy .................................................. 109

4.3.3. The nature of centre-line segregation ............................ 114

4.3.3.1. General characteristics ................................ 114

4.3.3.2. Phase identification .................................... 116

4.3.3.3. Hardness .............................................. 119

4.3.4. Stop-samples ................................................ 120

\section{CHAPTER 5 RESULTS-2}

5.1. Microstructure and mechanical properties of TRC and MC-TRC Mg-alloys during down-stream processing. 
5.1.1. Response to homogenization treatment ........................... 124

5.1.1.1. Effect of holding temperature ............................. 124

5.1.1.2. Effect of holding time ................................. 128

5.1.1.3. Nucleation sites for homogenization process ................. 132

5.1.2. Response to the hot rolling process .............................. 135

5.1.2.1. Effect of strain rate ..................................... 135

5.1.2.2. Effect of the hot rolling temperature ........................ 137

5.1.3. Mechanical properties of TRC and MC-TRC Mg-alloys during down-

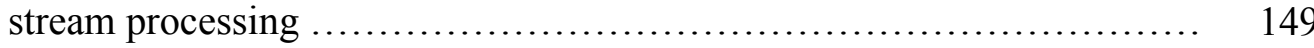

5.1.3.1. Macro-hardness tests ................................... 149

5.1.3.2. Tensile properties .................................... 150

\section{CHAPTER 6 DISCUSSION}

6.1. Solidification behaviour in the MC-TRC of magnesium alloys ................ 156

6.1.1. Nucleation under intensive forced convection....................... 156

6.1.2. Solidification behaviour of conditioned magnesium alloy melt ........... 161

6.1.3. Effect of casting parameters on microstructural evolution................. 163

6.2. Macro-segregation behaviour in TRC and MC-TRC processes .............. 167

6.2.1. Effect of grain size and its morphology............................. 168

6.2.2. Effect of casting parameters.................................... 170

6.2.3. Hot-tear formation......................................................... 171

6.3. Down-stream processing of magnesium alloy strip ....................... 173

6.3.1. Microstructural evolution at the homogenization stage.................. 173

6.3.2. Microstructural evolution at the hot rolling stage..................... 176

6.4. Mechanical properties of TRC and MC-TRC Mg-alloys .................... 178

6.4.1. Mechanical properties at room temperature........................ 178

6.4.2. Mechanical properties at elevated temperature....................... 183

6.4.3. Work hardening rate........................................... 184

CHAPTER 7 CONCLUSIONS ................................... 186 
CHAPTER 8 SUGGESTIONS FOR FURTHER WORK ....... 188

REFERENCES 


\section{LIST OF ABBREVIATIONS}

ABRC Alternate biaxial reverse corrugation

ARB Accumulative roll bonding

BCAST Brunel Centre for Advanced Solidification Technology

$\mathrm{CC} \quad$ Conventional continuous casting

CD Casting direction

CSIRO Commonwealth Scientific and Industrial Research Organisation

DC Direct chill casting

DRX Dynamic recrystallization

DSC Direct strip casting

DSR Differential speed hot-rolling

ECAE/ECAP Equal-channel angular extrusion or pressing

EDX Energy-dispersive X-ray spectroscopy

EMV Electromagnetic vibration

ETC Experimental Techniques Centre Brunel

HCP Hexagonal closed-packed

LS Longitudinal section

MCAST Melt conditioning by advanced shear technology

MC-TRC Melt conditioned twin roll casting

OM Optical microscopy

PD Planar direction

PFMS Planar-flow melt spinning

POSCO Pohang Iron and Steel Company

RD Rolling direction

RDX Rotation recrystallization

SEM Scanning electron microscopy 
SIBM Strain-induced grain boundary migration

SPD Severe plastic deformation

SRX Static recrystallization

SSM Semi-solid material

TS Transverse section

TRC Twin roll casting

XRD X-ray diffraction 


\section{CHAPTER 1}

\section{INTRODUCTION}

\subsection{Background}

Magnesium alloys have the potential to be candidates for replacing steel and other heavier materials, as they have good properties such as low density $\left(1.74 \mathrm{~g} \mathrm{~cm}^{-3}\right)$, particularly in some automotive applications, [Mordike and Lukáč 2006]. Magnesium sheet products offer a high-strength-to-weight ratio that makes them attractive for structural applications in the automotive, aerospace, electronics, healthcare and general engineering industries, [Polmear 2006]. However, conventional magnesium processing technologies are not effective for the commercially-viable manufacture of sheet and extruded sections. Increased penetration of wrought magnesium alloys into industrial applications is dependent upon developing improved process technologies that simplify the production route and enhance mechanical properties. Conventionally, magnesium alloy sheet products are produced by hot and cold rolling of large rolling blocks $\left(30 \times 1000 \times 2000 \mathrm{~mm}^{3}\right)$, which require repeated cycles of rolling and annealing, [Ferry 2006]. The rolling blocks have coarse grains and segregated microstructure, and the required repeated annealing and rolling is expensive and time consuming with a low metal yield. As a result the carbon footprint of the manufacturing process is very high.

Twin roll casting (TRC) has been an effective process for producing alloy strips. Sir Henry Bessemer patented a new design for metal-strip production in 1865 known as the TRC process, in which delivered molten metal (i.e. tin and lead alloy) from a holding furnace, was fed into the gap formed by the horizontally opposed water-cooled steel rolls 
to produce thin metal strip, [Bessemer 1865]. Regardless of this encouraging development, TRC of magnesium alloys is more difficult than other alloys, e.g. tin-lead alloys or aluminium alloys, since challenges like severe oxidation potential and costs and performance need to be met in order to commercialize the process. Recently TRC of magnesium alloy strip (i.e. $3 \mathrm{~mm}-6 \mathrm{~mm}$ in thickness) directly from a melt, has been developed to reduce the cost of strip production and the complications related to solid state deformation processing from large billets, [Liang and Cowley 2004]. TRC offers a more promising route for the economical production of magnesium sheet but unfortunately, it produces strip with a coarse and non-uniform microstructure, severe defects, and centre line segregation and poor surface quality, [Bian et al. 2009, Bayandorian et al. 2009].

TRC produces near-net-gauge strip and both a sound surface condition and internal quality are required since only limited secondary processing is available to alter these parameters, [Ferry 2006]. Internal and external defects may lead to cracking during subsequent rolling and forming. An obvious industrial challenge is to avoid the formation of defects or at least postpone their appearance to higher productivities. On a practical level, if the as-cast microstructure is segregation free it is likely that even critical end products can be made, [Thomas 2003, Forbord et al. 2006]. Therefore, there is a commercial need and a scientific challenge to overcome these problems. At the time of writing, there is very little published information on the development of the microstructure and properties of Mg alloys produced by the TRC process, [Kawalla et al. 2008, Kang et al. 2008]. Moreover, in order to improve the quality of the final gauge magnesium sheet produced by a twin roll casting process little effort has been devoted to develop down-stream processing cycles for magnesium thin strip production [Essadiqi et al. 2009, Kawalla et al. 2008, Duygulu et al. 2009a]. Previous research has shown that thin metallic strips produced by the 
TRC process, require various downstream processing cycles to manufacture highly formable strips, as the thin strips undergo different temperature and deformation gradients in the caster roll gap, [Sun et al. 2006, Bae et al. 2009, Birol 2009]. It is therefore of significant technological interest to develop suitable downstream processing cycles for the twin roll cast magnesium thin-strips.

Generally, the main limitations that restrict the application of wrought magnesium alloy sheets are poor ductility and sheet forming limits at ambient temperatures [Emley 1966]. This is a consequence of its hexagonal close-packed crystal structure which limits the number of operative slip systems at room temperature. However, before magnesium sheet can compete with current automotive sheet materials, it is required to improve its elevated temperature formability and room temperature mechanical properties [Essadiqi et al. 2009]. Previous research of diverse metallic alloys established that grain refinement could improve the strength and ductility at room temperature, [Koike et al. 2003, Chapman and Wilson 1962, Valiev et al. 1991, Matsubara et al. 2003, Yamashita et al. 2001]. In previous years the grain refinement of bulk $\mathrm{Mg}$ alloys was mainly achieved by severe plastic deformation (SPD) approaches. Nevertheless, these processes are unlikely to find widespread application, due to the small quantities of materials that can be obtained. Hence, significant investigations are still required to develop cost-effective $\mathrm{Mg}$ grain refinement techniques, [Del Valle et al. 2003, Barnett et al. 2009] 


\subsection{Objectives of the present study and investigation methodology}

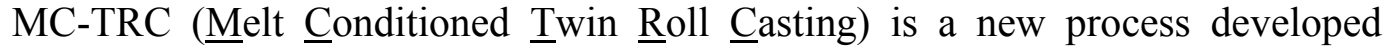
recently by BCAST at Brunel University [Fan et al. 1999, Fan et al. 2000], to overcome the disadvantages of the conventional TRC process, by conditioning the liquid metal prior to solidification processing in order to produce high quality grain-refined magnesium alloy thin-strips. This technology produces high quality strip by focusing on the control of

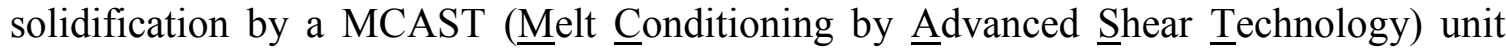
which feeds a twin roll caster. The MCAST unit consists of a twin screw device, in which a pair of co-rotating, fully intermeshing and self-wiping screws are rotating at high speed inside a heated barrel with precise temperature control. The especially-designed screws are able to provide a high shear rate and a high intensity of turbulence, [Ji and Fan 2002]. The conditioned melt is then supplied to a TRC machine for the direct production of high quality thin strip.

The MC-TRC is a cost-effective process that reduces processing steps, resulting in a significant saving in capital investment, operating cost and manpower compared with the conventional hot and cold rolling of the large rolling blocks route. The MCAST unit can be attached easily to different twin roll casters for the production of magnesium sheet for a wide range of alloys. High quality, lower cost magnesium sheet products could greatly facilitate the penetration of wrought magnesium alloys into transportation applications to provide both reduced fuel consumption and lower $\mathrm{CO}_{2}$ emissions.

This study aims to understand the scientific principles underpinning the development of the MC-TRC technology and the present study was initiated to explicate the effect of nucleation and nucleation control in developing a step-change technology on an 
industrial scale for the production of high quality magnesium alloys strip. The specific objectives of this study are:

1) To develop further the MC-TRC process as a step-change technology for the production of high quality magnesium alloy strip,

2) To understand the scientific principles underpinning the development of the MC-TRC technology,

3) To investigate the response of magnesium alloy strips produced by TRC and MCTRC processes to the newly-designed homogenization and annealing treatments and hot-rolling processes,

4) To further study the microstructural refinement of magnesium alloy sheets with the use of MC-TRC process associated with newly-designed annealing and hotrolling processes followed by evaluating the mechanical properties and heat treatability. 


\section{CHAPTER 2}

\section{LITERTAURE SURVEY}

\subsection{Metallurgy of Light metals - Magnesium alloys}

Magnesium and aluminium are referred to as 'light metals' because they are both regularly used to reduce the weight of components and structures. The lightness transforms directly to material property enhancement for several products since a decrease in density can cause the greatest weight reduction. This is a clear explanation to why light metals have been associated with transportation, especially aerospace, which during the last 50 years has provided significant motivation for the development of light alloys, [Polmear 2006].

\subsubsection{Magnesium and magnesium alloys}

Magnesium is available commercially with purities greater than $99.8 \%$ however it is barely used without being alloyed with other metals for engineering applications, [Polmear 2006, Greenfield 1972]. Magnesium with lattice parameters of $\mathrm{a}=0.3202 \mathrm{~nm}$ and $\mathrm{c}=0.5199 \mathrm{~nm}$ has a hexagonal close-packed (h.c.p) crystal structure, [Avedesian and Baker 1999]. At room temperature, plastic deformation of Mg crystal occurs generally by slip on the basal plane (0001) and in the close-packed $<11 \quad \overline{2} 0>$ directions. Secondary slip occurs in the $<11 \overline{2} 0>$ directions on the $\{10 \overline{10}\}$ vertical faces and by twinning on the pyramidal $\{10 \overline{12}\}$ planes, as seen in Figure 2.1. Above about $250^{\circ} \mathrm{C}$, additional 
pyramidal $\{10 \overline{1} 1\}$ and $\{11 \overline{2} 2\}$ slip planes become operative so that deformation becomes much easier and twinning is less important, [Polmear 2006, Mordike and Lukáč 2006].

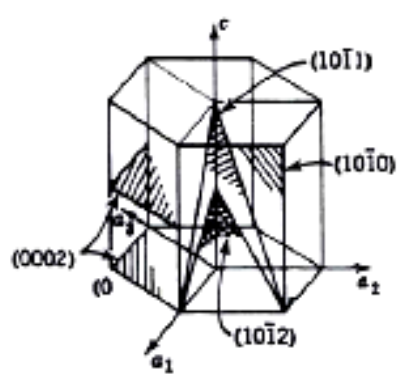

(1)

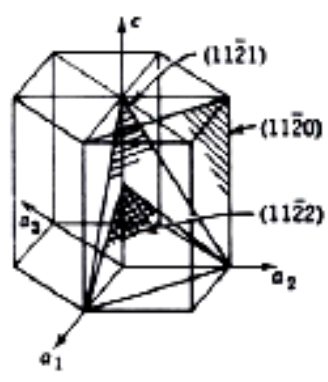

(II)

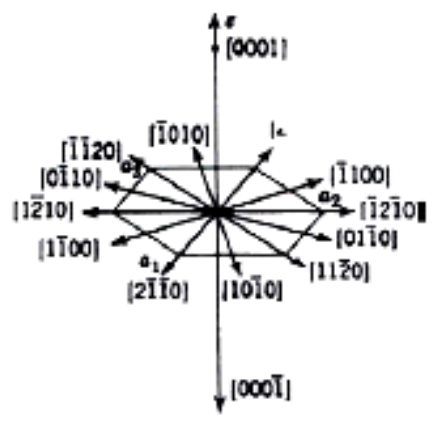

(III)

\section{Figure 2.1:}

Principal planes (I, II) and directions (III) in the magnesium hcp unit cell. [Polmear 2006]

The properties discussed above can lead to a hot-working process in order to produce wrought magnesium alloy products. The productions of wrought materials are generally conducted by extrusion, rolling and press forging at temperatures in the range $300-500^{\circ} \mathrm{C}$, [Polmear 2006].

There are different elements present in commercial Mg-alloys such as aluminium, zinc, cerium, silver, thorium, yttrium and zirconium. For both casting and wrought alloys for applications at ambient temperatures $\mathrm{Mg}-\mathrm{Al}-\mathrm{Zn}$ alloy systems are generally preferred amongst all others. The majority of alloys contain 3\%-9\% aluminum with about 1 wt. \% of zinc which provides some increase in tensile properties, and also manganese which improves corrosion resistance, e.g. AZ31 (Mg-3.34 Al, 0.97Zn, all in wt-\%) has been the most preferred alloy from the early days for sheet or plate applications as it is practical at room temperature as well as high temperatures, [Avedesian and Baker 1999]. These alloys have disadvantages including large grain size variations, resulting in poor mechanical properties and micro-porosity; however recently there has been the intention to overcome these drawbacks, [Polmear 2006]. 


\subsubsection{Microstructure of Mg-Al alloys}

$\mathrm{Mg}-\mathrm{Al}$ alloys comprise a vast proportion of commercially-viable magnesium alloys. Mg-Al-Zn alloys which are also known as AZ series alloys including AZ31, AZ61 and AZ91 are the most useful magnesium alloys in industry. In order to fully understand the microstructure of $\mathrm{Mg}-\mathrm{Al}$ magnesium alloys, it is essential to gain some basic knowledge about the characteristics of the solidification process throughout the formation of the alloys.

Figure 2.2 shows the phase diagram of the $\mathrm{Mg}$ - $\mathrm{Al}$ binary alloy system and exposes the different compositions of magnesium and aluminium at different temperatures. In Figure 2.2 the dashed line represents the solidification path of the $\mathrm{Mg}-9 \% \mathrm{Al}$ alloy. Solidification sequences of the AZ91 alloy have been suggested by Dahle et al. [Dahle et al. 2001] and Ohno et al. [Ohno et al. 2006]. The solidification sequences of this alloy begin with nucleation of primary magnesium $(\alpha-M g)$ below $600^{\circ} \mathrm{C}$, i.e. the liquidus temperature of the AZ91 alloy.

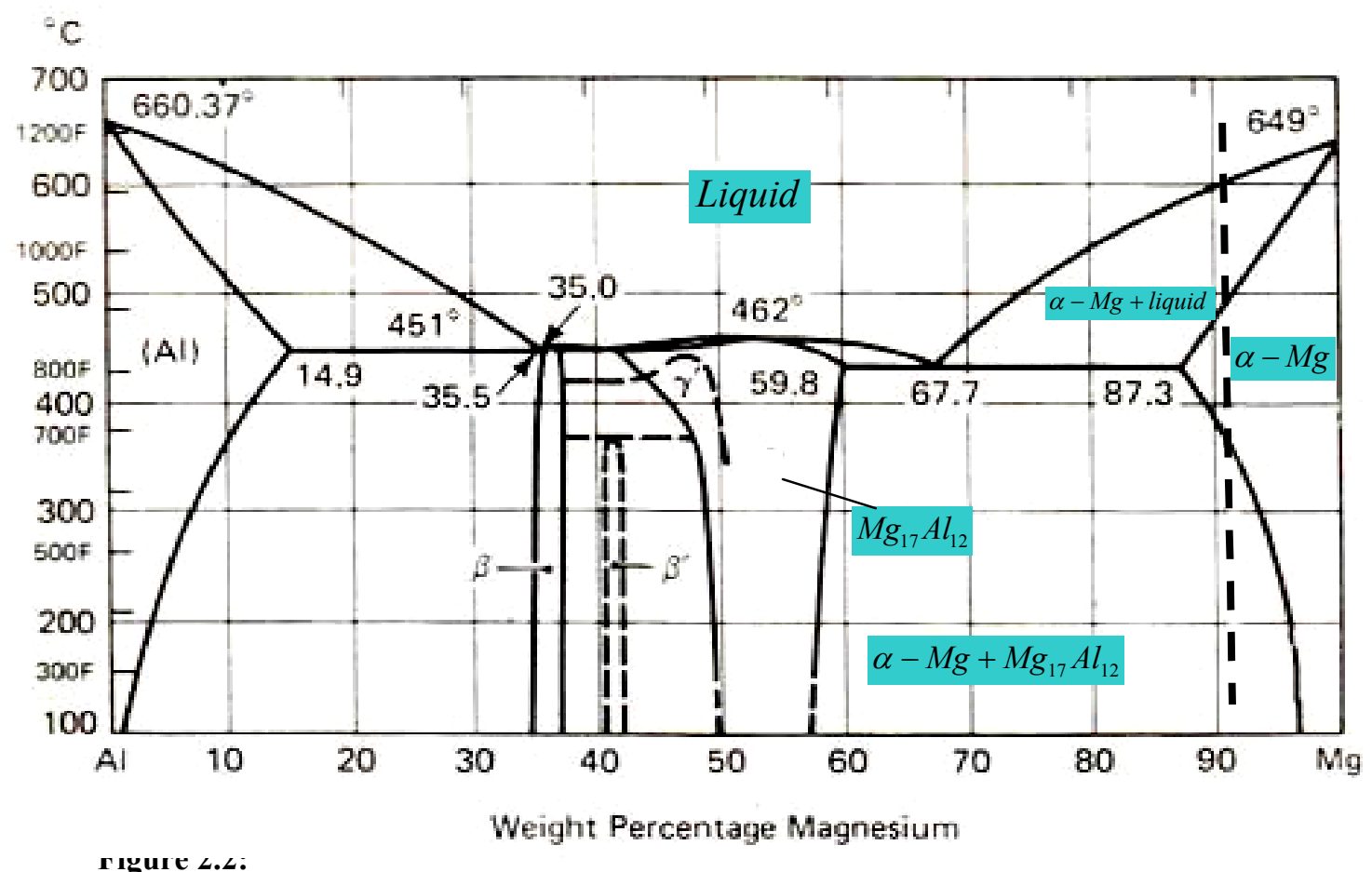

Equilibrium phase diagram for the Mg-Al binary alloy. [Brooks 1982] 
The primary magnesium, $(\alpha-M g)$, can be described as having the form of a dendritic structure, with six-fold symmetry. The important factors that affect the grain size are the cooling conditions, the alloy composition and the existence of nucleant particles throughout the process. The eutectic phase formation proceeds in the later solidification stage, with the $\mathrm{Mg}-\mathrm{Mg}_{17} \mathrm{Al}_{12}$ eutectic reaction occurring at $431^{\circ} \mathrm{C}$, [Dahle et al. 2001]. It is generally expected that the eutectic phase $\left(\mathrm{Mg}_{17} \mathrm{Al}_{12}\right)$ forms when the aluminium content is greater than about $13 \mathrm{wt} \%$, although for non-equilibrium cooling conditions usually encountered in castings the eutectic reaction occurs in alloys containing as little as $2 \mathrm{wt} \%$ Al, [Polmear 2006].

Depending on the composition and cooling rate the eutectic demonstrates a wide range of morphologies in hypoeutectic Mg-Al alloys. Eutectic morphologies may differ depending on factors such as cooling rate and aluminium content, in slow cooling rates or alloys with high aluminium contents approaching the eutectic composition ( $33 \mathrm{wt} \% \mathrm{Al}$ ), "regular lamellar or fibrous eutectic" microstructures are normally observed, whereas those with lower aluminium contents less that about $10 \mathrm{wt} \% \mathrm{Al}$ (i.e. commercial alloys) or in rapid cooling rates, display eutectic morphologies that are usually referred to as fully or partially divorced. Where the two eutectic phases are totally divided in the microstructure this is called a "fully divorced eutectic" morphology. A single $\beta$ $\mathrm{Mg}_{17} \mathrm{Al}_{12}$ particle surrounded by eutectic $\alpha-M g$, exists in every interdendritic region, which has grown from the primary dendrites. A "partially divorced eutectic" morphology is described by islands of eutectic $\alpha-M g$ within the $\beta-\mathrm{Mg}_{17} \mathrm{Al}_{12}$ phase, [Dahle et al. 2001].

The AZ series magnesium alloys, including AZ31, AZ61 and AZ91 have a multi-phase microstructure comprising an $\alpha-M g$ matrix fixed in the eutectic. The eutectic can appear 
in the form of an $(\alpha+\beta)$ lamellar structure. In the interdendritic spaces in the microstructure the secondary phase i.e. $\beta-\mathrm{Mg}_{17} \mathrm{Al}_{12}$ is observed [Dahle et al. 2001, Polmear 2006].

Recently thermodynamic and experimental approaches have both been used to assess the Mg-Al-Zn-Mn quaternary alloy system, [Ohno et al. 2006]. Based on the equilibrium phase diagram presented by Ohno et al., the solidification of the Mg-9Al-1Zn-0.2Mn alloy starts at $642^{\circ} \mathrm{C}$ by precipitation of $\mathrm{Al}_{8} \mathrm{Mn}_{5}$ intermetallics, and then as discussed earlier, is followed by the formation of an $\alpha-M g$ and eutectic reaction. Further investigation was carried out on the effect of nucleation particles by crystallographic analysis, which showed that dispersed $\mathrm{MgO}$ particles act as potent heterogeneous nucleation sites for both the $\mathrm{Al}_{8} \mathrm{Mn}_{5}$ and $\alpha-M g$ phases, [Fan et al. 2009a]. The summary diagram presented in Figure 2.3 displays the solidification process in terms of the microstructure of the AZ91 magnesium alloy.

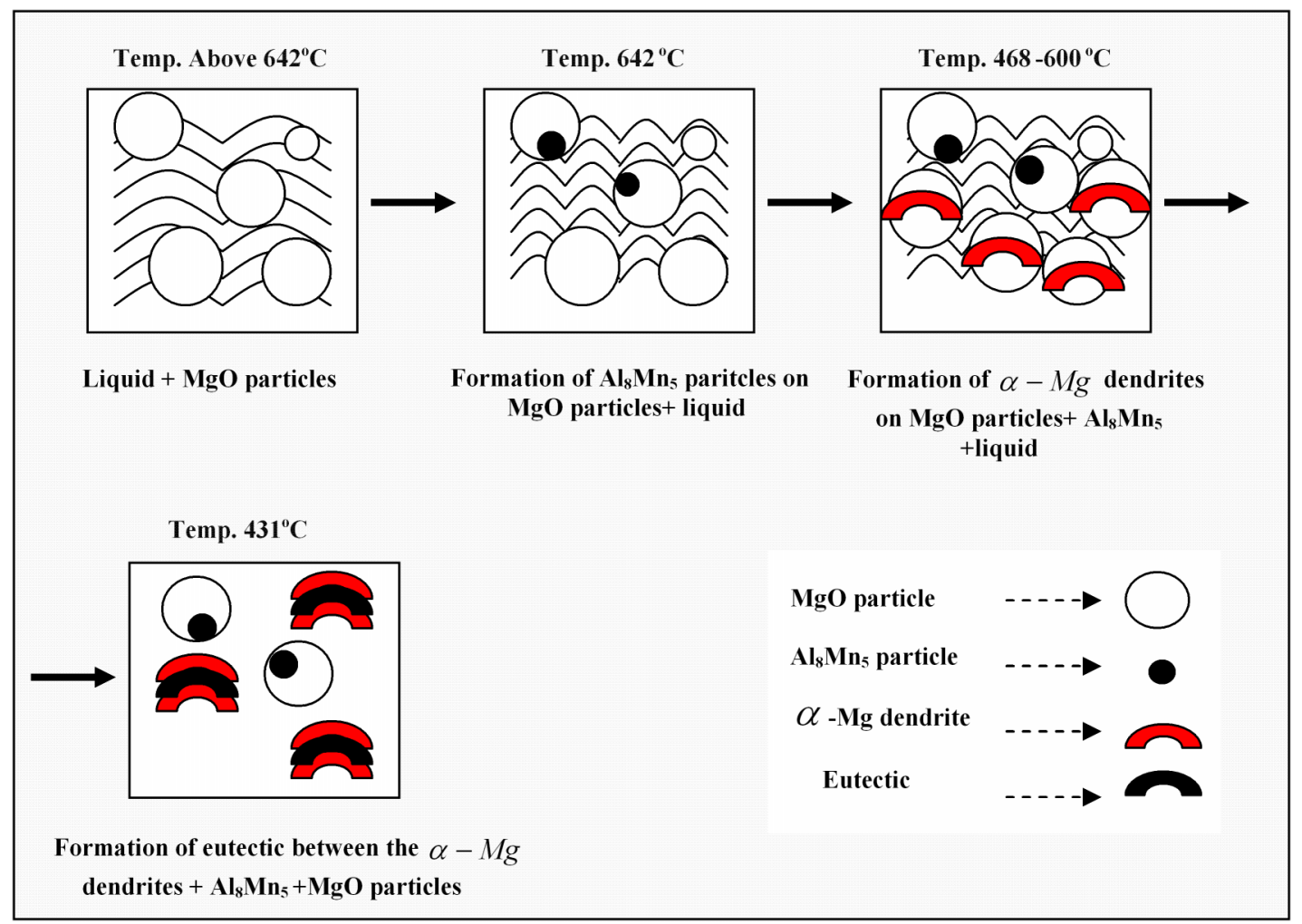

Figure 2.3:

Summary diagram of the solidification process in terms of the microstructure of the AZ91 magnesium alloy. [Based on Fan et al. 2009a, Ohno et al. 2006, Dahle et al. 2001] 
Figure 2.4 shows the fully divorced and lamellar structures of eutectic composition and $\mathrm{Al}_{8} \mathrm{Mn}_{5}$ particles in AZ91 magnesium alloy solidified at a cooling rate of 1 K.minute ${ }^{-1}$.
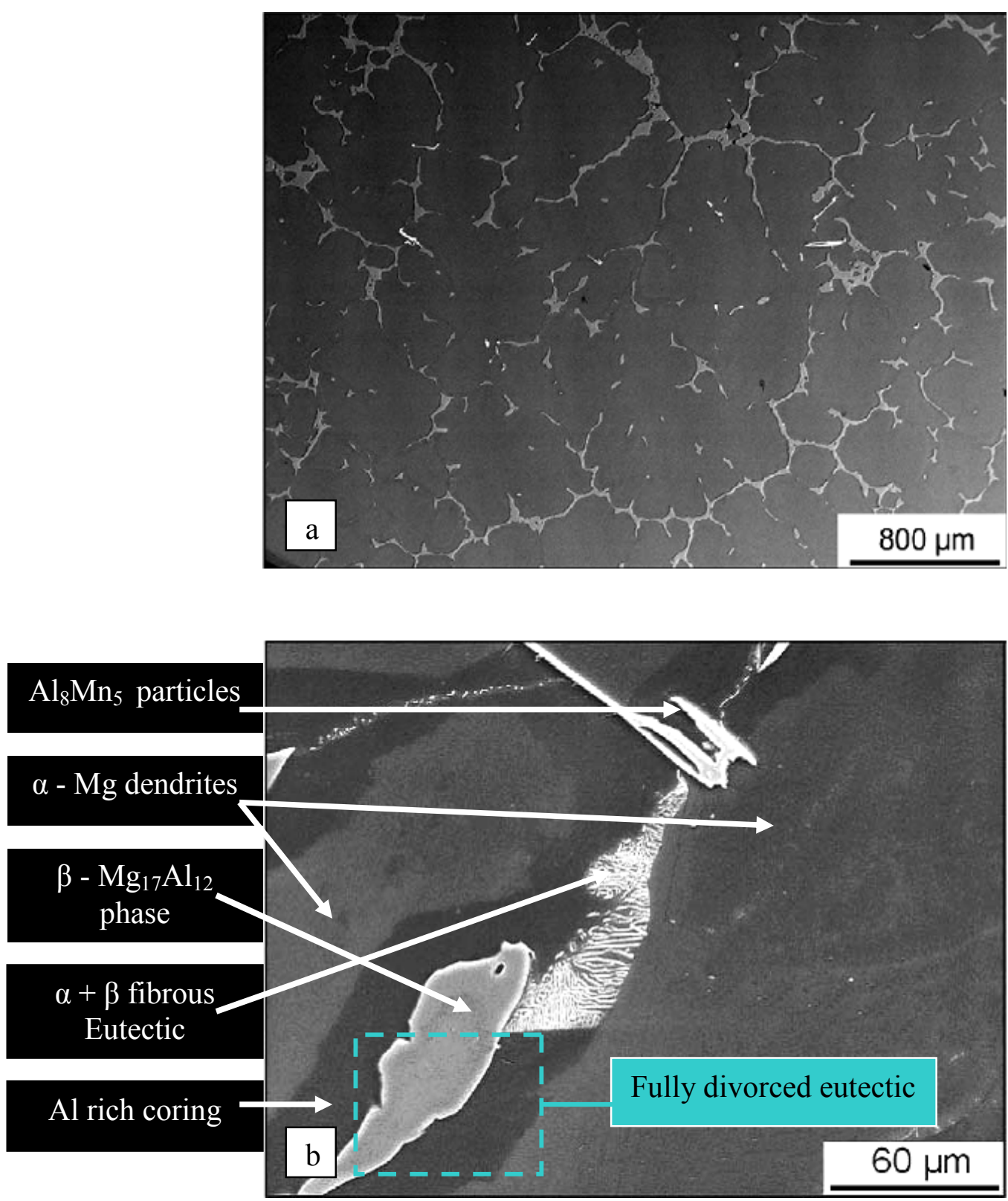

\section{Figure 2.4:}

SEM micrograph of AZ91 sample solidified at $1 \mathrm{~K} \cdot \mathrm{minute}^{-1}$ (a), and in higher magnification (b). [Ohno et al. 2006] 


\section{TWIN ROLL CASTING OF MAGNESIUM:}

\section{THE STATE OF THE ART}

\subsection{Introduction to the TRC process}

The introduction of conventional continuous casting technology during the 1950's gained ascendancy quickly over ingot casting. At this time all around the world a very high percentage of the semi-fabricated products are produced by continuous casting. The products are cast slabs and billets of at least $300 \mathrm{~mm}$ in thickness which require a large number of further thermomechanical processing steps to produce plate, sheet and strip. During the last few decades, a near-net-shape casting route was developed known as direct strip casting (DSC). DSC has the advantage over conventional routes because it produces sheet that does not require large amounts of down stream processing before it is used to make the final product. Therefore, there is the potential for large savings in the capital and operational costs. Thus, many processes for direct strip casting are being investigated by companies using laboratory or pilot plant studies, [Ferry 2006]. This section provides an overview of the direct strip casting technology, going into more detail on twin roll casting and its limitations.

\subsubsection{Moving mould casters}

Direct strip casting is also known as 'moving mould casters' and is categorized into three groups according to the type of mould wall. They are the twin-belt casters, wheel and belt casters and twin roll casters, [Hendricks 1995, cited in Ferry 2006]. Only a short description will be given here as they are extensively reviewed elsewhere, [Emley 1976]. Figure 2.5 presents the feasible classification scheme for direct strip casters. 
Group I-Twin-Belt machines. This group utilizes travelling conveyor belts. The metal is either cast onto the belt (Figure 2.5a(i)) or sprayed onto one side of the belt (Figure 2.5a(ii)). Occasionally, the melt may be poured between two belts either at an inclined angle or vertically, (Figure $2.5 \mathrm{a}$ (iii \& iv)).

Group II-Wheel and belt machines. This group consists of a single roll to produce thingauge strip. In the single roll process, the melt is dragged in to contact with the rotating wheel to produce the strip, (Figure 2.5b).

\section{Figure 2.5:}

Possible classification scheme for moving mould casters. [Hendricks 1995, cited in Ferry 2006]

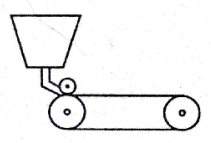

(i)

(a)

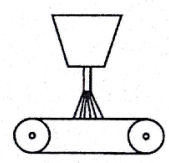

(ii)

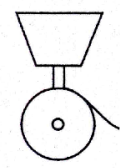

(b)

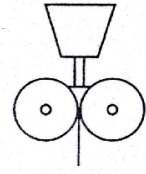

(i)

(c)

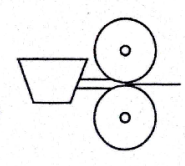

(ii)

$$
\text { GROUP I }
$$

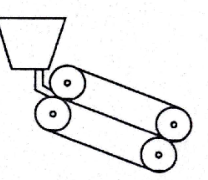

(iii)

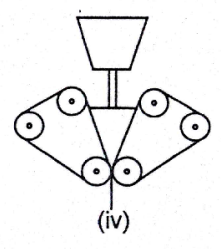

(iv)

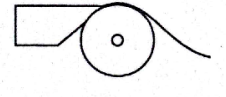

GROUP II

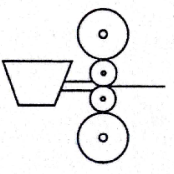

(iii)

GROUP III

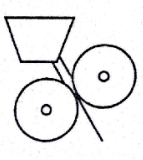

(iv)

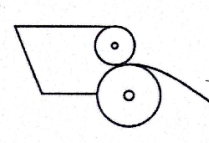

(v)

\section{Group III - Twin Roll machines.}

Twin roll casters can consist of either equal-sized rolls (Figure $2.5 \mathrm{c}(\mathrm{i})$ to $2.5 \mathrm{c}(\mathrm{iv})$ ), or unequal-sized rolls (Figure $2.5 \mathrm{c}(\mathrm{v})$ ). These processes may be arranged horizontally, vertically or inclined, depending on the alloy type.

The TRC process produces strip between 0.5 and $10 \mathrm{~mm}$ thick directly from the melt by combining continuous casting and hot rolling into a single process. Sir Henry Bessemer 
patented the original design in 1865 , which delivered molten metal (i.e. tin and lead) from a holding furnace, positioned above the rolls, into the gap formed by the horizontally opposed water-cooled steel rolls, [Bessemer 1865]. Figure 2.6 shows the schematically Bessemer's twin roll strip caster.

\section{Figure 2.6:}

Schematic diagram of Bessemer's twin roll strip caster. [Bessemer 1865]

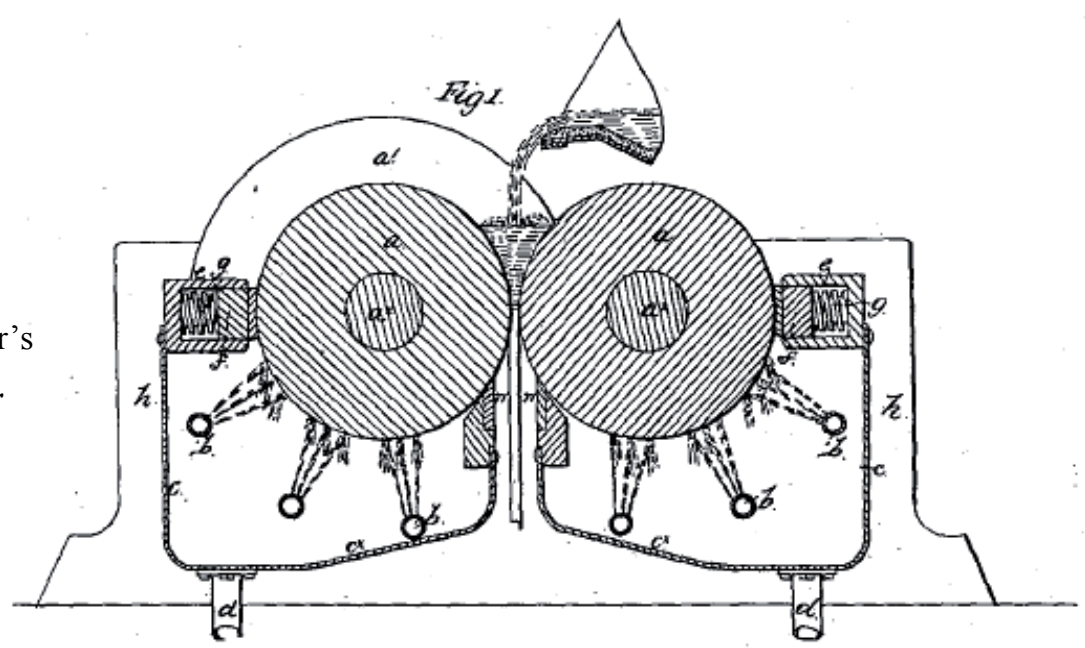

However, in Bessemer's twin roll strip caster the metal delivery system and the low surface quality of the strip produced delayed its progress which over the years was improved and commercialized by the aluminium industry in 1950's, [Ferry 2006].

\subsubsection{Current status of the strip casting of magnesium alloys}

Current usage of magnesium sheet, provided by conventional rolling production, is limited to 1,000 tonnes per annum because of the high production costs of the conventional process, [Liang and Cowley 2004]. This is mainly the reason for the large investments by many organizations in the strip casting of magnesium, particularly TRC by CSIRO in Australia, [Ferry 2006]. 


\section{Table 2.1:}

Challenges related with twin roll casting of magnesium alloys. [Liang and Cowley 2004, Löchte et al. 2005, Ferry 2006]

\begin{tabular}{|c|c|c|}
\hline Challenge & Features & Potential Solution \\
\hline Oxidation potential & $\begin{array}{l}\text { Molten } \mathrm{Mg} \text { oxidises easily and } \\
\text { ignites without good protective } \\
\text { atmosphere systems and control. }\end{array}$ & $\begin{array}{l}\text { Safe protection can be developed for } \\
\text { both molten magnesium and } \\
\text { containment materials which is vital } \\
\text { for achieving high quality strip and } \\
\text { preventing fire ignition. }\end{array}$ \\
\hline Solidification rate & $\begin{array}{l}\text { Lower specific heat and latent heat } \\
\text { of fusion causes molten } \mathrm{Mg} \text { to } \\
\text { freeze faster than wrought } \\
\text { aluminium alloys. This creates a } \\
\text { large difficulty to achieve uniform } \\
\text { solidification across the strip. }\end{array}$ & $\begin{array}{l}\text { Making sure that during casting the } \\
\text { interfacial heat transfer is under } \\
\text { control, e.g. thoroughly cleaning the } \\
\text { rolls. }\end{array}$ \\
\hline Freezing range & $\begin{array}{l}\text { Contrary to aluminium alloys, the } \\
\text { larger freezing range of Mg-based } \\
\text { alloys can lead to the formation of } \\
\text { cracks and segregation defects in the } \\
\text { as-cast strip. }\end{array}$ & $\begin{array}{l}\text { Designing newly-developed } \mathrm{Mg}- \\
\text { alloy compositions. }\end{array}$ \\
\hline Machine makeup & $\begin{array}{l}\text { Reaction of molten magnesium with } \\
\text { many materials, particularly those } \\
\text { containing silica }\end{array}$ & $\begin{array}{l}\text { Suitable selection of materials for } \\
\text { the melting furnace, launder system } \\
\text { and nozzle to prevent such } \\
\text { reactions. }\end{array}$ \\
\hline Costs and performance & $\begin{array}{l}\text { Operational cost reduction in the } \\
\text { manufacturing processes is a } \\
\text { constant requirement from industry. } \\
\text { In cost and performance magnesium } \\
\text { alloy sheet must compete with other } \\
\text { materials. }\end{array}$ & $\begin{array}{l}\text { TRC of magnesium is most cost- } \\
\text { effective for small tonnages } \\
(<50,000 \text { tones p.a.), similar to } \\
\text { aluminium. }\end{array}$ \\
\hline
\end{tabular}

Regardless of this encouraging development, TRC of magnesium alloys is more difficult than for other alloys, e.g. aluminium alloys, since the challenges summarized in Table 2.1 need to be met in order to commercialize the process. It can be concluded from Table 2.1 that the disadvantages can be divided into two categories: the physical and chemical properties of magnesium alloys and engineering design, i.e. tundish and tip construction [Kawalla et al. 2008]. However, overcoming these disadvantages adds to the complexity of twin roll casting of magnesium alloys. Recently, Liang et al. have successfully twin roll cast AZ31, AZ61, AZ91 and AM60 alloys which are expected to be produced commercially in the near future, [Liang et al. 2006]. 
TRC of magnesium alloys is a modern technology, however it requires in depth scientific research to be improved. During the past few years, researchers in Australia [Liang and Cowley 2004], South Korea [Kang et al. 2008], Germany [Kawalla et al. 2008, Engl 2005], Japan [Haga et al. 2006, Watari et al. 2007], China [Yang et al. 2005], Canada [Jackman et al. 2005], and Turkey [Duygulu et al. 2009a\&b], have carried out extensive research to develop this technology for magnesium alloys however further investigation needs to be done. For example; in CSIRO (Australia) magnesium alloy strips (AZ31, AZ61, AM60 and AZ91 alloys), with a width of $100-600 \mathrm{~mm}$ and thickness of $2.3-5 \mathrm{~mm}$ have been produced, [Liang and Cowely 2004]. POSCO Magnesium (South Korea) produces 530-600mm wide, 0.4-4.3mm thick AZ31 sheet or coils, [Kang et al. 2008]. Thyssen Krupp MgF Magnesium Flachprodukte GmbH (Germany) produces strips up to $700 \mathrm{~mm}$ wide and $4.5-7 \mathrm{~mm}$ thick, [Kawalla et al. 2008]. In Japan, AZ31, AZ61, AZ91, AM50 and AM60 strips are produced $4-5 \mathrm{~mm}$ in thickness and up to $250 \mathrm{~mm}$ in width, [Haga et al. 2006]. 


\subsection{Principles of the TRC process}

Molten metal is transferred from a holding furnace or crucible into a launder system where it loses heat as it falls into the tip of the launder (i.e. nozzle). In the TRC process the tip is critical; as it sustains the melt at a constant level which can improve the integrity of the solidified strip, minimize the turbulence and distribute the melt to the required strip width, [Merchant et al. 1989]. The melt enters the moving mould after leaving the tip.

Figure 2.7 is a schematic diagram showing the position of the nozzle and the liquid and solid zones in the roll gap of a twin roll caster. As soon as the liquid metal leaves the tip, solidification usually begins against the two water cooled rolls just by the meniscus region (Point A), and as a result, the growth of two shells or solid skins continues as it moves forward through the melt pool (Point B). Along the centre line the two solid skins congregate and form what is known as the 'sump' area ( $\beta$ arrow), [Ferry 2006, Cook et al. 1995, Zapuskalov 2003]. The conversion from liquid to solid includes a semi-solid region, referred to in Figure 2.7 as the 'mushy' zone. When the solidifying metal has reached adequate strength, determined by its 'rigidity point' (this is the point where the solid fraction is around $\sim 70 \%-90 \%$ and solidifying metal can maintain a load), the material experiences a degree of hot working before leaving the roll bite, [Bradbury 1994, Jarry et al. 1996]. So the TRC process combines solidification and hot rolling deformation into a single process. The tip setback, $\alpha$, depends on the width of lips of the nozzle, the closeness of fit of the nozzle between the rolls and the diameter of the rolls. The setback increases or decreases with an increase or decrease in the diameter of the rolls, respectively, [Liang et al. 2006]. 


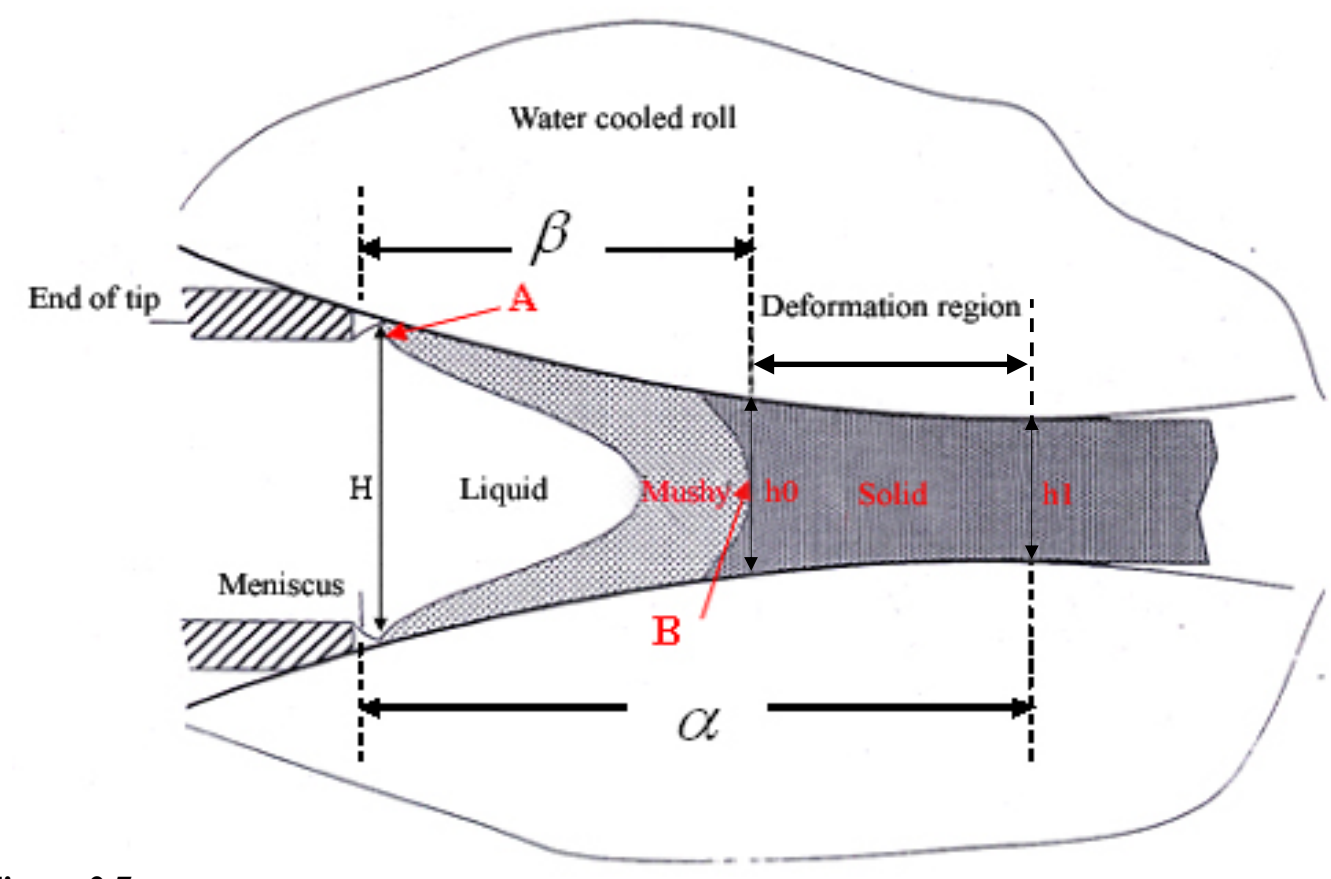

\section{Figure 2.7:}

Schematic diagram showing the position of the nozzle and the liquid and solid zones in the roll gap of a twin roll caster. [Bradbury 1994]

Westengen and Nes, from geometrical calculations, proposed the following formula to relate the various processing parameters:

$$
\beta=(H / 2),\left(\left(2(\alpha-\beta)^{2} / D\right)+h_{1} / h_{1}\right)^{2} \cdot \tan \phi_{0}
$$

where, $\beta$ is the length of the sump depth, $\alpha$ is the length of the tip set-back, D is the roll diameter, $\mathrm{h}_{1}$ is the final thickness of the strip and $\phi_{0}$ is the average angle between deformed grains and casting direction, [Westengen and Nes 1984]. Westengen and Nes also defined the degree of hot rolling during casting $\varepsilon(\%)$, as follows:

$$
\varepsilon(\%)=\frac{\left(h_{0}-h_{1}\right)}{h_{0}} \approx \frac{(\alpha-\beta)^{2}}{(\alpha-\beta)^{2}+h_{0} D} \times 100
$$


where, $\mathrm{h}_{0}$ is the initial thickness of the solidified strip, [Westengen and Nes 1984]. The thickness reduction in conventional casters is in the order of $30-60 \%$ depending on the roll diameter (D) and setback $(\alpha)$, [Berg et al. 1995].

\section{$\underline{\text { Roll separating forces }}$}

The considerable deformation in the hot rolling stage of a TRC process creates a steep pressure gradient along the arc of contact between the metal and the rolls with the maximum pressure being significantly greater than the flow stress of the material, [Ferry 2006, Liang et al. 2006]. Iricibar and Jin estimated the roll separating forces which are produced in TRC, as shown in Figure 2.8. This figure shows that the contact pressure is considerably greater than the flow stress of the solidified strip which results in plastic deformation of the strip through the roll bite, [Iricibar and Jin 1984].

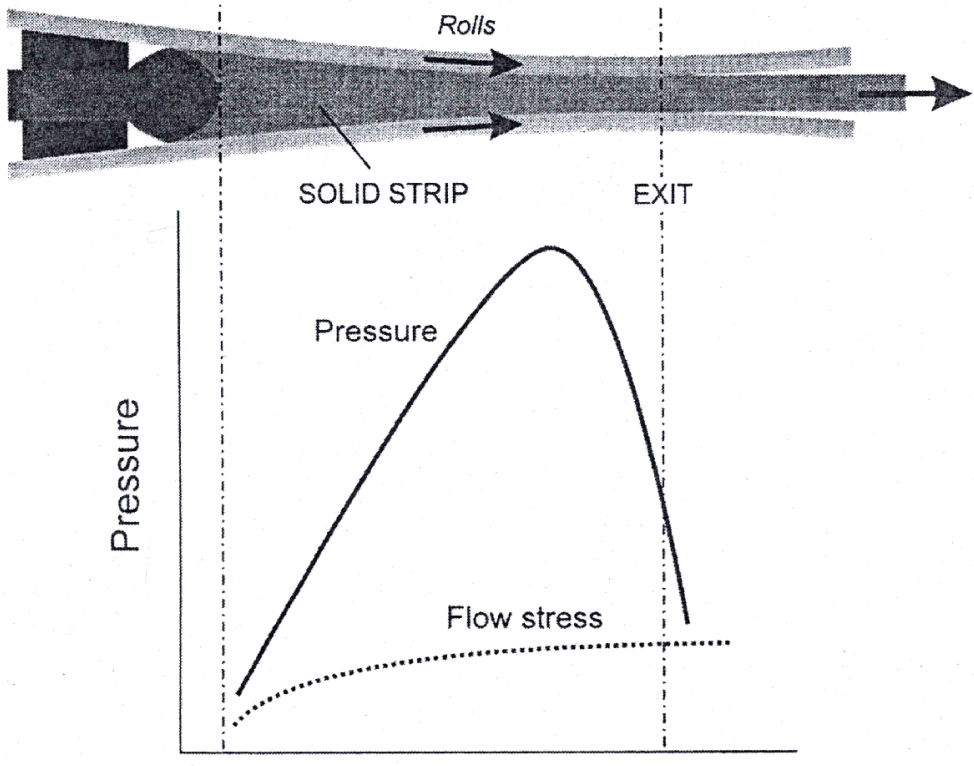

Distance from sump

\section{Figure 2.8:}

Schematic diagram showing the pressure distribution through the roll bite of a horizontal twin roll caster. [Iricibar and Jin 1984] 


\subsubsection{Influence of casting parameters on strip characteristics}

In order to prevent surface and internal defects and to improve the quality of casting strips it is crucial to explore the solidification and flow behaviour of the melt during TRC process, [Zeng et al. 2009]. Experimental difficulties prevent detection or measurement of the temperature and pressure distribution in a TRC process, which therefore requires a numerical simulation method, [Sarioğlu and Thevoz 2003]. The effect of casting parameters (i.e. casting speed, strip thickness, tip setback, alloy freezing range) on the shape of the liquid sump and pressure distribution profile in a TRC process have rarely been investigated, however these have been modelled by Hunt and co-workers for aluminium alloys, [Bradbury 1994, Bagshaw et al. 1986, Bradbury and Hunt 1995].

\section{Casting Velocity and Strip Thickness}

The roll speed during a TRC process has a substantial influence on the shape of the liquid metal sump, [Merchant et al. 1989]. Figure 2.9 and 2.10 show simulated results of the sump shape and pressure distribution with casting speed for the production of $2 \mathrm{~mm}$ gauge Al strip, [Bradbury 1994]. It has been shown that an increase in casting speed generates a deeper liquid and semi-solid zone (U-shape zone) with an associated increase in the exit temperature of the strip. Also a higher casting speed induces a lesser peak pressure. The shape of the sump in Figure 2.9 is in general accordance with the predictions of other researchers, [Zeng et al. 2009], [Lee et al. 2005], [Sarioğlu and Thevoz 2003], [Ju et al. 2005] and [Sahai and Saxena 2002]. It has been shown that the thickness of the magnesium strip produced by TRC process is related inversely to the casting velocity, [Watari et al. 2007, Carslaw and Jaeger 2004]. Hence a decrease in strip thickness or increase in casting velocity can deepen the sump depth, [Bradbury and Hunt 1995, Bradbury 1994]. 
(a)
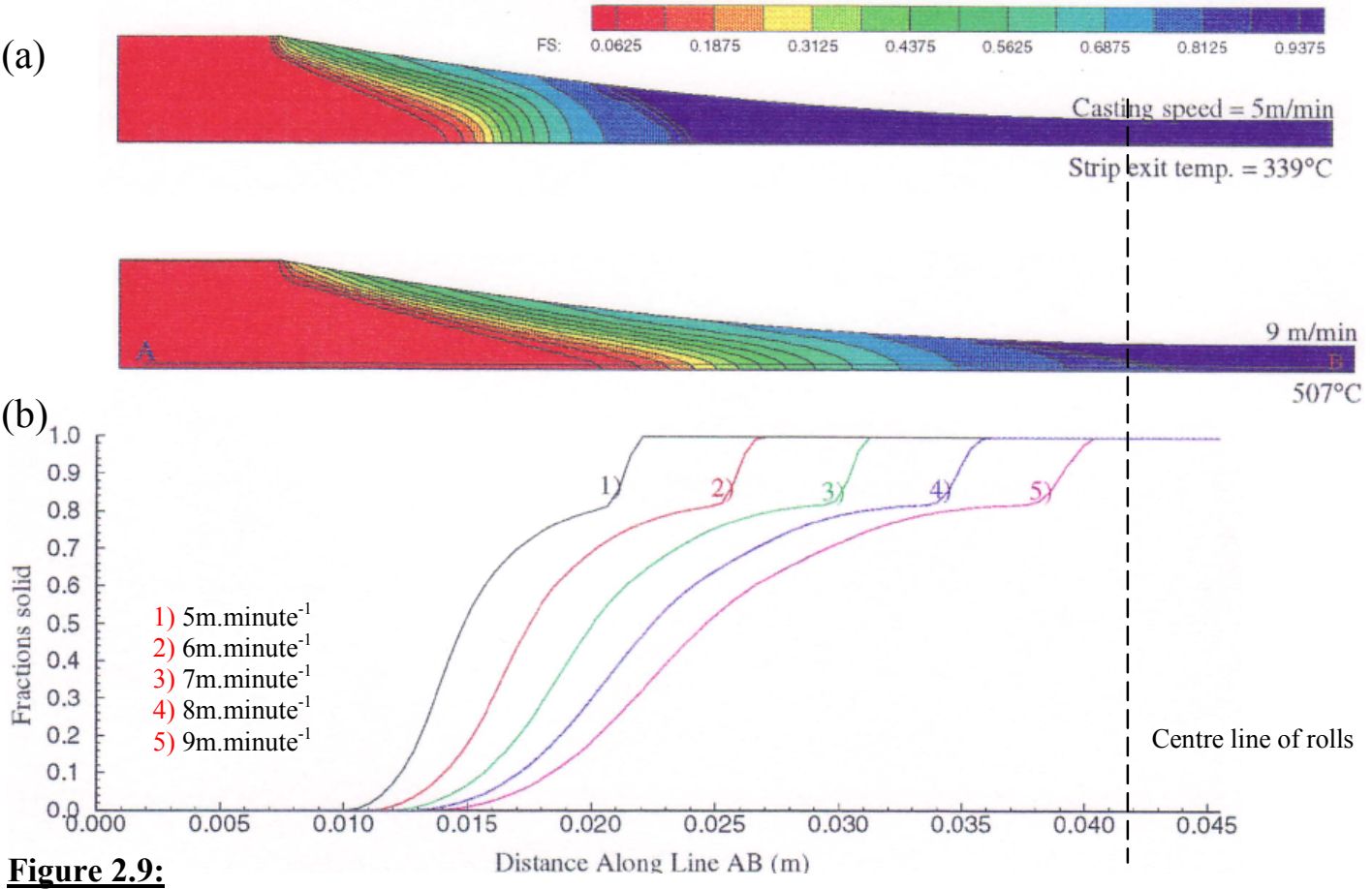

a) Predicted contours of solid fraction as a function of casting speed 5 m.minute ${ }^{-1}$ and 9 m.minute ${ }^{-1}$ for the twin roll casting of $2 \mathrm{~mm}$ gauge aluminium strip, b) Distribution of fraction solids along the longitudinal line of the strip for different casting speeds, 5-9 m.minute ${ }^{-1}$. [Bradbury 1994]

(a)
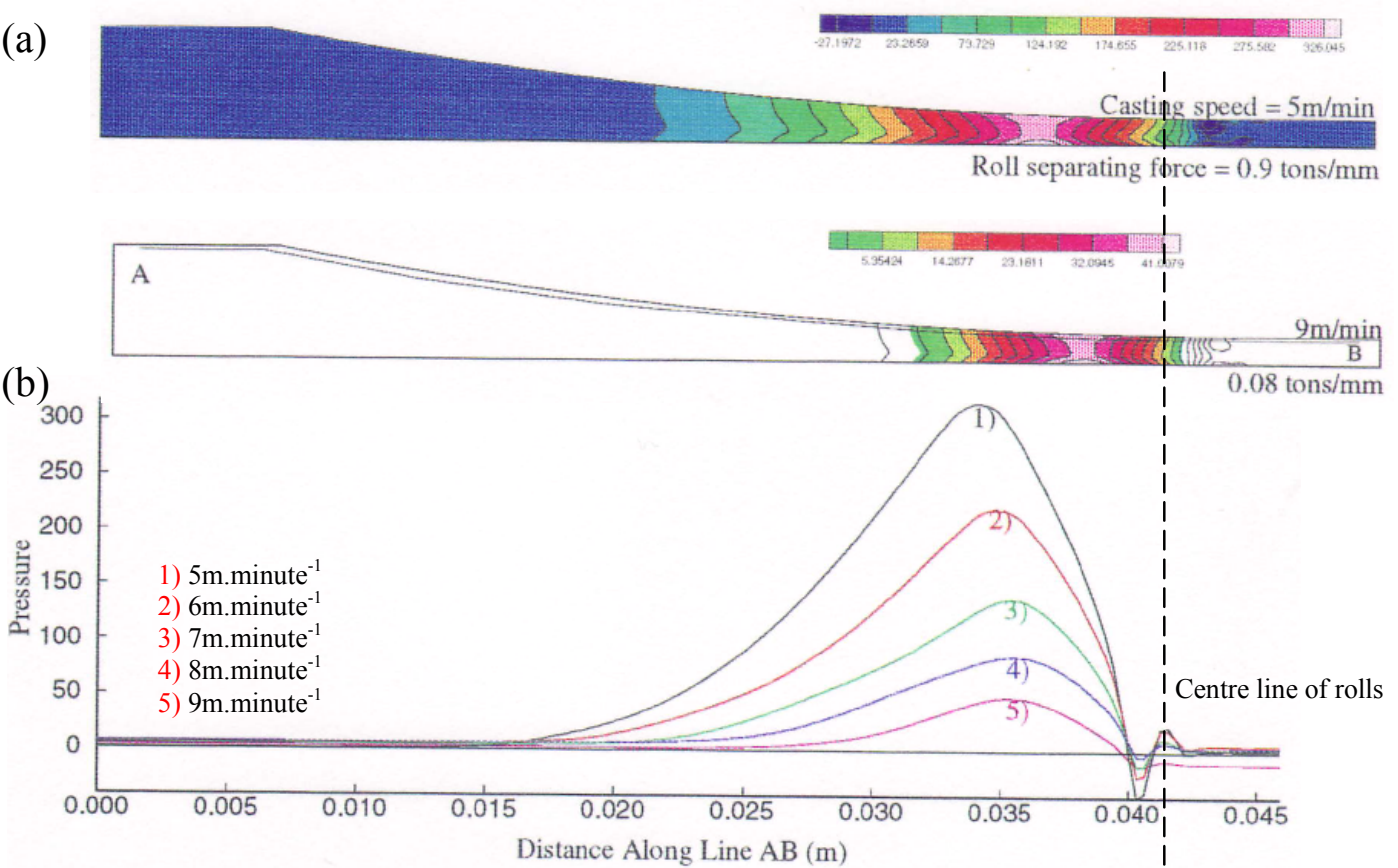

Figure 2.10:

a) Predicted isobars as a function of casting speed 5 m.minute ${ }^{-1}$ and 9 m.minute ${ }^{-1}$ for the twin roll casting of $2 \mathrm{~mm}$ gauge aluminium strip, b) Pressure distribution along the longitudinal line of the strip for different casting speeds, 5-9 m.minute ${ }^{-1}$. [Bradbury 1994] 


\section{$\underline{\text { Tip Setback }}$}

The behaviour of the TRC process is affected by the tip setback. Experimental results have shown that the roll separating force can be easily increased by increasing the tip setback or by decreasing the casting speed. This is due to an increase in the area for heat removal from the solidifying metal, [Bercovici 1985]. Bradbury simulated the effect of tip setback on sump depth in a TRC process for an $\mathrm{Al}-8 \% \mathrm{Cu}$ alloy. The results show that the sump depth slightly increases at higher setbacks while the end point of the mushy zone moves significantly towards the entry side of the caster at higher setbacks, as shown in Figure 2.11, [Bradbury 1994].

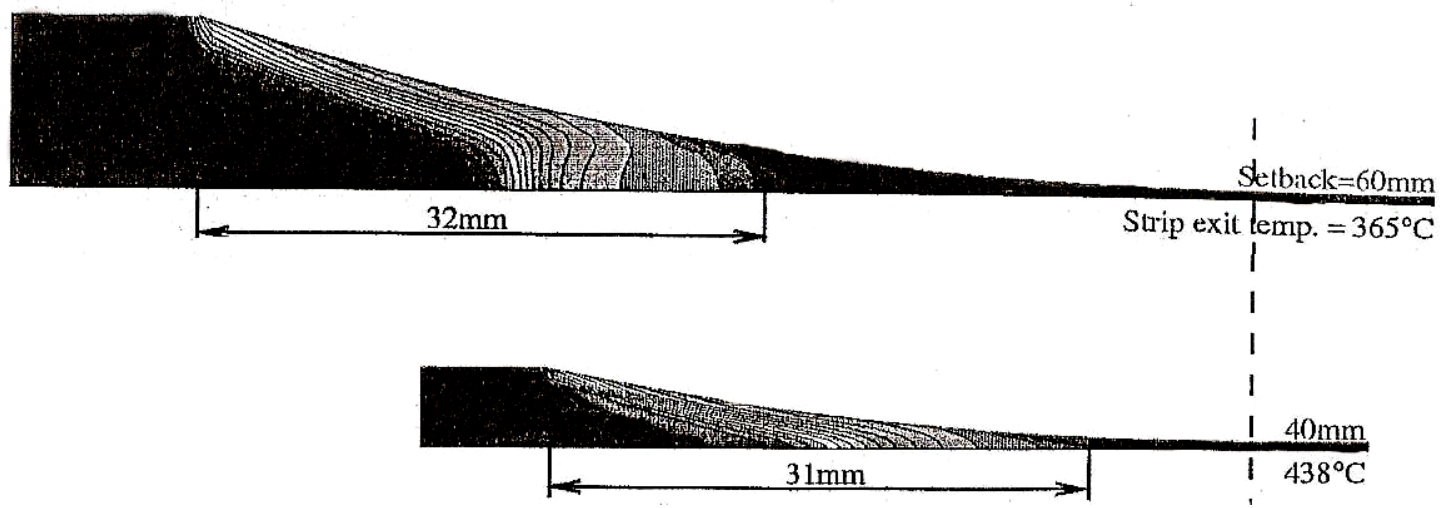

Figure 2.11:

Simulation results show the effect of different tip setback on the shape and size of the sump depth for an Al-8\%Cu alloy. [Bradbury 1994]

\section{Alloy Freezing Range}

For a large freezing range alloy $\left(>30^{\circ} \mathrm{C}\right)$ there is clearly less time to solidify the strip completely, [Edmonds et al. 1991]. Hence controlling the casting parameters (i.e. casting speed and setback) for large freezing range alloys are very crucial in order to achieve the desired sump depth in TRC process. Undesired sump depth can generate defects in strips such as heat lines or centre line segregation as will be discussed in Section 2.4. The results of simulation in Figure 2.12 shows that for a large freezing range alloy, the sump depth is larger and extends into the roll bite. 


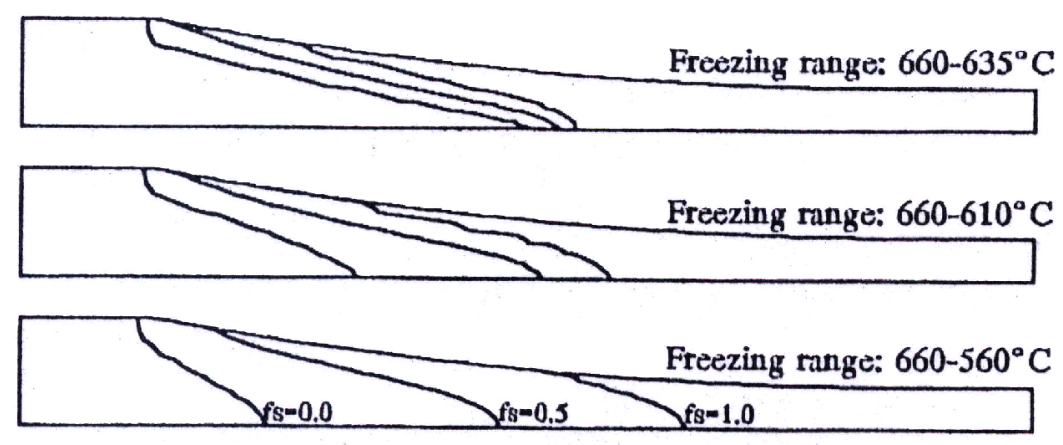

\section{Figure 2.12:}

Simulation results show the effect of different freezing range i.e. 25,50 and $100^{\circ} \mathrm{C}$ on the shape and size of the sump depth for Al-Cu alloys. [Bradbury 1994]

\subsubsection{Mechanical behaviour of the mushy zone}

\subsubsection{Rheological behaviour}

In a TRC process, an understanding of the rheological behaviour in the mushy or semi-solid zone, as depicted earlier in Figure 2.7, can help us to improve our understanding of fluid flow in the mushy zone and the origin of the defects forming in the final strip, e.g. centre line segregation.

The initial investigation of the rheology of semi-solid material (SSM), was performed on the Sn-Pb system by Spencer et al. at MIT, [Spencer et al. 1972]. They showed that the viscosity of stirred SSM slurry at a solid fraction higher than 0.2 is an order of magnitude less than that of an unstirred dendritic slurry. The reason for this phenomenon has been explained in an extensive study by Joly and Mehrabian, who demonstrated that vigorous mechanical stirring while in the freezing range, results in the dendritic network break down which is then replaced by rounded particles that can shift around freely, [Joly and Mehrabian 1976]. 

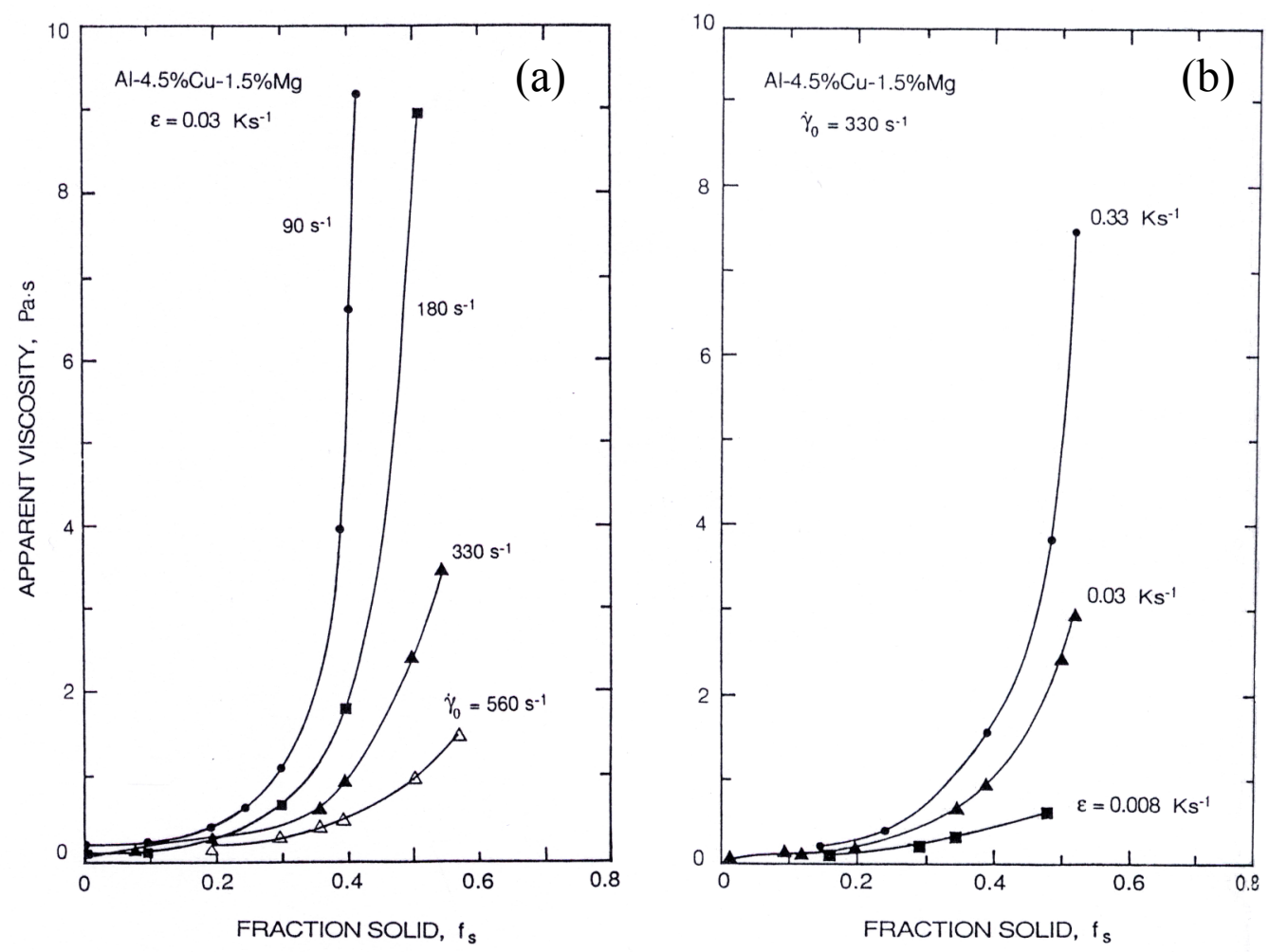

Figure 2.13:

a) Effect of shear rate on apparent viscosity of the semisolid alloy, Al-4.5\%Cu$1 \% \mathrm{Mn}$ and $\mathrm{b}$ ) effect of cooling rate on the apparent viscosity of the semisolid alloy. [Flemings 1991]

Figure 2.13 (a) and (b) show the effect of shear rate and cooling rate on the apparent viscosity of $\mathrm{Al}-4.5 \% \mathrm{Cu}-1.5 \% \mathrm{Mn}$. The impact that rheological properties of the semisolid have on a TRC process is still unknown. However, Bradbury based on the information obtained from the above figures suggested that it is likely for a sudden rise in the effective viscosity to occur at some fraction solid in the TRC of aluminium alloys, [Bradbury 1994].

\subsubsection{Deformation behaviour}

The existence of a solid skeleton is a feature of the semi-solid mushy zone with high solid fractions, [Fan 2002]. During solidification the volume fraction of the solid $\left(f_{s}\right)$ increases by crystal growth and the crystals impinge on one another at a critical value 
of $f_{s}$, resulting in a quick rise in the flow resistance (or increase in the solid-liquid strength), [Gourlay and Dahle 2007]. This $f_{s}$ is often called the dendrite coherency solid fraction $\left(f_{s}^{c h}\right)$ and is dependant on the size and shape of crystals [Sumitomo et al. 2000, Arnberg et al. 1993, Veldman et al. 2001].

Spencer et al. [Spencer et al. 1972], studied the effect of morphology on deformation behaviour of solid-liquid $\mathrm{Sn}-15 \mathrm{wt} \% \mathrm{~Pb}$ alloy. Figure 2.14 shows the effect of the shape and morphology of crystals on the strength of a $\mathrm{Sn}-15$ pct $\mathrm{Pb}$ alloy at different fraction solids. In the dendritic material the maximum stress at $f_{s}=0.4$ is around $200 \mathrm{kPa}$, in contrast the nondendritic material shows a much lower value at the same solid fraction, [Flemings 1991, Spencer et al. 1972]. This is due to easier deformation due to cooperated grain rearrangement in equiaxed microstructures via sliding and rolling [Tzimas and Zavaliangos 1999], which will be elucidated thoroughly later in the Discussion chapter, Section 5.2.1.

(a)

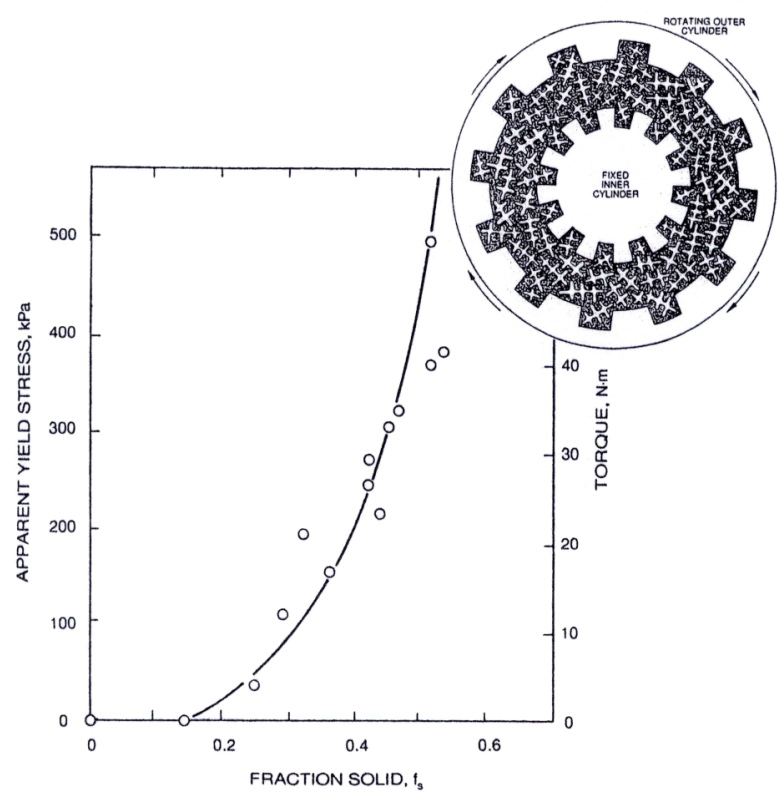

(b)

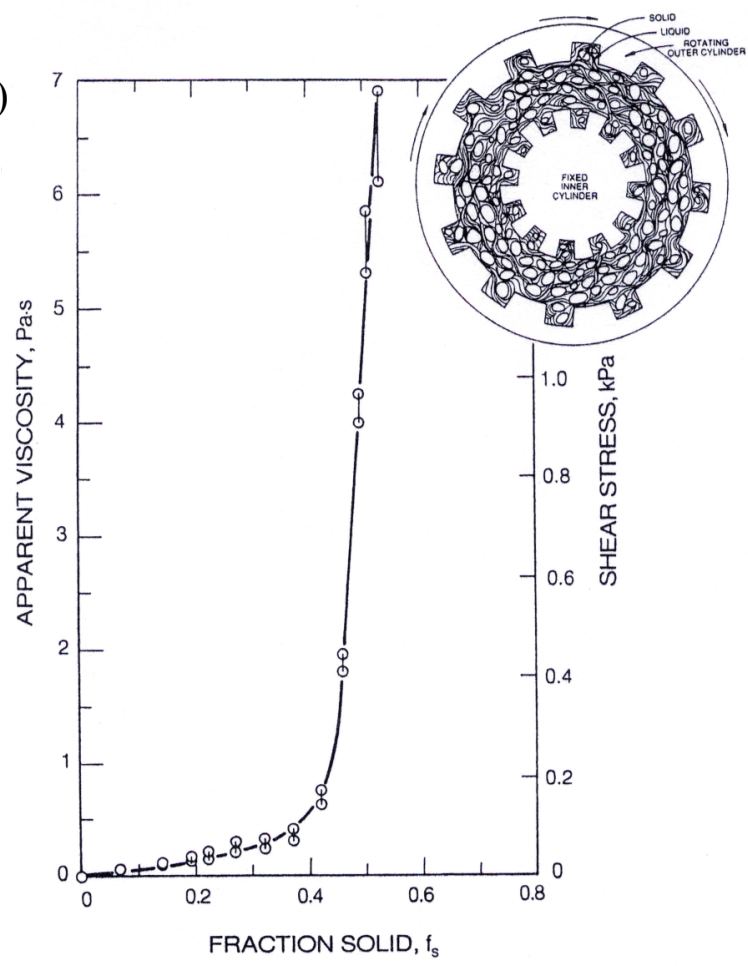

Figure 2.14:

The effect of the morphology and shape of crystals on the apparent yield strength, a) dendritic morphology and b) non-dendritic (or equiaxed dendrites) morphology. [Spencer et al. 1972] 
An applied pressure on the semisolid material causes solid-liquid separation (i.e. liquid segregation in the TRC process). Darcy's law that relates the volumetric flow rate of the liquid in a porous solid phase to the pressure gradient applied $\left(\nabla p_{L}\right)$ on the system is generally used, as follows:

$$
f_{L} v_{L}=-\frac{K}{\mu} \cdot\left(\nabla p_{L}-\rho_{L} g\right)
$$

where $K$ is the permeability factor, $g, v_{L}, \mu, f_{L}$ and $\rho_{L}$ are the gravity, velocity, viscosity, volume fraction and the density of the liquid phase respectively [Tzimas and Zavaliangos 1999]. The permeability is related to the structure of the solid phase and can be described by the modified Carman-Kozeny model, [Bear 1972]:

$$
K=\frac{d_{m}^{2}}{180} \frac{f_{L}^{3}}{\left(1-f_{L}^{2}\right)}
$$

where $d_{m}$ is the average grain size.

It has been found that a high strain rate of deformation, a low dendrite coherency solid fraction and a fine grain size can reduce the quantity of separation of solid-liquid phases during deformation of semi-solid materials, [Valer et al. 1998, Finke et al. 2000, Chen and Tsao 1999]. 


\subsection{Cast strip quality}

As mentioned earlier, the main benefit of TRC is based on the reduction and/or elimination of the large number of down stream processing steps and production costs, [Wechsler 2003]. However, TRC produces near-net-gauge strips in which sound surface conditions and internal quality are required since only limited secondary processing is available to modify these parameters, [Ferry 2006]. Cracking during subsequent rolling and forming may be caused by internal and external defects. The ability to prevent the formation of defects or at least postpone their appearance to higher productivities is a clear industrial challenge, [Forbord et al. 2006]. The following defects are well known by TRC operators, although some are better understood than others.

a) Centre Line Segregation. Macro-segregation in conventional casting processes is caused by the movement of liquid or solid phases within the mushy zone which is due to thermal contraction, solidification shrinkage and density difference within the mushy zone, [Flemings 1974]. However, Jin et al. suggested that centre-line segregation in a TRC process could be due to the squeezing effect of the rolls (i.e. roll separating force) on the mushy region forcing the remaining liquid, enriched in alloying elements, to be squeezed out towards the centre-line, [Jin et al. 1982]. On the other hand, the liquid movement in strip casting is mainly due to roll separating forces.

Barber and Bush, [Barber and Bush 2007] proposed a model for the prediction of segregation during slab casting of steel shown in Figure 2.15 which illustrates that roll separating forces act as a predominant factor on the formation of centre-line segregation. This illustrates the alloying elements (peak point) being pushed to the centre of as-cast slab under high pressure rolling force which causes fountain-like accumulation of solutes (i.e. centre line segregation). Based on these findings, it can be expected that in TRC process under high pressure rolling force same results might be obtained. 


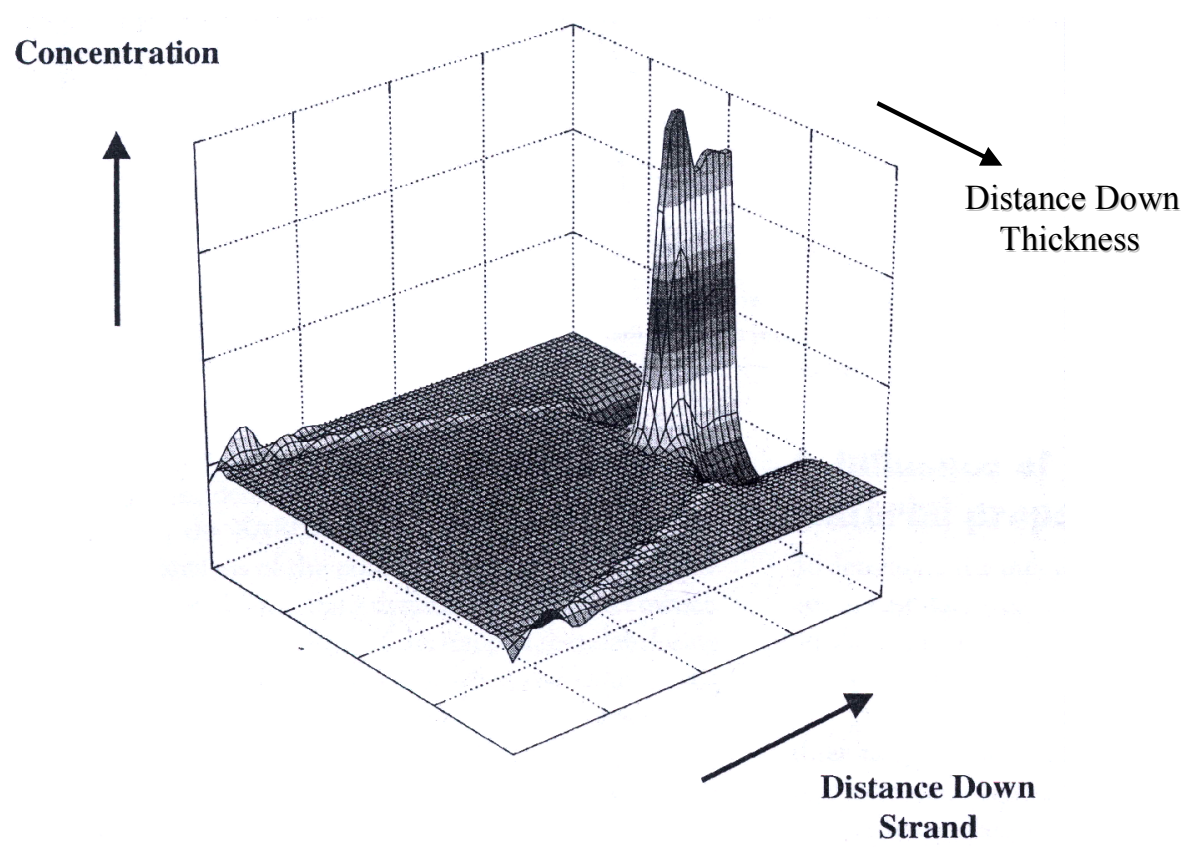

Figure _.....

Distribution of solute concentration as a result of the roll separating force simulated results of concentration compared with experimental results. [Barber and Bush 2007]

From a technological point-of-view, segregation has been associated with the V-shaped sump caused by altering the casting parameters as mentioned earlier, [Jin et al. 1982, Morris 1982]. On the other hand, when a casting process is carried out under hot conditions central segregation forms (i.e. small setback, high speed, large freezing range alloy and high metal feed temperatures) and can usually be reduced or removed by reverting to colder conditions by increasing the roll separating force, [Thomas 2003].

Cooper et al. observed that centre line segregation in twin roll cast AA1145 aluminium alloy strip can be minimized or eliminated by adding Al3Ti0.2B as an effective grain refiner, [Cooper et al. 1994]. But grain refiners have some disadvantages during hot and cold rolling of twin roll cast strip, since insoluble grain refiner particles in an alloy can act as nucleants for crack initiation during further down stream processing. There is a possibility that critical end products can be made if the as-cast microstructure is segregation free, [Thomas 2003]. Therefore, there is a global industrial interest in finding 
new solutions in order to produce critical end parts with fewer defects. The research described in this thesis investigates the effect of grain size on liquid segregation in a TRC process.

b) Ripple Defects. A series of level lines or ripples are frequently observed on the surface of the strip cast material which are recurrent and normal to the casting direction, [Bradbury 1994]. Espedal and Roder describe the effect of a high casting speed on the shape of level lines. They suggest that at a higher casting speed, the meniscus pulses unstably between two positions which leads to very uneven level lines, [Espedal and Roder 1993], as seen in Figure 2.16. The ripple defects in magnesium alloys can be minimized by stabilizing the meniscus shape, e.g. by gauge reduction and decreasing casting speed, [Nakaura and Ohori 2005]. The surface quality of the final cold rolled sheet can be influenced by the ripple marks on the TRC strips; such as, its detrimental effect on surface corrosion resistance of end products. Therefore, the optimum casting conditions need to be investigated to suppress ripple marks, [Esaki et al. 2006].

Figure 2.16:

Schematic drawing illustrating the ripple mark formation mechanism. [Esaki et al. 2006]

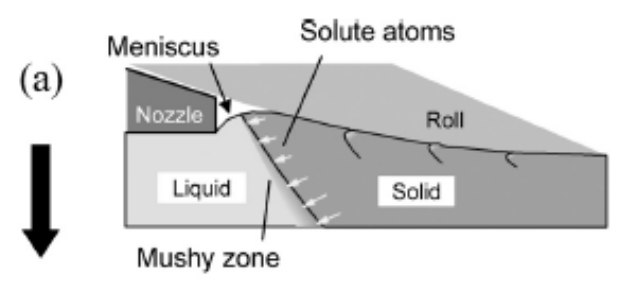

(b) Unstable meniscus

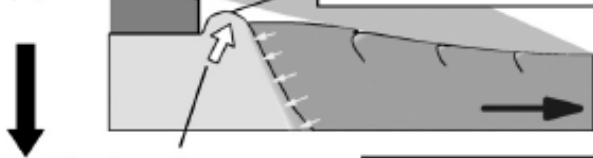

Metallostatic pressure $\quad$ Rapid cooling by roll shell

(c)

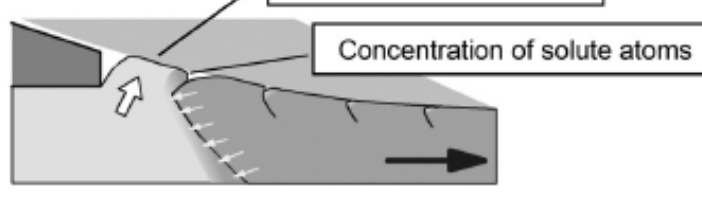

The dark regions of the ripple mark

(d)

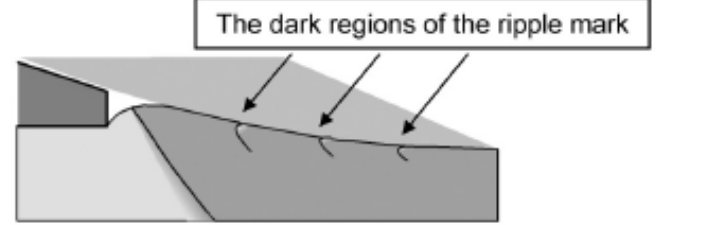


c) Edge Cracking. Edge cracking is a common defect in strip cast materials. In the TRC of aluminium, edge quality is not too critical as the edges of the as-cast strip are usually trimmed, [Menet et al. 1997]. In conventional strip rolling as the bulk material goes through the rolls, the thickness reduction in the centre of the sheet goes through a length increase, whilst part of the thickness decrease at the edges goes through a lateral spread. Tension can occur in the strained edges of the sheet, as there is a continuity between the edges and centre, a condition which leads to 'edge cracking', [Dieter 1986].

d) Heat lines. Heat lines form due to incomplete solidification of the strip before leaving the roll bite (i.e. inhomogeneous roll cooling), [Monaghan et al. 1993, Bercovici 1985]. Experimental work by Monaghan, [Monaghan 1993] confirmed the numerical model developed by Bagshaw et al., [Bagshaw et al. 1988], with regards to the effect of a reduction of heat transfer between the strip and the roll on heat lines formation. Monaghan found that anything that causes a breakdown in heat transfer, such as a greasy hand-print, between the strip and the roll surface will cause heat lines to form, [Monaghan et al. 1993]. Heat lines become visible as smooth lines elongated in the casting direction that may be a few centimetres wide, occasionally under severe conditions minor cracks and holes around the heat lines may form in the strip, [Bradbury 1994]. 


\subsection{As-cast Microstructure and Properties of TRC strip}

The association between the microstructure and properties need to be well understood in order to develop twin roll strip casting of magnesium alloys. In this section, the phenomenology of general solidification and common features of magnesium twin roll cast microstructures will be discussed.

\subsubsection{General solidification of metals}

It is well known that solute is moved around during the solidification process which is why the composition of the solid formed usually differs from that of the liquid. Various models have been proposed that can predict the distribution of solute within the solidified material. These models are explained in detail in standard texts such as Solidification Processing by Flemings, [Flemings 1974].

Consider steady-state solidification at a planar interface if the model of "No Diffusion in solid, Full Diffusional Mixing in Liquid" occurs in the system. Figure 2.17 shows the origin of the dendrite formation mechanism in the solidification process of metals. As a result of the varying solute concentration ahead of the solidification front there is a corresponding variation of the equilibrium solidification temperature, i.e. the liquidus temperature, as given by the line $\mathrm{T}_{\mathrm{e}}$ in Figure 2.17 (b). If the actual temperature of the liquid such as $\mathrm{T}_{\mathrm{L}}$, is less than the critical value shown in Figure 2.17, the liquid is supercooled in the solidification front which is known as Constitutional Supercooling (CS), [Porter and Easterling 1992]. 

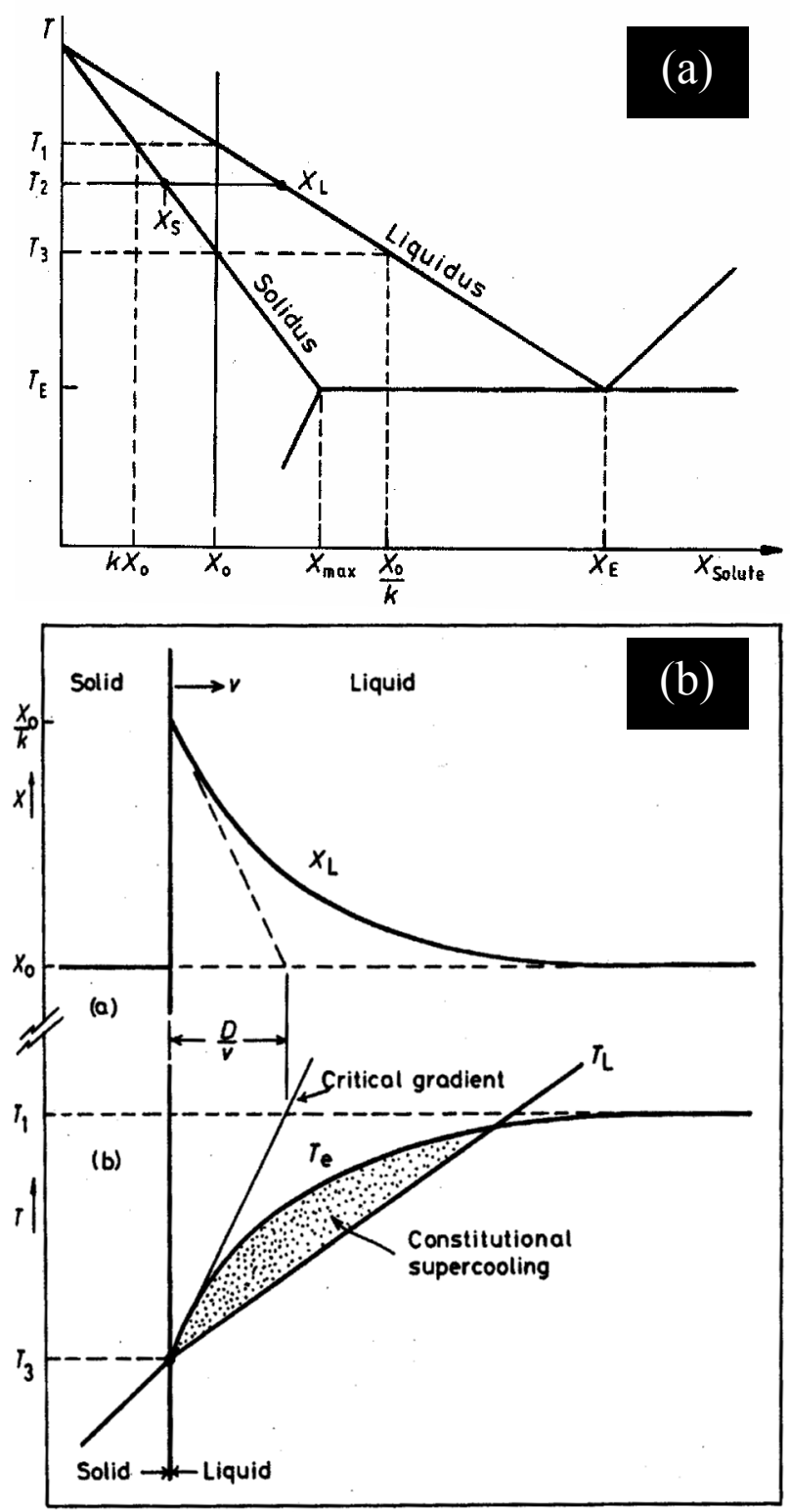

Figure 2.17:

(a) A principle binary alloy phase diagram and (b) the origin of constitutional supercooling ahead of a planar solidification front. [Porter and Easterling 1992]

If constitutional supercooling exists ahead of an initially planar solid/liquid interface a protrusion forms and at sufficiently low temperature gradients these protrusions change in shape to recesses and then to cells or primary arms. Figure 2.18 shows the correlation between the morphological transition and temperature gradient, G. It can be observed that by lowering the $\mathrm{G}$ (i.e. $\mathrm{G}_{\mathrm{d} / \mathrm{e}}$ ) the interface morphology changes from dendrites to equiaxed grains, [Stefanescu 2008, Porter and Easterling 1992]. 


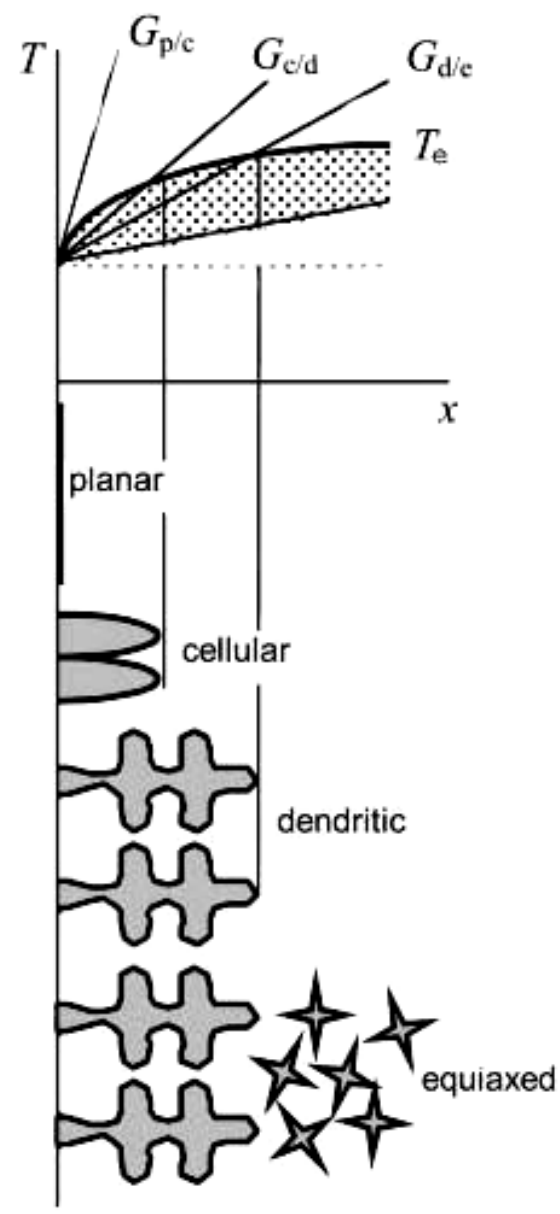

Figure 2.18:

Correlation between the thermal gradient at the interface and the interfacial morphology. [Stefanescu 2008]

Sometimes in solidified structures, the growth of columnar grains often ends with the appearance of an equiaxed zone or, possibly, a band of equiaxed grains. This is known as the columnar-to-equiaxed transition (CET), [Spittle 2006]. Spittle has reviewed various literature for the experimental parameters influencing CET. He listed the important parameters as alloy composition, superheat, fluid flow, casting size and inoculation grain refinement, [Spittle 2006].

The first analytical model of the columnar-to-equiaxed transition phenomenon was developed by Hunt, [Hunt 1984, Gäumann et al. 1997]. In addition, he proposed the most widely used to date criterion for the CET which assumes that equiaxed growth will occur when the volume fraction of equiaxed grains is greater than 0.49 (or an 'extended' volume fraction of 0.66), [Spittle 2006]. Hunt calculated that fully equiaxed growth occurs when the steady state temperature gradient is below a critical value given by: 


$$
G<0.617 N_{0}^{1 / 3}\left\{1-\left(\Delta T_{N}\right)^{3} /\left(\Delta T_{C}\right)^{3}\right\} \Delta T_{C}
$$

and it is fully columnar if :

$$
G>0.617\left(100 N_{0}\right)^{1 / 3}\left\{1-\left(\Delta T_{N}\right)^{3} /\left(\Delta T_{C}\right)^{3}\right\} \Delta T_{C}
$$

where $\mathrm{G}$ is the temperature gradient in the liquid, $N_{0}$ is the total number of heterogeneous particles available per unit volume, $\Delta T_{N}$ is the critical undercooling for nucleation and $\Delta T_{C}$ is the undercooling at the columnar front, [Hunt 1984]. The model was applied to Al-3 wt\% $\mathrm{Cu}$ and predicted that at low growth velocities, equiaxed growth depends on the efficiency of the grain refining effect of the casting process $\left(\Delta T_{N}\right)$, whereas at high gradients the number of nucleation sites is more important $\left(N_{0}\right)$, [Hunt 1984]. Previous studies show that Hunt's CET model fitted successfully to experimental data in various manufacturing processes for different metallic alloy systems, [Gäumann et al. 1997, Shibata et al. 2006, Kurz et al. 2001, Kim and Grugel 1992, Ares and Schvezov 2000, and Quested and Greer 2005].

\subsubsection{General features of magnesium alloy strip-cast microstructures}

Alteration of the cast structure of magnesium alloys can occur only by further secondary processing such as homogenization, hot or cold rolling and annealing since magnesium alloys do not have allotropic transformations like steel and the possible structural refinement during a conventional casting process is limited to some degree, [Ferry 2006]. A TRC process combines casting and hot rolling into a single step, having the 
advantages of hot or cold rolled products with a fine grain size, [Watari et al. 2004, Park et al. 2005]. Moreover according to other studies, due to the higher cooling rate offered by TRC process more structural refinement in magnesium alloy strips can be achieved compared with other conventional continuous casting processes, [Park et al. 2003, Lee et al. 2006].

Up to now, there is very little published information on the development of microstructure and properties of Mg alloys produced by a TRC process, [Kawalla et al. 2008, Watari et al. 2004, Watari et al. 2007, Liang et al. 2006, Liang and Cowley 2004, Kang et al. 2008, Haga et al. 2006, Jung et al. 2007 and Duygulu et al. 2009a]. Figure 2.19 (a), shows the roll gap area of the horizontal strip caster producing AZ31 Mg alloy sheet. As can be seen from the difference in grey scale, the mid-thickness area is in the semi-solid state before it reaches the roll bite. The microstructure of the twin roll cast $\mathrm{Mg}$ strip (AZ31) on so-called stop-samples, which are produced by suddenly interrupting the casting process is illustrated in Figure 2.19 (b). An enlarged view of the microstructure is demonstrated in Figure 2.19 (c). The microstructure of twin roll cast $\mathrm{Mg}$ strip demonstrates a fairly inhomogeneous structure across the strip thickness, (Figure 2.19 (b) \& (c)). Close to the surface of the strip a chilled grain structure appears followed by the formation of a columnar grain structure elongated towards the central strip region. The region between the surface and the middle of the strip is largely distinguished by a dendritic solidification structure. In the mid-region, equiaxed zone and centre line segregation can also be found. This segregation is a mixture of $\alpha-M g, \beta-\mathrm{Mg}_{17} \mathrm{Al}_{12}$ and $\mathrm{Al}_{\mathrm{x}} \mathrm{Mn}_{\mathrm{y}}$ phases, in the case of TRC AZ alloy strips [Jung et al. 2007, Kawalla et al. 2008]. 


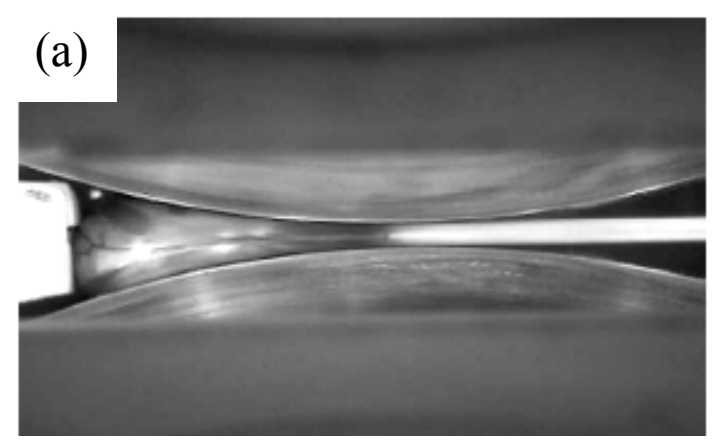

(b)

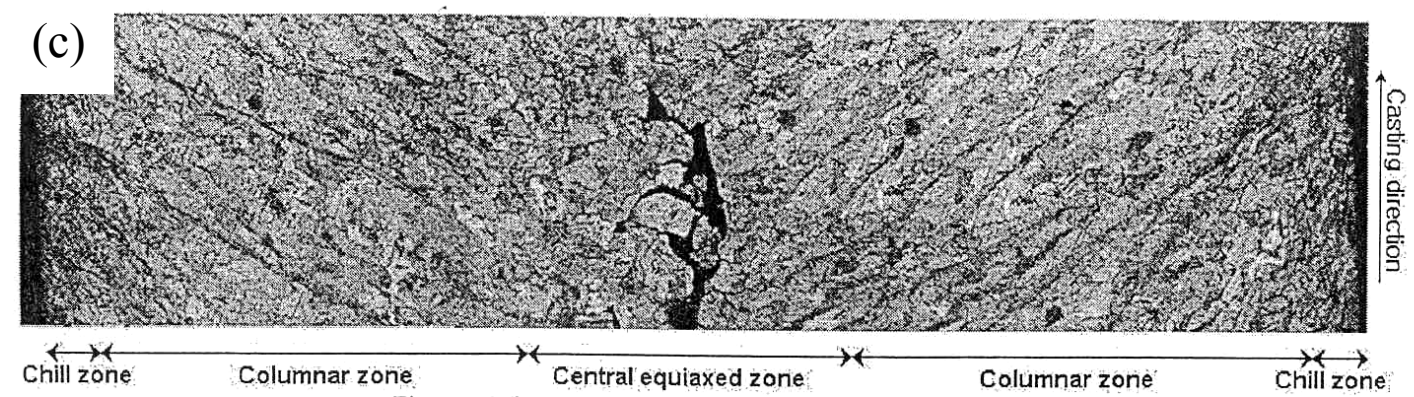

Figure 2.19:

Roll gap zone of the twin roll strip caster [Park et al. 2002] (a), microstructure of the twin roll cast stop sample of AZ31 Mg-strip [Kawalla et al. 2008] (b), enlarged cross sectional view of AZ31 Mg-strip [Jung et al. 2007] (c).

As mentioned earlier, the amount of centre line segregation is highly dependent on the process parameters and sump depth. In a TRC process, the deviation of the preferred growth direction of dendrites away from the maximum heat flux direction is caused by the flow of liquid metal parallel to the roll surface, [Takatani et al. 2000]. Further, the dendritic solidification structure deforms after complete solidification by partial rolling in the roll gap. In the as-cast condition a grain size of about $800 \mu \mathrm{m}$ close to the edge and about $1000 \mu \mathrm{m}$ in the centre has been observed for AZ31 twin roll cast strip, [Löchte et al. 2005].

TRC offers a more promising route for the economical production of magnesium sheet but unfortunately, it produces strip with a coarse and non-uniform microstructure, severe defects, centre line segregation and poor surface quality, [Engl 2005, Yun et al. 2000, Bian et al. 2009, Kawalla et al. 2008]. Therefore, there is a commercial need and a scientific challenge to overcome these problems. 


\subsection{Down-stream processing of magnesium alloy strip}

In the TRC process, thin gauge strips (2-8 $\mathrm{mm}$ for magnesium) with non-uniform microstructures are produced at high solidification rates, [Park et al. 2009b]. Therefore as-cast strip, has a particular microstructure and surface condition which may or may not be suitable for immediate fabrication into the desired component. It may be necessary to further modify the strip to some degree by hot and/or cold rolling and/or thermal processing in order to alter the strip dimensions, internal structure and surface conditions, [Ferry 2006].

Previous research has shown that thin metallic strips produced by a TRC process compared with conventional plate or strip production routes, require new downstream processing cycles to manufacture highly formable strips. This is because the thin strips undergo deformation gradients in the caster roll gap, [Sun et al. 2006, Bae et al. 2009, Birol 2009]. In order to improve the quality of the magnesium cast strip much research has been carried out to characterize the TRC process and to optimize casting parameters [Park et al. 2009b, Jung et al. 2007, Kang et al. 2008, Liang et al. 2006]. However not much effort has been devoted to develop down-stream processing cycles for magnesium thin strip production [Essadiqi et al. 2009, Kawalla et al. 2008, Duygulu et al. 2009b]. It is therefore of significant technological interest to develop suitable downstream processing cycles for twin roll cast magnesium thin-strips.

Homogenization, hot rolling and annealing processes are known to be consecutive stages required to generate fine grains and a more homogeneous final microstructure which may lead to improvement in mechanical properties of thin-gauge magnesium sheets, [Essadiqi et al. 2009, kawalla et al. 2008, Duygulu et al. 2009a\&b, Ferry 2006]. 


\subsubsection{Homogenization process}

There are very few studies on the effect of homogenization on the microstructure and mechanical properties of TRC Mg alloy, [Kawalla et al. 2008, Nakaura and Ohori 2005, Duygulu et al. 2009a \& b]. For example, Kawalla and co-workers showed that the elongation of TRC AZ31 alloy at room temperature increases from $\sim 5 \%$ in the as-received condition (directly after twin roll casting) to $15-25 \%$ due to homogenization at $350-450^{\circ} \mathrm{C}$, while the strength values run in the opposite direction. In another investigation, Duygulu and co-workers illustrated that by increasing the temperature and holding time in the homogenization stage the elongation of as-cast and hot-rolled AZ31 strip increases from $\sim 12 \%$ to $\sim 20 \%$. It is believed that the improvement of the elongation by such a homogenization process is considered to arise from dissolution of micro-segregation of $\mathrm{Al}$ and $\mathrm{Zn}$ atoms in the dendrite cell boundaries, [Nakaura and Ohori 2005]. At the time of this research, there are not any clear scientific explanations to justify these findings.

Recent investigations on down-stream processing of TRC AA3105 and Al-1 Fe-0.2 Si aluminium alloys show that the homogenization process results in a significant reduction of the recrystallized grain size and faster recrystallization kinetics. Coarsening of constituent particles through homogenization at high temperature is considered to be the reason for the higher recrystallization rate which can act as nucleation agents for new grains, [Birol 2009, Sun et al. 2006].

\subsubsection{Hot rolling process}

Hot rolling is usually conducted at high temperatures, i.e. $T>0.5 \mathrm{~T}_{\mathrm{m}}$ where $\mathrm{T}_{\mathrm{m}}$ is the absolute melting temperature of the alloy, [Avedesian and Baker 1999]. It has been 
reported that the starting temperature for recrystallization in extruded AZ91 alloy is around $175^{\circ} \mathrm{C}$ [Mabuchi et al. 1999], and its full recrystallization temperature would occur at $200^{\circ} \mathrm{C}$ [Czerwinski and Zielinska-Lipiec 2003]. Thus, dynamic recovery and dynamic recrystallization (DRX) in magnesium alloys is expected to occur during deformation at high temperatures. Up to now, two different recrystallization mechanisms have been proposed for magnesium alloys which are explained in the following sections.

\section{(a) Rotation recrystallization}

The mechanism suggested by Ion et al. [Ion et al. 1982], involves the progressive rotation of subgrains neighbouring to pre-existing grain boundaries as the material is strained. Local shearing caused by severe deformation close to grain boundaries is the driving force for this mechanism (Figure 2.20 (a)). This is due to the lack of independent slip systems in magnesium alloys. Subgrain boundaries may increase their misorientation by continuously absorbing lattice dislocations (Figure 2.20 (b)) to create new grains (Figure 2.20 (c)). This is termed rotation recrystallization or RDX, as shown in Figure 2.20.

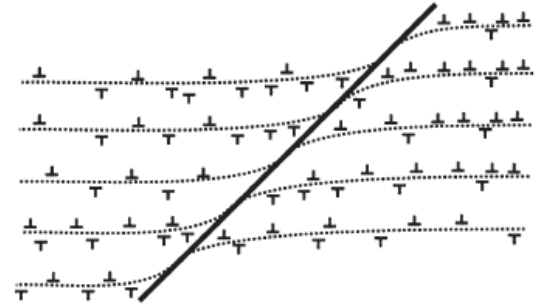

(a)

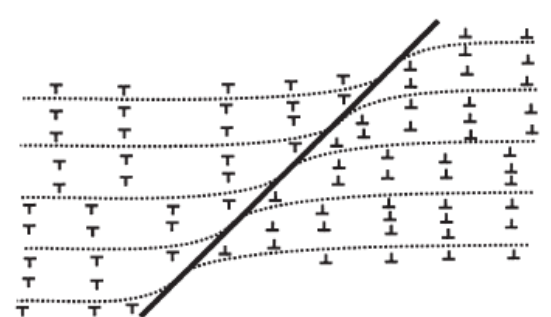

(b)

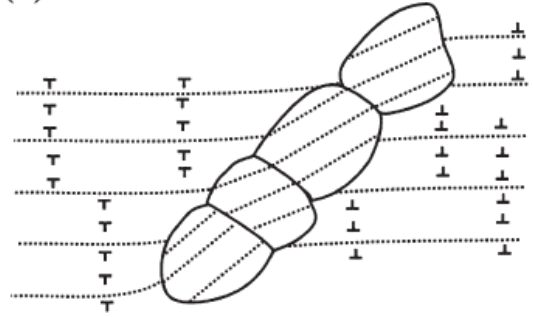

(c)

Figure 2.20:

Schematic diagram showing the rotation recrystallization in magnesium alloys. [Ion et al. 1982] 


\section{(b) Migration recrystallization}

Migration recrystallization, also termed strain-induced grain boundary migration (SIBM), usually arises from a difference in dislocation content on opposite sides of the grain boundary of a strained material (Figure 2.21 (a)). This leads to a difference in stored energy on opposite sides of the grain boundary which results in bulging part of a preexisting grain boundary (Figure 2.21 (b)), leaving a lower dislocation content region behind the migrating boundary (Figure 2.21 (c)). Further formation of new strain-free grains occurs in these serrated regions (Figure 2.21 (d)), [Beck et al. 1950, Humphreys and Hatherly 2004].

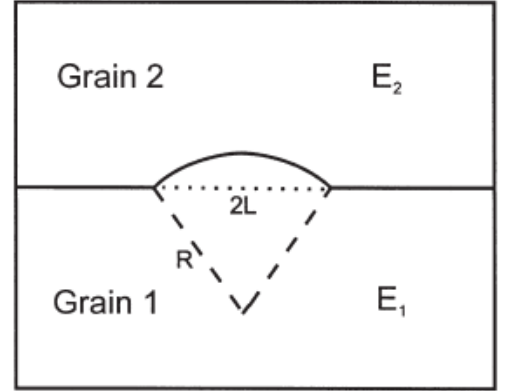

(a)

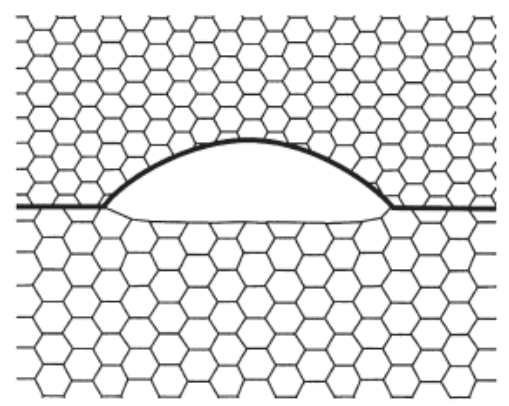

(c)

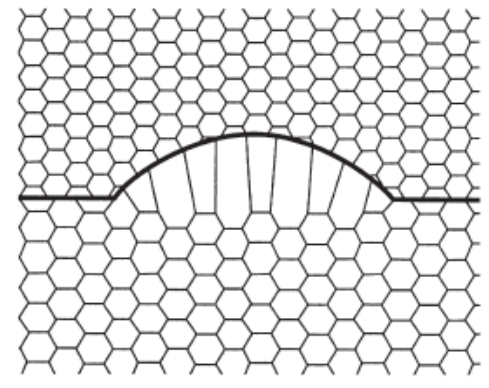

(b)

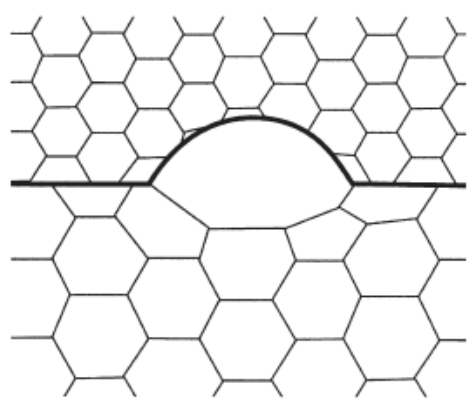

(d)

Figure 2.21:

(a) SIBM of a boundary separating a grain of low stored energy $\left(E_{1}\right)$ from one of higher energy $\left(E_{2}\right),(b)$ dragging of the dislocation structure behind the migrating boundary, (c) the migrating boundary is free from the dislocation structure, (d) SIBM originating at a single large subgrain. [Humphreys and Hatherly 2004]

It has been found that at high temperatures (i.e. $300-450^{\circ} \mathrm{C}$ ) in ZK60 magnesium alloy, deformation becomes more homogenous as the non-basal slip occurs more easily which leads to activation of a discontinuous SIBM mechanism [Galieyv et al. 2001]. By contrast at 
a similar temperature, deformed AZ61 [Del valle et al. 2003], AZ31 [Tan and Tan 2003] and Mg-0.8wt.\%Al [Ion et al. 1982] magnesium alloys show RDX to be the dominant recrystallization mechanism. Hence, it can be concluded that depending on the magnesium alloy type and historical thermomechanical processing the dominating recrystallization mechanism will vary.

In general, recrystallization can be classified into continuous and discontinuous types, [Humphreys and Hatherly 2004, Tan and Tan 2003, Galiyev et al. 2001]. In continuous recrystallization dislocations are left in the recrystallized grains (RDX) while in discontinuous recrystallization dislocations are removed through the sweeping action of migrating grain boundaries (SIBM), [Tan and Tan 2003]. Recrystallization will originate at inhomogeneities in a deformed microstructure such as; grain boundaries, twins and second phase particles, [Humphreys and Hatherly 2004]. Figure 2.22 shows the effect of grain boundary migration on nucleation of recrystallized grains in a magnesium alloy.

\section{Figure 2.22:}

Optical micrograph showing the effect of grain boundaries as nucleation sites for new rerystallized grains controlled by a SIBM mechanism in M16 magnesium alloy deformed to a true strain of 1.2. The arrows indicate the grain boundary bulging. [Robson et al. 2009]

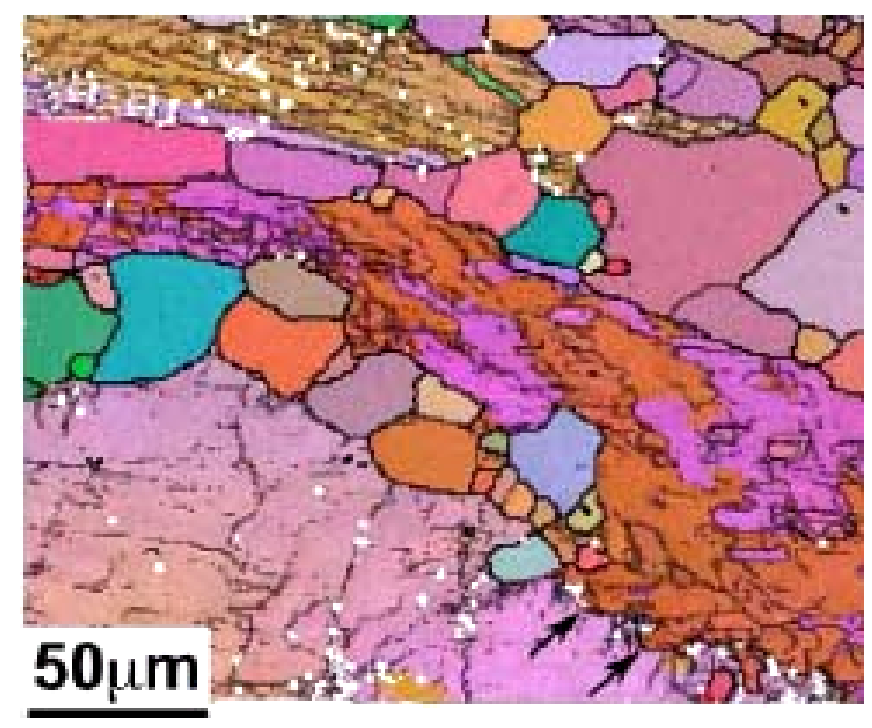

The effect of large particles in promoting recrystallization through the mechanism of particle-stimulated nucleation (PSN) is well recognized and will only be possible if 
dislocations accumulate at the large particles ( $>1 \mu \mathrm{m}$ diameter) during deformation to form deformation zone [Humphreys and Hatherly 2004]. Recently, the effect of particles on recrystallization in magnesium alloys, e.g. $\mathrm{Mg}-\mathrm{Si}, \mathrm{Mg}-\mathrm{Mn}$ and $\mathrm{Mg}$-rare earth metals, have been studied [Robson et al. 2009, Bae et al. 2009, Bohlen et al. 2007, Ball and Prangnell 1994, Mabuchi et al. 1996] but as yet there are few studies on the effect of $\beta-\mathrm{Mg}_{17} \mathrm{Al}_{12}$ eutectic particles on the recrystallization behaviour of Mg-Al-Zn alloys, [Li et al. 2007a].

\subsubsection{Annealing process}

Because dynamic recovery and recrystallization has already occurred during hot rolling, microstructural changes due to static recovery and recrystallization during further annealing process are generally small, [Humphreys and Hatherly 2004]. In depth knowledge of static recrystallization and related phenomena is given by Humphreys and Hatherly, [Humphreys and Hatherly 2004].

Löchte and co-workers have carried out tensile testing of AZ31 TRC rolled sheet in hotrolled condition followed by annealing for 30 minutes at various temperatures. Their results showed that the elongation of annealed samples is increased from $\sim 10 \%$ to $\sim 15 \%$ and the yield strength decreased from $190 \mathrm{MPa}$ to $150 \mathrm{MPa}$ after annealing at $350^{\circ} \mathrm{C}$ for half an hour, [Löchte et al. 2005]. Recently, Duygulu and co-workers have shown approximately the same trend of elongation and yield strength variation in TRC AZ31 hot-rolled and annealed strip at $400^{\circ} \mathrm{C}$ for 6 hours, [Duygulu et al. 2009b]. There is not enough evidence published so far related to the optimum conditions and microstructural evolution for annealing TRC magnesium alloy strips and further work is needed to understand the behaviour of this important class of material, [Ferry 2006, Essadiqi et al. 2009]. 
The mechanical property data published for TRC processed magnesium alloy hot-rolled sheets are limited compared with conventional continuous cast and rolled (CC) magnesium alloy sheets. Some mechanical behaviour of TRC processed magnesium alloy hot-rolled sheets have been reported to demonstrate improvements over CC products, as given in Table 2.2. It is shown that mechanical tests of TRC AZ31B sheet compare favourably with those of conventional wrought magnesium AZ31B sheet. This has been attributed to the rapid rates of solidification in a TRC process which gives marked differences in grain structure, dendrite arm spacing, micro- and macrosegregation, porosity, distribution and size of primary constituents, [Liang and Cowley 2004, Ferry 2006]. These factors will strongly influence the mechanical behaviour of TRC magnesium alloys hot-rolled sheets.

Table 2.2:

Mechanical properties of magnesium alloy hot-rolled sheets produced by TRC and Conventional casting processes.

\begin{tabular}{|c|c|c|c|c|c|}
\hline Materials & $\begin{array}{l}\text { Processing } \\
\text { condition }\end{array}$ & $\mathrm{YS}, \mathrm{MPa}$ & UTS, MPa & $\begin{array}{l}\% \text { Elongation- } \\
\text { to-failure }\end{array}$ & Reference \\
\hline \multirow{7}{*}{ AZ31B } & \multirow{6}{*}{$\mathrm{TRC}^{*}$} & 236 & 284 & 15.3 & [Park et al. 2004] \\
\hline & & 170 & 240 & 17 & [Thyssenkrupp 2009] \\
\hline & & 120 & 240 & 18 & [Kawalla et al.2008] \\
\hline & & 293 & 310 & 6.5 & [Nakaura and Ohori 2005] \\
\hline & & $\begin{array}{l}195-210 \\
250-265\end{array}$ & $\begin{array}{l}280-295 \\
305-310\end{array}$ & $\begin{array}{l}18-21 \\
13-15\end{array}$ & [Jung et al. 2007] \\
\hline & & 213 & 288 & 21 & \multirow{2}{*}{ [Liang and cowley 2004] } \\
\hline & $\mathrm{CC}^{* *}$ & 202 & 266 & 17 & \\
\hline AZ41M & TRC & 218 & 330 & 12.3 & [Kang et al. 2008] \\
\hline \multirow{2}{*}{ AZ91 } & \multirow{2}{*}{ TRC } & 167 & 264 & 6.2 & \multirow{2}{*}{ [Park et al. 2003] } \\
\hline & & 197 & 246 & 1.5 & \\
\hline
\end{tabular}

* TRC and rolled

** Conventional Continuous cast and rolled 


\subsection{Technologies for production of grain-refined feedstock}

Improvement of elevated temperature formability and room temperature mechanical properties of magnesium sheet are essential in order to compete with current automotive sheet materials, [Essadiqi et al. 2009]. The main limitations that restrict the application of wrought magnesium alloys are poor ductility and sheet forming limits at ambient temperatures [Emley 1966]. This is a consequence of its hexagonal close-packed crystal structure which limits the number of operative slip systems at room temperature. Previous research on diverse metallic alloys established that grain refinement could improve strength and ductility at room temperature, and make alloys superplastic at elevated temperatures, [Koike et al. 2003, Chapman and Wilson 1962, Valiev et al. 1991, Matsubara et al. 2003, Yamashita et al. 2001]. Moreover, recent research has shown that a refined grain size in magnesium alloys can minimize the formation of twinning during severe deformation which is detrimental to the mechanical properties of a final product. Twins can promote voids and crack formation in deformed Mg alloys, [Barnett et al. 2009, Barnett 2007, Jain et al. 2008]. Presently, the technologies which are able to produce either grain-refined feedstock for sheet manufacturing industries or near-net shape grain-refined product can be categorized into liquid state or solid state processing.

\subsubsection{Solid state processing}

\section{(A) Severe plastic deformation (SPD) processes,}

Up to now, significant efforts to use solid state processing to produce magnesium alloy billets/strips/sheets with extremely fine grain structure have been made. Recently, the grain refinement of $\mathrm{Mg}$ alloys on coarse-grained bulk materials produced by 
conventional casting methods were applied by severe plastic deformation (SPD) approaches, such as:

- Equal-Channel Angular Extrusion or Pressing (ECAE/ECAP), (Figure 2.23 (a))

[Yamashita et al. 2001, Mukai et al. 2001, Lee and Huang 2004, Lin et al. 2005].

- Accumulative Roll Bonding (ARB), (Figure 2.23 (b)) [Del Valle et al. 2005, Pérezprado et al. 2004].

- Differential Speed Hot-Rolling (DSR) [Watanabe et al. 2007, Huang et al. 2009] and Cross-roll hot-rolling [Chino et al. 2009, Chino et al. 2006] (Figure 2.23 (c)).

- Alternate Biaxial Reverse Corrugation (ABRC), (Figure 2.23 (d)) [Yang and Ghosh 2006].
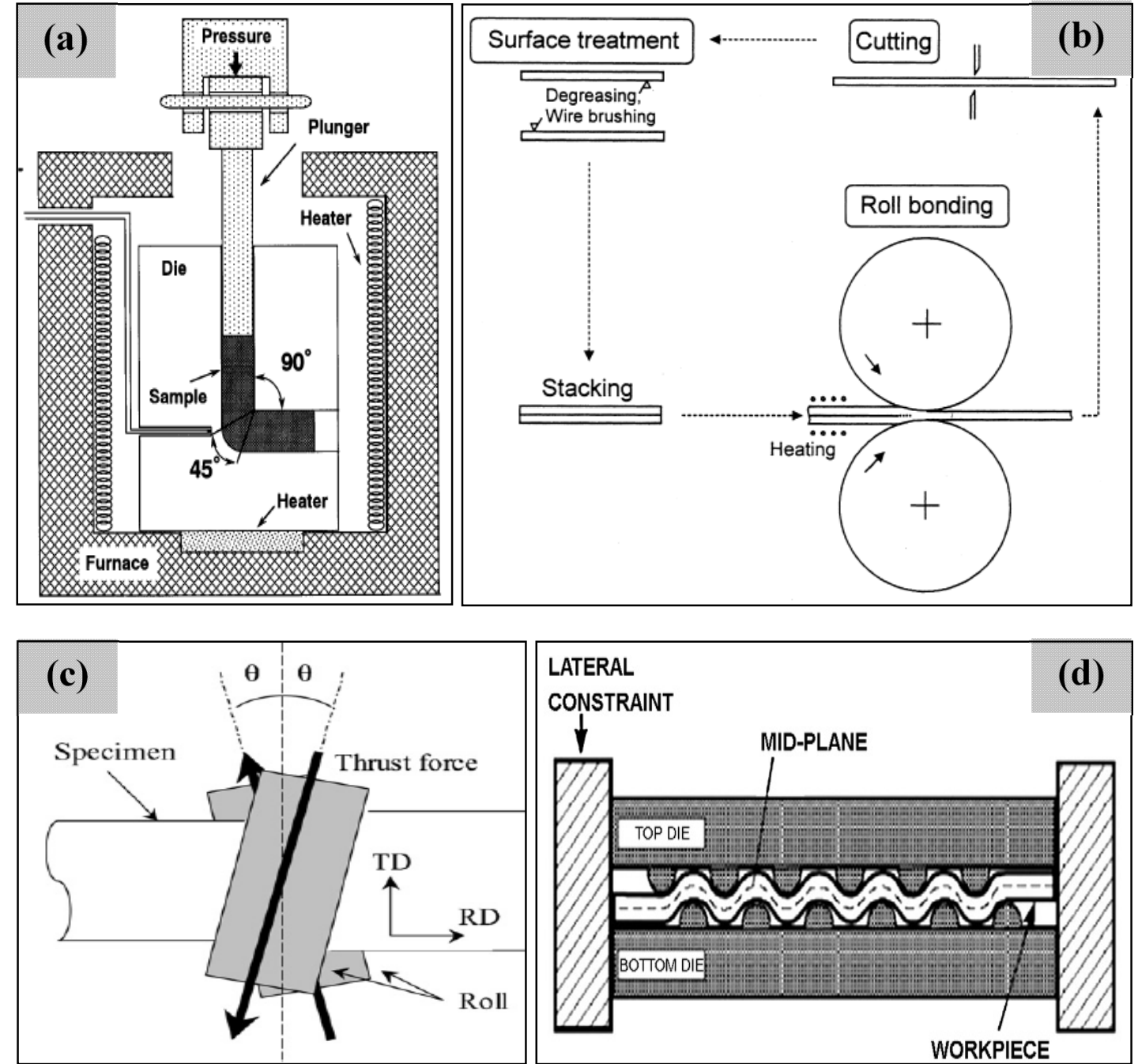

Figure 2.23:

Schematic diagram showing the major SPD processes for magnesium alloys, (a) ECAE/ECAP process [Yamashita et al. 2001], (b) ARB process [Saito et al. 1999], (c) Cross-roll hot rolling process [Chino et al. 2006] and (d) ABRC process [Yang and Ghosh 2006] 
$\underline{\text { ECAE/ECAP }}$ is a technique which uses a die that contains an inner channel bent through a sharp angle. Samples in the form of machined rods or bars to fit within the channel are pressed through the die using a plunger. Consequently as the sample passes through the channel, severe strain is forced on it. In order to reduce the grain size of the final product this technique has to be repeated numerous times. Accurate control of the manufacturing conditions for $\mathrm{Mg}$ alloys is required, otherwise the process may lead to cracking of $\mathrm{Mg}$ billets or massive segmentation during solid-state processing, [Figueiredo et al. 2007, Yamashita et al. 2001].

$\underline{\mathrm{ARB}}$ is the only SPD process appropriate to continuous production of bulk materials. In this process the initial material is rolled to $50 \%$ of its thickness, then the rolled material is cut in to two pieces followed by the two pieces being stacked into its original dimension and then rolled again, [Tsuji et al. 2003].

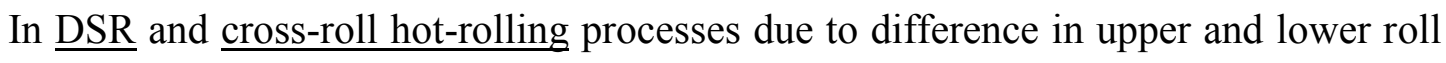
speeds or angles, severe shearing at high temperature is applied to the specimen which causes grain refining of the sample through the DRX mechanism, [Huang et al. 2009, Chino et al. 2009].

In the $\underline{\mathrm{ABRC}}$ process, a flat metal work piece is isothermally pressed and corrugated between sinusoidal wave dies. The wavy work piece will be rotated through $90^{\circ}$, and again corrugated. With successive rotation and flipping, all parts of the bulk material are deformed heavily, [Yang and Ghosh 2006].

Generally, the grain size of the final refined structure obtained by these processes is in the micrometre or submicrometre range. The dynamic recovery and recrystallization (DRX) mechanisms, as described in Section 2.6.2., were found to be responsible for grain refinement for most of those processes. This leads to an increase in tensile 
elongation; for example, Yamashihta and co-workers found that by using an equalchannel angular extrusion (ECAE), the grain size was reduced from $400 \mu \mathrm{m}$ to $17 \mu \mathrm{m}$ which resulted in increasing the elongation-to-failure up to $15 \%$, [Yamashita et al. 2001]. Nevertheless, none of the above processes are likely to find widespread application in the magnesium industry due to only small amounts of final produced materials, the requirement of a critical control on the manufacturing conditions and the high capital cost for maintenance and preparing initial feedstock. Hence, significant investigations are yet required to develop cost-effective $\mathrm{Mg}$ grain refinement solid-state techniques, [Del Valle et al. 2003, Barnett et al. 2009, Liu and Ghosh 2005].

\subsubsection{Liquid state processing}

\section{(A) Mechanical stirring, [Mehrabian and Flemings 1972]}

This procedure is thought to be the simplest and one of the most used processes to date for achieving grain-refined structures, [Flemings 1991]. To advance the formation of grain-refined structure by a shearing force, Augers, impellers or multi-paddle agitators are placed on a central rotating shaft to establish melt agitation, [Flemings et al. 1976], as illustrated in Figure 2.24. The final grain-refined bulk material can be used as a feedstock for down-stream processing.

Figure 2.24:

Schematic diagram of a high temperature mechanical stirrer, [Flemings et al. 1976].

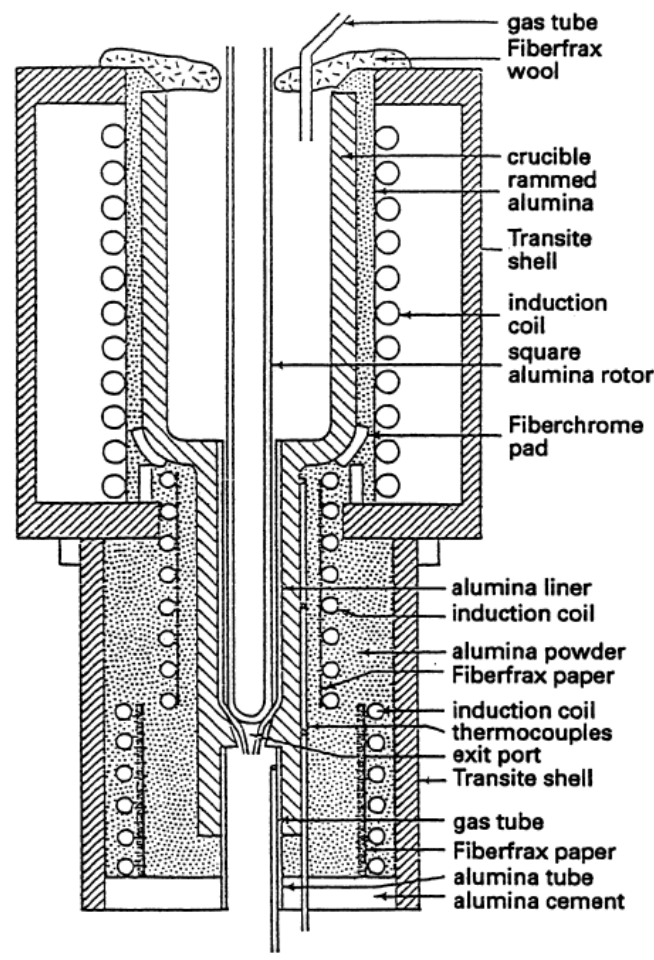




\section{(B) Electromagnetic vibration (EMV), [Kenney et al. 1988]}

In this technique, the interaction between the applied stationary and variable magnetic fields generate high local shear within a continuous casting mould, and as a result continuous billets of solidified grain-refined alloys are produced, [Gue et al. 2005, Kirkwood 1994]. There is no stirring device used in this process, therefore the melt contains low levels of contamination, [Fan 2002]. The disadvantages of this technology are; high production costs (up to $50 \%$ of the component cost) [Hall et al. 2000], microstructural non-uniformity in the cross-section of the cast billet and further large-size billet forming methods such as extrusion or forging are needed, [Fan 2002, Park et al. 2009a].

\section{(C) Rapid cooling,}

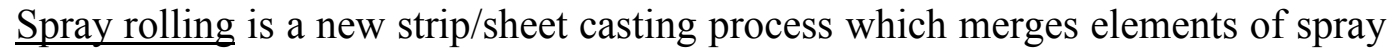
forming and TRC, [McHugh et al. 2004]. In this process a high velocity inert gas causes molten metal to atomize then the formed droplets are quenched in flight $\left.\left(\sim 10^{3} \mathrm{~K}^{-1}\right)^{-1}\right)$ and the spray placed onto mill rolls, [McHugh et al. 2008]. The resulting microstructure is compromised of very fine equiaxed grains. High production cost, the difficulty of the accurate control of droplet solid fractions and the dependency of strip quality to gas-to-metal mass flow ratios are the disadvantages of this process, [McHugh et al. 2008, Lin et al. 2004].

Planar-flow melt spinning (PFMS), also known as planar-flow spin casting is another rapid cooling process. In this technique, molten metal flows through a planar nozzle which is close to a rotating metallic wheel and then solidifies at a high cooling rate $\left(\sim 10^{4}-10^{8} \mathrm{~K} \cdot \mathrm{s}^{-1}\right)$. Eventually, a thin grain-refined ribbon comes out from the caster, [Byrne et al. 2007, Narasimhan 1979]. Only low-dimensional samples, e.g. fine threads can be fabricated with this method because of the strict requirement in heat extraction, [Li et al. 2007b]. 


\section{(D) Chemical grain refining,}

Chemical grain refinement is a rare practice in continuous casting of Al-bearing $\mathrm{Mg}$ alloys, since there is no effective grain refiner available for this group of alloys. In chemical grain refining, the insoluble particles may impair the processability of the semifinished stock and the mechanical properties and recycleability of the final Mg-based alloy product, [Fan 2002, Mizutani et al. 2005]. Sr, Re, Th, Si, Ca, B, Ti, AlN, TiB $2, \mathrm{TiC}, \mathrm{SiC}$, $\mathrm{ZnO}$ are examples of grain refining additives for Al-bearing $\mathrm{Mg}$ alloys, [Fan et al. 2009a]. It is noteworthy to say that chemical grain refining as a method for releasing heterogeneous nucleation agents, is not used alone but used in conjunction with other feedstock production methods such as electromagnetic vibration (EMV) and liquidus casting, [Wang et al. 2007a \& b, Fan 2002]. More detailed information can be found in a review paper by StJohn et al. [StJohn et al. 2005].

\section{(E) Liquidus casting, [Xia and Tausig 1998, Yurko et al. 1999]}

Liquidus casting is also known as low superheat casting. Here a melt with a uniform temperature just above its liquidus temperature is poured into a mould for solidification. The resulting microstructures are usually fine and non-dendritic, [Fan 2002].

All the technologies described above except the single stage strip production in the rapid cooling technique require extensive thermo-mechanical processing on the continuously cast feedstock to achieve microstructural refinement and compositional uniformity. Such thermo-mechanical processing is usually low in material yield, intensive in energy consumption, capital investment and manpower, and hence, inevitably high in cost. A grand challenge is to develop solidification processing technologies which can ensure a fine and uniform as-cast microstructure free from macro-segregation and cast defects, so 
that the cast products can be either used directly in the as-cast state, or only require minimal thermo-mechanical processing, [Fan et al. 2009b].

Table 2.3 shows mechanical properties of grain-refined magnesium alloy feedstocks or sheets produced by the above mentioned solid- or liquid-state processes. The data given in this table shows a wide variation of grain size and percentage of elongation-to-failure for magnesium alloy feedstocks/sheets produced by different available manufacturing processing routes which are not consistent at a constant level.

\section{Table 2.3:}

Mechanical properties of magnesium alloy feedstocks or sheets produced by solid state or liquid state processing.

\begin{tabular}{|c|c|c|c|c|}
\hline Materials & Processing condition & $\begin{array}{l}\text { Grain size } \\
(\mu m)\end{array}$ & $\begin{array}{l}\text { Elongation- } \\
\text { to-failure } \\
(\%)\end{array}$ & Reference \\
\hline \multirow{7}{*}{ AZ31B } & $\begin{array}{l}\text { Extruded billet }+ \text { Hot-rolled } \\
\text { at } 723 \mathrm{~K} \\
\text { at } 618 \mathrm{~K}\end{array}$ & $\begin{array}{l}15 \\
44\end{array}$ & $\begin{array}{l}20 \\
16\end{array}$ & $\begin{array}{l}\text { [Chino and Mabuchi 2009] } \\
\text { [Chino et al. 2009] }\end{array}$ \\
\hline & $\begin{array}{l}\text { EMV } \\
\text { EMV-0.01 } \mathrm{Ti}^{* *}\end{array}$ & $\begin{array}{l}46 \\
25\end{array}$ & $\begin{array}{l}18.5 \\
21.5\end{array}$ & [Wang et al. 2007b] \\
\hline & $\mathrm{ARB} *$ & 2.4 & 19.6 & [Zhan et al. 2007] \\
\hline & $\begin{array}{r}\text { DSR * at } 573 \mathrm{~K} \\
\text { at } 523 \mathrm{~K} \\
\text { at } 473 \mathrm{~K} \\
\end{array}$ & $<20$ & $\begin{array}{l}13.6 \\
17.3 \\
18.5 \\
\end{array}$ & [Watanabe et al. 2007] \\
\hline & Cross-roll hot rolling at $618 \mathrm{~K}^{*}$ & 40 & 24 & [Chino et al. 2009] \\
\hline & $\mathrm{ECAP}^{* *}$ & 0.7 & 30 & [Lin et al. 2005] \\
\hline & $\begin{array}{l}\text { ECAP+annealing at } 573 \mathrm{~K} \text { for } \\
24 \mathrm{hrs}\end{array}$ & 15 & 45 & [Mukai et al. 2001] \\
\hline $\mathrm{Mg}-0.9 \mathrm{Al}$ & $\operatorname{ECAP}^{* *}$ & 17 & 15 & [Yamashita et al. 2001] \\
\hline
\end{tabular}

* Final sheet

** Primary feedstock

To tackle this grand challenge, during the past few years Fan and co-workers, [Fan et al. 2000], developed an innovative casting process known as MCAST (Melt Conditioning by Advanced Shear Technology). This novel process uses a twin screw extruder into which superheated liquid metal is poured and is continuously sheared and cooled to around its 
liquidus temperature before being relocated to a fixed or moving mould caster such as a TRC machine for strip production [Bayandorian et al. 2009], DC (direct chill) caster for continuous cast billet production [Haghayeghi et al. 2008] and die-casting machine to produce near-net shape products, [Fan et al. 1999, Ji and Fan 2000 \& 2002]. A fine grain size and much improved chemical and microstructural uniformity are the microstructural features offered by the MCAST process, [Fan and Liu 2005, Wang et al. 2006, Bayandorian et al. 2009, Fan et al. 2006, Hitchcock et al. 2007, Haghayeghi et al. 2008]. The advantages of the MCAST process are its simplicity and it is cost effectiveness for feedstock production. However the accuracy and uniformity of the temperature control, and consistency of the results in large scale production, are the challenges for industrial applications, [Fan 2002].

\subsubsection{Mechanisms for grain refinement under forced convection}

To describe the microstructural evolution from a coarse dendritic to a refined equiaxed morphology under forced convection in the MCAST process several mechanisms have been proposed. These mechanisms are summarized below, [Fan 2002]:

- Dendrite arm fragmentation mechanism

- Dendrite arm root remelting mechanism

- Growth controlled mechanism.

\subsubsection{Dendrite fragmentation theory}

Vogel et al. [Vogel et al. 1979], suggested a dendrite fragmentation mechanism to explain the grain refined microstructure observed during a melt stirring process. They suggested that under the shear forces created by melt stirring the dendrite arms bend 
plastically and the plastic strain is accompanied by dislocation production. At high temperature, grain boundaries can form by climbing and uniting the produced dislocations. When the grain boundary energy exceeds twice the solid/liquid interfacial energy, metal will wet the grain boundary and resulting in the detachment of the dendrite arms, [Vogel et al. 1979, Doherty et al. 1984, Flemings 1991], as shown schematically in Figure 2.25.

Figure 2.25:

Schematic illustration of the dendrite arm fragmentation mechanism. (a) Un-deformed dendrites, (b) after bending, (c) re-organization of lattice bending to give grain boundaries, (d) for $\gamma_{g b} \succ 2 \gamma_{s / l}$, when grain boundaries have been wetted, [Doherty et al. 1984].

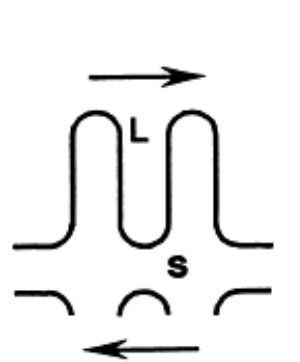

(a)

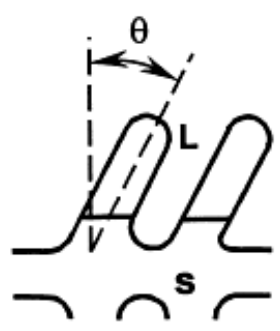

(c)

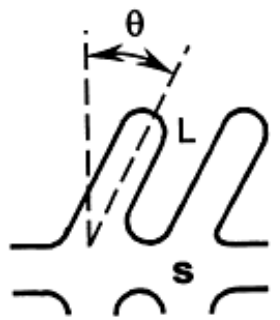

(b)

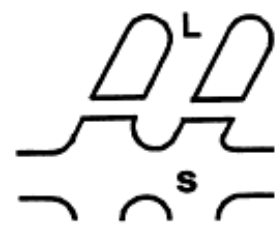

(d)

\subsubsection{Dendrite remelting theory}

Hellawell [Hellawell 1996], suggested that the driving force for refinement of the microstructure during melt stirring might be caused by temperature fluctuations induced by physical melt stirring, rather than by purely mechanical interactions. In this situation, solute enrichment and thermo-solutal convection can cause the detachment of the secondary dendrite arms from their roots.

\subsubsection{Enhanced heterogeneous nucleation and growth controlled theory}

In opposition to the theories explained above, this theory suggests that at low and intermediate shear rate the flow is essentially laminar, and it is unlikely that a laminar flow can interact with the secondary dendrite arms to apply a bending force. In addition, all the experimental and theoretical investigations on microstructural evolution 
under forced convection have been limited to simple shear flow with a low to intermediate shear rate usually less than $1000 \mathrm{~s}^{-1}$, [Fan 2002, Ji and Fan 2002]. Hence, Fan et al. proposed another mechanism under a high shear rate and high intensity of turbulence provided by MCAST process which can be understood from two different levels.

At the microscopic level, recently Fan and co-workers found out for the first time that the intensive melt shearing of AZ91 magnesium alloy provided by the MCAST process can effectively disperse the oxide films and oxide skins into individual $\mathrm{MgO}$ particles of 100-200 $\mathrm{nm}$ in diameter. They discovered that these fine $\mathrm{MgO}$ particles with a suitable size and size distribution and sufficient numbers [Quested and Greer 2004], can act as potent nucleation sites for both $\mathrm{Al}_{8} \mathrm{Mn}_{5}$ intermetallics and the primary $\alpha-\mathrm{Mg}$ phase. This results in significant grain refinement of both the primary $\alpha-\mathrm{Mg}$ and the $\mathrm{Al}_{8} \mathrm{Mn}_{5}$ intermetallics which is termed the enhanced heterogeneous nucleation mechanism, [Fan et al. 2009 a \& b]. At the macroscopic level previously other researchers have shown that under a high shear rate of flow the forced convection enhances both the mass and thermal transport away from the interdendritic region. As a consequence, the thickness of both the thermal and solutal-diffusion boundary layers is reduced, which results in the reduction of the constitutional undercooling (CS) phenomena, [Ji et al. 2002].

The theoretical analysis by Qin and Fan [Qin and Fan 2000] supports the statements explained above, using a boundary layer model to account for liquid penetration into the interdendritic region. Moreover, Das and co-workers simulated the microstructural evolution under forced convection using the Monte Carlo technique, [Das et al. 2002]. They found that the morphological development of the solid is dependant on the geometry of the diffusion zone around the growing particles. 
Based on the above considerations, experimental investigations on the effect of various turbulent flow on the solidification morphology of different alloy systems were carried out by Ji and Fan, [Ji and Fan 2000 \& 2002, Ji et al. 2001, Ji et al. 2002] and a systematic study by Das, [Das and Fan 2003], which has revealed that:

- Forced convection promotes finer particles with a non-columnar dendritic morphology.

- Forced convection accelerates crystal growth due to the enhanced mass transport during solidification.

- Turbulent flow influences much more significantly the particle size and morphology than does laminar flow.

Hence, due to the extreme uniformity of both the temperature and chemical composition fields of the sheared melt by the MCAST process heterogeneous nucleation will take place throughout the whole volume of the melt and all the nuclei discussed earlier, will have a chance to survive and eventually contribute to the microstructural refinement, [Fan et al. 2009 a \& b]. 


\section{CHAPTER 3}

\section{EXPERIMENTAL PROCEDURES}

\subsection{Materials preparation}

The magnesium alloys studied in this research were AZ91D and AZ31 provided by, MEL, Magnesium Elektron, Manchester, UK. The chemical compositions of the as-received Mg ingots are shown in Table 3.1, which are compared with the standard specifications of Mg-alloys [Avedesian and Baker 1999]. All alloy compositions are shown in wt.\% except when specified otherwise. Table 3.2 shows some selected physical properties and fabrication characteristics of the AZ91D and AZ31 Mg-alloys, [Avedesian and Baker 1999].

\section{Table 3.1:}

Chemical composition and the standard specification of AZ91D and AZ31 Mg-alloy (wt\%).

\begin{tabular}{|c|c|c|c|c|c|c|c|l|l|}
\hline Alloy & Type & \multicolumn{6}{l|}{ Chemical composition (in wt. \%) } \\
\cline { 3 - 10 } & & Zn & $\mathrm{Al}$ & $\mathrm{Mn}$ & $\mathrm{Fe}$ & $\mathrm{Si}$ & $\mathrm{Cu}$ & $\mathrm{Be}$ & Others \\
\hline \multirow{3}{*}{ AZ91D } & As-received & 0.9 & 8.9 & 0.2 & 0.003 & 0.05 & 0.001 & 0.0011 & Each $<0.015$ \\
\cline { 2 - 11 } & Standard & $\begin{array}{c}0.35- \\
1\end{array}$ & $\begin{array}{c}8.3- \\
9.7\end{array}$ & $\begin{array}{c}0.15- \\
0.5\end{array}$ & $<0.004$ & $<0.1$ & $<0.03$ & ------- & Each $<0.02$ \\
\hline \multirow{3}{*}{ AZ31 } & As-received & 0.97 & 3.34 & 0.22 & 0.0038 & 0.051 & 0.032 & 0.0004 & Total $<0.21$ \\
\cline { 2 - 11 } & Standard & $\begin{array}{c}0.6- \\
1.4\end{array}$ & $\begin{array}{c}2.5- \\
3.5\end{array}$ & $0.2-1$ & $<0.005$ & $<0.1$ & $<0.05$ & -------- & Total $<0.3$ \\
\hline
\end{tabular}

\section{Table 3.2:}

Physical properties and fabrication characteristics of AZ91D and AZ31 Mg-alloys [Avedesian and Baker 1999].

\begin{tabular}{|c|c|c|c|c|c|c|}
\hline Alloy & $\begin{array}{l}\text { Density } \\
\mathrm{gr} / \mathrm{cm}^{3}\end{array}$ & $\begin{array}{l}\text { Liquidus } \\
\text { Temp. }{ }^{\circ} \mathrm{C}\end{array}$ & $\begin{array}{l}\text { Solidus } \\
\text { Temp. }{ }^{\circ} \mathrm{C}\end{array}$ & $\begin{array}{l}\text { Ignition } \\
\text { Temp. }{ }^{\circ} \mathrm{C}\end{array}$ & $\begin{array}{l}\text { Casting } \\
\text { Temp. }{ }^{\circ} \mathrm{C}\end{array}$ & $\begin{array}{c}\text { Hot-working } \\
\text { Temp. }{ }^{\circ} \mathrm{C}\end{array}$ \\
\hline AZ91D & 1.81 & 598 & 468 & 532 & $640-675$ & ------- \\
\hline AZ31 & 1.78 & 632 & 566 & 581 & ------- & $230-425$ \\
\hline
\end{tabular}


The Mg-alloys were melted in $10 \mathrm{~kg}$ batches in a steel crucible using a Carbolite VCF $12 / 23$ electric resistance furnace at a temperature of $700^{\circ} \mathrm{C}$. To avoid severe oxidation and burning of the molten Mg-alloys, the following solutions were carried out:

- Addition of Al-5Be master alloy, supplied in the form of small ingots by, $M E L$, Magnesium Elektron, Manchester, UK, at an appropriate quantity ( 3 gr) to the melt at $700^{\circ} \mathrm{C}$.

- Inserting a protective gas mixture of $\mathrm{N}_{2}$ containing 0.4 vol. $\% \mathrm{SF}_{6}$ to the melting system through a narrow steel tube $(\sim 3 \mathrm{~mm}$ in diameter) which was carefully placed on top of the melt surface. The gas flow was set at 6 litres/minute for $\mathrm{N}_{2}$ and 0.025 litres/minute for $\mathrm{SF}_{6}$.

A steel rod was used to stir the melt to ensure complete dissolution of the master alloy in the magnesium melt. The temperature was then lowered to $670^{\circ} \mathrm{C}$ and the melts left to homogenize for 1 hour. The protective gas level was checked at regular intervals to avoid the severe oxidation during Mg-melt preparation.

\subsubsection{Chemical composition analysis}

A 'Worldwide Analytical Systems (WAS) AG, Foundry Master' was used for chemical composition analysis of the materials provided in order to compare with the standard compositional data, as shown in Table 3.1. The 'WAS Foundry Master' is an 'Arc-spark Optical Emission Spectrometer' which contains a solid state spark source, a vacuum system, an optical system and an output system (PC). A small piece $(5 \mathrm{~cm} \times 5 \mathrm{~cm})$ of the Mg-alloy ingots supplied was surface ground using a SiC 120 paper to produce a flat surface and then washed with ethanol and blow dried. The sample was then positioned on the spark stand for chemical composition analysis which was performed at least 8 times at different locations for each specimen. 


\subsection{Strip-Casting processes}

\subsubsection{The Brunel University twin roll caster}

The twin roll caster used in this study was a small-scale version of a 'horizontal twin roll casting machine' built by, Zyomax Ltd., Uxbridge, UK. A schematic diagram of a twin roll caster machine is shown in Figure 3.1. The strip exits horizontally as the TRC machine consists of two rolls vertically opposed to one another. The stainless steel rolls are $318 \mathrm{~mm}$ in diameter and $350 \mathrm{~mm}$ in width which are internally water cooled and separately driven by electric motors. The axle of each roll went through a 'chock' with the intention that by altering manually the number of screw spacers between the chocks it was possible to change the opening between the rolls, i.e. the 'roll gap'. The gap between the rolls is controlled manually, and can be varied between $1 \mathrm{~mm}$ and $8 \mathrm{~mm}$, even whereas a cast is in progress. The maximum peripheral roll speed was around 30 m.minute ${ }^{-1}$.

To feed molten metal between the rolls, which were cleaned by 320 grit SiC grinding paper, a stainless steel 'tundish' is used. This contains a stainless steel head box to perform as a container for the metal from the crucible and a nozzle to lead the liquid metal into the roll gap. As the melt exits the nozzle, sideways flow of the liquid is controlled by the attached stainless steel 'side-dams' on both side of the tip. Figure 3.2 shows a schematic diagram of a headbox of TRC process used for $\mathrm{Mg}$ strip casting. These are passed through the roll bite, and form a fixed seal against the rolls. To limit heat losses throughout the pouring stage, boxes covered with insulating blankets and bricks are placed around the headbox and crucible. The adjustable tip table can move the tundish tip back and forth so that desired setback distance can always be achieved and the nozzle tip is in contact midway between the rolls. 


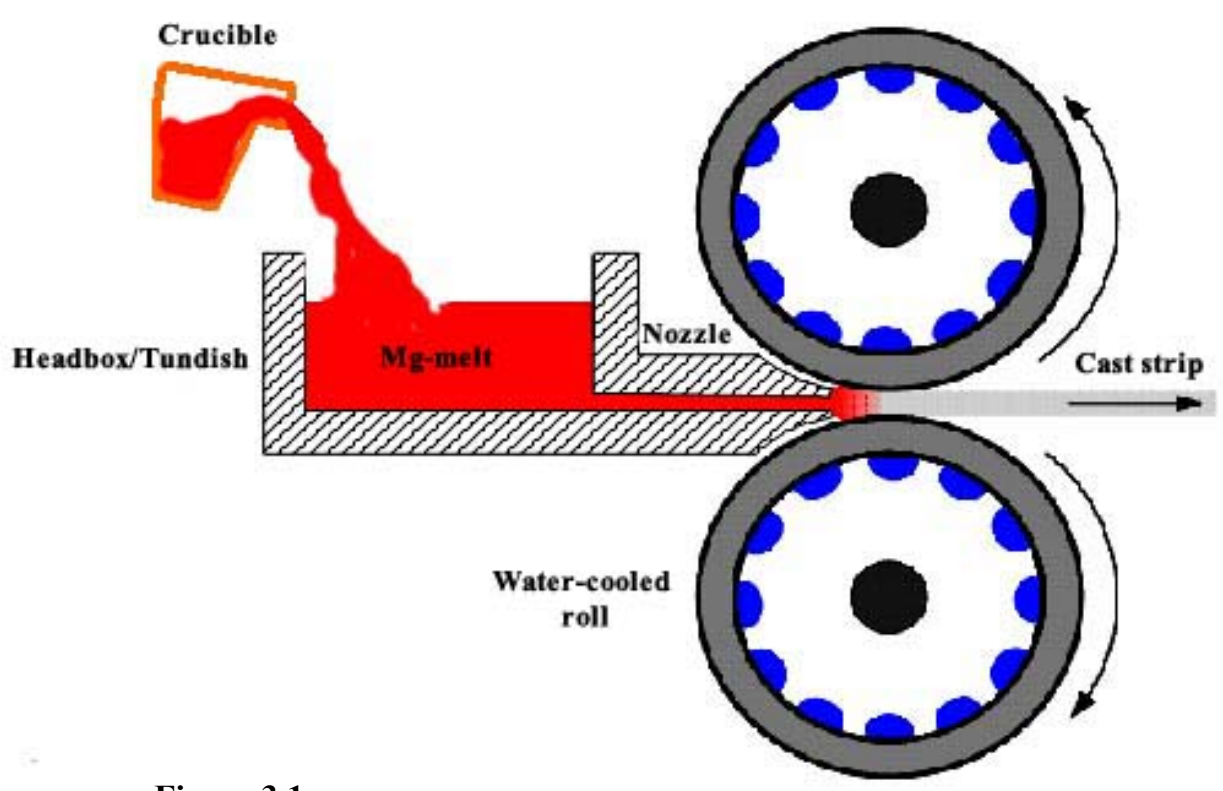

Figure 3.1:

A schematic diagram of the TRC machine used for strip casting of Mg alloys.

Before the casting procedure begins, an isolated stainless steel crucible and stainless steel head box are fully sprayed with Boron-Nitride lubricant to minimize sticking of the magnesium melt to the walls of the containers. Afterwards the containers were preheated in an electric resistance furnace to $780^{\circ} \mathrm{C}$ for at least 2 hours.

The Mg-melt was removed from the furnace into a pre-heated stainless steel crucible, using steel ladles. A thermocouple was placed in the melt to monitor its temperature and also a protective gas line $\left(\mathrm{N}_{2}\right.$ [flow rate $=6$ litres/minute] containing 0.4 vol. $\% \mathrm{SF}_{6}$ [flow rate $=0.025$ litres/minute]) was used to prevent surface melt oxidation. Once the melt reached the desired temperature, the tundish was removed from the pre-heating furnace and placed on the tip table. When the caster motor is switched on, it causes rotation of the rolls, and then the water cooling is turned on. Furnace and melt temperatures, before and after removal from the furnace plus the roll surface, cooling water and strip exit temperatures are monitored by thermocouples. The alloy melt is poured into the back of the tundish to a level determined by a metallic overflow guideline bar which was welded properly into the 
bottom side of the headbox. Keeping the level is crucial for strip quality and should be as constant as possible.

The process of casting begins with a piece of stainless steel thin strip being placed in between the roll gap in order for the metal to solidify as it touches the cold surface of the stainless steel. This stainless thin strip was pushed out by the solidified Mg-strip. The Mg-solid strip is then carried by hand. However problems occurred when handling the strip produced by long casts, but there was not any tension applied on the solidifying strip. The real machine in operation is shown in Figure 3.3(a) \& (b). The actual control panel of the TRC machine is shown in Figure 3.3(c). The central control unit of the TRC panel consists of a RPM dial, a torque reading of the upper and lower rolls and switches for starting and stopping the rolls, as shown in Figure 3.3(c). In each day of experiment, just 2 runs could be carried out since only 2 head-boxes were available to use for twin roll casting and they were not operable after casting and had to be cleaned thoroughly. The operation of the caster requires a minimum of 4 people.

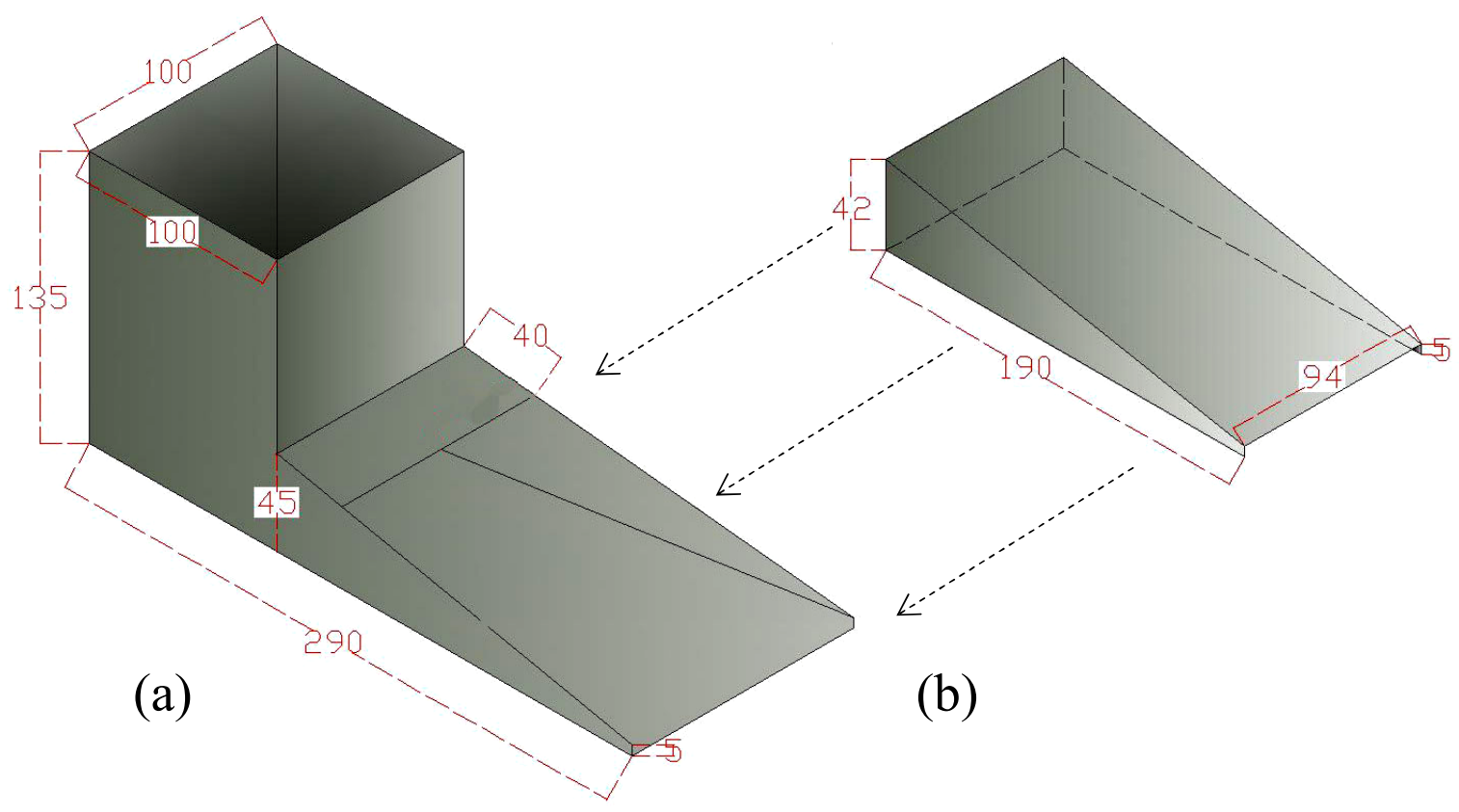

\section{Figure 3.2:}

A schematic diagram of a well-isolated stainless steel headbox for TRC machine (a), with its open top lid (b). The lid will fit properly on headbox's base before starting the casting experiment. All dimensions are in $(\mathrm{mm})$ unless otherwise stated, [BCAST]. 

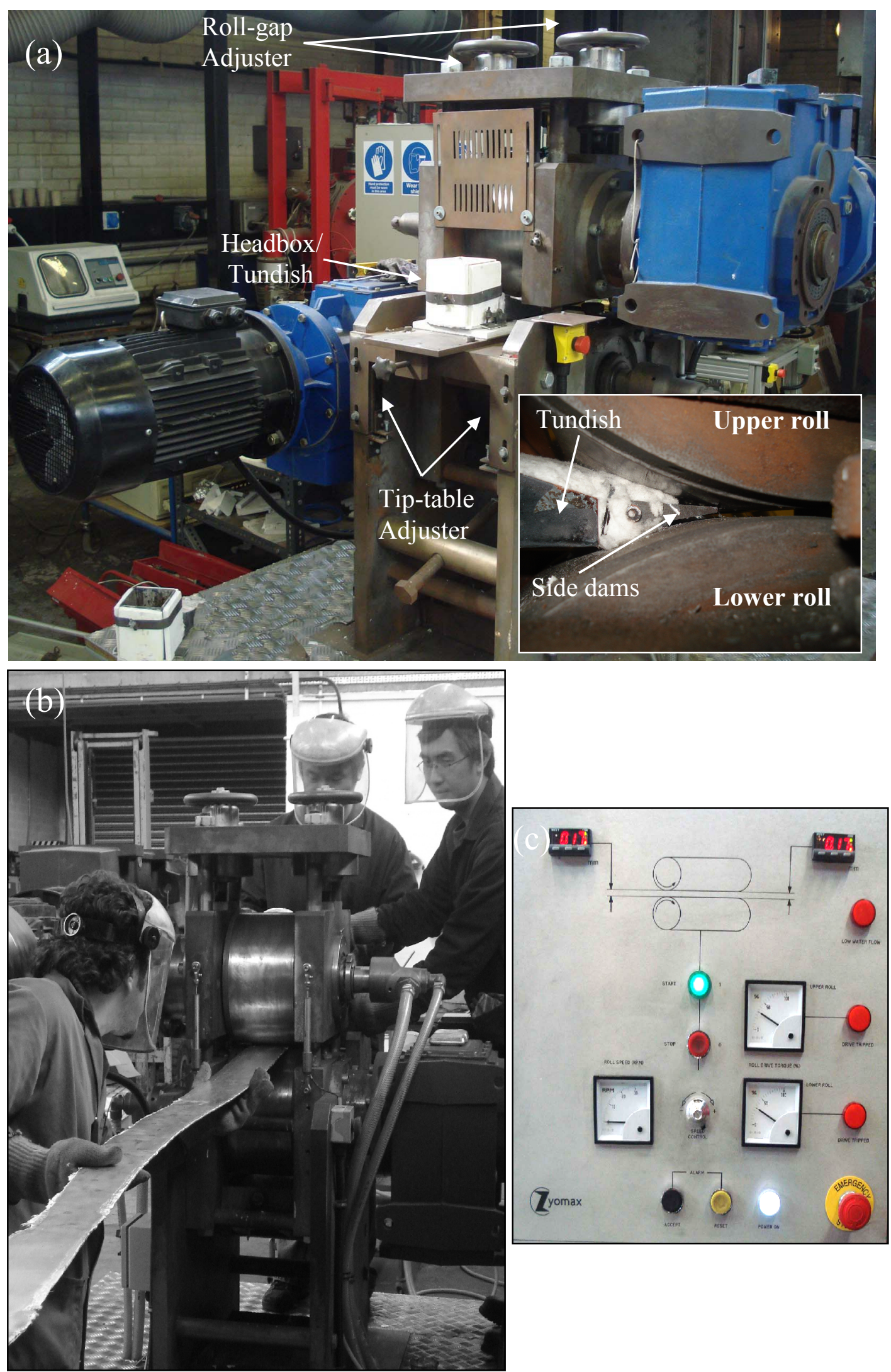

\section{Figure 3.3:}

An actual photograph of the TRC machine from its entry side with a close-up of the headbox tip and side dams which have been placed in between of the upper and lower rolls (a), a cast in progress from the metal exit side of the caster (b), central control panel of the TRC machine (c), [BCAST]. 


\subsubsection{Melt conditioned twin roll casting (MC-TRC) process}

The main aspect of this investigation is the Melt Conditioned Twin Roll Casting (MC-TRC) process. The MC-TRC process is a novel process developed recently by BCAST at Brunel University to overcome the disadvantages of the conventional TRC process, by conditioning the liquid metal prior to solidification processing, [Bayandorian et al. 2009, Bian et al. 2009]. This technology produces high quality strip by focusing on the control of solidification at the casting stage by a MCAST unit which feeds a twin roll caster. The conditioned melt is then supplied to a TRC machine for the direct production of high quality thin strip, as shown in Figure 3.4. In what follows in this section, the MCAST unit characteristics will be discussed in detail.

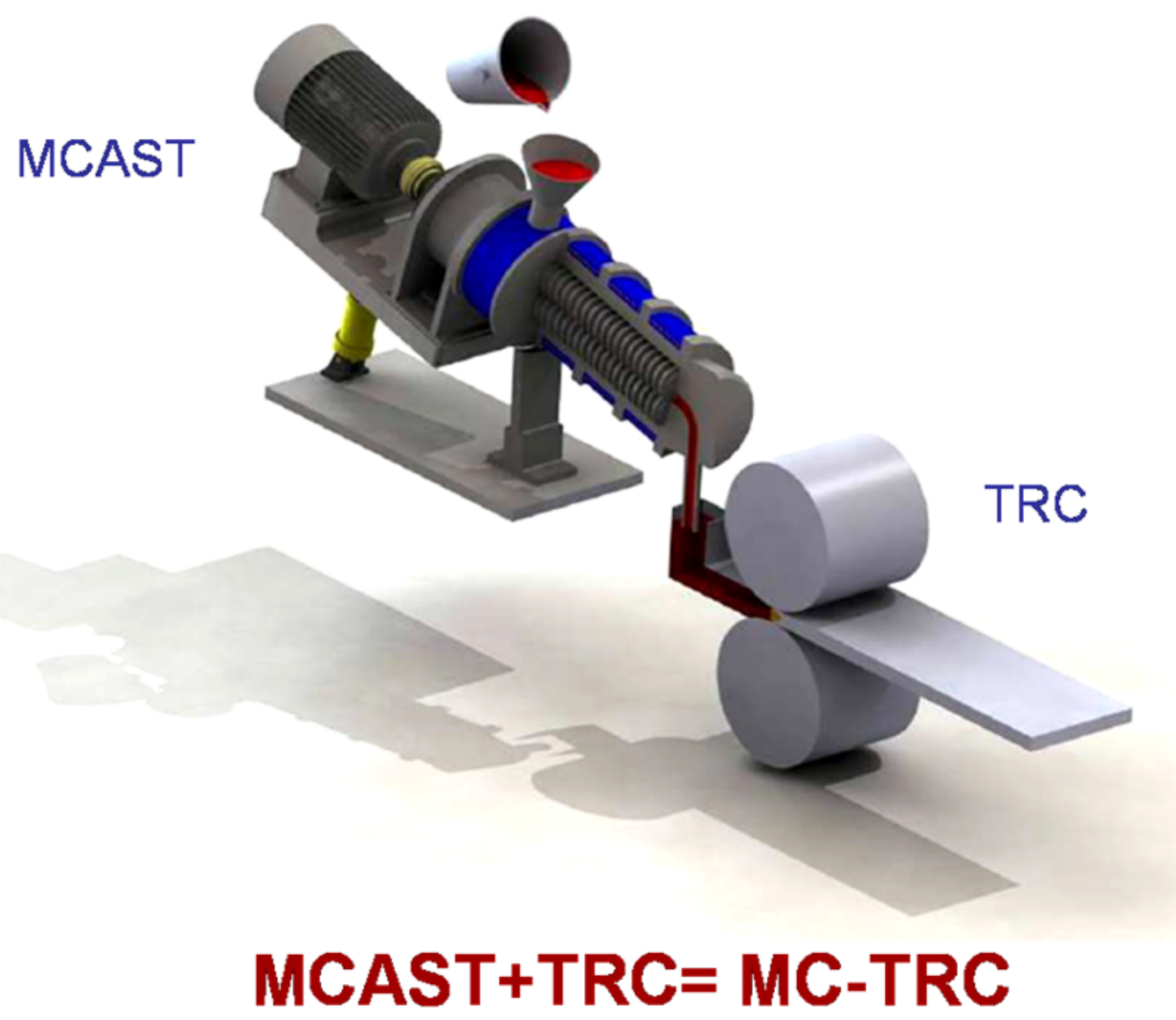

Figure 3.4:

A schematic diagram of the 'Melt Conditioned Twin-roll casting' (MC-TRC) process as a novel process used for production of high quality $\mathrm{Mg}$ alloys strips, [BCAST]. 


\subsubsection{MCAST machine}

The MCAST ( $\underline{\text { Melt }}$ Conditioning by $\underline{\text { Advanced }} \underline{\text { Shear }}$ Technology) machine used in this study is an in-house development at BCAST, Brunel University, UK, and patented by Fan and co-workers [Fan et al. 1999], which was built by Zyomax Ltd., Uxbridge, UK. Figures 3.5 and 3.6 show a schematic diagram and a photograph of the MCAST unit, respectively. MCAST unit consists of a liquid metal feeder, a twin-screw extruder and a central control unit. The most vital feature of the MCAST machine is a twin-screw extruder which consists of a barrel and a pair of closely intermeshing, self-wiping and corotating screws. The screws have a particular designed profile to achieve a high shear rate and high intensity of turbulence, and to improve the positive displacement pumping action. Consequently, a progressive movement in 'figure 8' motions around the periphery of the screws and also a cyclic variation of shear rate due to a continuous change of the gap between the screw and the barrel are applied to the melt placed between the rotating screws, as illustrated in Figure 3.7(a) \& (b). However the shear rate can not be accurately calculated due to the complexity of the screw geometry, the shear rate between the screw and the twin-screw extruder can be predicted by the equation shown below:

$$
\gamma^{\circ}=\pi N\left(\frac{D}{G}-2\right) / 60
$$

where $N$ is the rotating speed of the screw (in 'rpm'), $D$ is the outer diameter of the screw (54 $\mathrm{mm}$ ), and $G$ is the gap between screw flight and the barrel surface (1mm), [Ji et al. 2001]. A high shear rate, high intensity of turbulence and cyclic variation of shear rate are characteristics of the fluid flow in the closely intermeshing, self-wiping and co-rotating twin-screw extruder in the MCAST machine. Consequently, the temperature field and 
composition field in a MCAST machine are anticipated to be enormously homogeneous and uniform.

The MCAST unit is functioned in a way to receive liquid metal through an inlet positioned close to one end and to release the final conditioned melt through an outlet positioned at the other end of the unit. The MCAST machine consists of heating elements and cooling channels along the axis of the twin-screws which separates the twin-screws into the five heating and cooling regions. These regions can sustain the twin-screw container at the required temperatures for each individual region by balancing the heating and cooling power input through a central control unit. The central control unit of the MCAST machine has a RPM dial, a torque reading of the screws, temperature controls for all the heating regions, a timer and switches for opening and closing the exit valve, as shown in Figure 3.8. In order to obtain the preferred temperature of the MCAST unit the heating time for the elements is about 3 hours. The screws rotation speed with desired mixing and discharging time can be set before starting the experiment, [Fan et al. 2001].

The procedure for melt conditioning before the twin roll casting process, are as follows:

(a) An appropriate amount of $\mathrm{Mg}$-melt $(\sim 3.5 \mathrm{~kg})$ at a temperature of $\sim 30^{\circ} \mathrm{C}$ above the alloys liquidus temperature was taken from the melting furnace.

(b) Once in the passageway of the MCAST machine, the fed liquid alloy is quickly cooled to the desired temperature while being mechanically sheared by twin screws in a pre-set shearing time $\left(t_{\text {shear }}\right)$, and screw rotation speed $(N)$.

(c) The conditioned liquid under a protective gas mixture of $\mathrm{N}_{2}$ containing 0.4 vol. $\%$ $\mathrm{SF}_{6}$ is injected at a pre-determined discharge time from the outlet valve into a wellisolated stainless steel crucible. 
(d) The conditioned $\mathrm{Mg}$ melt is then transferred under the protective gas and fed into the TRC machine to produce MC-TRC Mg strips. The procedure for twin roll strip casting is the same as a TRC process which was explained in detail earlier, Section 3.2.1.

During MC-TRC strip casting, the melt temperature in the tundish is measured to ensure the actual pouring temperature is nearly the same as the shearing temperature in the MCAST machine. The transfer time of the conditioned Mg melt from the MCAST unit into the TRC machine should be as quick as possible $(\sim 5 \mathrm{~s})$, to avoid severe burning and oxidation of the Mg-melt which has a detrimental effect on the final strip quality and also a hazardous issue for workers during strip production. Similar to the TRC process, only 2 runs could be completed for each day of MC-TRC experiment since the procedure carried out was in a batch manner. After completing all the runs any spillages of $\mathrm{Mg}$ melt were cleaned out from the feeder and outlet valve area of the MCAST unit. 


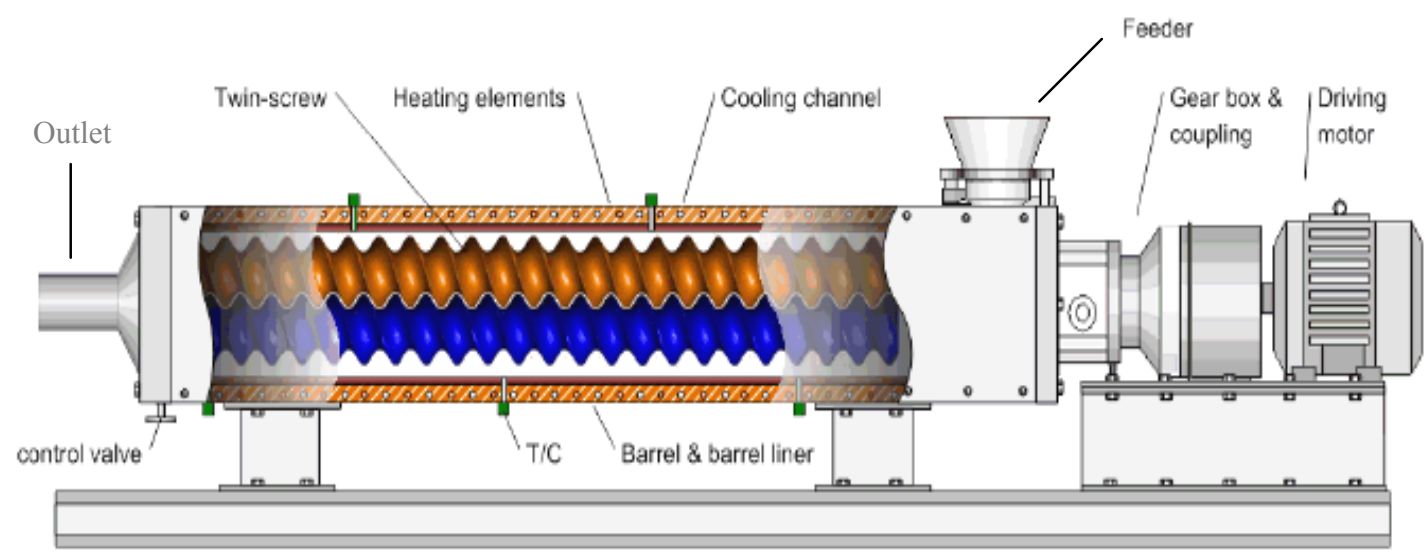

\section{Figure 3.5:}

A schematic diagram of the 'MCAST' machine as a novel process used for production of high quality $\mathrm{Mg}$ alloys strips. [BCAST]

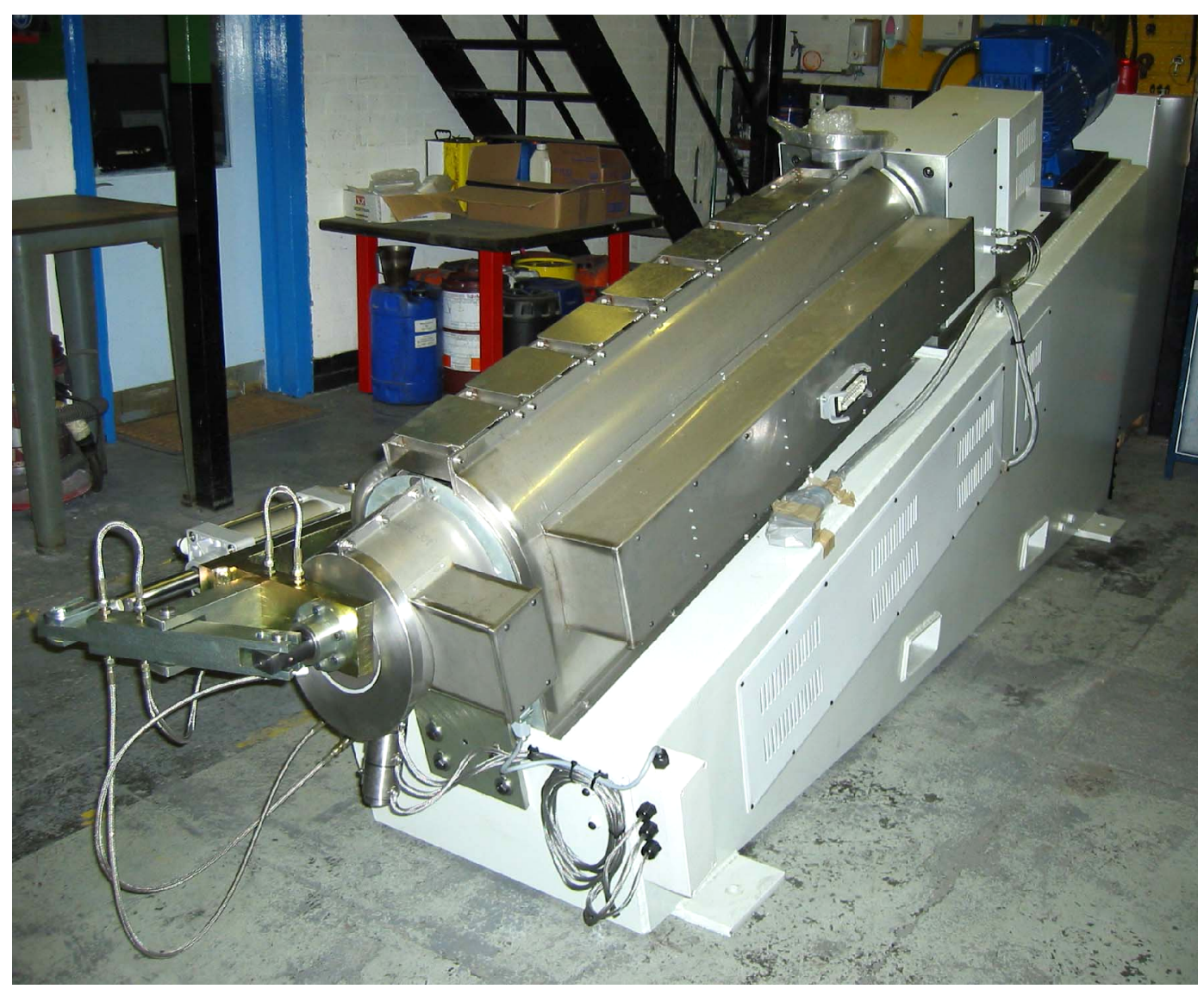

\section{Figure 3.6:}

An actual photograph of the 'MCAST' machine as a novel process used for production of high quality $\mathrm{Mg}$ alloys strips. [BCAST] 

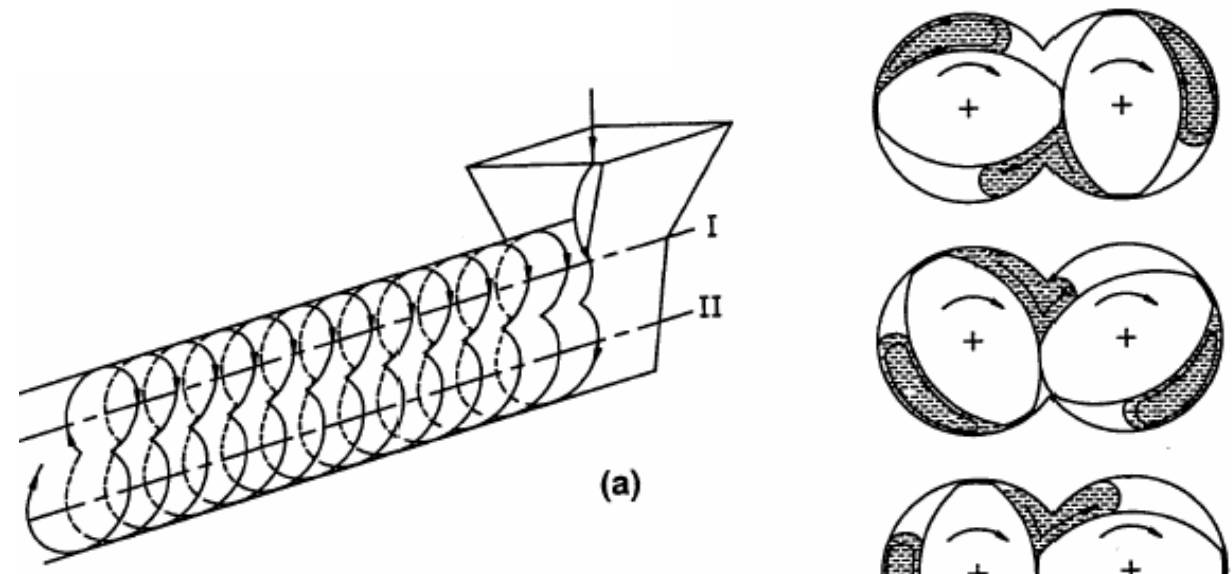

(b)

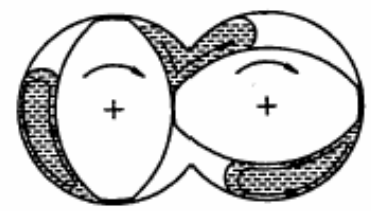

\section{Figure 3.7:}

Schematic diagram showing the fluid flow characteristics in a closely intermeshing and corotating extruder. (a) 'Figure 8' flow pattern along the screw channels; (b) the flow pattern on the cross section of the extruder. [Ji et al. 2001]

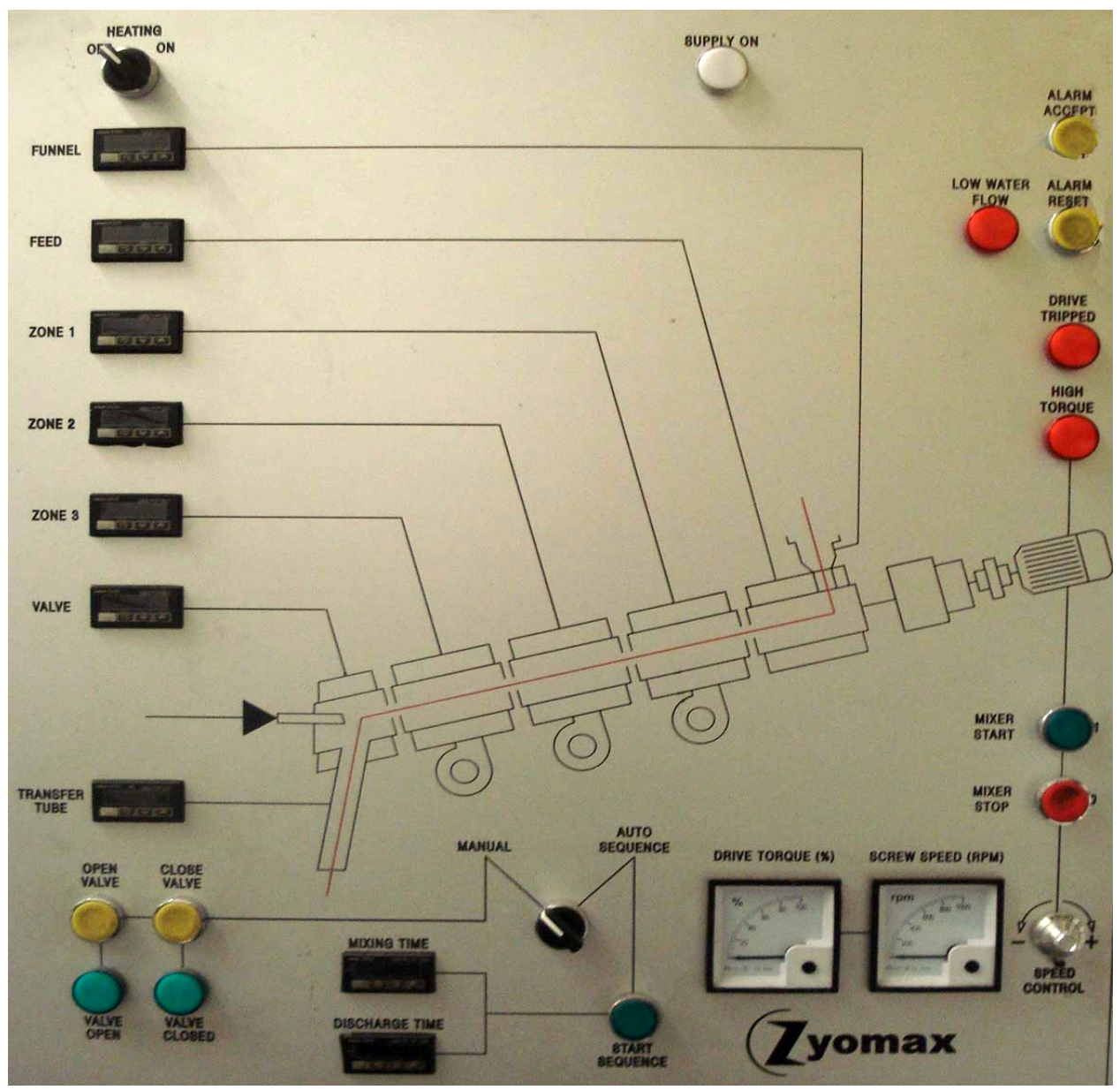

Figure 3.8:

A photograph showing the central control panel on the MCAST machine. [BCAST] 


\subsubsection{Major casting parameters}

The main parameters and their ranges for process optimization charts for TRC and MC-TRC processes are listed in Tables 3.3 and 3.4. The AZ91D Mg-alloy was selected as an experimental Mg-based material for the development of TRC and MC-TRC processes since it had been expected that the twin roll casting of this alloy would be more difficult than the AZ31 alloy due to its larger temperature freezing range which causes severe defects such as centre line segregation. Optimization of TRC processing parameters includes the effect of the pouring temperature, roll speed, roll gap and roll setback, as shown in Table 3.3. The best optimized conditions for the TRC process have been further investigated in more detail for MC-TRC processing optimization, as shown in Table 3.4. For general microstructural investigations and further down-stream processing of $\mathrm{Mg}$-alloys the best processing parameters for TRC and MC-TRC processes are shown in Table 3.5. The AZ91D optimized processing conditions shown in Table 3.5 have been used for TRC and MC-TRC AZ31 Mg alloys strip production except the pouring/shearing temperature.

Table 3.3:

The TRC parameters investigated for AZ91D Mg-alloy.

\begin{tabular}{|c|c|c|c|c|c|}
\hline \multicolumn{6}{|c|}{ TRC AZ91D } \\
\hline $\begin{aligned} & \text { Effect of pouring temperature }\left({ }^{\circ} \mathrm{C}\right) \\
& \text { fixed at: } \cdot \text { roll speed }=22.5 \mathrm{~mm} \cdot \mathrm{s}^{-1} \\
& \cdot \text { roll gap }=3 \mathrm{~mm} \\
& \cdot \text { roll setback }=41 \mathrm{~mm}\end{aligned}$ & 605 & 615 & 635 & 650 & 670 \\
\hline $\begin{aligned} \text { Effect of roll speed }\left(\mathrm{mm}^{-1} \mathrm{~s}^{-1}\right) & \\
\text { fixed at: } & \cdot \text { pouring temperature }=615 \pm 5^{\circ} \mathrm{C} \\
& \cdot \text { roll gap }=3 \mathrm{~mm} \\
& \cdot \text { roll setback }=43 \mathrm{~mm}\end{aligned}$ & 22.5 & 30.9 & 38.3 & 78.3 & 129.9 \\
\hline $\begin{aligned} & \text { Effect of roll setback }(\mathrm{mm}) \\
& \text { fixed at: } \cdot \text { pouring temperature }=615 \pm 5^{\circ} \mathrm{C} \\
& \bullet \text { roll gap }=3 \mathrm{~mm} \\
& \cdot \text { roll speed }=22.5 \mathrm{~mm} \cdot \mathrm{s}^{-1}\end{aligned}$ & 38 & 41 & 43 & 46 & 49 \\
\hline 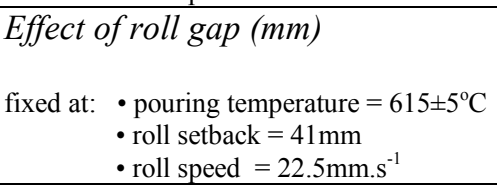 & 1 & 1.5 & 3 & 4 & 5 \\
\hline
\end{tabular}


Table 3.4:

The MC-TRC parameters investigated for AZ91D Mg-alloy.

\begin{tabular}{|c|c|c|c|c|c|}
\hline \multicolumn{6}{|c|}{ MC-TRC AZ91D } \\
\hline $\begin{aligned} & \text { Effect of shearing temperature }\left({ }^{\circ} \mathrm{C}\right) \\
& \text { fixed at: } \cdot \text { roll speed }=22.5 \mathrm{~mm} \cdot \mathrm{s}^{-1} \\
& \cdot \text { roll gap }=3 \mathrm{~mm} \\
& \cdot \text { roll setback }=43 \mathrm{~mm} \\
& \cdot \text { shearing speed }=600 \mathrm{rpm} \\
& \cdot \text { shearing time }=60 \mathrm{~s}\end{aligned}$ & 598 & 605 & 615 & 635 & 650 \\
\hline $\begin{aligned} & \text { Effect of shearing speed }(\mathrm{rpm}) \\
& \text { fixed at: } \cdot \text { roll speed }=22.5 \mathrm{~mm} \cdot \mathrm{s}^{-1} \\
& \cdot \text { roll gap }=3 \mathrm{~mm} \\
& \cdot \text { roll setback }=43 \mathrm{~mm} \\
& \cdot \text { shearing temperature }=615^{\circ} \mathrm{C} \\
& \cdot \text { shearing time }=10 \mathrm{~s}, 60 \mathrm{~s}\end{aligned}$ & 150 & 600 & & & \\
\hline $\begin{aligned} & \text { Effect of roll setback }(\mathrm{mm}) \\
& \text { fixed at: } \cdot \text { roll speed }=22.5 \mathrm{~mm} \cdot \mathrm{s}^{-1} \\
& \cdot \text { roll gap }=3 \mathrm{~mm} \\
& \cdot \text { shearing temperature }=615^{\circ} \mathrm{C} \\
& \cdot \text { shearing speed }=600 \mathrm{rpm} \\
& \cdot \text { shearing time }=60 \mathrm{~s} \\
&\end{aligned}$ & 38 & 39 & 41 & 43 & 46 \\
\hline
\end{tabular}

\section{Table 3.5:}

Optimum casting parameters of TRC and MC-TRC processes used for high-quality AZ91D Mg strip production in order to investigate the microstructural evolution and further down-stream processing.

\begin{tabular}{|l|l|l|l|l|l|l|l|}
\hline Process & $\begin{array}{l}\text { Roll speed } \\
\left(\mathrm{mm}^{-1}\right)\end{array}$ & $\begin{array}{l}\text { Roll gap } \\
(\mathrm{mm})\end{array}$ & $\begin{array}{l}\text { Roll } \\
\text { setback } \\
(\mathrm{mm})\end{array}$ & $\begin{array}{l}\text { Pouring } \\
\text { temperature } \\
\left({ }^{\circ} \mathrm{C}\right)\end{array}$ & $\begin{array}{l}\text { Shearing } \\
\text { temperature } \\
\left({ }^{\circ} \mathrm{C}\right)\end{array}$ & $\begin{array}{l}\text { Shearing } \\
\text { speed } \\
(\mathrm{rpm})\end{array}$ & $\begin{array}{l}\text { Shearing } \\
\text { time }(\mathrm{s})\end{array}$ \\
\hline$\underline{\mathrm{TRC}}$ & 22.5 & 3 & $38-43$ & $615 \pm 2$ & ------ & ----- & ----- \\
\hline$\underline{\mathrm{MC}-T R C}$ & 22.5 & 3 & 43 & ------ & $615 \pm 2$ & 600 & 60 \\
\hline
\end{tabular}

For AZ31 alloy, a superheated temperature around $10-15^{\circ} \mathrm{C}$ above the liquidus temperature of the alloy has been chosen as a pouring or shearing temperature for TRC and $\mathrm{MC}-\mathrm{TRC}$ processes, i.e. $\sim 640-645^{\circ} \mathrm{C}$ for $\mathrm{AZ3} 1$ alloy. 


\subsection{Down-stream processing}

\subsubsection{Homogenization treatment}

The AZ91D and AZ31 Mg alloy strip-cast samples, produced by both TRC and MC-TRC processes, were subjected to a subsequent homogenization treatment. In the present study, the homogenization treatment of small samples of $\mathrm{Mg}$-strips $(2 \mathrm{~cm} \times 2 \mathrm{~cm})$, was carried out at different temperatures and holding times i.e. $350,370,400$ and $450^{\circ} \mathrm{C}$, for up to $6 \mathrm{~h}$ as shown in Table 3.6. The heat treatment procedure was carried out in air with the protection of carbon powder on the surface of the samples using an Elite BSF $12 / 6$ chamber furnace with a maximum working temperature of $1200^{\circ} \mathrm{C}$.

\section{Table 3.6:}

Homogenization treatment parameters investigated in this study to find the optimum conditions for homogenizing the TRC and MC-TRC Mg alloys strip.

\begin{tabular}{|c|c|c|c|c|c|c|}
\hline $\begin{array}{l}\text { Homogenization temperature }\left({ }^{\circ} \mathrm{C}\right) \\
\text { fixed at: } \bullet \text { homogenization time }=45 \text { minutes }\end{array}$ & 350 & 370 & 400 & 450 & & \\
\hline $\begin{array}{l}\text { Homogenization time }(s) \\
\text { fixed at: } \bullet \text { homogenization temperature }=400^{\circ} \mathrm{C}\end{array}$ & 10 & 30 & 60 & 90 & 180 & 360 \\
\hline
\end{tabular}

\subsubsection{Rolling and annealing processes}

The rolling machine used in this study was a small-scale version located in Imperial College London, London, UK, built by, Farmer Norton Rolling Mill, UK. A photograph of the rolling machine used in this study is shown in Figure 3.9. The stainless steel rolls are $254 \mathrm{~mm}$ in diameter and are independently driven by electric motors. The roll separating force applied during rolling was approximately $1000 \mathrm{kN}$ at $8 \mathrm{~m} \cdot$ minute $^{-1}$ and $800 \mathrm{kN}$ at 23 m.minute ${ }^{-1}$. The maximum peripheral roll speed was around 23 m.minute ${ }^{-1}$. 'ROCOL-ULTRACUT 250 plus' as a water based soluble oil lubricant for stainless steel rolls was used during rolling of Mg-strips. The gap between the rolls was 
controlled accurately by a hydraulic motor and could be set at a desired value with an accuracy of $0.001 \mathrm{~mm}$.

Based on the experimental findings from the homogenization procedures, hot-rolling procedure was investigated for AZ91D and AZ31 Mg-alloys produced by TRC and MC-TRC processes. The homogenized cast strips in optimum conditions were rolled at temperatures of 350,370 and $400^{\circ} \mathrm{C}$ (fixed rolling speed of $190 \mathrm{~mm} \cdot \mathrm{s}^{-1}$ ) and rolling speeds of 63,190 and $314 \mathrm{~mm} \cdot \mathrm{s}^{-1}$ (fixed rolling temperature of $400^{\circ} \mathrm{C}$ ). The range of hot-rolling temperatures and rolling speeds were suggested by Innoval Technology Ltd., Banbury, UK and MEL, Magnesium Elektron, Manchester, UK and also some other researchers, [Essadiqi et al. 2009, Del valle et al. 2003, Tan and Tan 2003, Kawalla et al. 2008, Duygulu et al. 2009b].

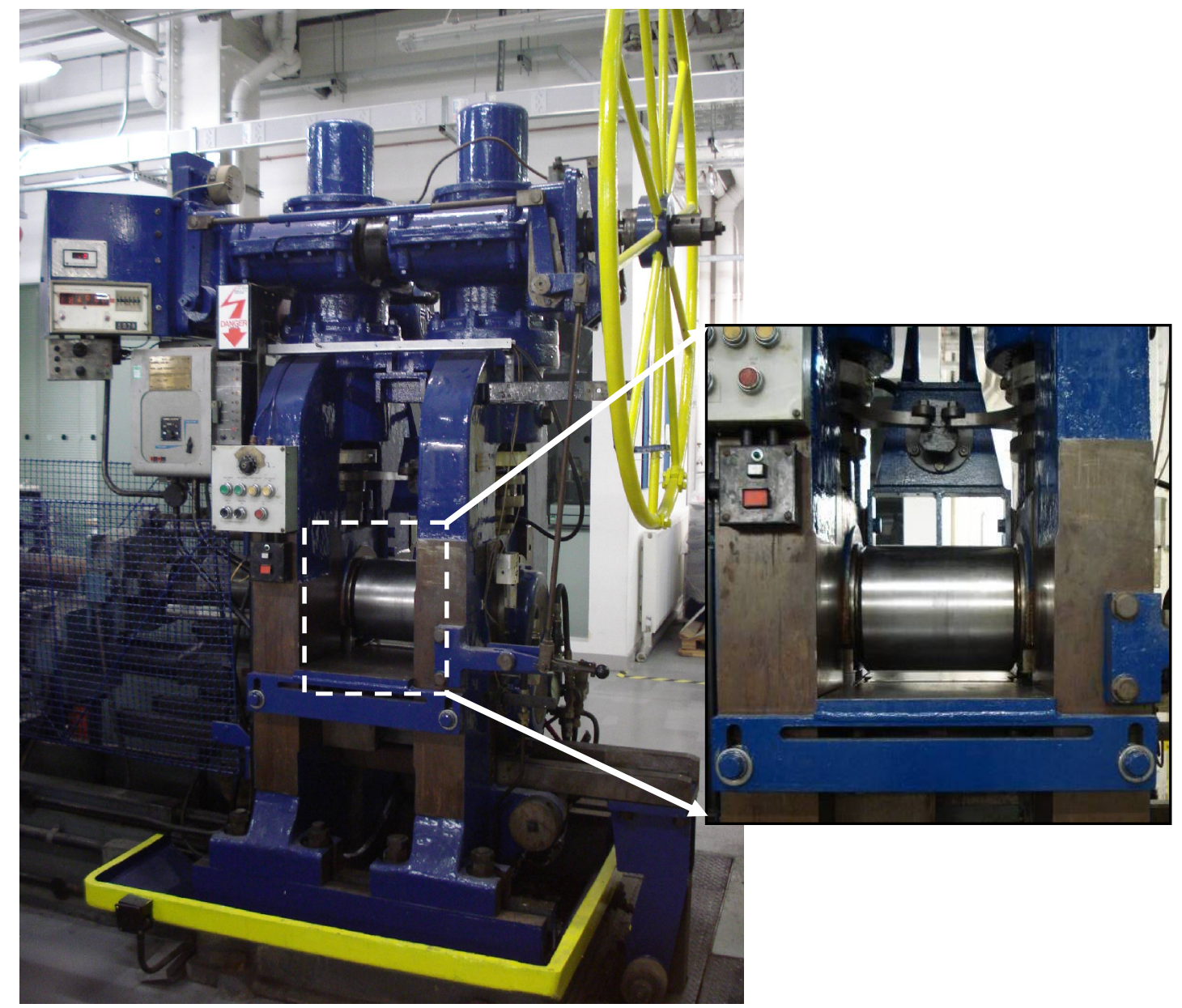

Figure 3.9:

A photograph showing the Hot-rolling machine located at Imperial College of London, UK, with a close-up of its entry side where Mg alloy strip was placed to be rolled down to lower thickness. 
The homogenized strip was rolled from the cast gauge of $6 \mathrm{~mm}$ down to $1.6 \mathrm{~mm}$ using 9 passes of $15 \%$ thickness reduction in each step. The thickness reduction was set at a constant level of $15 \%$ in each step since by increasing the thickness reduction, severe cracks formed on the strip surface due to a limited available slip systems of the material used in this study. Between each pass, the strip was re-heated for 15 minute to stabilize the rolling temperature. The re-heating procedure between each pass using two large chamber furnaces made by Carbolite and Lenton was carried out in air with the protection of carbon powder on the surface of the samples. The final gauge rolled sheets were annealed at $345^{\circ} \mathrm{C}$ for 2 hours to minimize the stress induced during the final stage of hot-rolling Mg-strips. This annealing condition was suggested by MEL, Magnesium Elektron, Manchester, UK.

\subsection{Microstructural characterization}

\subsubsection{Metallographic sample preparation}

Specimens for microstructural characterization were cut from the mid-way across the width of the twin roll cast magnesium strips and rolled magnesium sheets, where edge effects are minimized, and in both longitudinal and transverse directions. Sometimes plane sections, looking down on the surface, were also taken. The cut samples, $25 \mathrm{~mm}$ in length, have been prepared at five different locations along each strip/sheet in order to investigate the effect of manufacturing parameters on the final microstructure. The cut specimens were mounted in 'bakelite' (Buehler-Met Phenolic Powder) using a Buehler, Simplimet 1000 automatic mounting press, which included 90 seconds of heating at $150^{\circ} \mathrm{C}$ at a pressure of 290 bar followed by 180 seconds of water cooling. For the easier identification of the samples, a vibro-etching machine was used to label the mount. 
Metallographic sections for optical microscopy (OM) and scanning electron microscopy (SEM) were prepared using standard metallographic procedures, as follows. The mounted samples were ground using 120, 320, 500, 800, 1200, 2400, 4000 grit SiC abrasive papers and polished on a $250 \mathrm{~mm}$ diameter Struers MD-Nap diamond oxide cloth with an Struers OP-S colloidal silica $(0.04 \mu \mathrm{m}$ in grain size) suspension solution mixed with detergent. The detergent used in this study was a mixture of normal washing-up liquid and Aldrich ethanol. Detergent solution used in this study could effectively remove the stains remained on the sample surface after polishing with OP-S solution. Grinding and polishing were both carried out on a Buehler, Phoenix 4000 semiautomatic sample preparation system. The mounted samples, $30 \mathrm{~mm}$ in diameter, were gripped three or four at a time in a circular holder which rotated against the polishing wheel. For the polishing stage, the wheel rotation speed, amount of applied pressure and polishing time were $300 \mathrm{rpm}, 10-15 \mathrm{lbs}$ and 5 minutes, respectively. To reveal the normal microstructure of Mg-alloys, the polished samples were etched by a solution of Nital ( $5 \mathrm{ml} \mathrm{HNO}_{3}$ (conc.) in $95 \mathrm{ml}$ ethanol, swab for 3-4s). In order to obtain accurate grain size of the sample, acetic-picral colour etching (4.2g picric acid (conc.), $70 \mathrm{~mL}$ ethanol, $15 \mathrm{~mL}$ distilled water and $15 \mathrm{~mL}$ acetic acid (conc.), swab for 1-2secs), was used on some Mg-alloy polished samples. The specimens were washed in ethanol and blow dried between grinding, polishing and after etching.

\subsubsection{Optical microscopy (OM)}

The microstructure was studied under a 'Zeiss' light microscope. In order to obtain colourful micrographs for further grain size measurement and microstructural characterization, samples were studied under polarized light. To record the observed microstructure at desired magnifications, an 'AxioCam MRC' digital camera was linked between the microscope and a PC. All the images taken could be downloaded on to a hard disk of the PC and quantified using an 'AxioVison' image analysis system on the 
PC. To determine the 'grain size' of the micrographs, the linear intercept method was used according to the 'ASTM E112-96' standard method, (ASTM E112-96 linear intercept method for determining average grain size). The intercept method involves an actual count of the number of grains intercepted by a test line or the number of grain boundary intersections with a test line. The values of grain size reported in this study are measured from at least 5 different locations along the strip cast magnesium alloys at the distance specified from the surface of strip. For the as-cast samples, the grain size measurements carried out visually by drawing 5 horizontal and 5 vertical test lines on the digital micrograph taken by the optical microscope. For the as-homogenised, as-rolled and asannealed samples the grain size measurements carried out automatically by 'AxioVison' image analysis system on digital micrograph taken by optical microscope. The image analysis system can analyze the volume fraction, grain size and area fraction of grains. The 'average grain size' of the strip is determined by the average of all grain sizes obtained from the micrographs taken from the surface to the centre of strip. The error bars in all the graphs demonstrated in this study were calculated based on the standard deviation method.

The percentage of average centre line segregation area is measured by the following formula:

$$
\text { Average centreline segregation area } \%=\frac{\text { Segregated area }}{\text { Total area }}
$$

The values reported in this study are measured from at least 5 different locations along the strip cast magnesium alloys by a graph pad paper printed on cross sectional micrographs of strip. The etched sample shows the segregated area in black, therefore the percentage of centre line segregation can be measured easily by counting the number of black areas in a graph pad paper printed on micrograph divided by the total number of areas. 


\subsubsection{Scanning electron microscopy (SEM)}

A 'JEOL $J X A-840 A$ ' scanning electron microscope, equipped with a 'LINK AN10000' energy dispersive X-ray spectroscope (EDX/EDS) was used in this study to investigate microstructures morphologically and quantitatively at high magnifications $(<50,000$ times $)$ and also analyzing the chemical composition of small areas within the microstructure. In order to obtain a better contrast in images, some of the SEM samples were etched by Nital solution. An accelerating voltage of $20 \mathrm{kV}$ used in SEM observations.

\subsection{Mechanical property testing}

\subsubsection{Tensile testing}

(a) At Room Temperature: 'Rectangular tensile test samples' with a gauge length of $60 \mathrm{~mm}$ for the as-cast strip and $32 \mathrm{~mm}$ for the annealed rolled-sheet, parallel to the casting or rolling direction $(\mathrm{RD})$, were machined in accordance with ASTM-E8M standard. A schematic diagram of the two types of tensile test samples $(60 \mathrm{~mm}$ and $32 \mathrm{~mm}$ gauge length) is shown in Figure 3.10. The extensometers used in this study were $50 \mathrm{~mm}$ and $25 \mathrm{~mm}$, respectively. The preparation of tensile test $\mathrm{Mg}$ alloy samples from strip/sheet required an advanced $\mathrm{CNC}$ machine equipped with proper jigs and fixtures, which was carried out by John Douse Machining Ltd., Banbury, UK. The testing was carried out at room temperature in the laboratory on a 'LIoyd Instrument EZ50' tensile test machine connected to a PC for automated testing and calculation of tensile results such as yield stress $(0.2 \%$ proof strength), UTS and elongation at maximum strength and elongationto-fracture. A primary crosshead strain rate of $6.7 \times 10^{-4} \mathrm{~s}^{-1}$ was used throughout and external Epsilon extensometers of $25 \mathrm{~mm}$ and $50 \mathrm{~mm}$ gauge length was attached by hand to individual test pieces to get precise elongation results. 


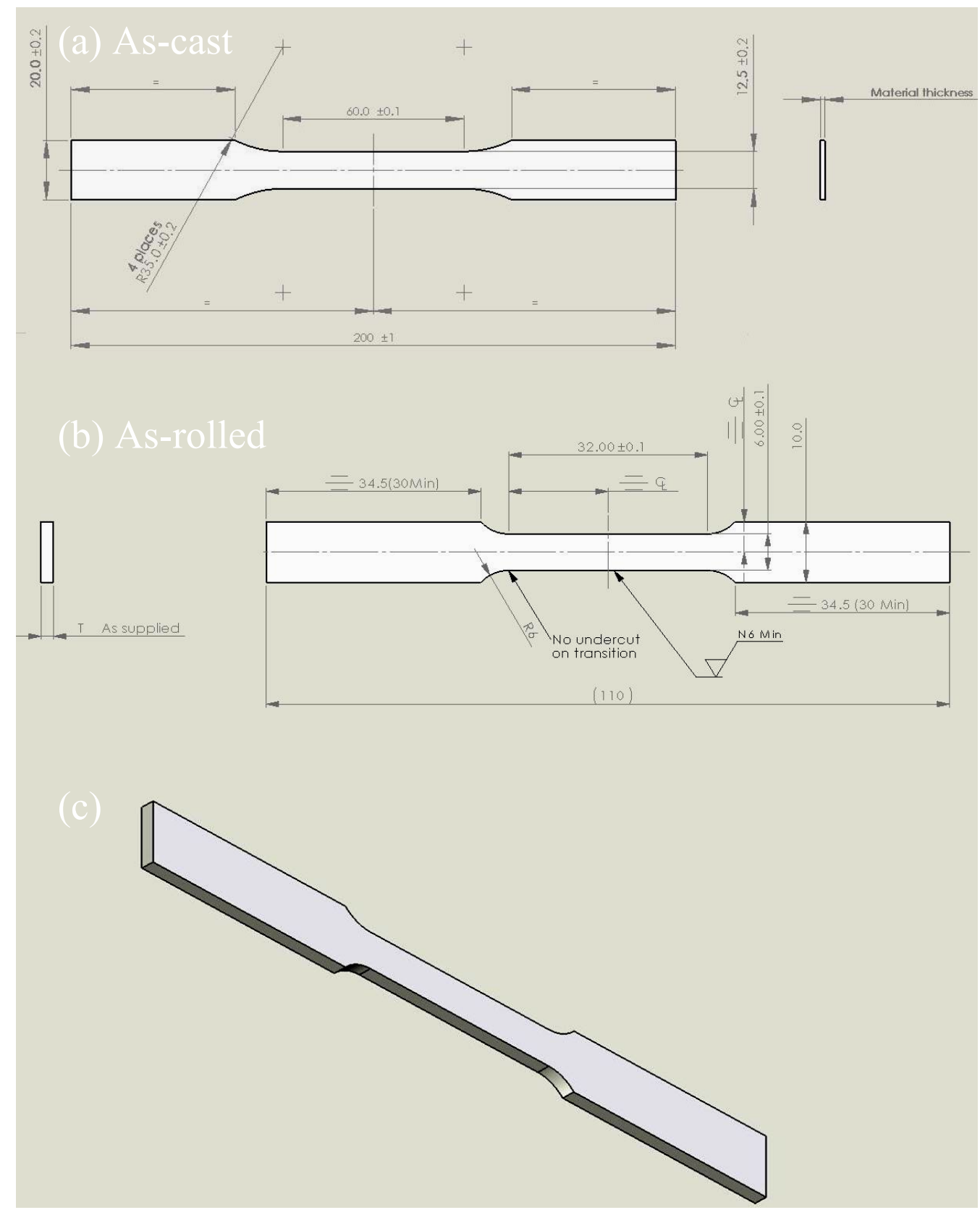

\section{Figure 3.10:}

A schematic diagram showing the tensile test samples machined in order to investigate the effect of MC-TRC novel process compared with TRC process on mechanical properties of (a) as-cast Mg alloy strips and (b) as-rolled final gauge Mg alloy rolled sheets. (c) A 3D-view of the tensile test sample is shown. All dimensions and tolerances are in $(\mathrm{mm})$ unless otherwise stated.

(b) At High Temperature $\left(\sim 350^{\circ} \mathrm{C}\right)$ : In order to investigate the mechanical behaviour of TRC and MC-TRC Mg strips during the hot-rolling process, 'rectangular tensile test samples' with a gauge length of $60 \mathrm{~mm}$ for the as-cast strip, parallel to the casting 
direction (CD), were machined in accordance with ASTM-E21 and BS-4A4 standards. A $50 \mathrm{~mm}$ extensometer was used in this study. A drawing similar to the standards of high temperature tensile test sample is shown in Figure 3.11. The preparation of tensile test $\mathrm{Mg}$ alloy samples from twin roll cast strip required advanced $\mathrm{CNC}$ machine equipped with proper jigs and fixtures, which was carried out by Incotest UK Ltd., Hereford, UK. The test carried out at $\underline{350^{\circ} \mathrm{C}}$ with no soak time was performed with a ' $Z$ wick' tensile test machine connected to a PC for automated testing and calculation of tensile results at a starting strain rate of $5.1 \times 10^{-3} \mathrm{~s}^{-1}$.

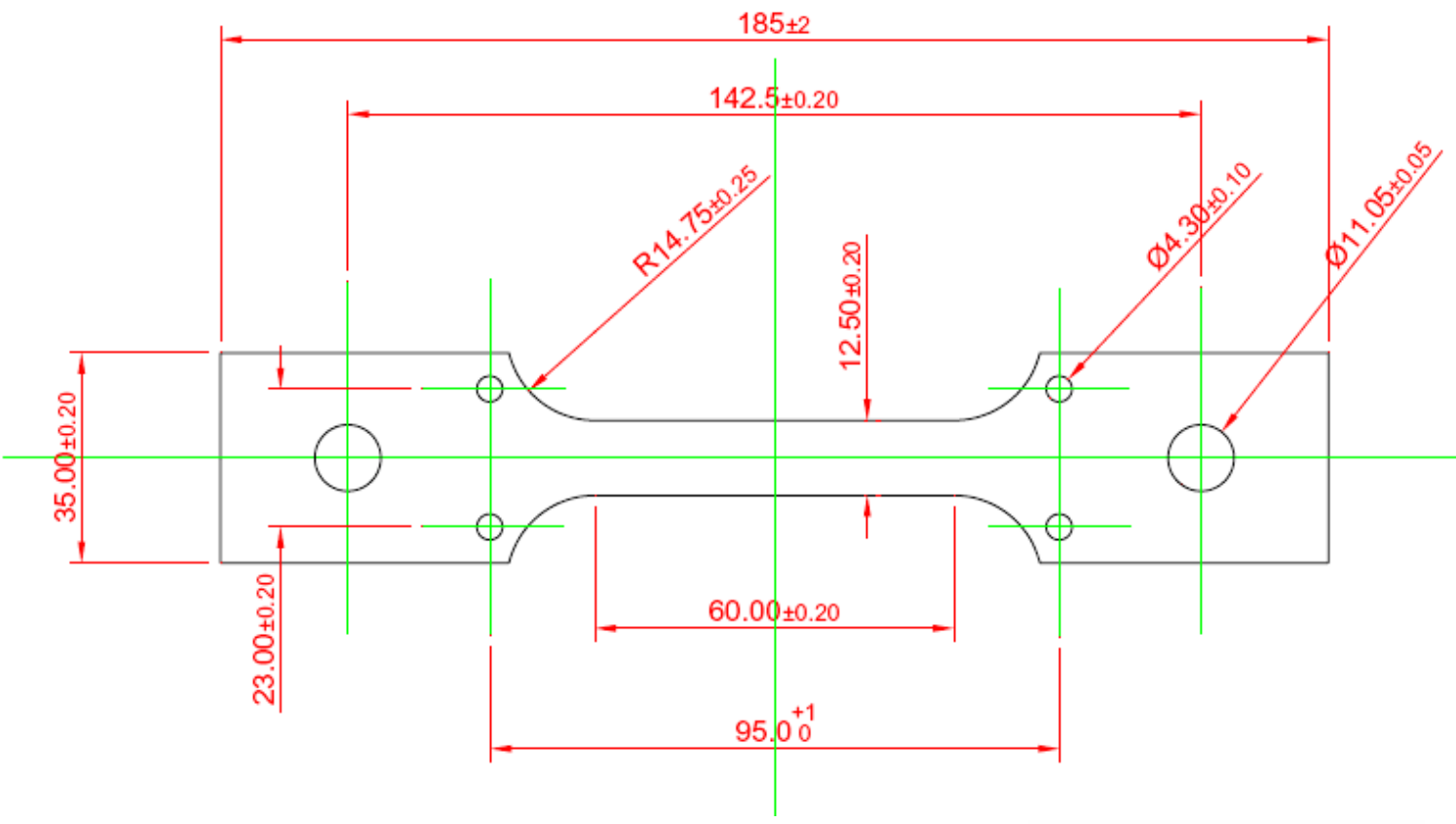

Thickness As Supplied

Figure 3.11:

A schematic diagram showing the high temperature tensile test sample machined in order to investigate the effect of the MC-TRC novel process compared with the TRC process on the mechanical behaviour of as-cast strips during the hot rolling procedure. All dimensions and tolerances are in $(\mathrm{mm})$ unless otherwise stated.

All the high temperature tensile tests were completed by Incotest UK Ltd., Hereford, UK. The ASTM-E21 standard suggests that for high temperature tensile testing the tensile sample should soak for 20minutes at the desired temperature; however in this study this was detrimental to the microstructure. Hence, since the sample has its own thermocouple 
the test started as soon as its temperature reached $350^{\circ} \mathrm{C}$. The furnaces used in this study for heating up the tensile tests were manufactured at Incotest UK Ltd. using heaters made of Kanthal or Brightray alloys.

\subsubsection{Vickers hardness measurements}

(a) Microhardness

The microhardness of the alloys was measured with a Vicker's diamond pyramid indenter at a load of $0.1 \mathrm{~N}$ on polished and etched samples taken from the transverse sections of the TRC and MC-TRC Mg strips. The microindentation hardness tester 'Micromet 5101' used in this study was made by Buehler, Japan. To minimize the reading scatter, a series of five indentations were made around each point where the hardness was to be measured. In this study, microhardness test was carried out on the mid-way across the width of the strips/sheets from the surface through to the middle area in order to verify the existence of centre line segregation and grain size variation.

(b) Macrohardness

The homogenization, hot rolling and annealing response of the AZ91D and AZ31 Mg alloys produced by TRC and MC-TRC processes was determined by macrohardness measurements of the alloys. The macrohardness measurements were carried out on polished and etched samples taken from the planar sections of the as-cast and hot-rolled TRC and MC-TRC strips using the Vicker's diamond pyramid indenter, 'VHT5-100', at a load of $98 \mathrm{~N}$. To minimize the reading scatter a series of at least eight indentations was made around each point where the hardness was to be measured. 


\section{CHAPTER 4}

\section{RESULTS-1}

\subsection{Optimization of the TRC process}

The MC-TRC process, as described in Section 3.2.2, is a combination of the novel MCAST machine and a conventional TRC machine. Therefore, the qualities of MC-TRC Mg strips are related significantly to the performance of the twin roll caster. In this study, the effect of pouring temperature $\left(\mathrm{T}_{\mathrm{p}}\right)$, tip set-back $(\alpha)$, roll gap $\left(\mathrm{h}_{1}\right)$ and roll speed $(v)$ on microstructural evolution, formation of defects and centre line segregation in as-twin roll cast AZ91D Mg strips were investigated. These parameters are shown schematically in Figure 2.7 in Chapter 2. In this research fluidity of the melt through the feeding system, microstructural characterisation and surface quality of produced AZ91D Mg strips were utilized as criteria to optimize the TRC processing conditions for $\mathrm{Mg}$ strip production.

\subsubsection{Pouring temperature}

Temperature of the melt in the headbox is a crucial factor in a conventional TRC process, therefore, it was the first parameter considered for process optimization. Hence, in this study in order to find out the optimum pouring temperature, a tip setback of $41 \mathrm{~mm}$, a roll gap of $3 \mathrm{~mm}$ and a roll speed of $22.5 \mathrm{~mm} \cdot \mathrm{s}^{-1}$ were kept constant, however different pouring temperatures in the range $605^{\circ} \mathrm{C}-670^{\circ} \mathrm{C}$ were investigated. The effects of the pouring temperature on the microstructures of TRC AZ91D alloy are presented in Figure 4.1. As a result of varying the pouring temperature the following can be stated: 
- The grain size variations depend significantly on the pouring temperature. By increasing the pouring temperature, the grain size variation, its non-uniformity and centre line segregation increased.

- The morphology of grains depends considerably on the pouring temperature.

The effect of the pouring temperature on microstructural evolution of TRC AZ91D strip is shown in more details in Figure 4.2. The measured grain size in the longitudinal and transverse directions of AZ91D strip as a function of distance from surface to the centre of strip is shown in Figure 4.3. The grain size variation and microstructural observations show that there are three distinctive zones across the cross section of AZ91D twin roll cast strips. These zones can be categorized as a chill zone, columnar zone and central equiaxed zone. In the columnar grain zone the grain sizes increased rapidly compared to chill zone, followed by a central equiaxed grain zone, the grain size decreased extensively compared to columnar zone, as shown in Figures 4.2 (a) and 4.3. Significant centre line segregation, as shown in Figure 4.2 (a), can also be observed in the TRC strip. Figure 4.3 suggests that the AZ91D TRC strip showed a significant variation of grain size between $200 \mu \mathrm{m}$ and $750 \mu \mathrm{m}$ through the thickness of the strip dependent on the pouring temperature. It is demonstrated that by decreasing the pouring temperature the predominant morphology of columnar grains, Figure 4.2 (a), changed to equiaxed grains and there was no indication of distinguished zones, as shown in Figure 4.2 (b). The microstructure of the TRC Mg-alloy strip in Figure 4.2 (a) is dominated by the growth of a columnar grain structure although a more equiaxed grain structure is noticeable in the central section. 

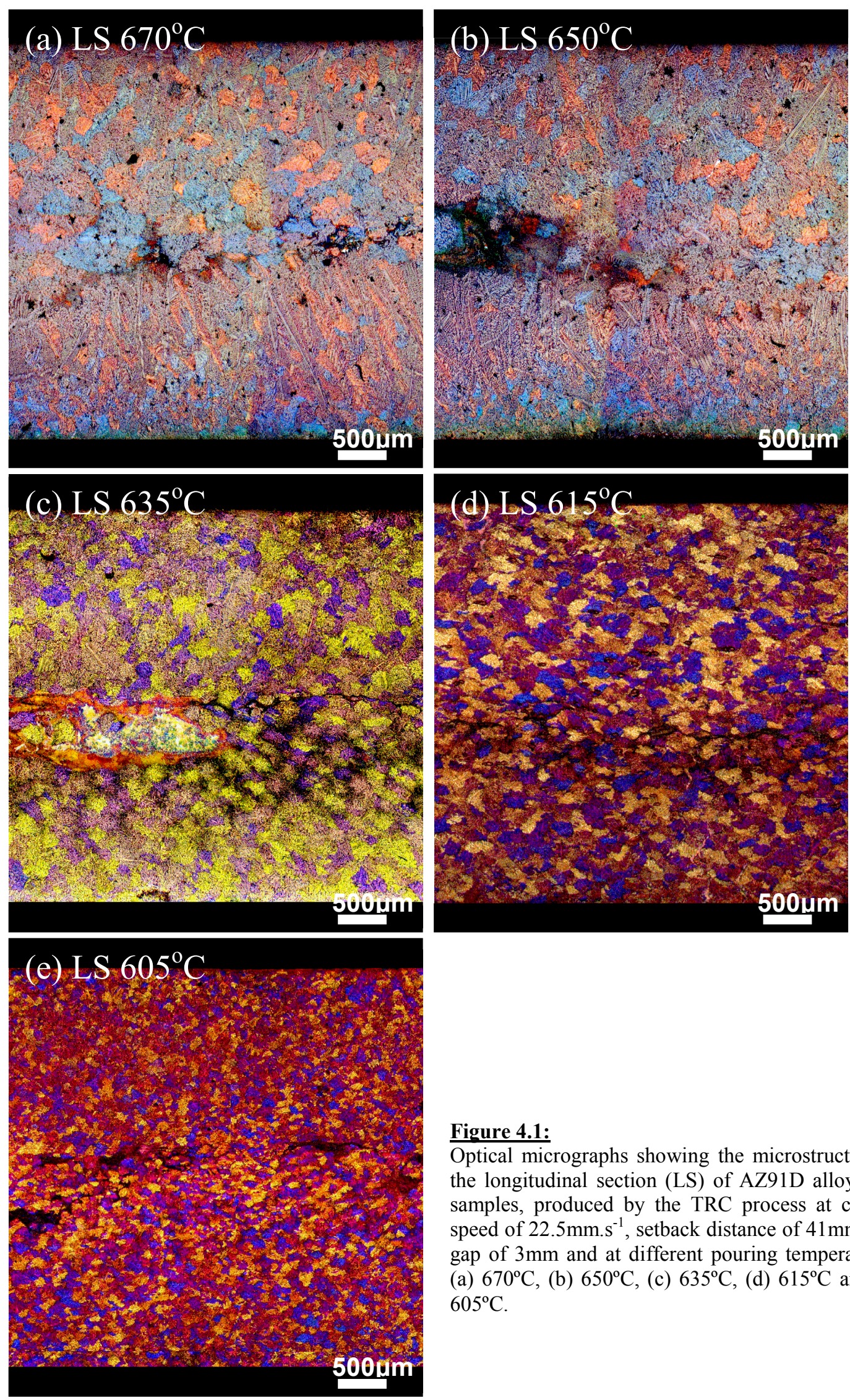

\section{Figure 4.1:}

Optical micrographs showing the microstructure in the longitudinal section (LS) of AZ91D alloy strip samples, produced by the TRC process at casting speed of $22.5 \mathrm{~mm} . \mathrm{s}^{-1}$, setback distance of $41 \mathrm{~mm}$, roll gap of $3 \mathrm{~mm}$ and at different pouring temperatures, (a) $670^{\circ} \mathrm{C}$, (b) $650^{\circ} \mathrm{C}$, (c) $635^{\circ} \mathrm{C}$, (d) $615^{\circ} \mathrm{C}$ and (e) $605^{\circ} \mathrm{C}$. 

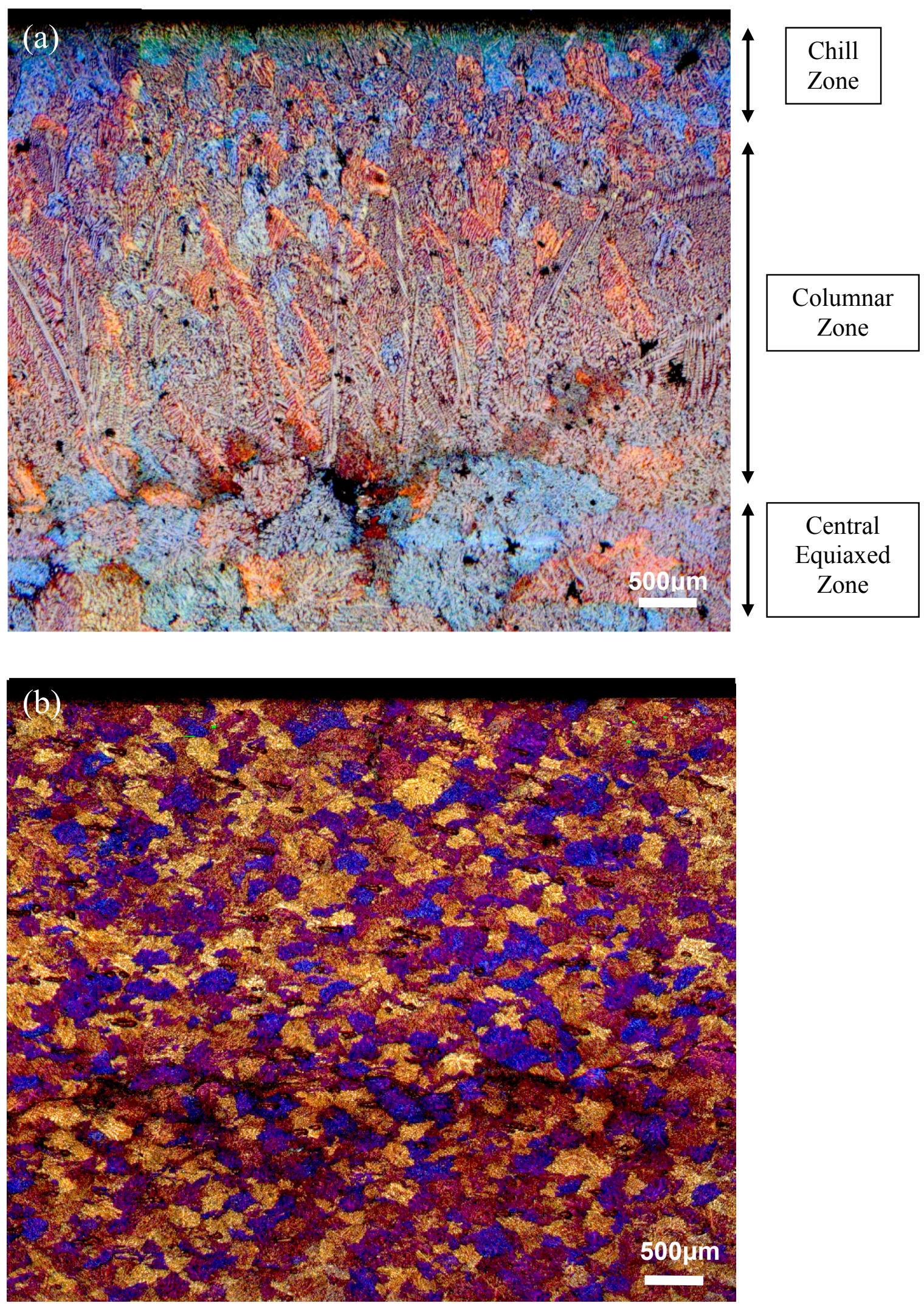

\section{Figure 4.2:}

Optical micrographs showing the microstructure of the longitudinal section (LS) of AZ91D alloy strip samples, produced by a TRC process at a casting speed of $22.5 \mathrm{~mm} \cdot \mathrm{s}^{-1}$, setback distance of $41 \mathrm{~mm}$, roll gap of $3 \mathrm{~mm}$ and at different pouring temperatures, (a) $670^{\circ} \mathrm{C}$, (b) $615^{\circ} \mathrm{C}$. 


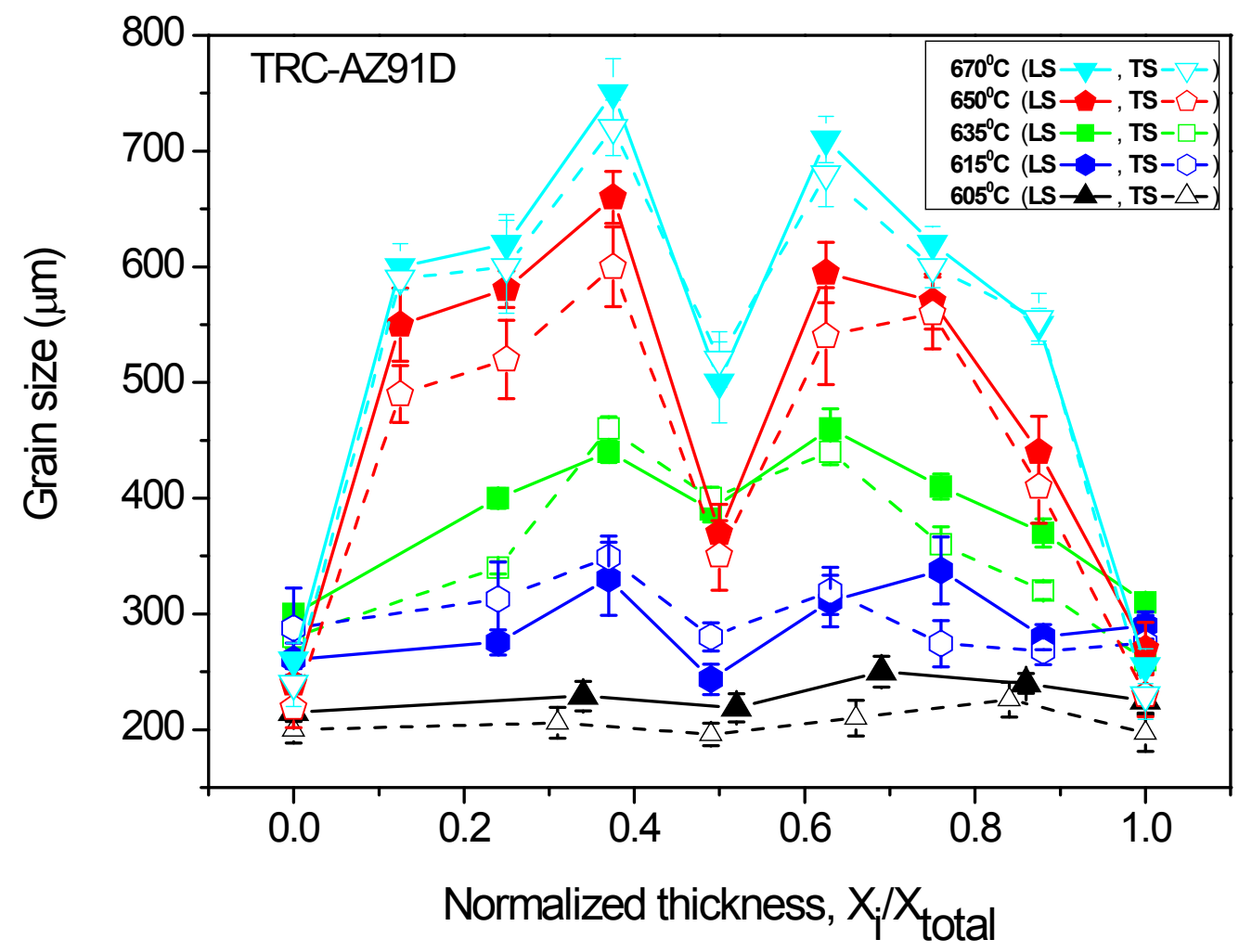

Figure 4.3:

Quantitative analysis showing grain size variations of the longitudinal and transverse sections (LS \& TS) of AZ91D alloy strip samples as a function of normalized thickness $X_{i} / X_{\text {total }}$, produced by a TRC process at casting speed of $22.5 \mathrm{~mm} \cdot \mathrm{s}^{-1}$, setback distance of $41 \mathrm{~mm}$, roll gap of $3 \mathrm{~mm}$ and at different pouring temperatures, $650^{\circ} \mathrm{C}, 635^{\circ} \mathrm{C}, 615^{\circ} \mathrm{C}$ and $605^{\circ} \mathrm{C}$. The standard deviation method was used in this study to calculate the error bars.

A very high pouring temperature $\left(>640^{\circ} \mathrm{C}\right)$ gives some manufacturing problems such as severe surface oxidation and the danger of severe burning of the magnesium melt during casting. Sometimes a very low pouring temperature $\left(<605^{\circ} \mathrm{C}\right)$ results in pre-solidification of magnesium molten metal at the tundish tip before reaching the rolls which results in experimental failure. These experimental considerations and microstructural investigations resulted in selecting a moderate pouring temperature of $615 \pm 5^{\circ} \mathrm{C}$ (i.e. $\sim 15-20^{\circ} \mathrm{C}$ superheat temperature) for further experimental investigation on the TRC processing development of AZ91D alloy. 


\subsubsection{Casting speed}

During the twin roll casting process optimization, it was found that one of the most important factors that affects the microstructure and surface quality of as-cast strips is the casting speed $(v)$. Hence, in this study in order to find out the optimum casting speed, a tip setback of $43 \mathrm{~mm}$, a roll gap of $3 \mathrm{~mm}$ and a pouring temperature of $615 \pm 5^{\circ} \mathrm{C}$ were kept constant, however different casting speeds in the range between $22.5 \mathrm{~mm} . \mathrm{s}^{-1}$ $-129.9 \mathrm{~mm} . \mathrm{s}^{-1}$ were applied in each experiment. By increasing the casting speed, due to the higher cooling rate a lower average grain size can be obtained, as shown in Figures 4.4 and 4.5. By increasing the casting speed from $22.5 \mathrm{~mm} \cdot \mathrm{s}^{-1}$ to $38.3 \mathrm{~mm} \cdot \mathrm{s}^{-1}$, the percentage of central line segregation increases from $4.1 \%$ to about $8.1 \%$, as shown in Figure 4.4.

In addition, it is well known that the casting speed will affect metal flow conditions to a certain extent. The parameter of casting speed was varied from $22.5 \mathrm{~mm} . \mathrm{s}^{-1}$ to $129.9 \mathrm{~mm} . \mathrm{s}^{-1}$. At higher casting speeds $\left(>38 \mathrm{~mm} . \mathrm{s}^{-1}\right)$, some noticeable marks like 'ripple marks' appeared and disappeared regularly at the surface area of the strips produced. The position and morphology of the defects are shown in Figure 4.6. Further microstructural observations, as shown in Figure 4.7, revealed that large voids with cracks around are formed near these marks and they only appeared when the casting speed was above about $38 \mathrm{~mm} \cdot \mathrm{s}^{-1}$. Also, a whole cross-section view of these marks are shown in Figure 4.7, which indicates that the unstable meniscus pulses at a higher casting speeds $\left(>38 \mathrm{~mm} \cdot \mathrm{s}^{-1}\right)$, leads to non-uniformity in the melt/roll contact area during the TRC process and very uneven depression marks at these areas in the final strip. Therefore, a casting speed of $22.5 \mathrm{~mm} . \mathrm{s}^{-1}$ was selected for further investigation in TRC processing of Mg-alloys. 


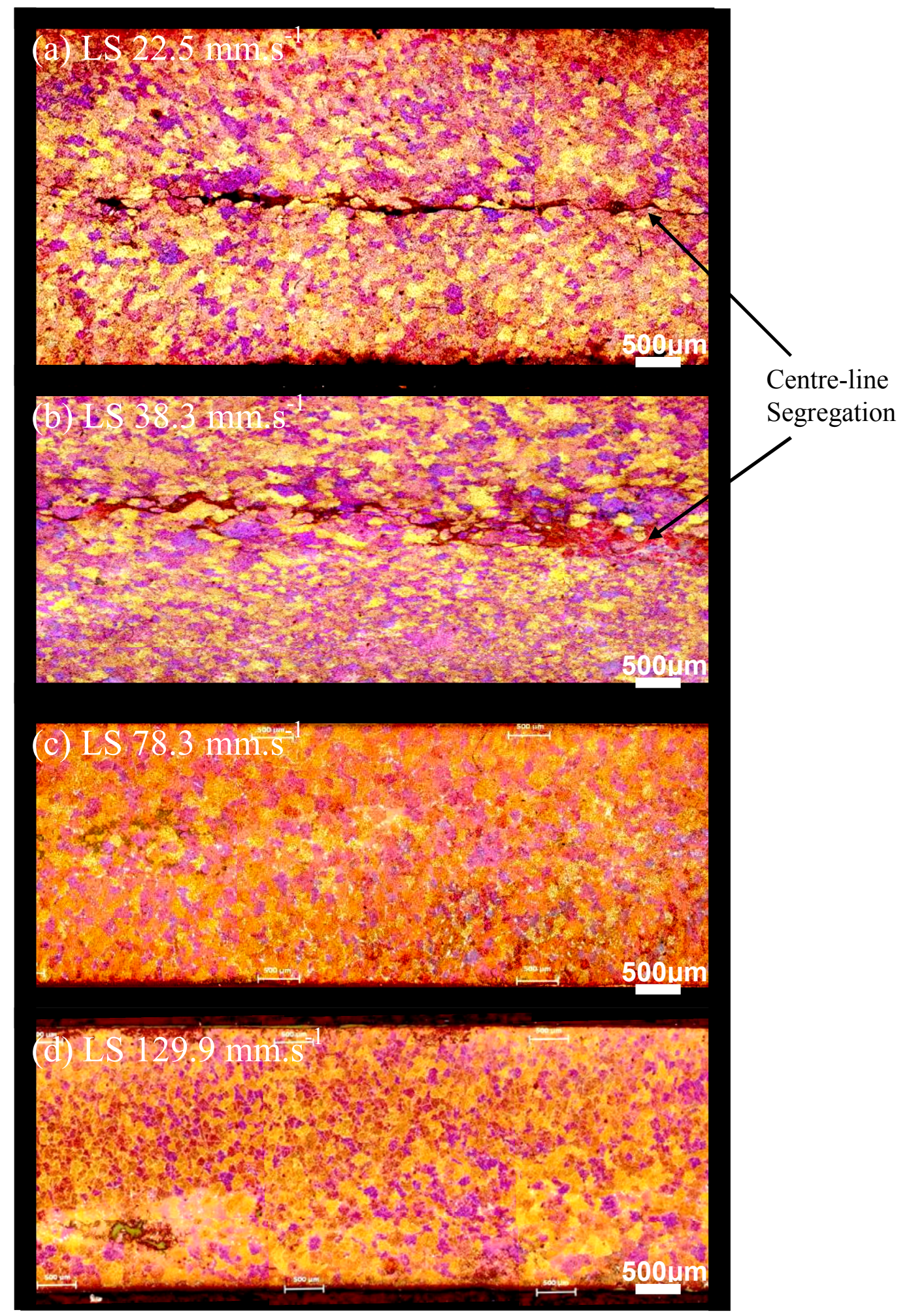

\section{Figure 4.4:}

Optical micrographs showing the microstructure of the longitudinal section (LS) of AZ91D alloy strip samples, produced by a TRC process at a setback distance of $43 \mathrm{~mm}$, roll gap of $3 \mathrm{~mm}$, pouring temperature of $615 \pm 5^{\circ} \mathrm{C}$ and at different casting speeds, (a) $22.5 \mathrm{~mm} . \mathrm{s}^{-1}$, (b) $38.3 \mathrm{~mm} . \mathrm{s}^{-1}$, (c) $78.3 \mathrm{~mm} \cdot \mathrm{s}^{-1}$ and (d) $129.9 \mathrm{~mm} \cdot \mathrm{s}^{-1}$. 


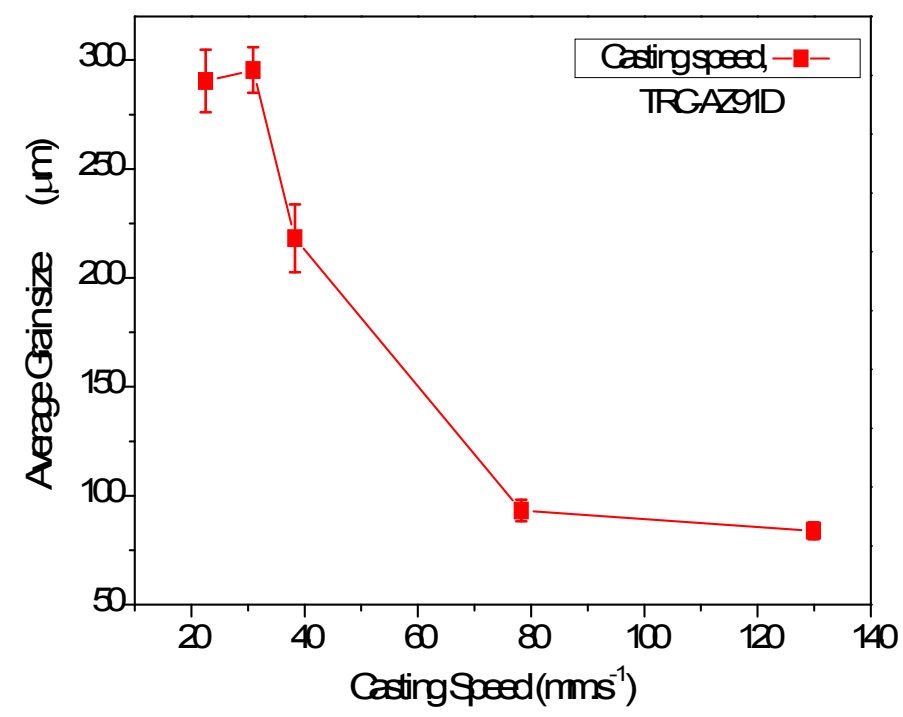

Figure 4.5:

Quantitative analysis showing grain size variation for the longitudinal section (LS) of AZ91D alloy strip samples produced by a TRC process at a setback distance of $43 \mathrm{~mm}$, roll gap of $3 \mathrm{~mm}$, pouring temperature of $615 \pm 5^{\circ} \mathrm{C}$ and at different casting speeds.

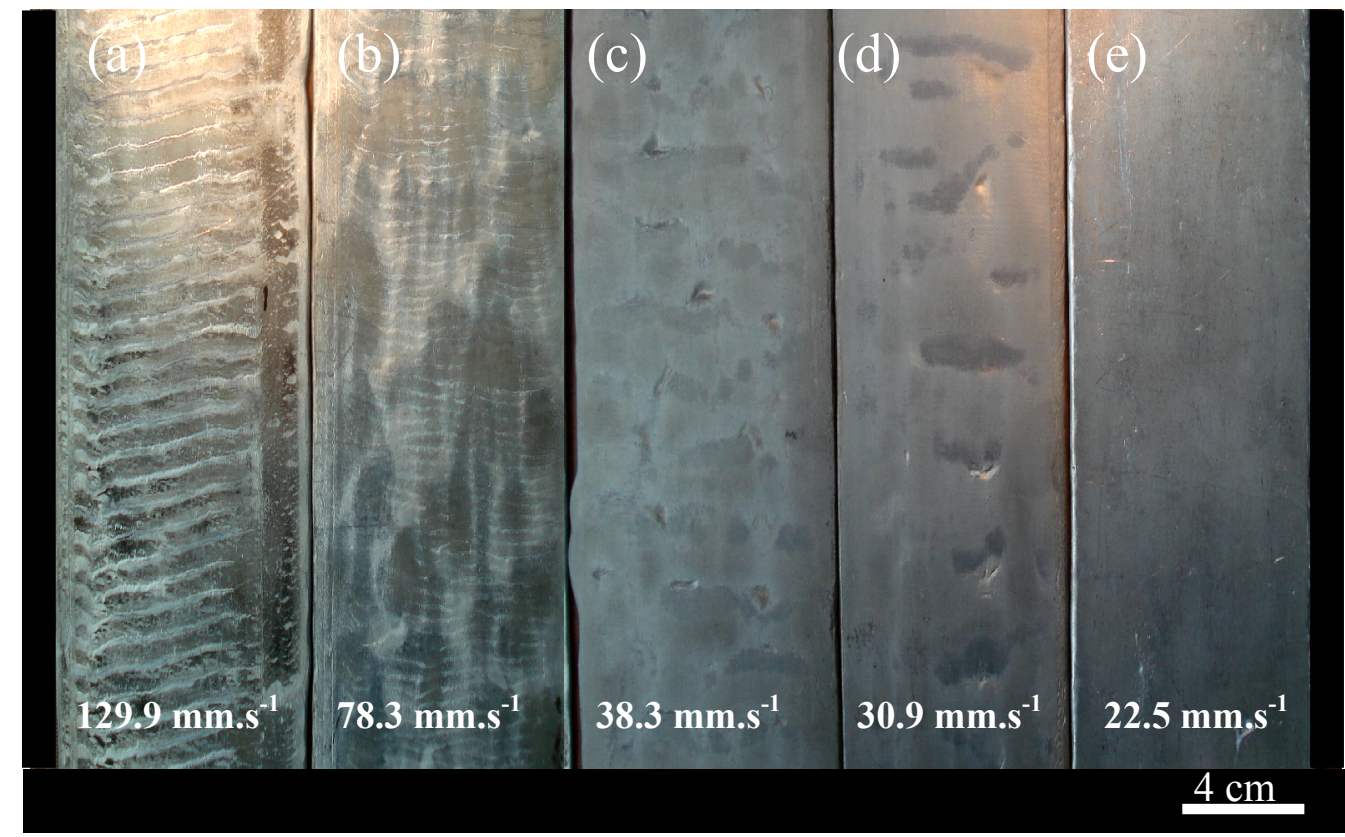

\section{Figure 4.6:}

Optical micrographs showing, photograph of the TRC AZ91D strips produced at a setback distance of $43 \mathrm{~mm}$, roll gap of $3 \mathrm{~mm}$, pouring temperature of $615 \pm 5^{\circ} \mathrm{C}$ and at different casting speeds, (a) $129 \mathrm{~mm} \cdot \mathrm{s}^{-1}$, (b) $78.3 \mathrm{~mm} \cdot \mathrm{s}^{-1}$, (c) $38.3 \mathrm{~mm} \cdot \mathrm{s}^{-1}$, (d) $30.9 \mathrm{~mm} \cdot \mathrm{s}^{-1}$ and (e) $22.5 \mathrm{~mm} \cdot \mathrm{s}^{-1}$. Ripple marks are found at higher casting speeds. The effect of high casting speeds in the formation of surface defects for AZ91D TRC strip is clearly visible. 


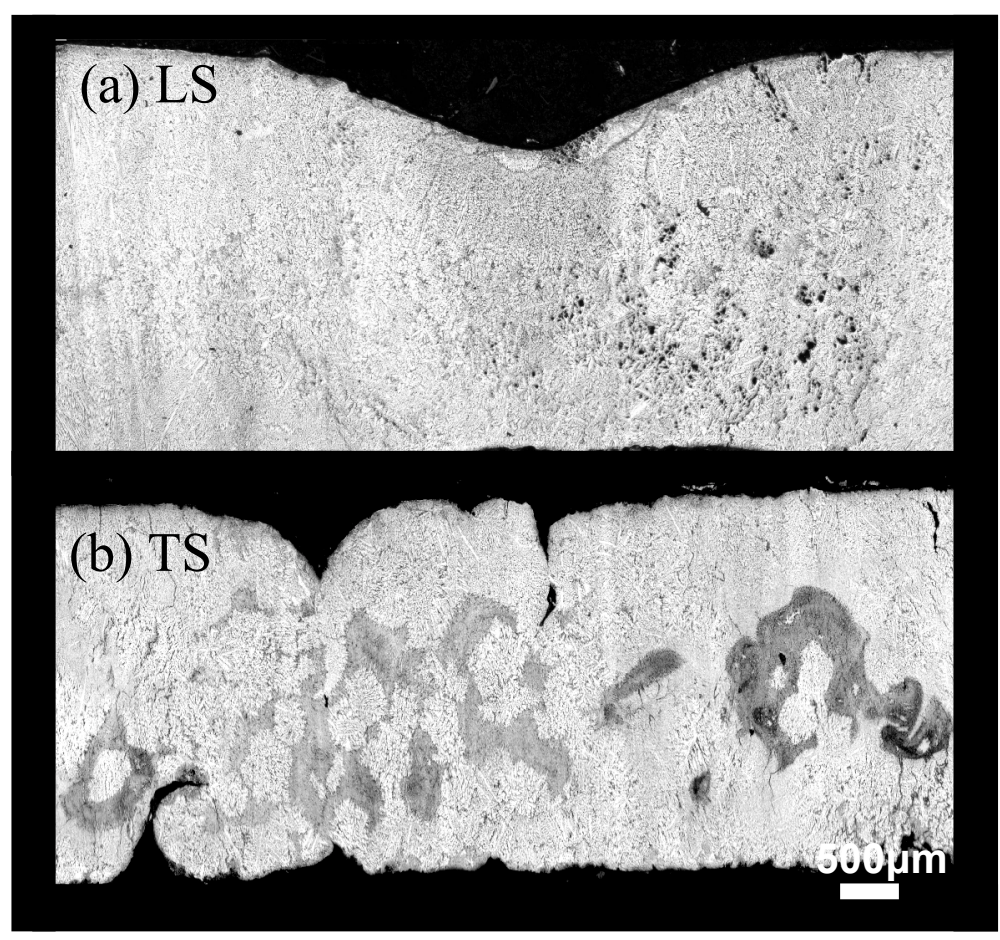

\section{Figure 4.7:}

Optical micrographs showing, (a) longitudinal section (LS) and (b) transverse section (TS) of ripple defects of the TRC AZ91D strips produced at a setback distance of $43 \mathrm{~mm}$, roll gap of $3 \mathrm{~mm}$, pouring temperature of $615 \pm 5^{\circ} \mathrm{C}$ and at a casting speed of $129.9 \mathrm{~mm} \cdot \mathrm{s}^{-1}$ shown previously in Figure 4.6. The non-uniform centre-line segregation and sever collapse of the strip in some regions and also severe cracks propagated into the middle region of AZ91D strip are shown.

\subsubsection{Tip setback}

As seen in the previous section it is absolutely essential for the TRC process to produce strips with high surface quality and lower amount of defects such as centre line segregation, ripple defects and non-uniformity in the whole cross-section of microstructure. Tip setback $(\alpha)$, is another important manufacturing parameter which can affect these demands in final produced strips. Hence, in this study in order to find out the optimum tip setback, a pouring temperature of $615 \pm 5^{\circ} \mathrm{C}$, a roll gap of $3 \mathrm{~mm}$ and a casting speed of $22.5 \mathrm{~mm} . \mathrm{s}^{-1}$ were kept constant, however different tip setbacks in the range between $38 \mathrm{~mm}-49 \mathrm{~mm}$ were applied in each experiment. Figures 4.8 and 4.9 show the effect of setback on grain size and centre line segregation area in longitudinal and transverse sections for AZ91D magnesium strip produced by the TRC process. 

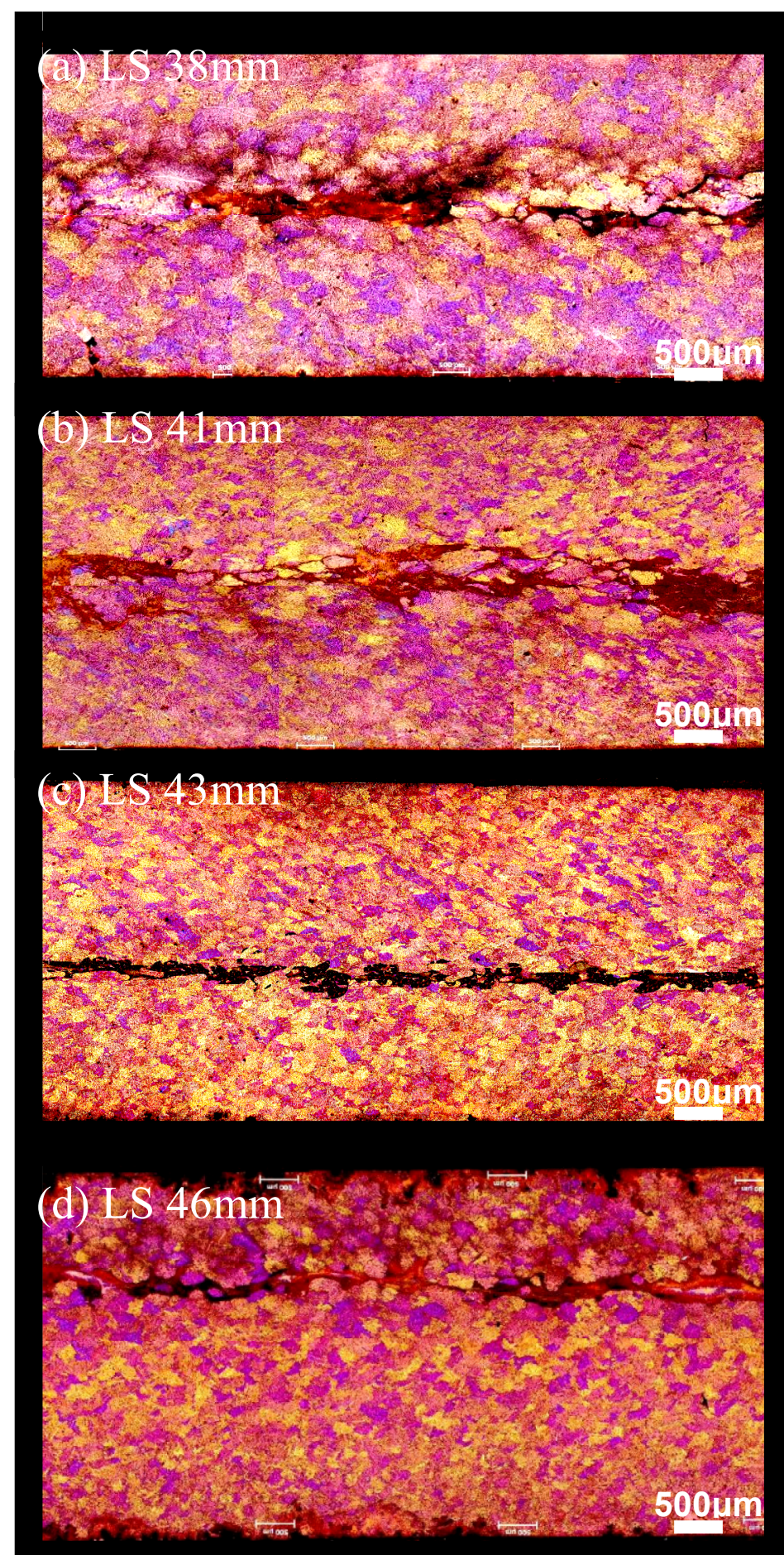

\section{Figure 4.8:}

Optical micrographs showing the microstructure of the longitudinal section (LS) of AZ91D alloy strip samples, produced by TRC process at a roll gap of $3 \mathrm{~mm}$, pouring temperature of $615 \pm 5^{\circ} \mathrm{C}$, casting speed of $22.5 \mathrm{~mm} \cdot \mathrm{s}^{-1}$ and at different setback distances of, (a) $38 \mathrm{~mm}$, (b) $41 \mathrm{~mm}$, (c) $43 \mathrm{~mm}$, (d) $46 \mathrm{~mm}$ and (e) $49 \mathrm{~mm}$.

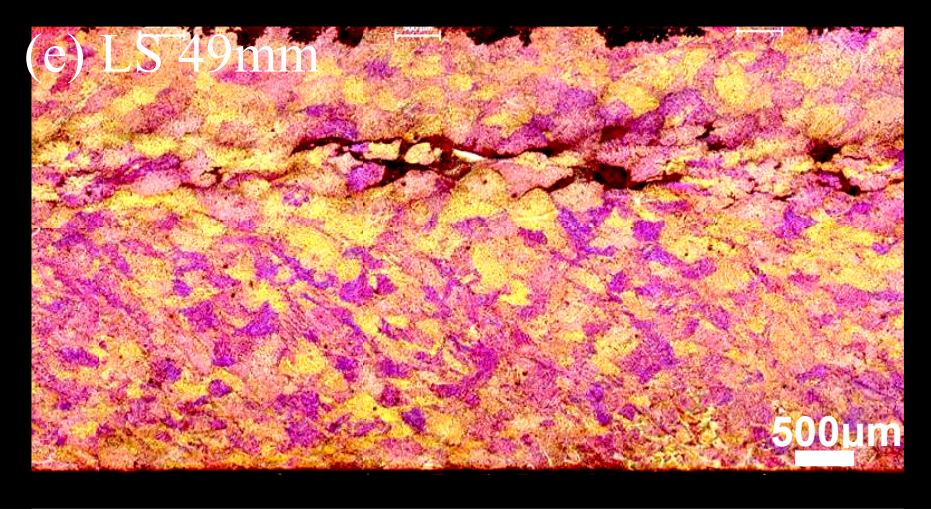



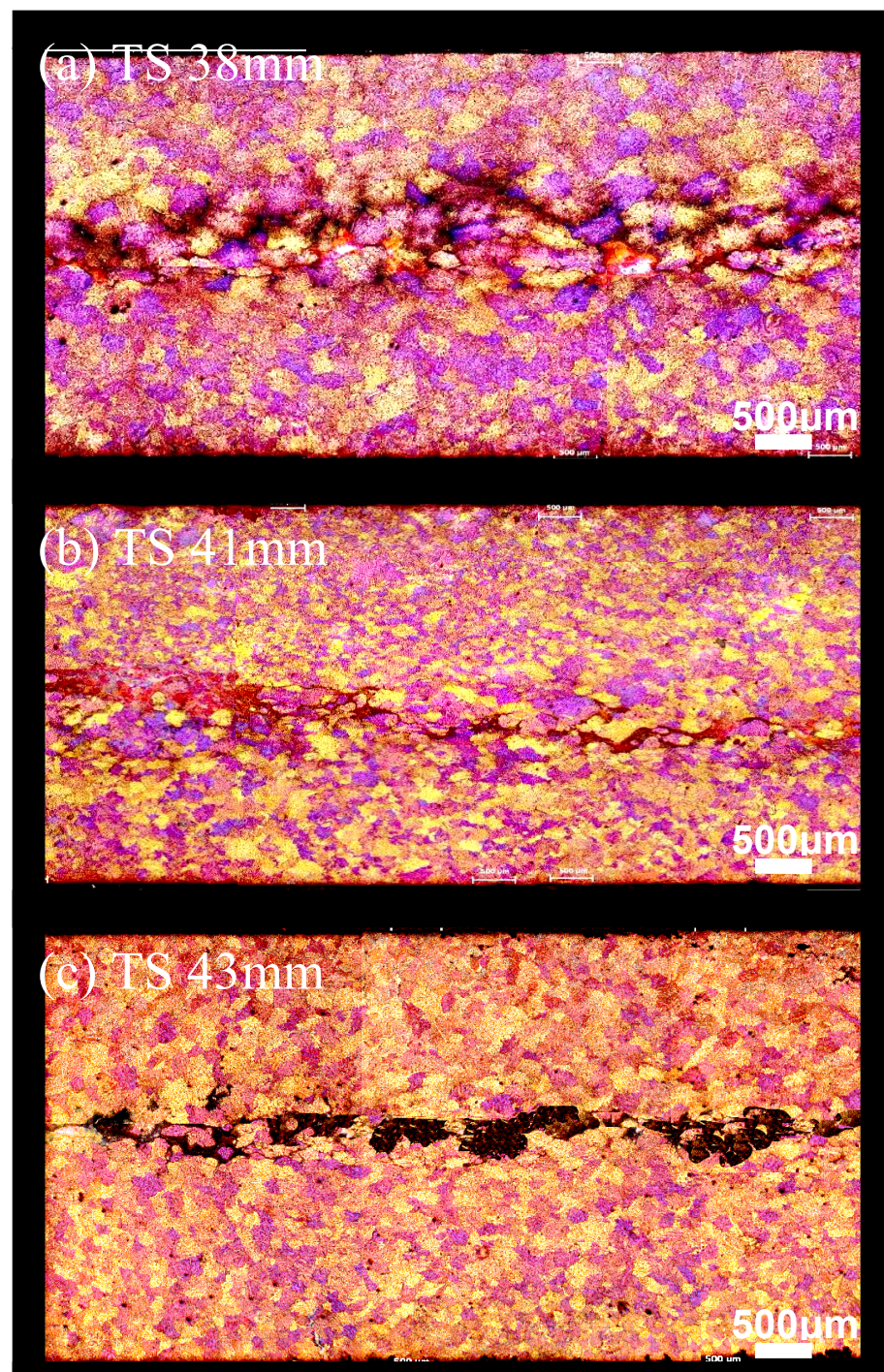

Figure 4.9:

Optical micrographs showing microstructures of the transverse section (TS) of AZ91D alloy strip samples, produced by TRC process at a roll gap of $3 \mathrm{~mm}$, pouring temperature of $615 \pm 5^{\circ} \mathrm{C}$, casting speed of $22.5 \mathrm{~mm} . \mathrm{s}^{-1}$ and at different setback distances of, (a) $38 \mathrm{~mm}$, (b) $41 \mathrm{~mm}$, (c) $43 \mathrm{~mm}$, (d) $46 \mathrm{~mm}$ and (e) $49 \mathrm{~mm}$.
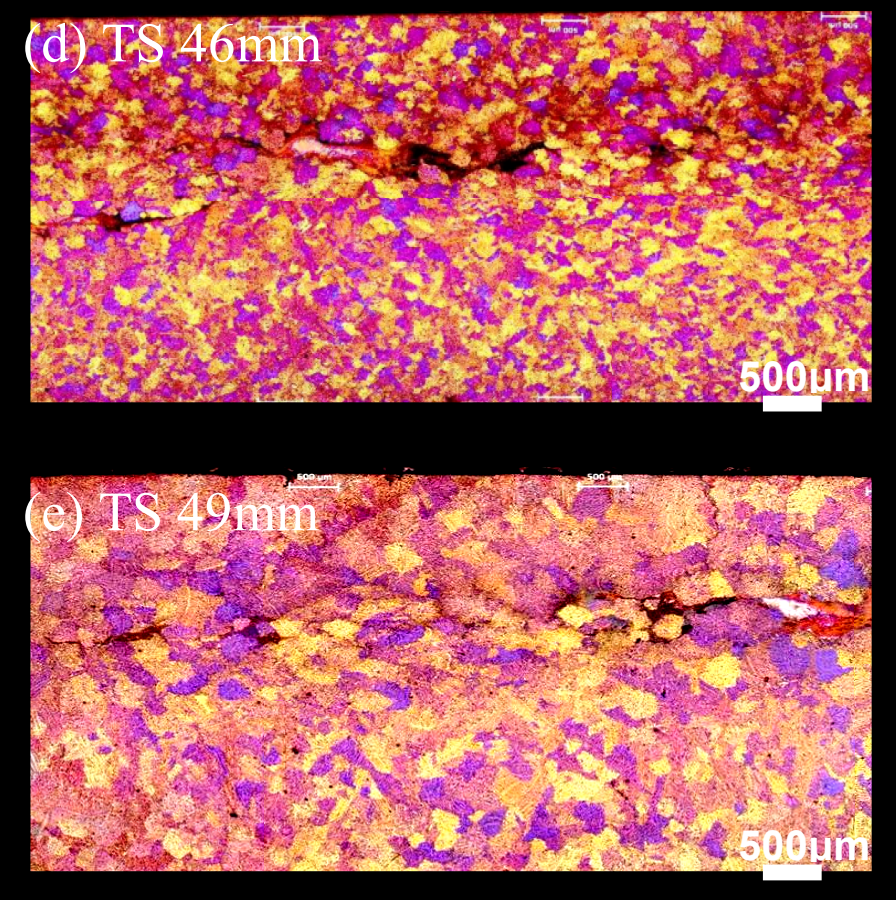
It can be seen that as the setback value increases the amount of compactness ${ }^{1}$ of the centre line segregation and also the average grain size value increase. The quantitative analysis, shown in Figure 4.10 (a) \& (b), verifies these findings and shows the average grain size and centre line segregation area as a function of tip setback distance. Therefore, a higher setback distance is desirable in reducing the defects such as centre line segregation, but experimentally it has been found that with a higher setback distance of $44 \mathrm{~mm}$, a considerable amount of melt overflows and spills in a backward motion from the tundish tip on the lower roll, which causes lesser contact of $\mathrm{Mg}$ liquid on the top roll. In addition, a lower tip setback $(<38 \mathrm{~mm})$ causes dragging the tip of tundish between two rolls which leads to experimental failure. Hence, the optimum tip setback distance for TRC AZ91D strip was found to be in the range of ' $38 \mathrm{~mm}-43 \mathrm{~mm}$ '. Figure 4.11 shows the effect of tip setback distance on the microstructure of AZ91D strip surfaces. The occurrence of voids and inhomogeneous solidification in the surface of strip at a higher tip setback distance can be readily seen in the planar sections shown in Figure 4.11 and also longitudinal and transverse sections shown in Figure 4.8 and 4.9.

(a)

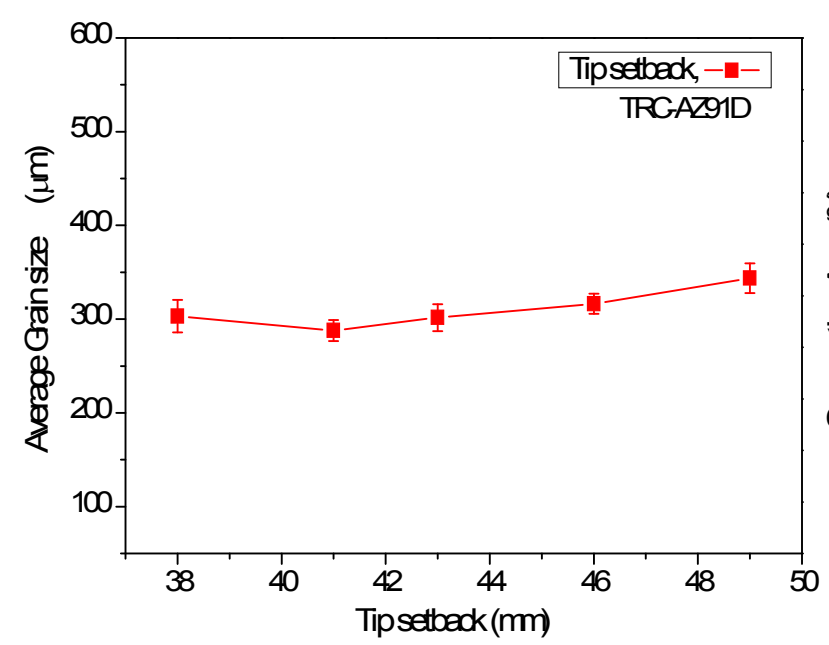

(b)

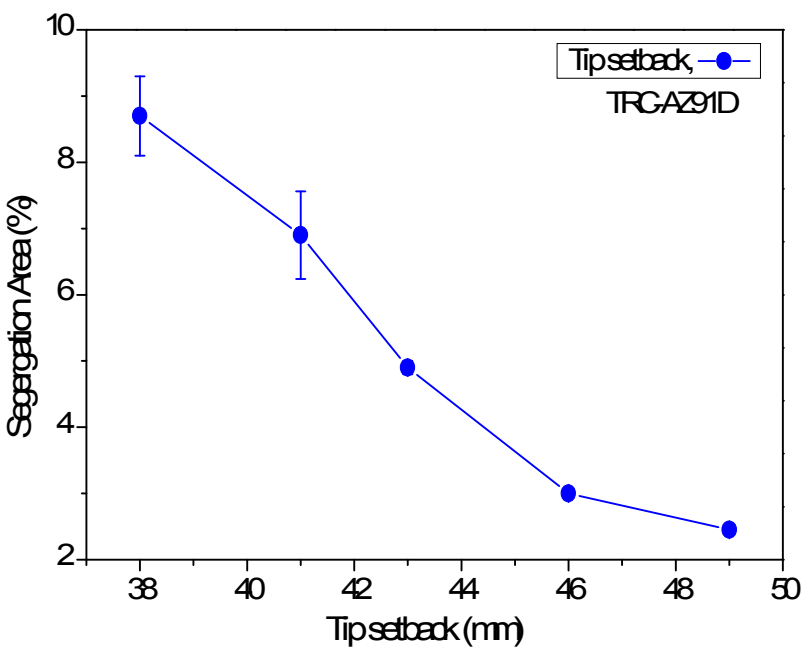

Figure 4.10:

Quantitative analysis showing, (a) grain size variation and, (b) percentage of centre-line segregation as a function of tip setback ( $\mathrm{mm}$ ) for the longitudinal section (LS) of AZ91D alloy strip samples produced by a TRC process at a roll gap of $3 \mathrm{~mm}$, pouring temperature of $615 \pm 5^{\circ} \mathrm{C}$, casting speed of $22.5 \mathrm{~mm} \cdot \mathrm{s}^{-1}$ and at different tip setback distances.

\footnotetext{
${ }^{1}$ The visual inspected closeness of segregated liquid zones to each other
} 

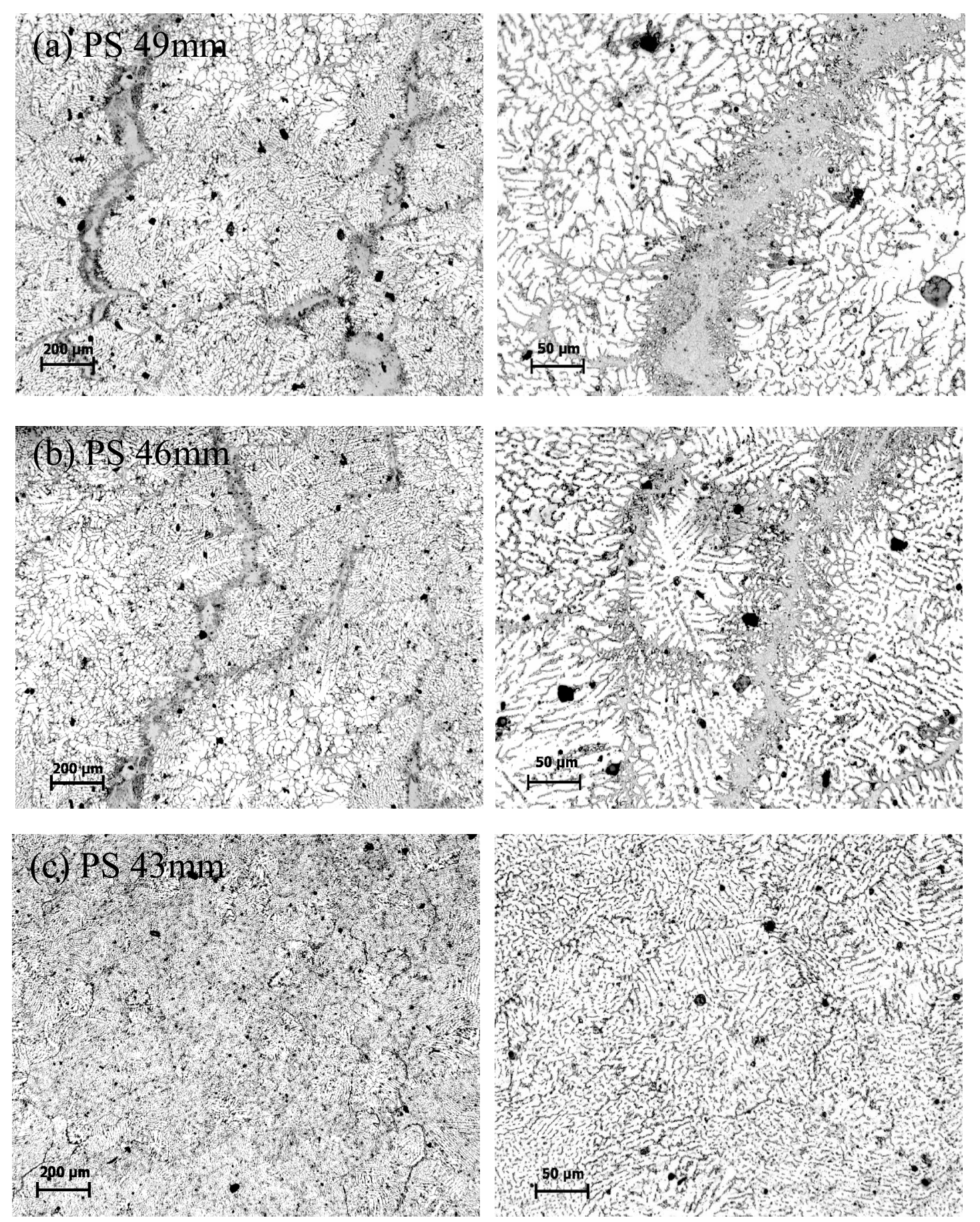

Figure 4.11:

Optical micrographs at two different magnifications of planar sections (PS) obtained from the AZ91D TRC strip at a roll gap of $3 \mathrm{~mm}$, pouring temperature of $615 \pm 5^{\circ} \mathrm{C}$, casting speed of $22.5 \mathrm{~mm} . \mathrm{s}^{-1}$ and at different tip setback distances, (a) $49 \mathrm{~mm}$, (b) $46 \mathrm{~mm}$ and (c) $43 \mathrm{~mm}$.

\subsubsection{Roll gap}

Similar to previous sections in the TRC process optimization, the effect of the roll gap as a last major casting parameter in the optimization of the TRC process has been evaluated by two different criteria, i.e. surface quality of the final strip and 
microstructural characterisation. In this study in order to find out the optimum roll gap, a pouring temperature of $615 \pm 5^{\circ} \mathrm{C}$, a tip setback of $41 \mathrm{~mm}$ and a casting speed of $22.5 \mathrm{~mm} . \mathrm{s}^{-1}$ were kept constant, however different roll gaps in the range between $1 \mathrm{~mm}-5 \mathrm{~mm}$ were applied in each experiment. The effect of roll gap on the grain size is shown in Figure 4.12. It can be stated that by increasing the roll gap from $1 \mathrm{~mm}$ to $5 \mathrm{~mm}$, the average grain size increases.

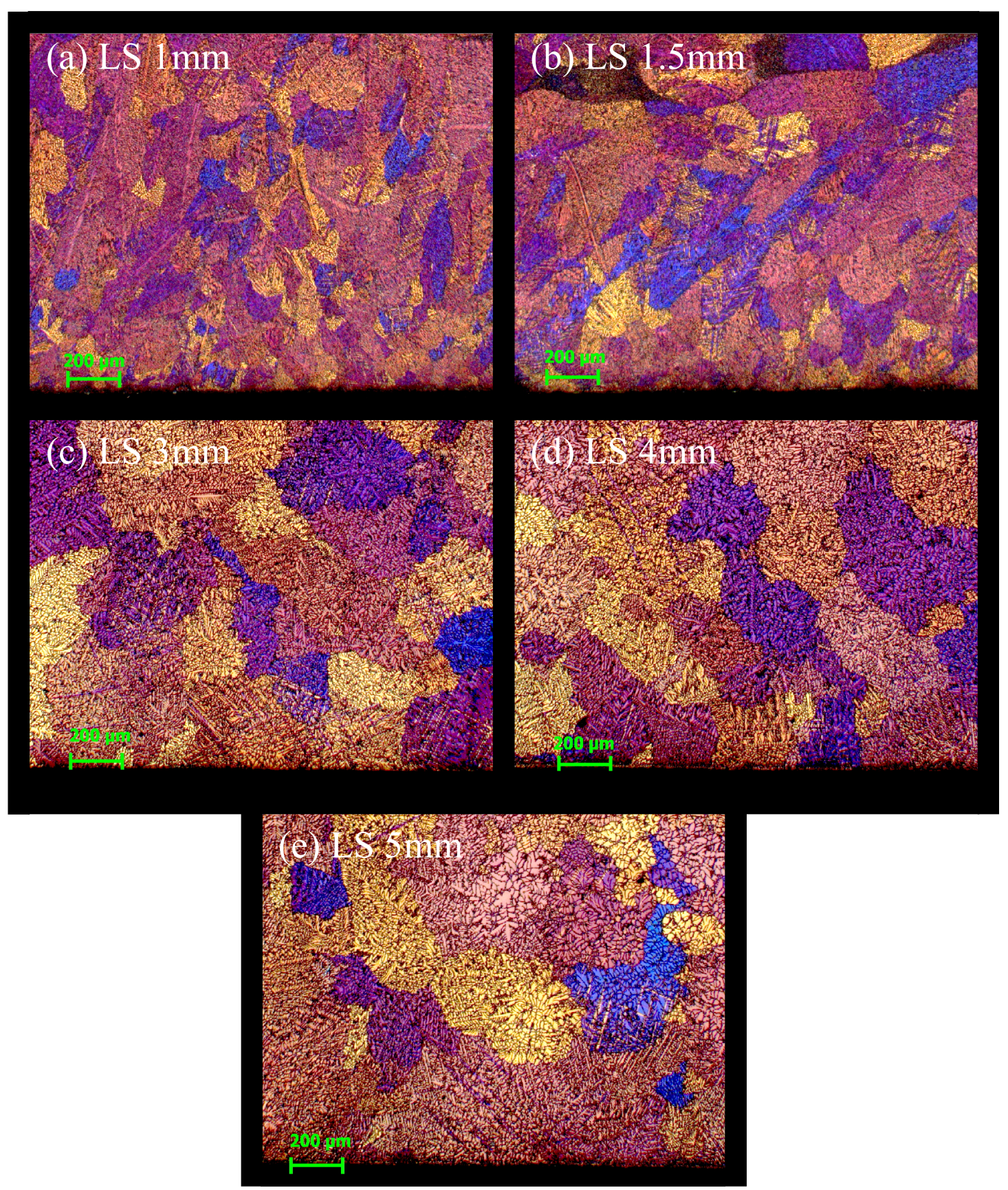

\section{Figure 4.12:}

Optical micrographs showing the grain size variation of the longitudinal section (LS) of AZ91D alloy strip samples, produced by a TRC process at a pouring temperature of $615 \pm 5^{\circ} \mathrm{C}$, casting speed of $22.5 \mathrm{~mm} \cdot \mathrm{s}^{-1}$, setback distance of $41 \mathrm{~mm}$ and at different roll gaps of, (a) $1 \mathrm{~mm}$, (b) $1.5 \mathrm{~mm}$, (c) $3 \mathrm{~mm}$, (d) $4 \mathrm{~mm}$ and (e) $5 \mathrm{~mm}$. 
(a)

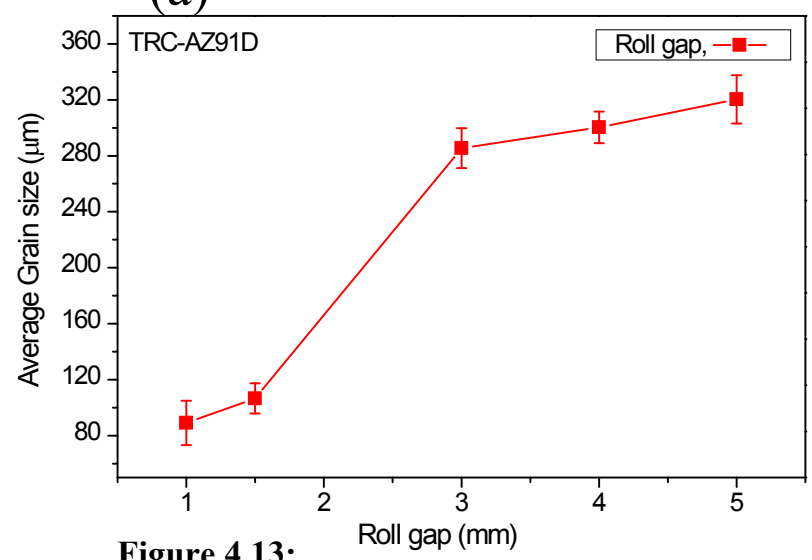

(b)

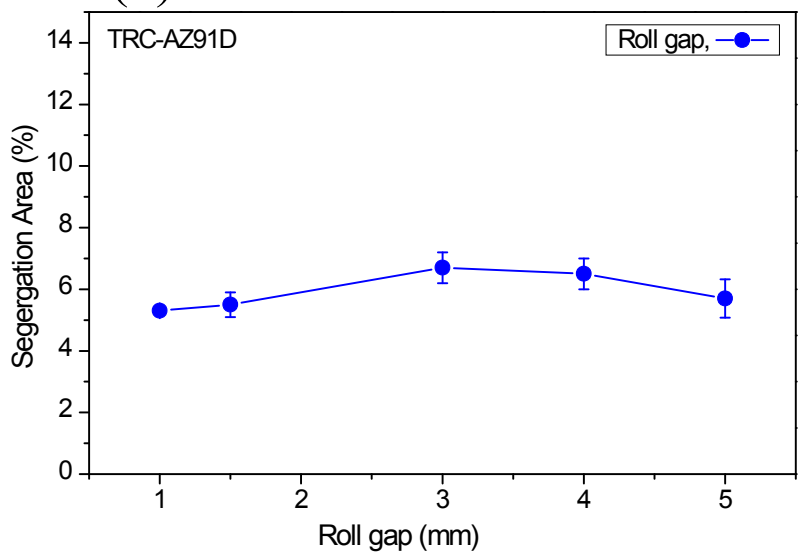

Quantitative analysis showing, (a) grain size variation and, (b) percentage of centre-line segregation as a function of roll gap $(\mathrm{mm})$ for longitudinal section (LS) of AZ91D alloy strip samples produced by a TRC process at a pouring temperature of $615 \pm 5^{\circ} \mathrm{C}$, casting speed of $22.5 \mathrm{~mm} \cdot \mathrm{s}^{-1}$, roll setback distance of $41 \mathrm{~mm}$ and at different roll gap.

Quantitative analysis in Figure 4.13 (a) verifies the finding in Figures 4.12 which shows that by increasing the roll gap from $1 \mathrm{~mm}$ to $5 \mathrm{~mm}$, the average grain size increases from $89.1 \mu \mathrm{m}$ to $320.3 \mu \mathrm{m}$.

The effect of roll gap on the formation of defects in AZ91D magnesium strip produced by a TRC process is shown in Figure 4.14. By setting the roll gap from a higher to lower range, the amount of centre line segregation in the middle of the strip is not changed significantly, as confirmed by quantitative analysis shown in Figure 4.13 (b). However, as shown in Figures 4.14 (a) \& (b) and Figure 4.15 at very low roll gap values (i.e. $\sim 1 \mathrm{~mm}-1.5 \mathrm{~mm}$ ) macro- and micro-voids and cracks appear on the surface of the final thin strips which in a more detailed observation are connected to a liquid segregation.

Based on these findings and the experimental facilities in BCAST, it can be concluded that a very low roll gap, i.e. $\sim 1 \mathrm{~mm}-1.5 \mathrm{~mm}$, results in low quality $\mathrm{Mg}$ strips. However a very high roll gap, i.e. $\sim 4 \mathrm{~mm}-5 \mathrm{~mm}$, results in very thick $\mathrm{Mg}$ strip which needs a great 
deal of down-stream processing to produce thin $\mathrm{Mg}$ strip. As a result, a roll gap of around $3 \mathrm{~mm}$ was selected as an ideal roll gap for $\mathrm{Mg}$ strip production by the TRC process.

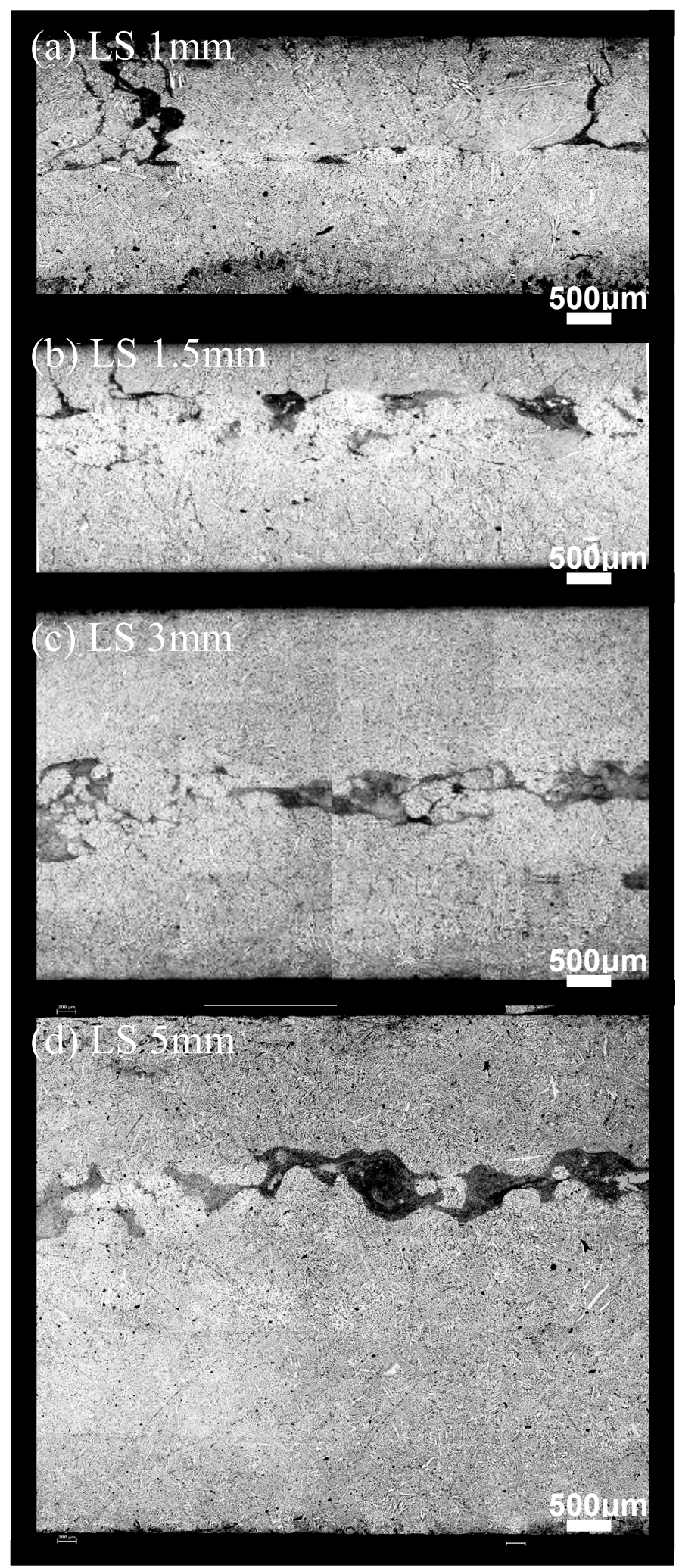

\section{Figure 4.14:}

Optical micrographs showing the microstructure of longitudinal section (LS) of AZ91D alloy strip samples, produced by a TRC process at a pouring temperature of $615 \pm 5^{\circ} \mathrm{C}$, casting speed of $22.5 \mathrm{~mm} \cdot \mathrm{s}^{-1}$, setback distance of $41 \mathrm{~mm}$ and at different roll gaps of, (a) $1 \mathrm{~mm}$, (b) $1.5 \mathrm{~mm}$, (c) $3 \mathrm{~mm}$ and (d) $5 \mathrm{~mm}$. 


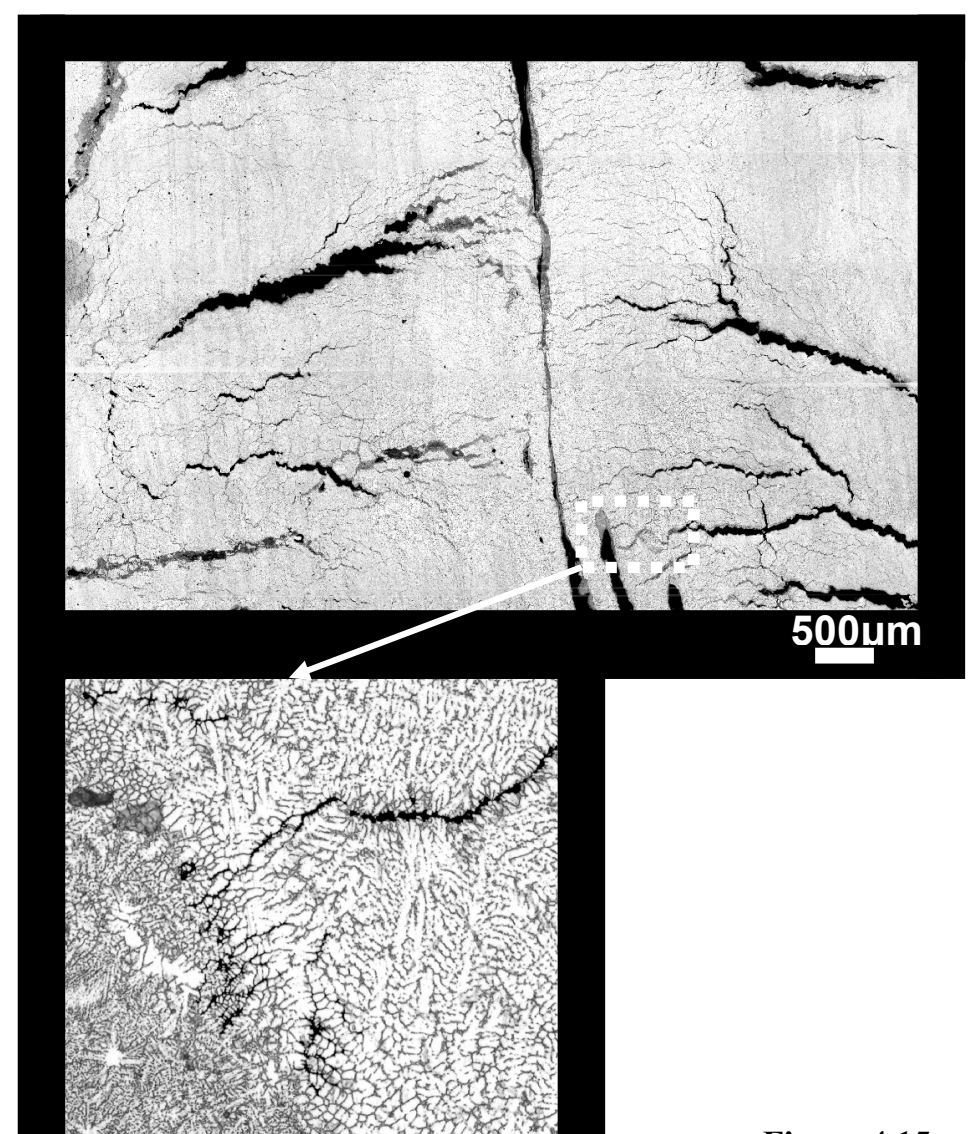

\section{Figure 4.15:}

Optical micrographs at two different magnifications showing defects formed in the planar section of TRC AZ91D strips produced at a roll gap of $1.5 \mathrm{~mm}$, setback distance of $41 \mathrm{~mm}$, pouring temperature of $615 \pm 5^{\circ} \mathrm{C}$ and casting speed of $22.5 \mathrm{~mm} . \mathrm{s}^{-1}$. The severe cracks propagating on the surface of the very thin strip $(\sim 1.5 \mathrm{~mm})$ are clearly illustrated at low and high magnifications. 


\subsubsection{The selected processing parameters}

Based on the experimental results of previous Sections 4.1.1 - 4.1.4, optimized processing conditions can be obtained for twin roll casting of AZ91D Mg alloy, as summarized in Table 4.1.

Table 4.1:

The optimized processing parameters for TRC of AZ91D Mg-alloy.

\begin{tabular}{ccccc} 
Process & $\begin{array}{c}\text { Roll speed } \\
\left(\mathrm{mm}^{-1} \mathrm{~s}^{-1}\right.\end{array}$ & $\begin{array}{c}\text { Roll gap } \\
(\mathrm{mm})\end{array}$ & $\begin{array}{c}\text { Tip setback } \\
(\mathrm{mm})\end{array}$ & $\begin{array}{c}\text { Pouring } \\
\text { temperature } \\
\left(\mathrm{C}^{2}\right)\end{array}$ \\
\hline TRC AZ91D & 22.5 & 3 & $38-43$ & $615 \pm 5$ \\
\hline
\end{tabular}

Figure 4.16 shows that the AZ91D strip produced with optimized conditions has a high surface quality with minimal noticeable defects such as ripples and hot cracks indicating a very good surface finish produced by the optimized TRC process. Figure 4.17 (a) shows the microstructure of the through thickness cross-section of the AZ91D TRC strip in the longitudinal direction produced under the optimized conditions, shown in Table 4.1, with a tip setback of $41 \mathrm{~mm}$. Figure 4.17 (b) shows detailed information on the microstructure from the top to the bottom of the strip. The microstructure of the TRC Mg-alloy strip is dominated by the growth of a columnar grain structure although a more equiaxed grain structure is noticeable in the central section. Significant central line segregation, as illustrated in Figure 4.17 (b)-C, can also be observed in the TRC AZ91D strip.

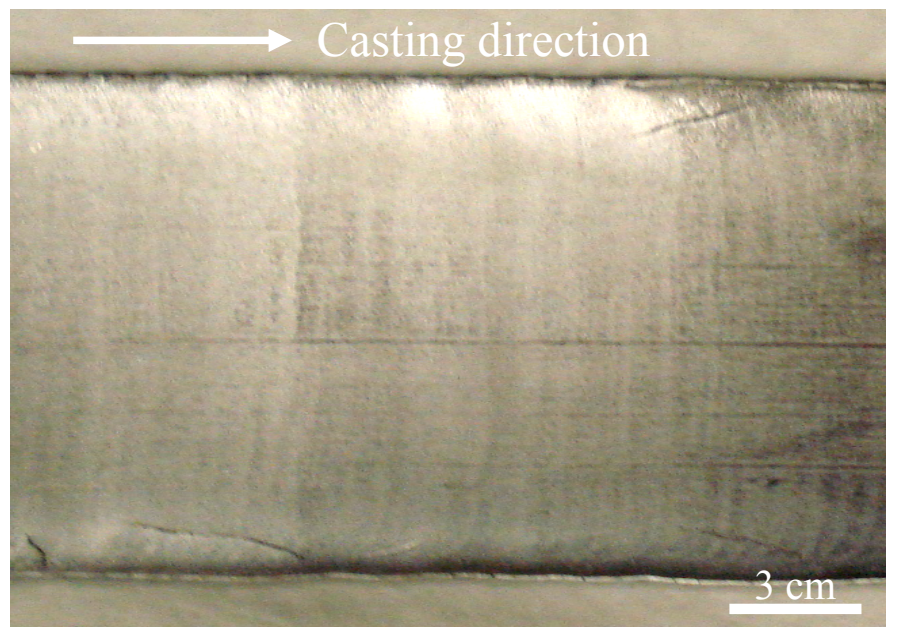

\section{Figure 4.16:}

A photograph illustrating the surface quality of TRC AZ91D alloy strip, produced with optimized processing conditions, i.e. pouring temperature of $615 \pm 5^{\circ} \mathrm{C}$, casting speed of $22.5 \mathrm{~mm} . \mathrm{s}^{-1}$, roll setback distance of $41 \mathrm{~mm}$ and roll gap of $3 \mathrm{~mm}$. 
(a)

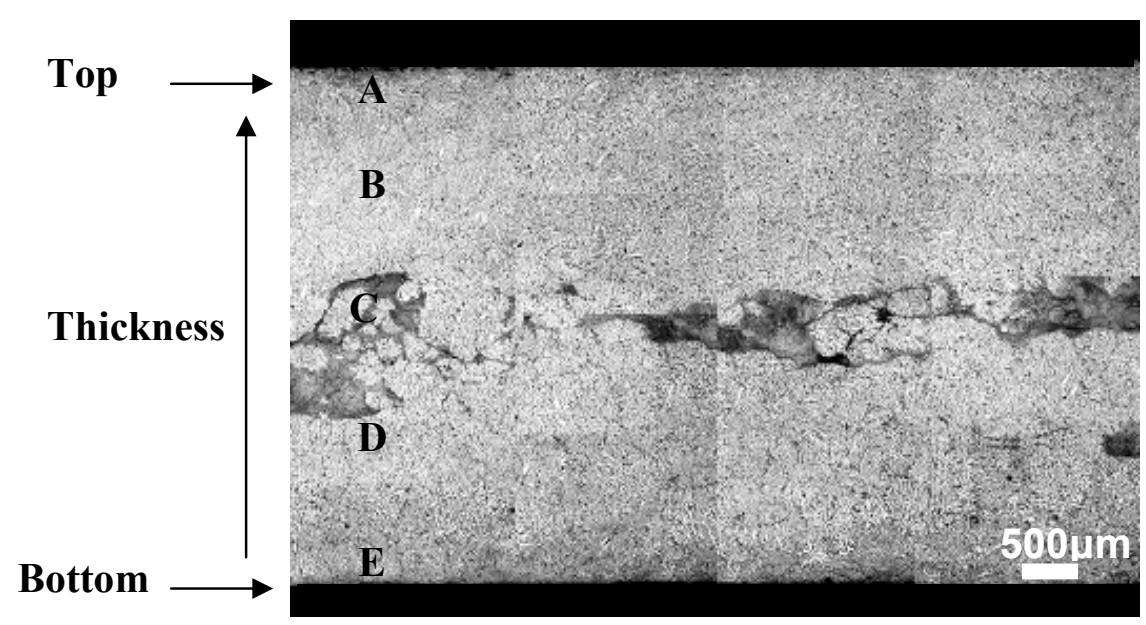

(b)

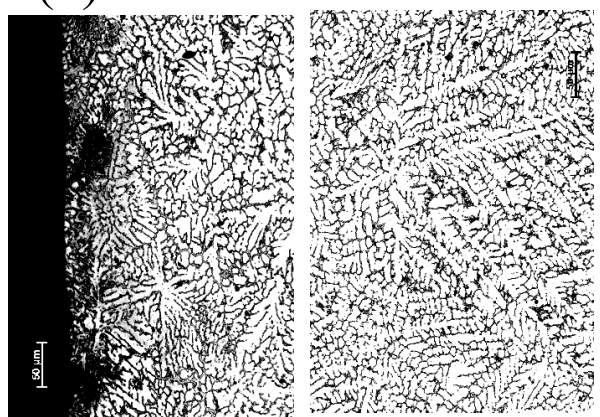

A

B

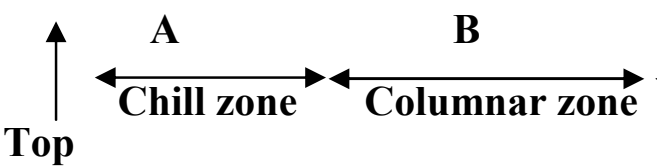

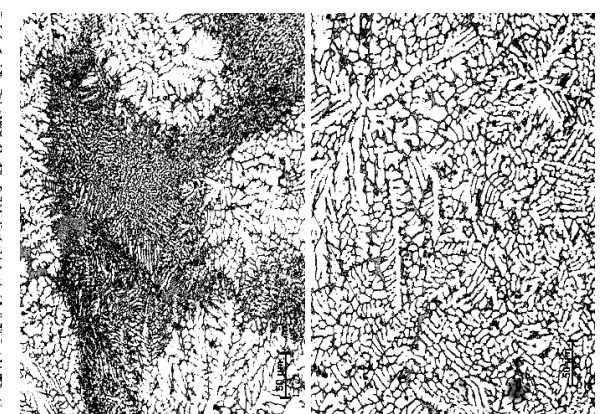

D

C

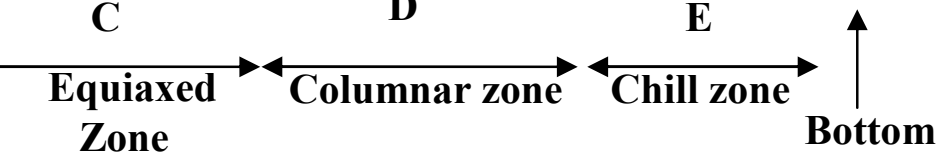

Figure 4.17:

(a) Microstructure of the entire cross-section of TRC AZ91D strip along the longitudinal direction produced with optimized processing conditions i.e. a pouring temperature of $615 \pm 5^{\circ} \mathrm{C}$, casting speed of $22.5 \mathrm{~mm} . \mathrm{s}^{-1}$, roll setback distance of $41 \mathrm{~mm}$ and roll gap of $3 \mathrm{~mm}$. (b) (A-E) microstructural variations throughout the whole thickness direction from the top to the bottom.

A more detailed investigation on centre line segregation formed in the middle of magnesium strip is given in Section 4.3.3. 


\subsection{Optimization of the Melt Conditioned Twin Roll Casting (MC-TRC)}

The selected optimized parameters for the TRC process was also applied to the MC-TRC process. In addition, there are three other parameters involved in the optimization of MC-TRC process:

- Shearing temperature $\left(\mathrm{T}_{\mathrm{sh}}\right)$

- Shearing speed

- Shearing time

The shearing temperature was also optimized and the selected value was applied. However, due to economic consideration, optimization of shearing speed and shearing time selection was based on broad research carried out previously on the MCAST machine at the BCAST research centre.

\subsubsection{Shearing temperature $\left(\mathbf{T}_{\underline{\mathrm{Sh}}}\right)$}

To investigate the effects of shearing temperature on the microstructure of MC-TRC AZ91D alloy, the shearing temperature was varied between $598^{\circ} \mathrm{C}$ to $650^{\circ} \mathrm{C}$ with a constant shearing speed and shearing time of $600 \mathrm{rpm}$ and $60 \mathrm{~s}$, respectively. The shearing temperature was constant in all five zones of the MCAST machine. Figure 4.18 shows typical optical micrographs of longitudinal and transverse sections (LS and TS) of the MC-TRC AZ91D strip produced at different shearing temperatures. This figure clearly shows that the intensive melt shearing results in significant grain refinement and reduced centre line segregation in AZ91D alloy strip for all the different shearing temperatures. 


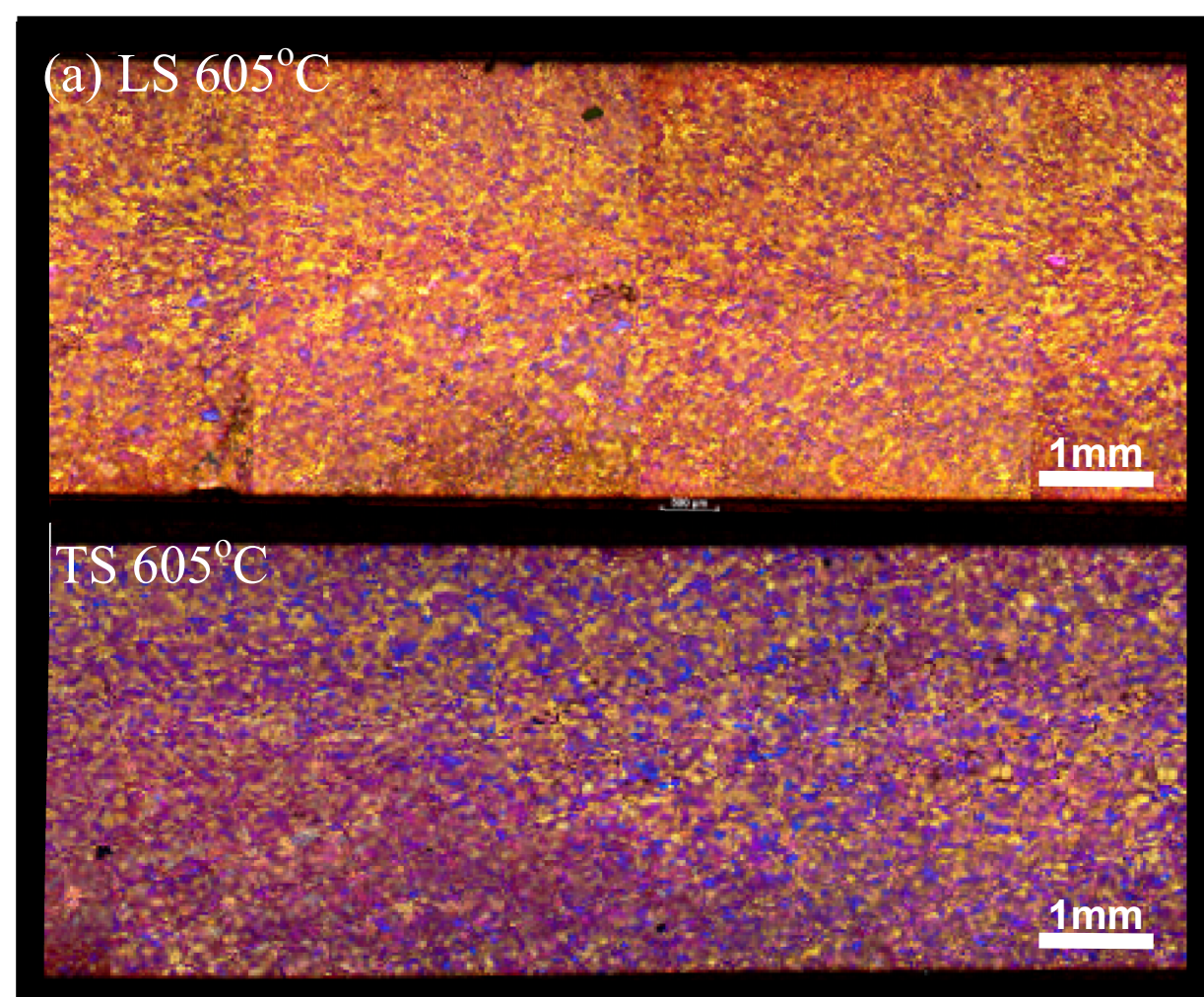

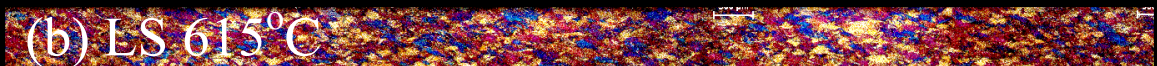
s.

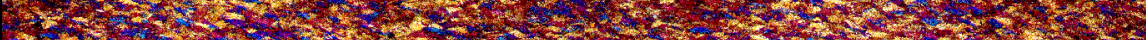

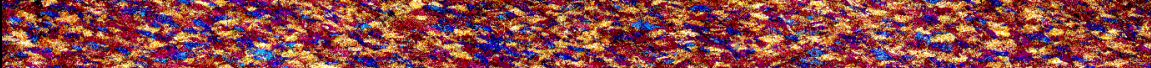

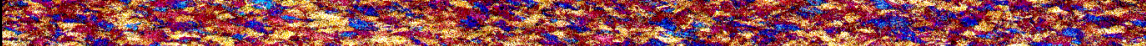

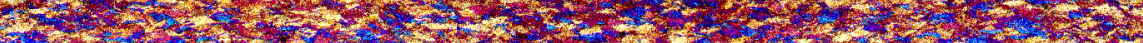

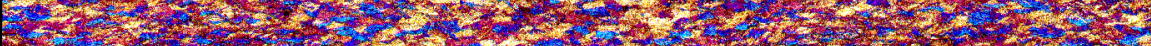

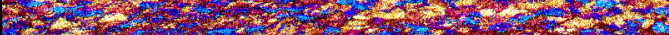

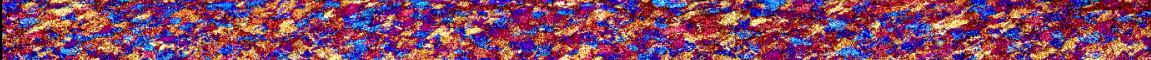

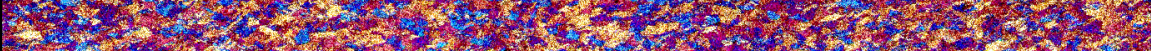

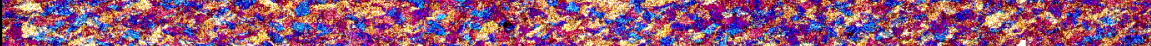

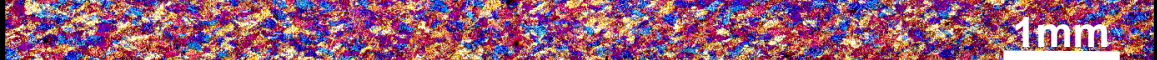

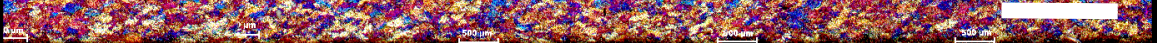

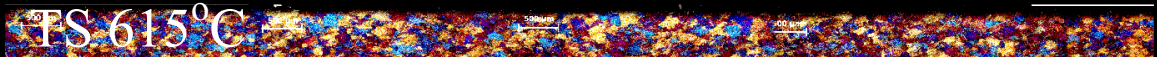

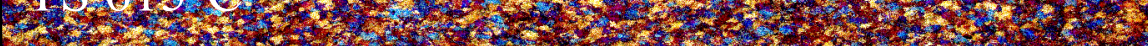

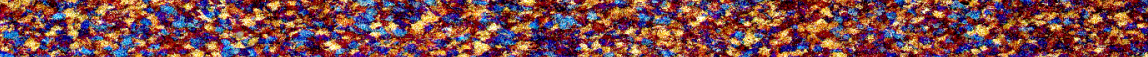

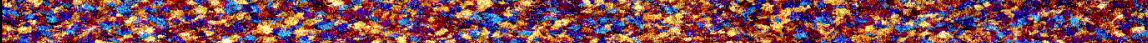

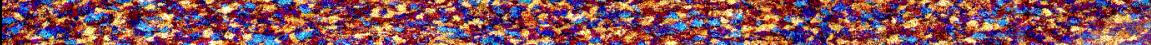

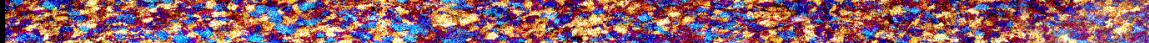

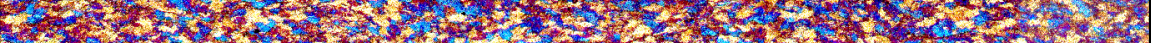

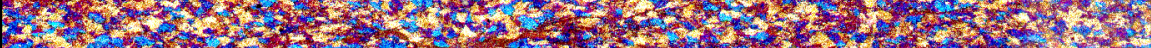

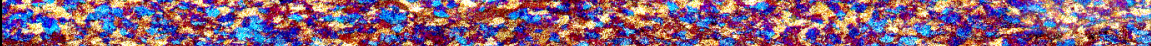
w.

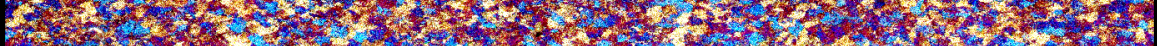

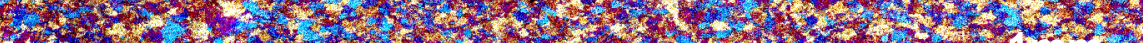

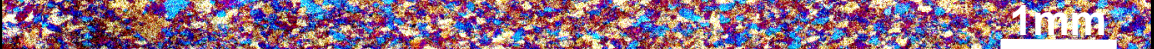

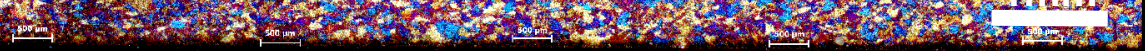




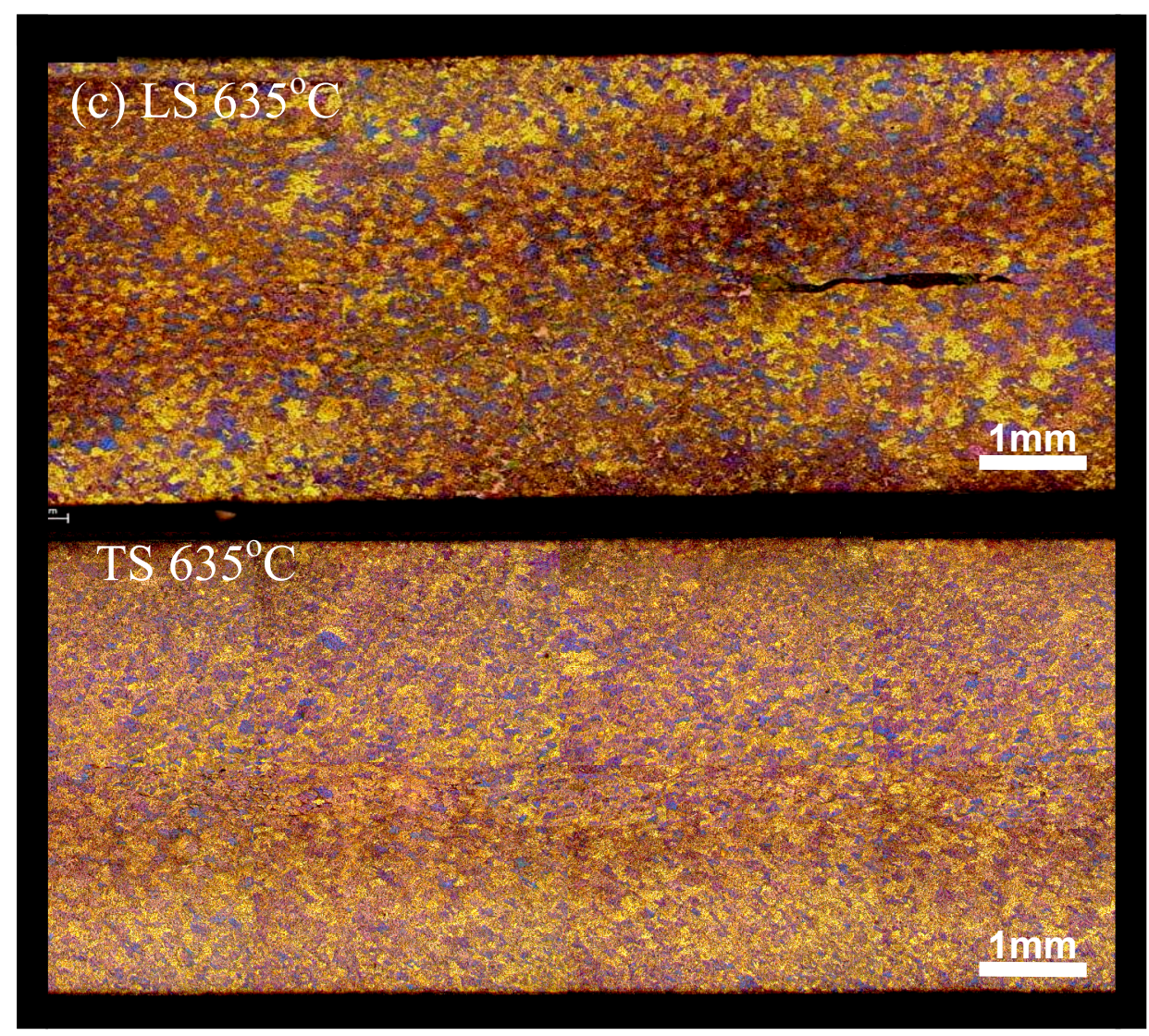

\section{Figure 4.18:}

Optical micrographs showing the microstructures of longitudinal and transverse sections (LS and TS) of AZ91D alloy strip samples with melt shearing, produced by the MC-TRC process at a casting speed of $22.5 \mathrm{~mm} \cdot \mathrm{s}^{-1}$, setback distance of $43 \mathrm{~mm}$, roll gap of $3 \mathrm{~mm}$ and different shearing temperatures of, (a) $605^{\circ} \mathrm{C}$, (b) $615^{\circ} \mathrm{C}$ and (c) $635^{\circ} \mathrm{C}$. The melt shearing was carried out at $600 \mathrm{rpm}$ for $60 \mathrm{~s}$ without any chemical addition

More detailed cross-sectional views of the MC-TRC samples are depicted at higher magnification in Figure 4.19 which shows that only equiaxed grains with a uniform grain size distribution were seen across the MC-TRC AZ91D strip. 


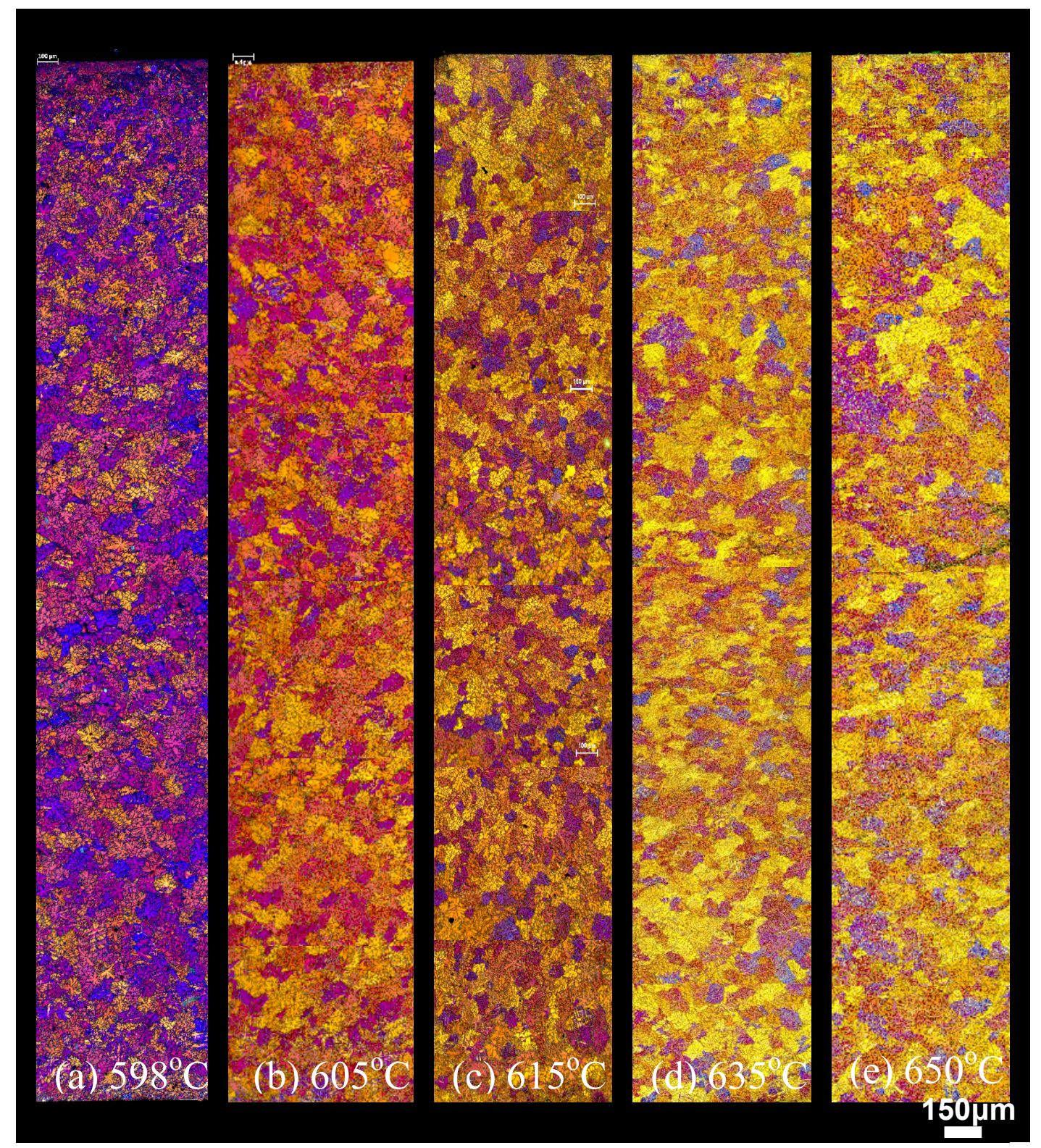

\section{Figure 4.19:}

Optical micrographs showing higher magnification of microstructures of transverse section (TS) of AZ91D alloy strip samples with melt shearing, produced by the MC-TRC process at a casting speed of $22.5 \mathrm{~mm} . \mathrm{s}^{-1}$, setback distance of $43 \mathrm{~mm}$, roll gap of $3 \mathrm{~mm}$ and different shearing temperatures of, (a) $598^{\circ} \mathrm{C}$, (b) $605^{\circ} \mathrm{C}$ and (c) $615^{\circ} \mathrm{C}$, (d) $635^{\circ} \mathrm{C}$ and (e) $650^{\circ} \mathrm{C}$. The melt shearing was carried out at $600 \mathrm{rpm}$ for 60 s without any chemical addition

The mean grain size throughout the thickness in the longitudinal (LS) and transverse direction (TS) in the MC-TRC AZ91D strip was investigated in detail and the results are shown in Figure 4.20. The mean size of equiaxed grains dependant upon the shearing 
temperature is about $60-90 \mu \mathrm{m}$ and also is extremely uniform. No significant change is observed in grain size in both the longitudinal and transverse directions.

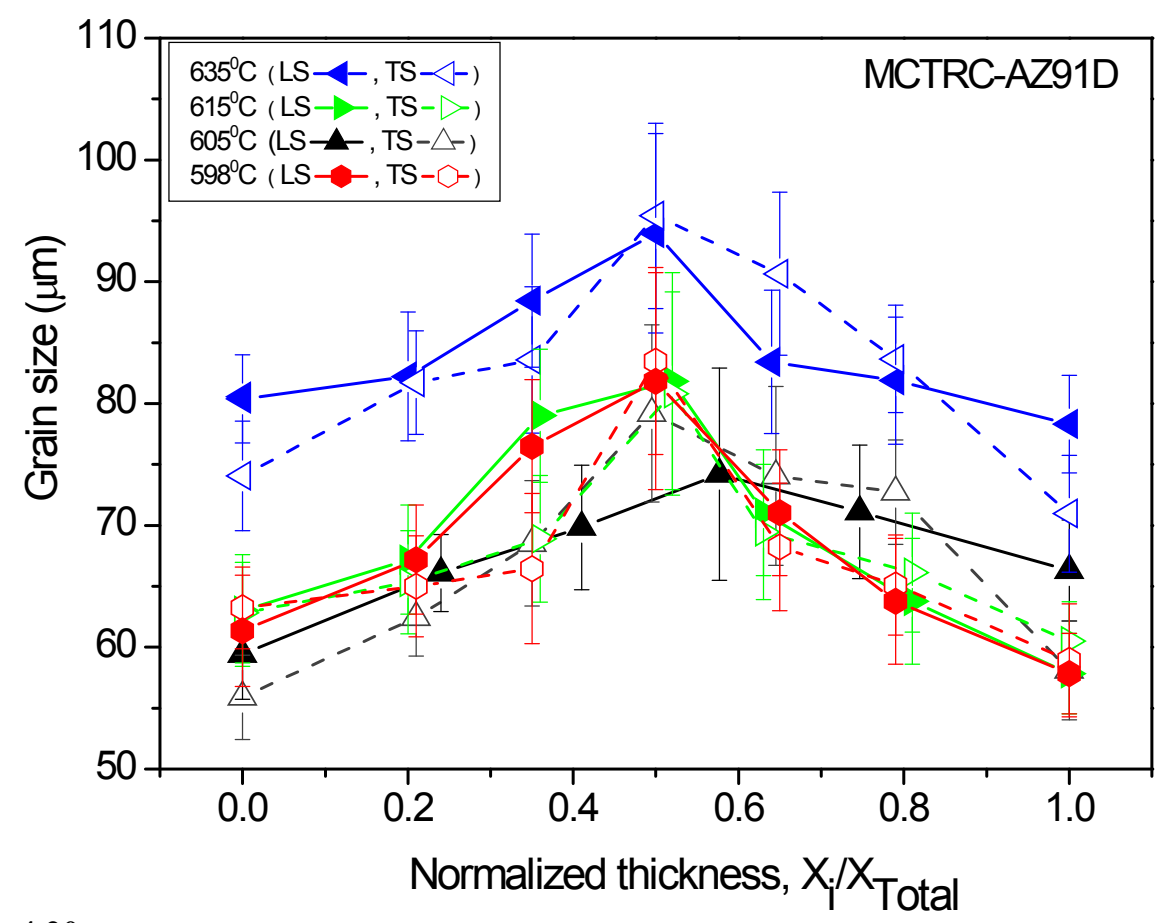

Figure 4.20:

Quantitative analysis showing grain size variation in the longitudinal and transverse sections (LS and TS) of AZ91D alloy strip samples as a function of normalized thickness $\mathrm{X}_{\mathrm{i}} / \mathrm{X}_{\text {total }}$, produced by the MC-TRC process at a casting speed of $22.5 \mathrm{~mm} \cdot \mathrm{s}^{-1}$, setback distance of $43 \mathrm{~mm}$, roll gap of $3 \mathrm{~mm}$ and at different shearing temperatures of, $635^{\circ} \mathrm{C}, 615^{\circ} \mathrm{C}, 605^{\circ} \mathrm{C}$ and $598^{\circ} \mathrm{C}$.

\subsubsection{Shearing speed and shearing time}

The graphs below, Figure 4.21, were produced by previous research in BCAST [Fan et al. 2009a, Xia et al. 2009], on shearing time and shearing speed by a MCAST unit similar to the unit used in this study for AZ91D magnesium alloy. Neither rotation speed nor shearing time significantly affect the grain size, provided the rotation speed is faster than $100 \mathrm{rpm}$ and the shearing time is longer than 10 seconds. Based on this, a shearing speed of $600 \mathrm{rpm}$ and shearing time of 60 seconds were selected. 
In order to confirm the accuracy of the Figure 4.21, a simple trial was designed. The basic idea was to check the structural evolution of the strips under the worst processing conditions, i.e. very low shearing speed and short shearing time, at a shearing speed of $150 \mathrm{rpm}$ and shearing time of $8-10 \mathrm{~s}$. The strip microstructure was investigated and is shown in Figure 4.22. It can be noticed that no columnar dendrites were observed. The strip has a microstructure that consists of equiaxed grains with a mean size of $120 \mu \mathrm{m}$. It is also important to note that both the morphology and the size of grains do not vary in the different zones, (Figure 4.22 (b) \& (c)). These results are in good agreement with the previous MC-TRC results shown in Figure 4.18 and 4.19 and the accuracy of the graphs is confirmed.
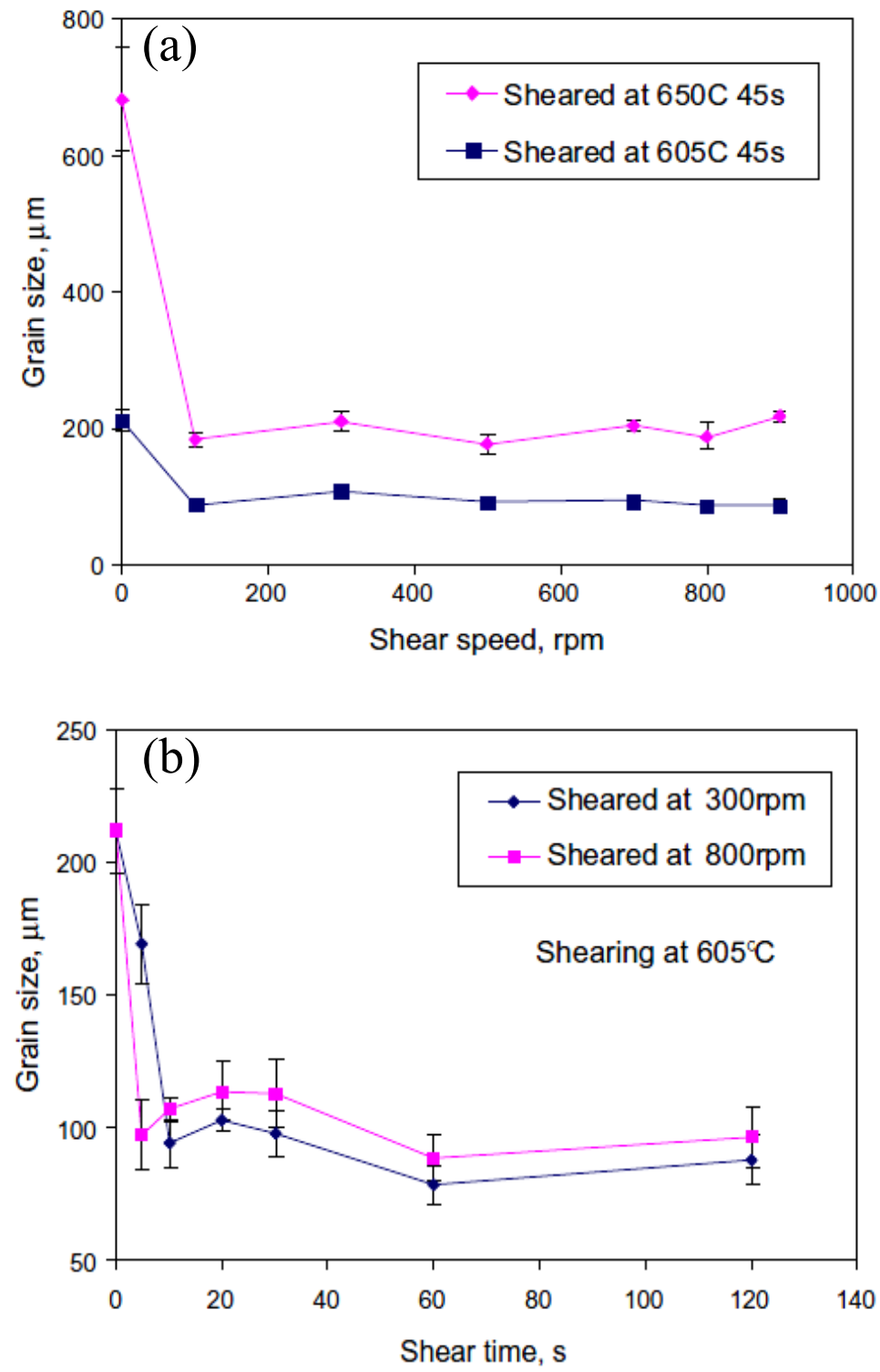

\section{Figure 4.21}

The dependence of grain size on (a) shearing speed and (b) shearing time for AZ91D magnesium alloy. The figure presents a sharp reduction in grain size which does not fluctuate much when the shearing speed is higher than 100rpm and shearing time is longer than 10 seconds. [Fan et al. 2009a]. 

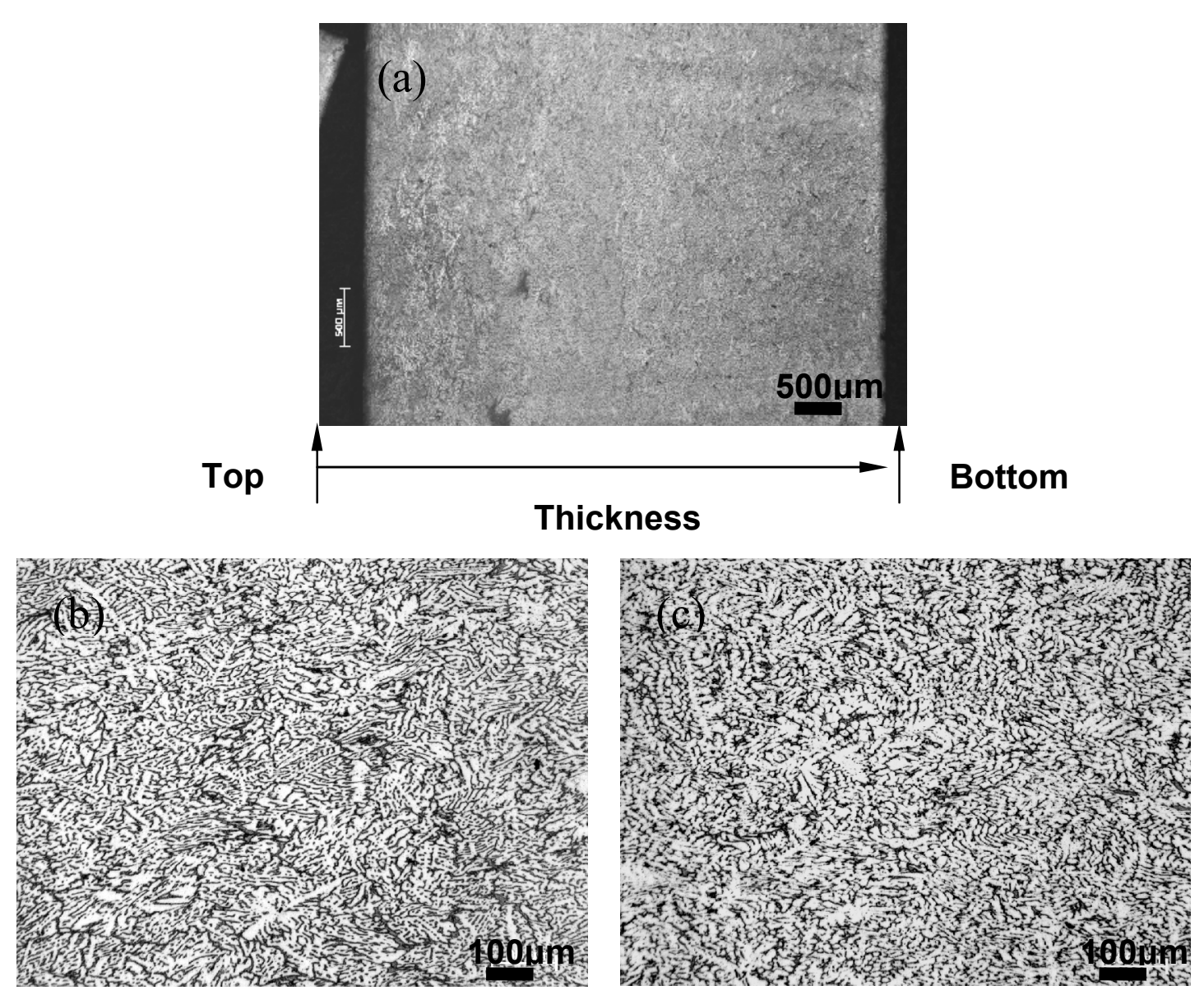

Figure 4.22:

(a) Microstructure of the through thickness cross-section of MC-TRC AZ91D alloy strips in the longitudinal section fabricated under the conditions of a low shearing speed and short shearing time and at a shearing temperature of $615^{\circ} \mathrm{C}$. Microstructures of both (b) the bottom portion and (c) the central portion show the strip consists of equiaxed grains with a mean size of $120 \mu \mathrm{m}$.

\subsubsection{Effect of tip setback}

- Tip setback The optimized tip setback for the TRC process of AZ91D alloy i.e. '38mm - 43mm', referred to Section 4.1.3, was utilized for the MC-TRC processing of AZ91D alloy. To investigate the effects of tip setback on the microstructure of MC-TRC AZ91D alloy, the tip setback was varied between ' $38 \mathrm{~mm}-46 \mathrm{~mm}$ ' with a constant shearing speed, shearing time and shearing temperature of $600 \mathrm{rpm}, 60 \mathrm{~s}$ and $615^{\circ} \mathrm{C}$, respectively. The micrographs of longitudinal and transverse sections of MC-TRC AZ91D alloy, as shown in Figure 4.23 demonstrate that a $43 \mathrm{~mm}$ setback distance is 
found as an optimal setback distance for producing the melt conditioned AZ91D strips. A $43 \mathrm{~mm}$ setback distance is selected because the lowest percentage of centre line segregation can be achieved. The effect of different tip setbacks on the average grain size is shown in Figure 4.24 which indicates that by increasing the tip setback the average grain size slightly changes.

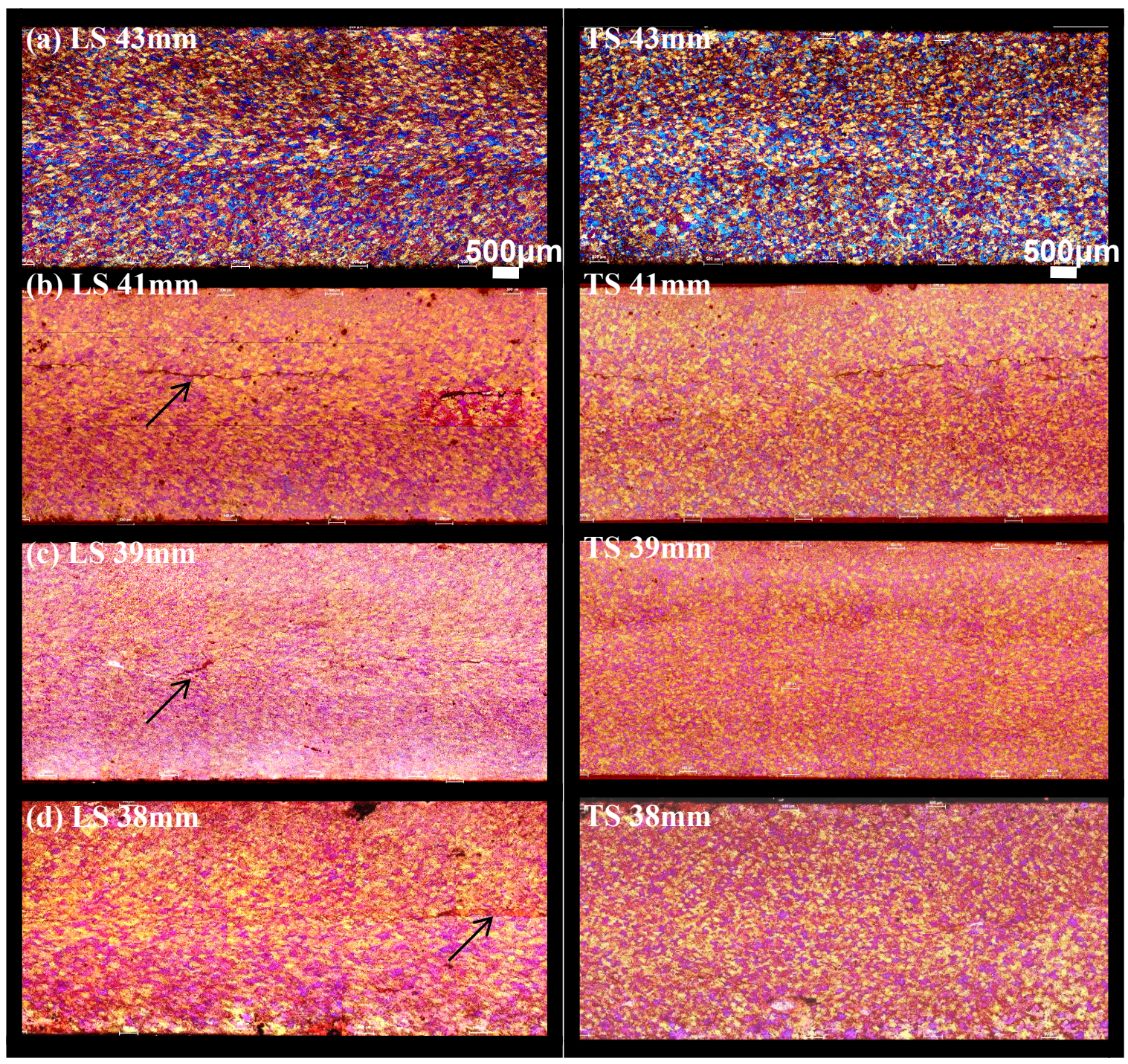

\section{Figure 4.23:}

Optical micrographs showing microstructures of longitudinal and transverse sections (LS and TS) of AZ91D alloy strip samples with melt shearing, produced by the MC-TRC process at a casting speed of $22.5 \mathrm{~mm} \cdot \mathrm{s}^{-1}$, shearing temperature of $615^{\circ} \mathrm{C}$, roll gap of $3 \mathrm{~mm}$ and different tip setbacks of, (a) $43 \mathrm{~mm}$, (b) $41 \mathrm{~mm}$ (c) $39 \mathrm{~mm}$ and (d) $38 \mathrm{~mm}$. The melt shearing was carried out at $600 \mathrm{rpm}$ for $60 \mathrm{~s}$ without any chemical addition. The arrow bars indicate the centre line segregation area in MC-TRC strips. 


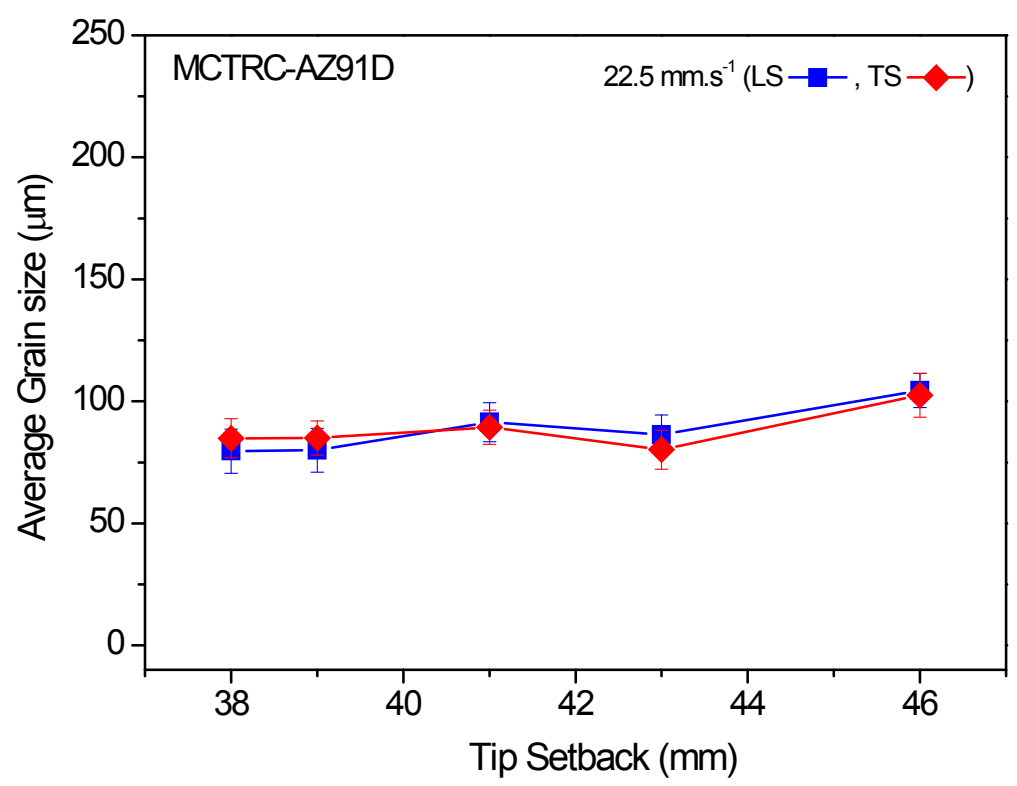

\section{Figure 4.24:}

Quantitative analysis showing grain size variation in the longitudinal and transverse sections (LS and TS) of AZ91D alloy strip samples as a function of tip setback (mm), produced by the MC-TRC process at a casting speed of $22.5 \mathrm{~mm} \cdot \mathrm{s}^{-1}$, roll gap of $3 \mathrm{~mm}$, shearing temperatures of $615^{\circ} \mathrm{C}$ and at different tip setback distances.

\subsubsection{The selected processing parameters}

Based on the experimental results of previous Sections 4.2.1 - 4.2.3, optimized processing conditions can be obtained for melt conditioned twin roll casting of AZ91D $\mathrm{Mg}$ alloy, as summarized in Table 4.2.

\section{Table 4.2:}

The optimized processing parameters for MC-TRC of AZ91D Mg-alloy.

\begin{tabular}{lcccccc}
\hline $\begin{array}{l}\text { Process } \\
\text { AZ91D }\end{array}$ & $\begin{array}{l}\text { Roll speed } \\
\left(\mathrm{mm}_{\mathrm{s}}^{-1}\right)\end{array}$ & $\begin{array}{l}\text { Roll gap } \\
(\mathrm{mm})\end{array}$ & $\begin{array}{l}\text { Tip } \\
\text { setback } \\
(\mathrm{mm})\end{array}$ & $\begin{array}{l}\text { Shearing } \\
\text { temperature } \\
(\mathrm{C})\end{array}$ & $\begin{array}{l}\text { Shearing } \\
\text { speed } \\
(\mathrm{rpm})\end{array}$ & $\begin{array}{l}\text { Shearing } \\
\text { time }(\mathrm{s})\end{array}$ \\
\hline MC-TRC & 22.5 & 3 & 43 & $615 \pm 5$ & 600 & 60 \\
\hline
\end{tabular}




\subsection{Comparison of microstructure and hardness between TRC and MC-TRC Mg-alloy strips}

In order to better understand the process of MC-TRC, some results including AZ91D and AZ31 Mg-alloy strips obtained from this process and TRC are compared in this section.

\subsubsection{AZ91D Mg-alloy}

According to the experimental results presented in Sections 4.1 and 4.2, Table 4.3 shows the optimized processing condition for producing TRC and MC-TRC AZ91D alloy strips.

Table 4.3:

The optimized processing parameters for TRC and MC-TRC of AZ91D Mg-alloy.

\begin{tabular}{cccccccc}
\hline $\begin{array}{l}\text { Process } \\
\text { AZ91D }\end{array}$ & $\begin{array}{l}\text { Roll speed } \\
\left(\mathrm{mm}^{-1}\right)\end{array}$ & $\begin{array}{l}\text { Roll gap } \\
(\mathrm{mm})\end{array}$ & $\begin{array}{l}\text { Tip } \\
\text { setback } \\
(\mathrm{mm})\end{array}$ & $\begin{array}{l}\text { Pouring } \\
\text { temperature } \\
(\mathrm{C})\end{array}$ & $\begin{array}{l}\text { Shearing } \\
\text { temperature } \\
(\mathrm{C})\end{array}$ & $\begin{array}{l}\text { Shearing } \\
\text { speed } \\
(\mathrm{rpm})\end{array}$ & $\begin{array}{l}\text { Shearing } \\
\text { time }(\mathrm{s})\end{array}$ \\
\hline$\underline{\mathrm{TRC}}$ & 22.5 & 3 & $38-43$ & $615 \pm 5$ & & \\
\hline$\underline{\mathrm{MC}-\mathrm{TRC}}$ & 22.5 & 3 & 43 & & $615 \pm 5$ & 600 & 60 \\
\hline
\end{tabular}

Figure 4.25 illustrates the effect of manufacturing methods (i.e. TRC and MC-TRC) on the general microstructure of AZ91D produced strips. Results show that the melt shearing not only provides significant grain refinement, but also reduces the grain size dependence on the pouring temperature. The grain sizes of MC-TRC AZ91D strip are about 5 times smaller than the grain size of TRC AZ91D strip. Moreover, the MC-TRC process reduces considerably or eliminates defects such as the centre line segregation, voids and cracks at or near the strip surface that are always present in conventional TRC strip. Figures 4.26 and 4.27 verify these findings through grain size and centre line segregation measurements. The temperature dependence of the average grain size for both the sheared and non-sheared samples of AZ91D alloy strip was measured by systematically varying the pouring temperature between $598^{\circ} \mathrm{C}$ and $650^{\circ} \mathrm{C}$ as shown in Figure 4.26. 
(a) LS

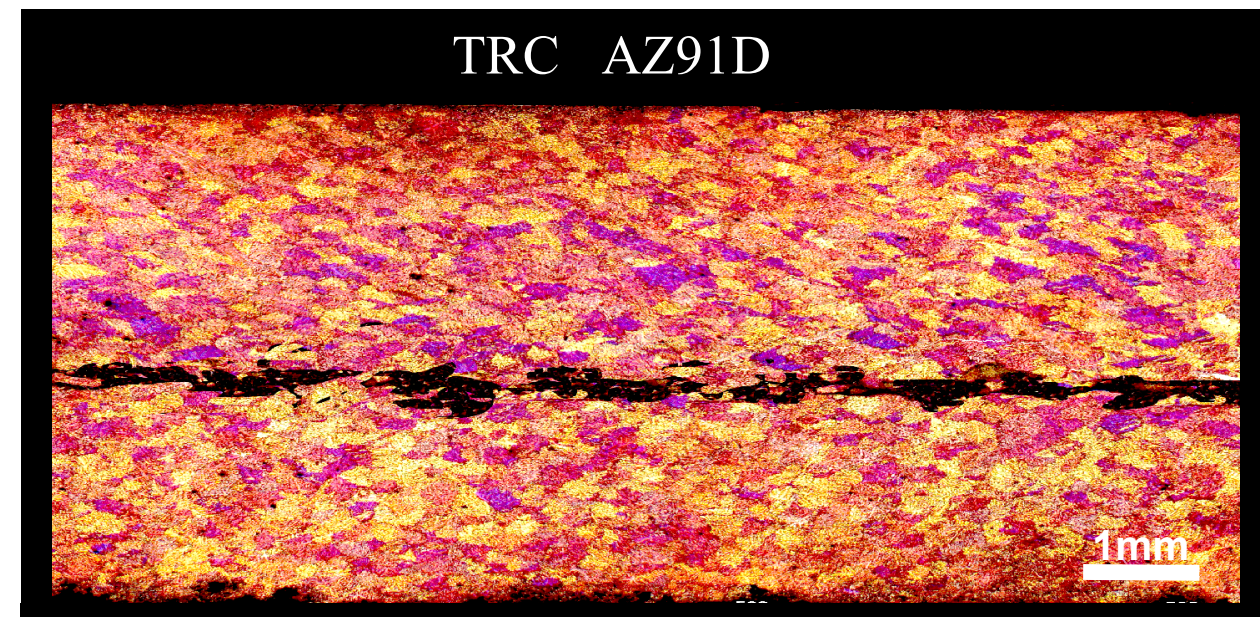

(b) TS

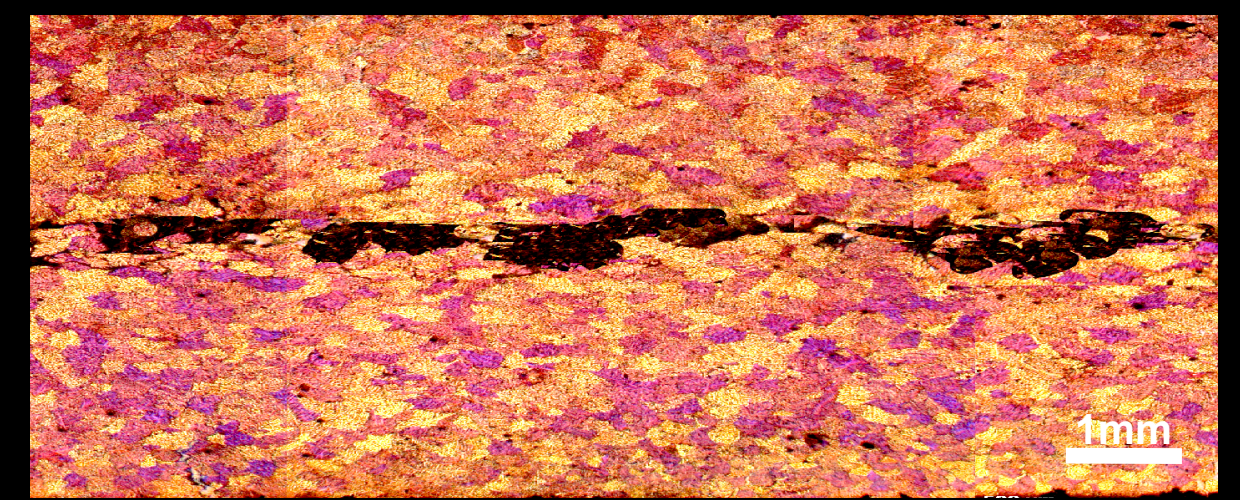

(c) LS

(d) LS

\section{MC-TRC AZ91D}
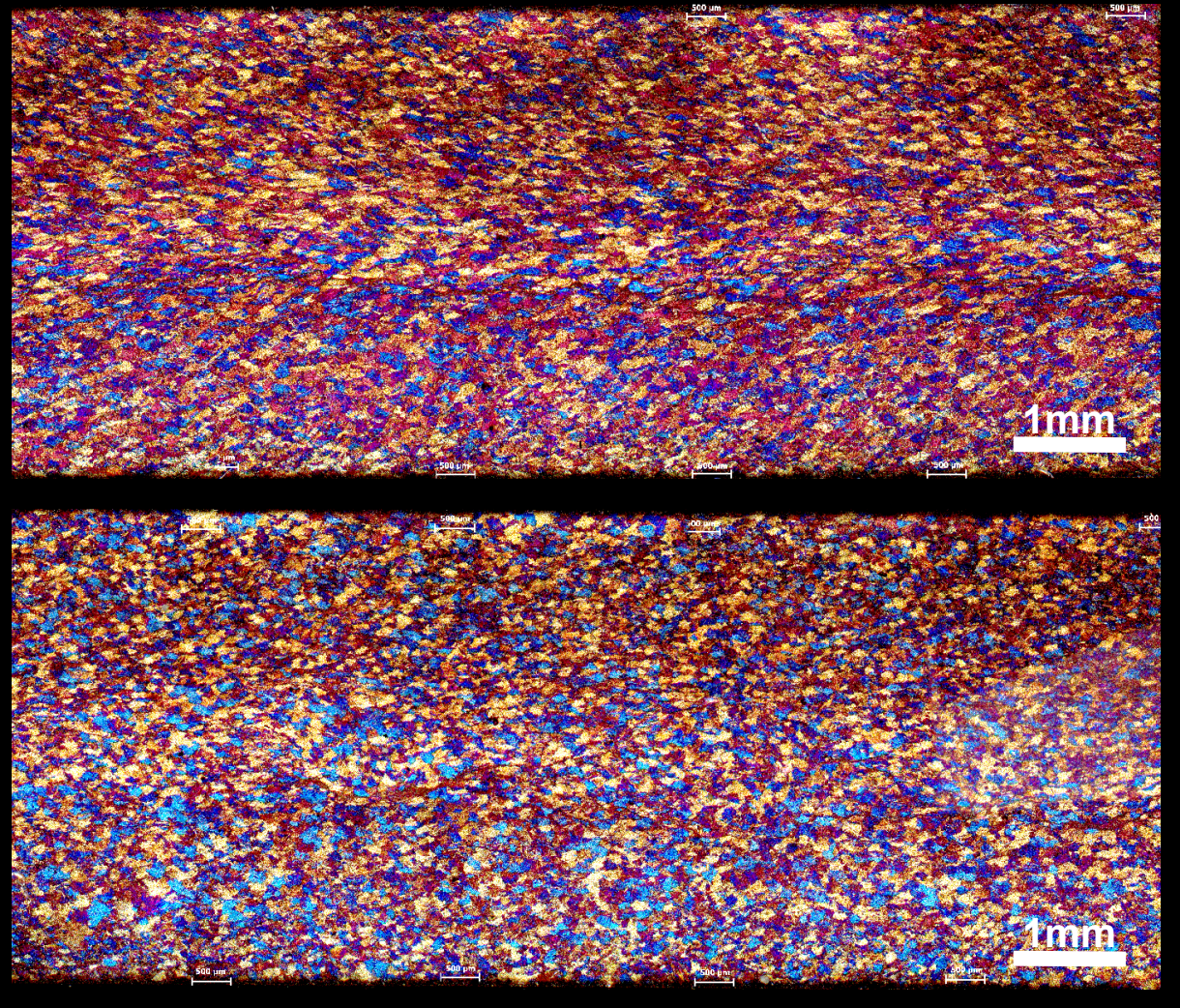

Figure 4.25:

Optical micrographs showing microstructures of longitudinal and transverse sections (LS and TS) of AZ91D alloy strip samples ( $\mathrm{a}$ and $\mathrm{b}$ ) without and ( $\mathrm{c}$ and $\mathrm{d}$ ) with melt shearing, produced by TRC and MC-TRC processes at $615^{\circ} \mathrm{C}$, a casting speed of $22.5 \mathrm{~mm} . \mathrm{s}^{-1}$ and $43 \mathrm{~mm}$ setback distance. The average grain size was reduced from $426 \mu \mathrm{m}$ to $62 \mu \mathrm{m}$ by the melt shearing at $600 \mathrm{rpm}$ for $60 \mathrm{~s}$ without any chemical addition. 
Without shearing, as previously shown in Figure 4.3, the grain size increases significantly with an increase in the pouring temperature, while with intensive melt shearing the grain size is finer at all pouring temperatures tested with a reduced grain size dependence on the pouring temperature. The average grain size of AZ91D strip was reduced from $302 \mu \mathrm{m}$ in the optimised non-sheared sample to $69 \mu \mathrm{m}$ in the optimised sheared sample at the same casting temperature of $615^{\circ} \mathrm{C}$ without any chemical addition, as shown in Figure 4.26.

Figure 4.27 illustrates the average segregated area of sheared (MC-TRC) and non-sheared (TRC) melt as a function of tip setback. Without shearing, the average segregation area is significant and a function of the tip setback (i.e. $\sim 5.5-7.95 \%$ ), while with intensive melt shearing the average segregation area is lowered notably with a reduced segregation area dependence on the tip setback, (i.e. $\sim 0.09-0.25 \%$ ).

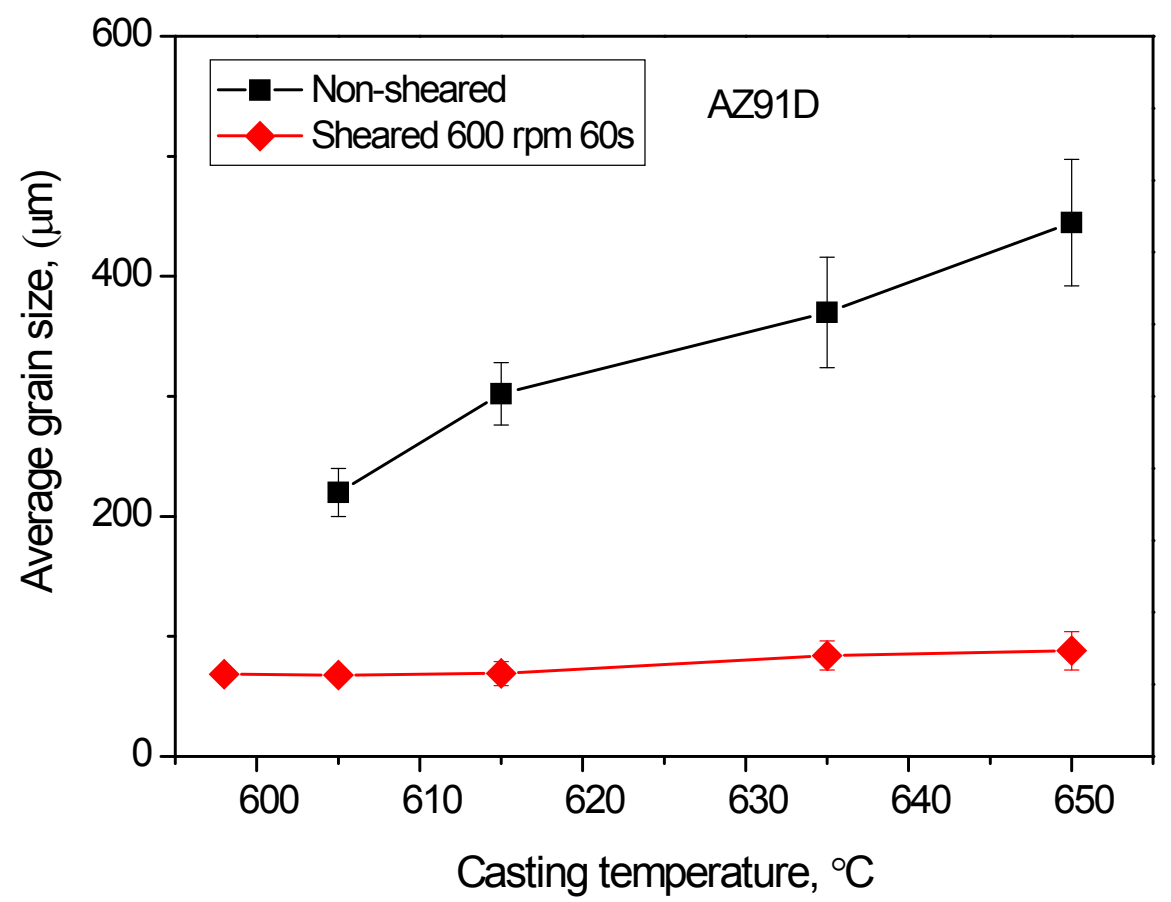

Figure 4.26:

Average grain size variation of AZ91D alloy strip as a function of pouring temperature showing the effect of melt shearing. For the sheared samples, the shearing speed and shearing time were 600 rpm and 60 s, respectively. 


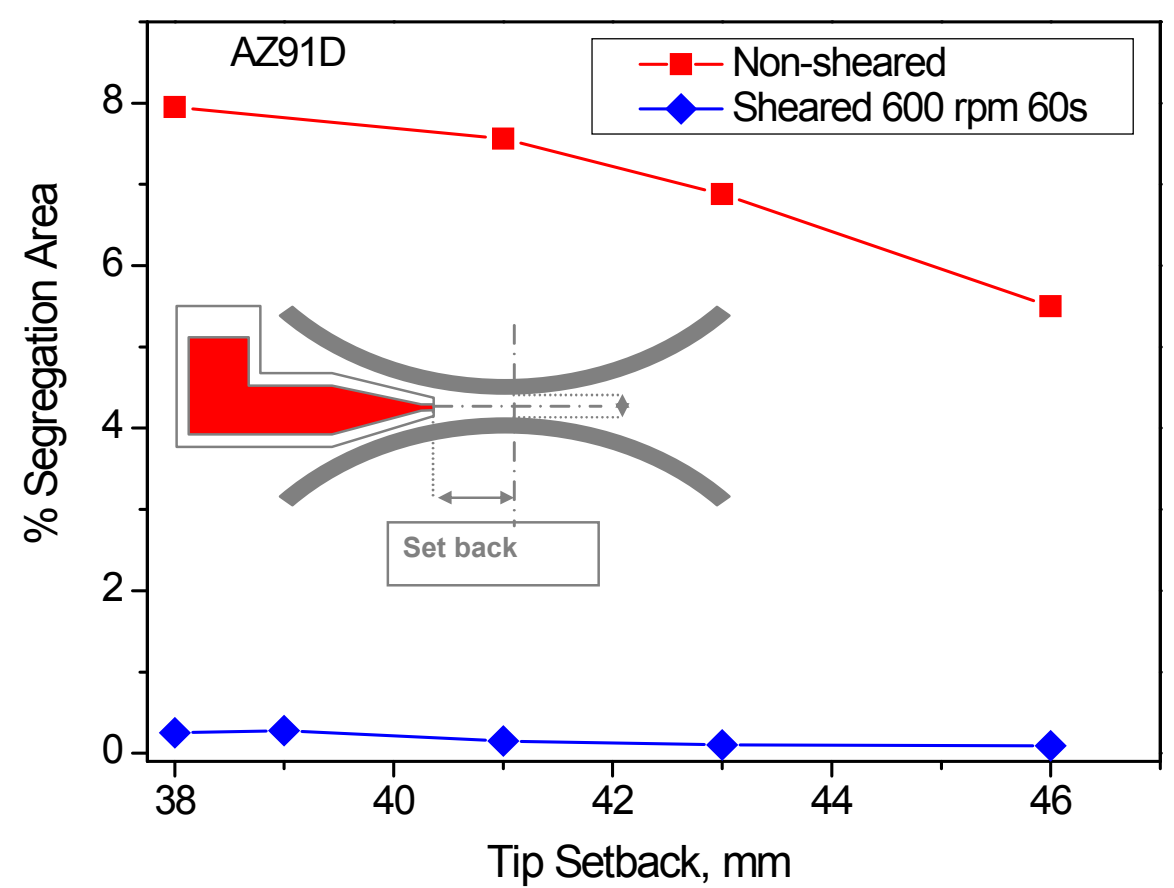

Figure 4.27:

Average segregation area of AZ91D alloy strip as a function of tip setback showing the effect of melt shearing. For the sheared samples, the shearing temperature, shearing speed and shearing time were $615^{\circ} \mathrm{C}, 600 \mathrm{rpm}$ and $60 \mathrm{~s}$, respectively.

\subsubsection{AZ31 Mg-alloy}

TRC and MC-TRC AZ31 Mg alloy strips were produced with the same optimized processing conditions for the AZ91D alloy strip. For the AZ31 TRC process, a melt superheat of $15 \pm 2^{\circ} \mathrm{C}$ i.e. $645 \pm 2^{\circ} \mathrm{C}$, tip setback of $43 \mathrm{~mm}$, roll gap of $3 \mathrm{~mm}$ and casting speed of $22.5 \mathrm{~mm} . \mathrm{s}^{-1}$ were utilized as the same optimum conditions for the AZ91D TRC process. For the AZ31 MC-TRC process, a shearing temperature of $645 \pm 3^{\circ} \mathrm{C}$, shearing speed of $600 \mathrm{rpm}$ and shearing time of $60 \mathrm{~s}$ were applied.

Figure 4.28 shows the microstructures of longitudinal and transverse sections of AZ31 TRC and MC-TRC strips. It is clearly shown for the AZ31 alloy in Figure 4.28 that the intensive melt shearing results in significant grain refinement and reduced centre line segregation. The average grain size was reduced from $616 \mu \mathrm{m}$ in the non-sheared sample (Figure 4.28 (a) \& (b)) to $74 \mu \mathrm{m}$ in the sheared sample (Figure 4.28 (c) \& (d)) without any chemical addition. 
(a) LS

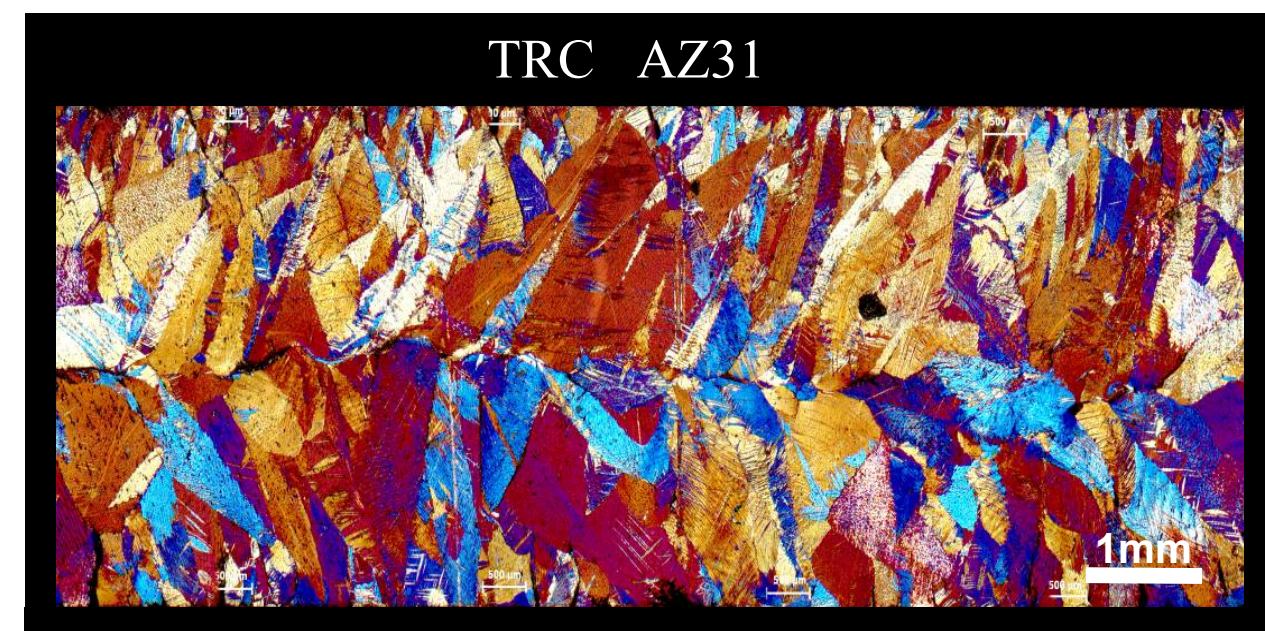

(b) $\mathrm{TS}$

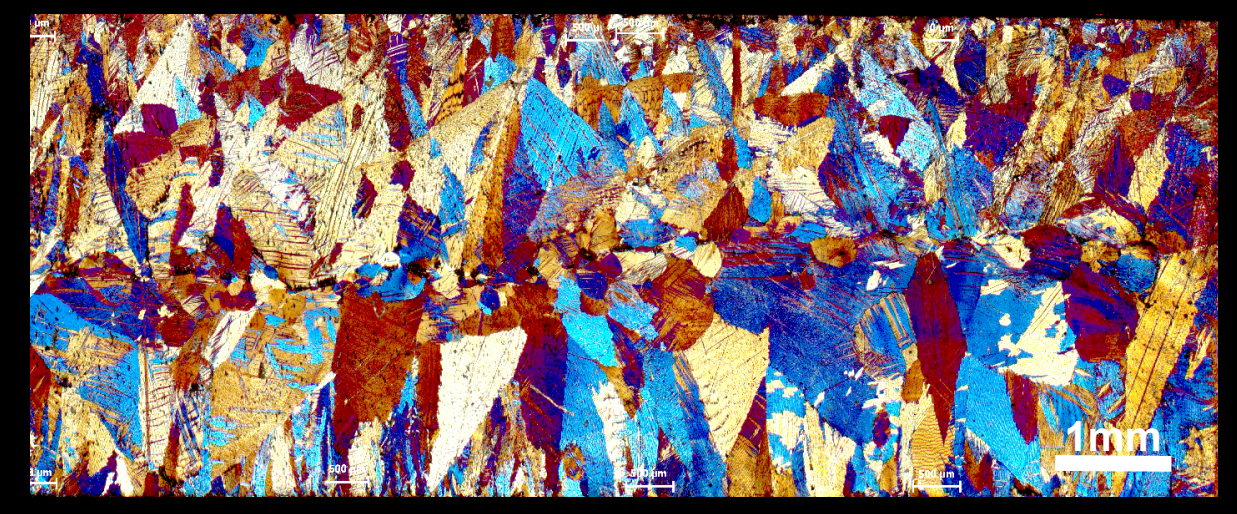

(c) LS

\section{MC-TRC AZ31}

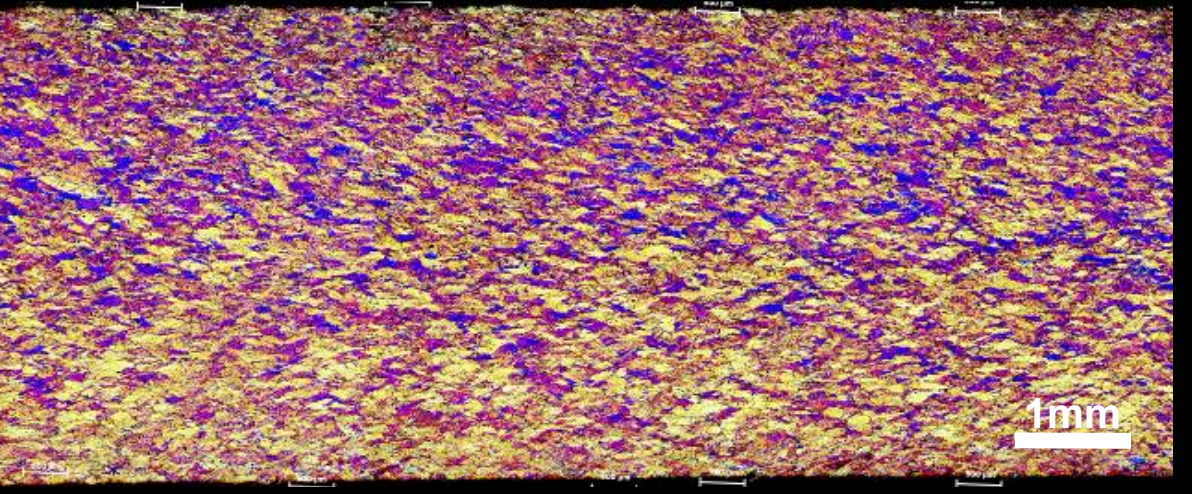

(d) TS

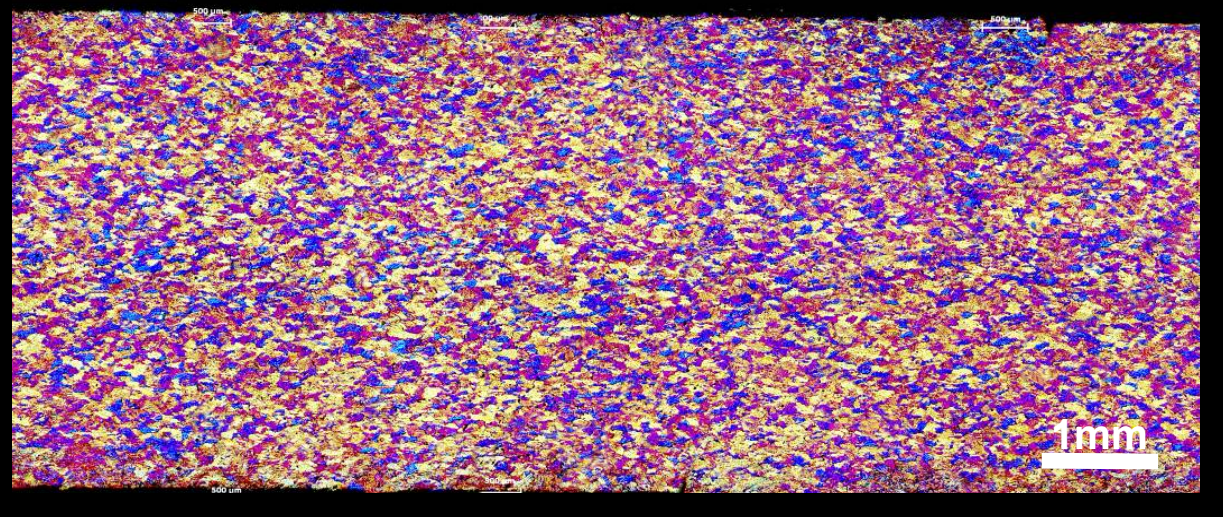

Figure 4.28:

Optical micrographs showing microstructures of longitudinal and transverse sections (LS and TS) of AZ31 alloy strip samples ( $a$ and b) without and ( $c$ and d) with melt shearing, produced by TRC and MC-TRC processes at $645^{\circ} \mathrm{C}$, casting speed of $22.5 \mathrm{~mm} . \mathrm{s}^{-1}$ and $43 \mathrm{~mm}$ setback distance. The average grain size was reduced from $616 \mu \mathrm{m}$ to $74 \mu \mathrm{m}$ by the melt shearing at $600 \mathrm{rpm}$ for $60 \mathrm{~s}$ without any chemical addition. 


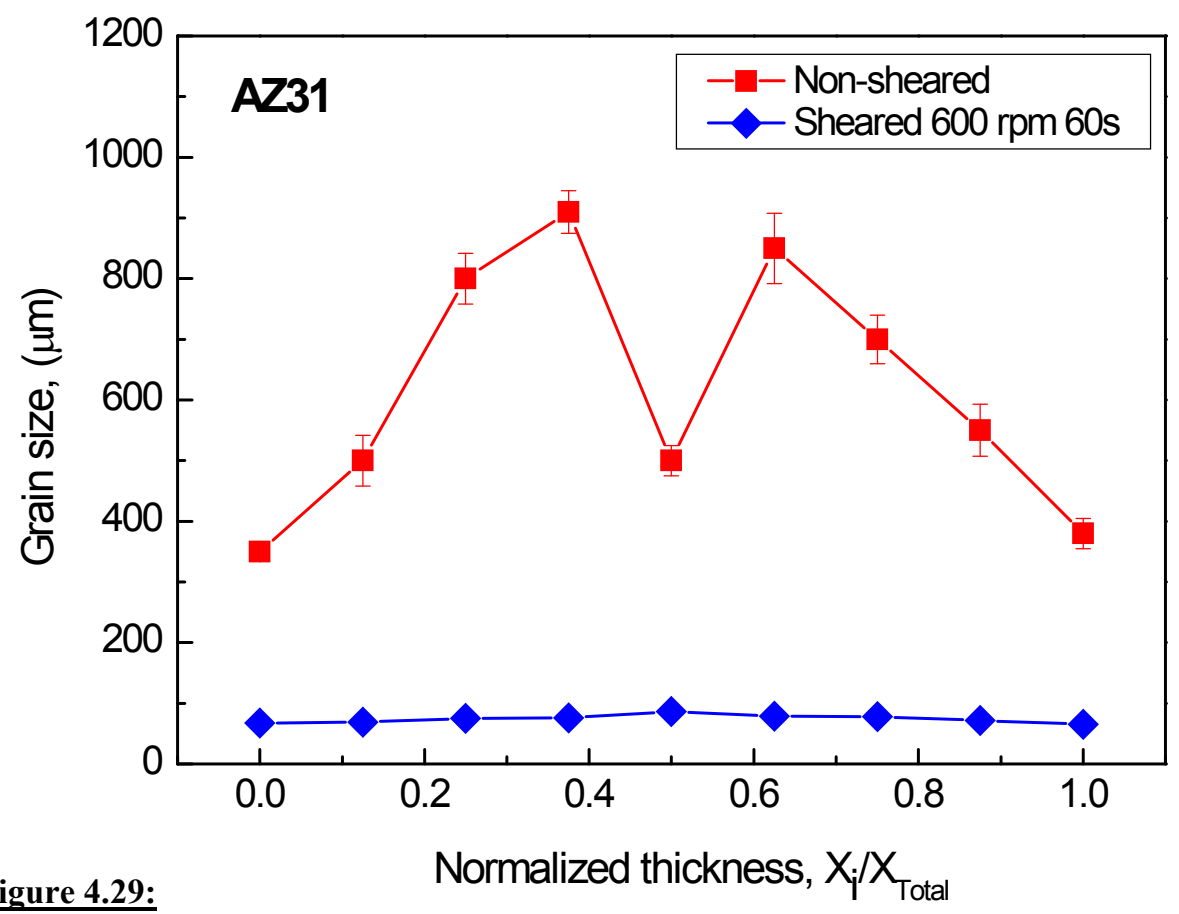

Grain size variation through thickness of AZ31 alloy strip showing the effect of melt shearing. For the sheared samples, the shearing temperature, shearing speed and shearing time were $645^{\circ} \mathrm{C}$, $600 \mathrm{rpm}$ and $60 \mathrm{~s}$, respectively.

The measured grain size in the longitudinal section of AZ31 strip as a function of distance from surface to the centre of the strip is shown in Figure 4.29. The TRC strip has a surface chill zone of fine equiaxed grains with large columnar grains extending from the chill zone towards the strip centre and relatively coarse equiaxed grains at the centre of the strip. By contrast the as-cast MC-TRC strip has a uniform and fine grain structure across the whole section width. Melt conditioning has suppressed both columnar grain growth and centre line segregation. The grain size of the AZ31 TRC strip varied from $350 \pm 11 \mu \mathrm{m}$ within the chilled zone at the edge of the strip to $910 \pm 35 \mu \mathrm{m}$ for the columnar grain region to $500 \pm 25 \mu \mathrm{m}$ at the centre of the strip, while the grain size of the MC-TRC strip was $70-90 \pm 7 \mu \mathrm{m}$ from the edge to centre, showing a uniform microstructure throughout the entire strip thickness.

In addition to the above distinction, more detailed microstructural investigation of TRC and MC-TRC AZ31 strips shows that TRC AZ31 strip includes large voids along 
grain boundaries and severe twinning within the elongated columnar grains, as shown in

Figures 4.30 (a, c and e). In contrast, the MC-TRC AZ31 strip is a void and crack-free product which includes minor twins inside some of the fine equiaxed grains, as shown in Figure 4.30 (b, $d$ and $\mathrm{f})$.

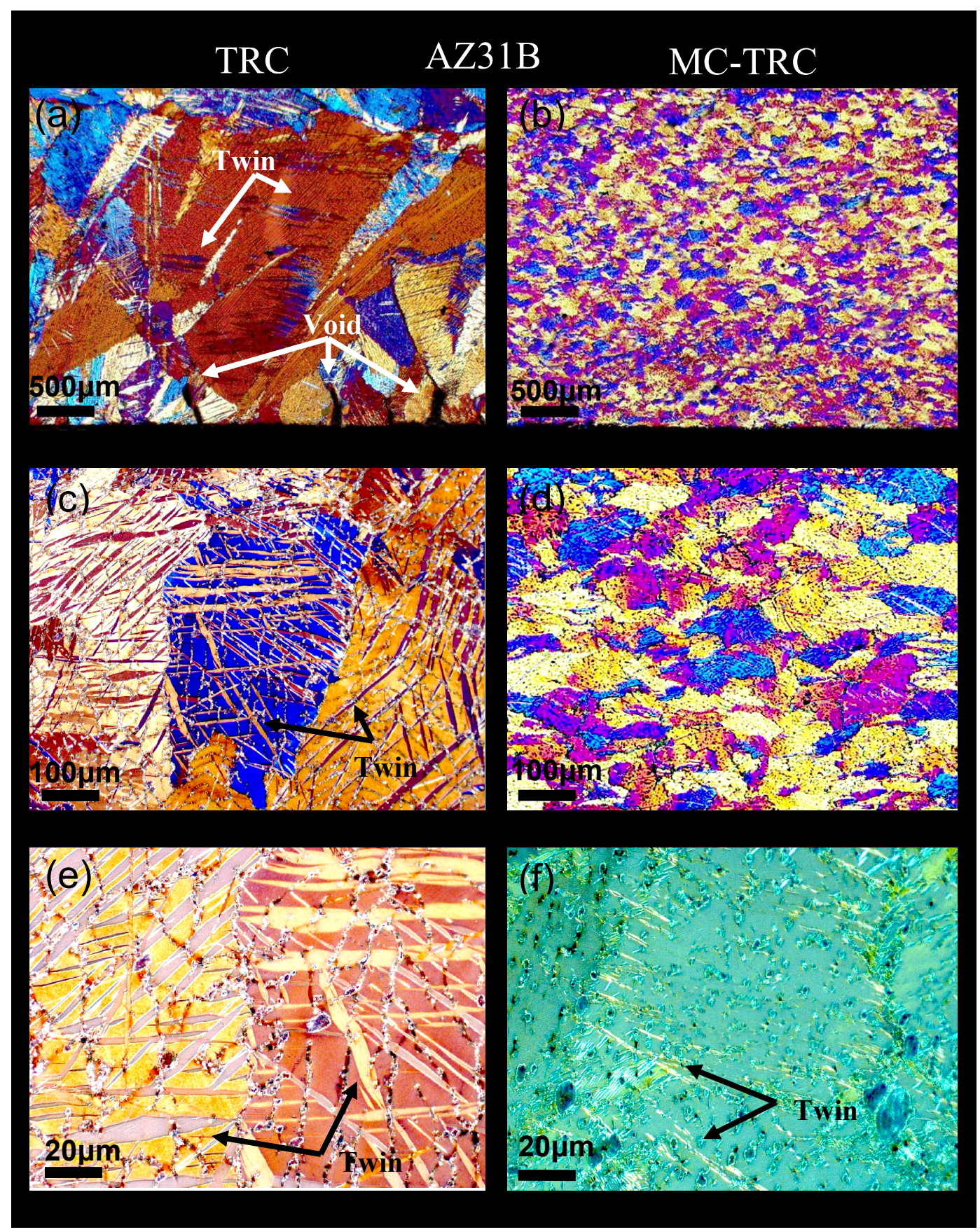

\section{Figure 4.30:}

Optical micrographs at different magnifications for the detailed microstructure of TRC (a,c and e) and MC-TRC (b, d and f) AZ31 as-cast strips showing (a) voids and cracks at the surface of a conventional AZ31 TRC strip, and (c and e) elongated columnar grains with severe twinning. The very fine and uniform grain size of MC-TRC AZ31 as-cast strip (b, d) shows that it contains much fewer intergranular twins ( $d$ and f) compared with the TRC AZ31 sample (c and e). 
Figure 4.31 shows optical micrographs of the strip surface of twin roll cast AZ31 alloy samples without and with melt shearing, at a casting temperature of $645^{\circ} \mathrm{C}$ and casting speed of $22.5 \mathrm{~mm} . \mathrm{s}^{-1}$. The average grain size was reduced from $520 \mu \mathrm{m}$ (Figure 4.31 (a) \& (c)) in conventional TRC strip to $72 \mu \mathrm{m}$ (Figure 4.31 (b) \& (d)) after the melt shearing. There are defects such as hot-tearing in interdendritic spaces on the surface of the nonsheared AZ31 twin roll cast strip although no surface defects were detected in the melt conditioned AZ31 strip.
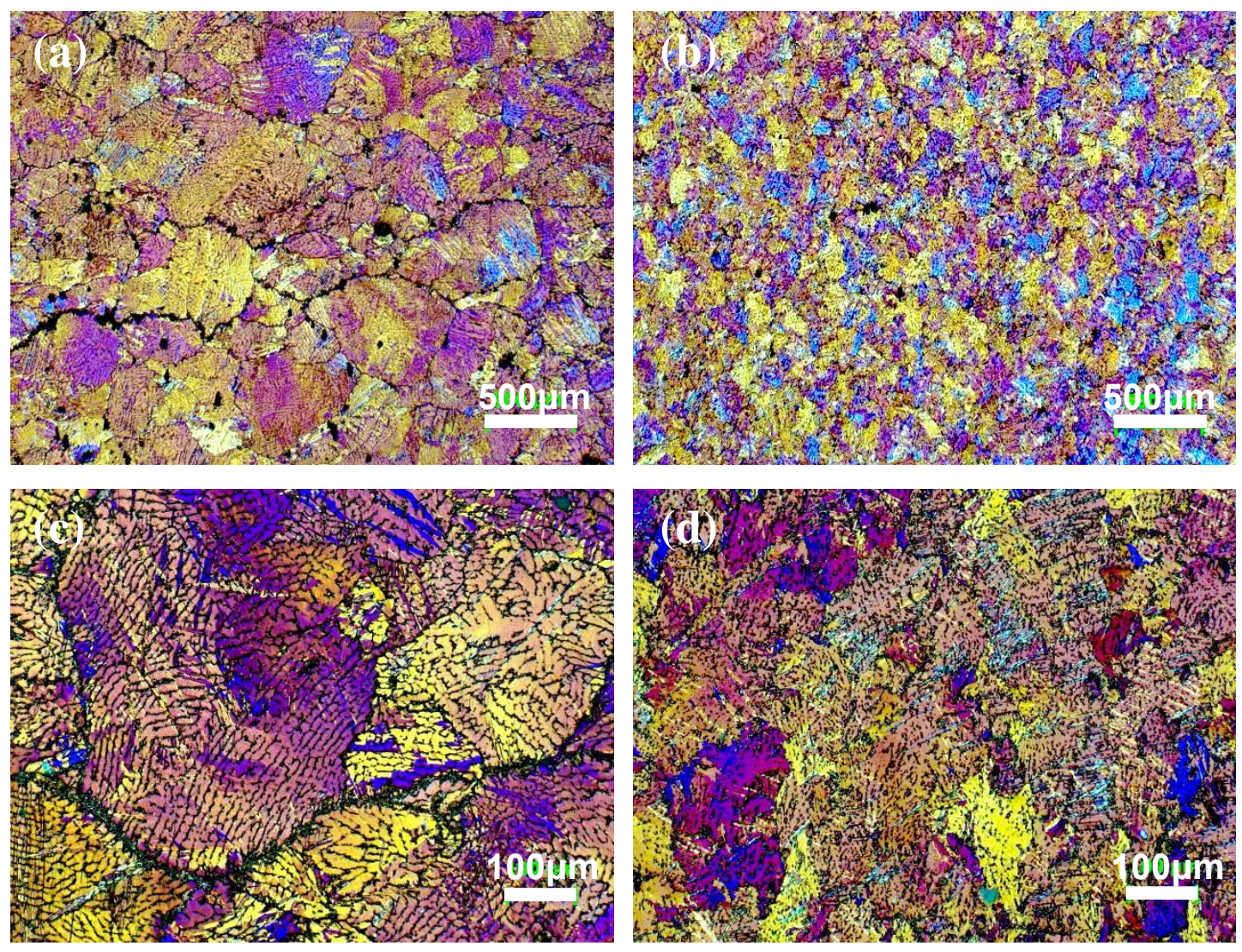

Figure 4.31:

Optical micrographs showing microstructures of the strip surface of twin roll cast AZ31 alloy samples (a and c) without and (b and d) with melt shearing, at $645^{\circ} \mathrm{C}$, a casting speed of $22.5 \mathrm{~mm} . \mathrm{s}^{-1}$ and $43 \mathrm{~mm}$ setback distance. The average grain size was reduced from $520 \mu \mathrm{m}$ to $72 \mu \mathrm{m}$ by the melt shearing at $600 \mathrm{rpm}$ for 60s without any chemical addition. There are defects such as hot-tears on the surface of the non-sheared AZ31 twin roll cast strip. 


\subsubsection{The nature of centre-line segregation}

\subsubsection{General characteristics}

Centre-line segregation is the most common among internal defects observed in the middle of the twin roll cast strip. These segregations have irregular morphology, are black in colour and almost elongated through the strip in the longitudinal direction.

Figure 4.32 (a) \& (c) shows the centre-line segregation in AZ31 and AZ91D TRC strip, respectively. Figure 4.32 (b) \& (d) illustrates the middle of the AZ31 and AZ91D MC-TRC strip which indicates that they are almost segregation-free samples.
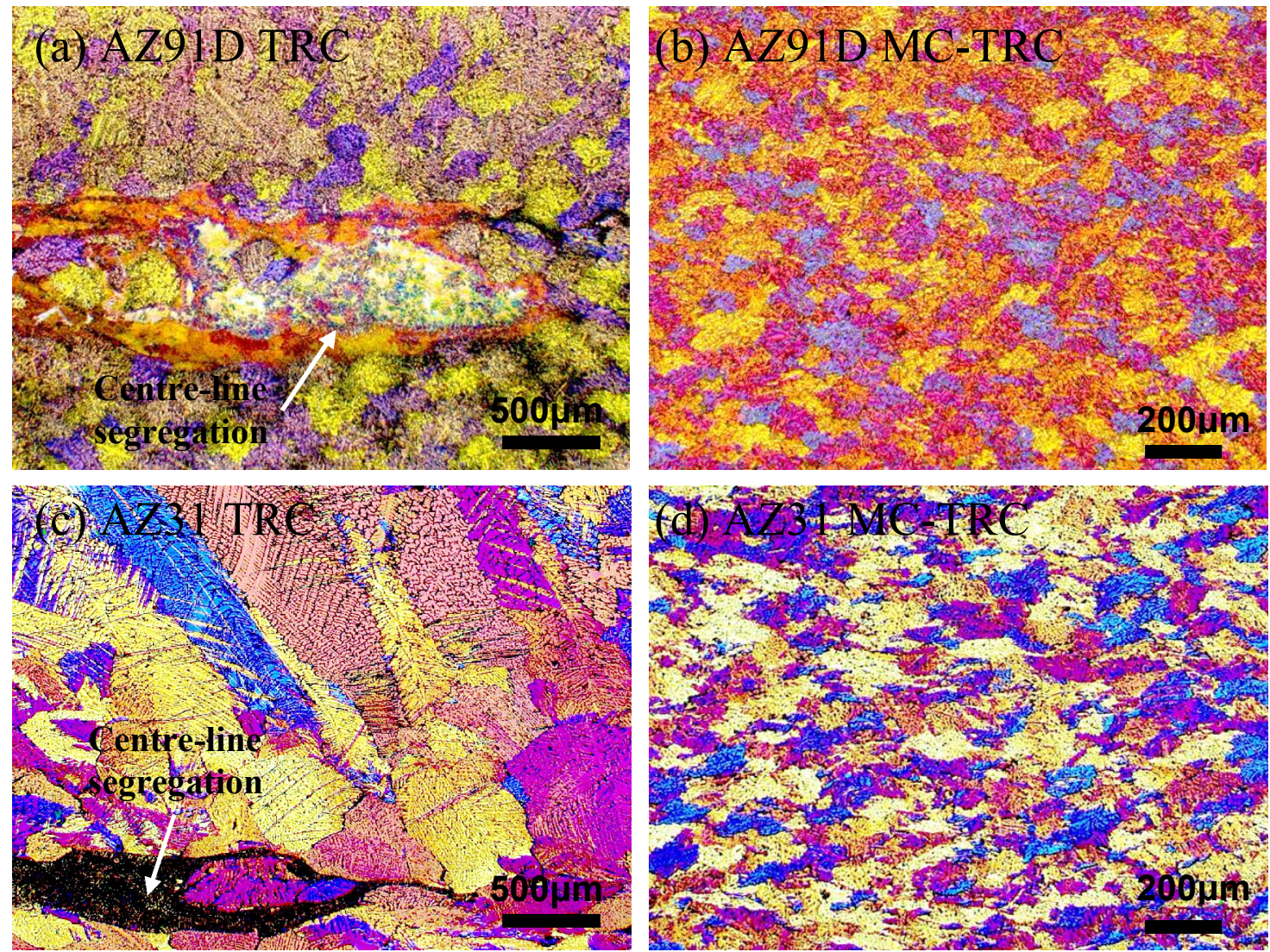

\section{Figure 4.32:}

Micrographs of the general microstructure of centre-line segregation (middle section of strip) for AZ91D ( $a$ and b) and AZ31 ( $\mathrm{c}$ and d) alloys produced by TRC (a and c) and MC-TRC (b and d) processes. Severe segregation in the middle of the TRC strips is clearly visible, although there are not any defects observable in MC-TRC strips.

More detail of the optical micrographs of the central segregation region in conventional

TRC AZ91D strip and at higher magnification are shown in Figure 4.33 (a) \& (b) which 
illustrate that the nature of centre line segregation is the enriched-solute that is being rejected and piled up in front of the columnar dendrites. It seems that the centre-line segregation is formed at the end of solidification in which incomplete solidification of liquid $\mathrm{Mg}$ in the middle of the strip causes the formation of liquid segregation.

(a)

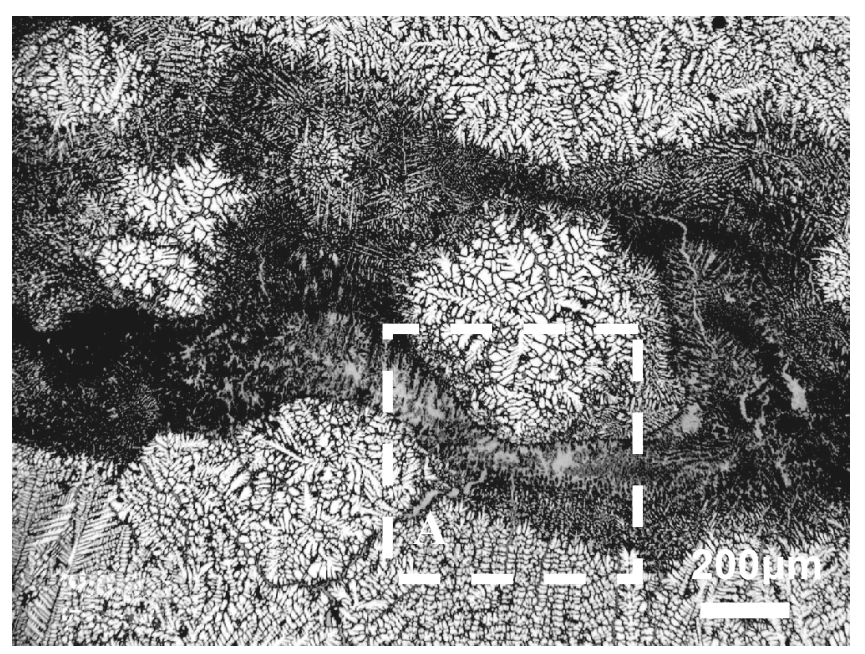

(b)

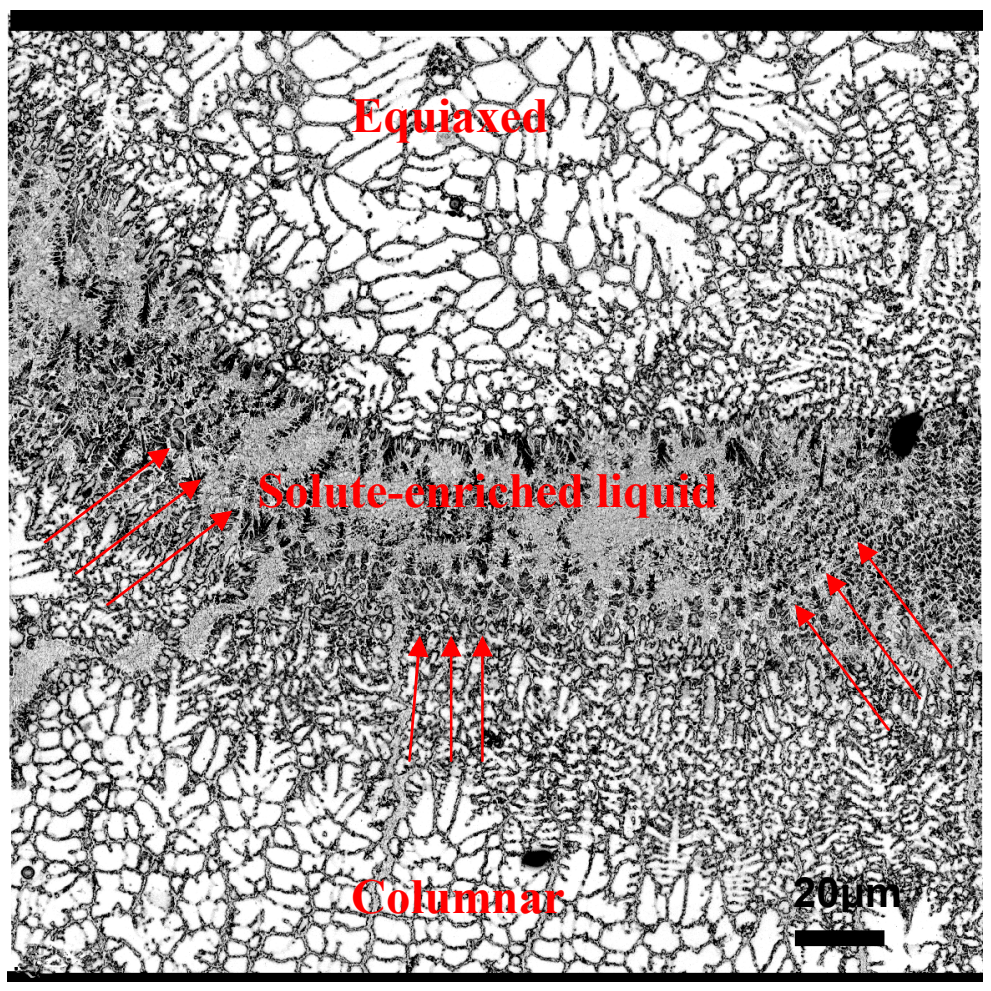

\section{Figure 4.33:}

Optical micrographs showing the, (a) central segregation region in TRC AZ91D strip and (b) higher magnification of the area marked in segregation zone. Solute was rejected and piled up in front of the columnar dendrites as marked with an arrow, which resulted in equiaxed grain nucleation in highly enriched solute because of higher 'constitutional supercooling'. 


\subsubsection{Phase identification}

The AZ91D alloy is a well studied and extensively used commercial alloy but there is little literature available on its microstructure of the twin roll cast strip and particularly the phase identification of its centre-line segregation. Therefore, it is appropriate to carry out a brief phase identification analysis on the microstructure of the TRC and MC-TRC AZ91D alloy strips in this investigation.

Figure 4.34 (a) shows a SEM micrograph of the central region of the TRC AZ91D strip. The detailed microstructures of locations A and B in Figure 4.34 (a) are presented in Figure 4.34 (b) \& (c), respectively. The results of EDX area analysis of location A are presented in Figure 4.34 (d). Further EDX spot analysis confirmed that the white flowerlike phase in Figure 4.34 (b) is the $\mathrm{Al}_{8} \mathrm{Mn}_{5}$ intermetallic phase, the grey phase (in Figure 4.34 (b)) is eutectic $\mathrm{Mg}_{17} \mathrm{Al}_{12}$ intermetallic phase, and that the dark phase in Figure 4.34 (b) is the eutectic $\alpha-\mathrm{Mg}$ phase. This microstructural observation is in good agreement with the EDX area analysis of location A (Figure 4.34 (a)) which indicates that the composition of location A corresponds to the $\mathrm{Mg}-\mathrm{Al}$ eutectic composition (i.e. $32 \mathrm{wt} \%$ Al). In addition, Figure 4.34 (c) shows that location B is typical $\alpha-\mathrm{Mg}$ dendrites with the dendrite arms delineated by the fine eutectic regions. It is clear that the centre line segregation consists of fine eutectic regions (A) surrounded by $\alpha-\mathrm{Mg}$ dendrites (B).

This analysis confirms the nature of centre-line segregation as being the solute rejected and piled up at the dendrites tips as the solidification proceeds. The segregations were formed by squeezing of solute rejected liquid at the dendrite tips due to a large amount of deformation during the twin roll casting. The measured $\mathrm{Mg} / \mathrm{Al}$ weight ratio at $\mathrm{A}, 2.01$, is higher than the stoichiometric weight ratio at eutectic $\mathrm{Mg}_{17} \mathrm{Al}_{12}$, 1.31, attributed to the 
high cooling rate of the TRC process which resulted in increased solid solubility in the matrix, [Ferry 2006]. The $\mathrm{Al}$ and $\mathrm{Zn}$ percentages in A show the pushing of these elements to the centre of the cast strip during the twin roll casting process.
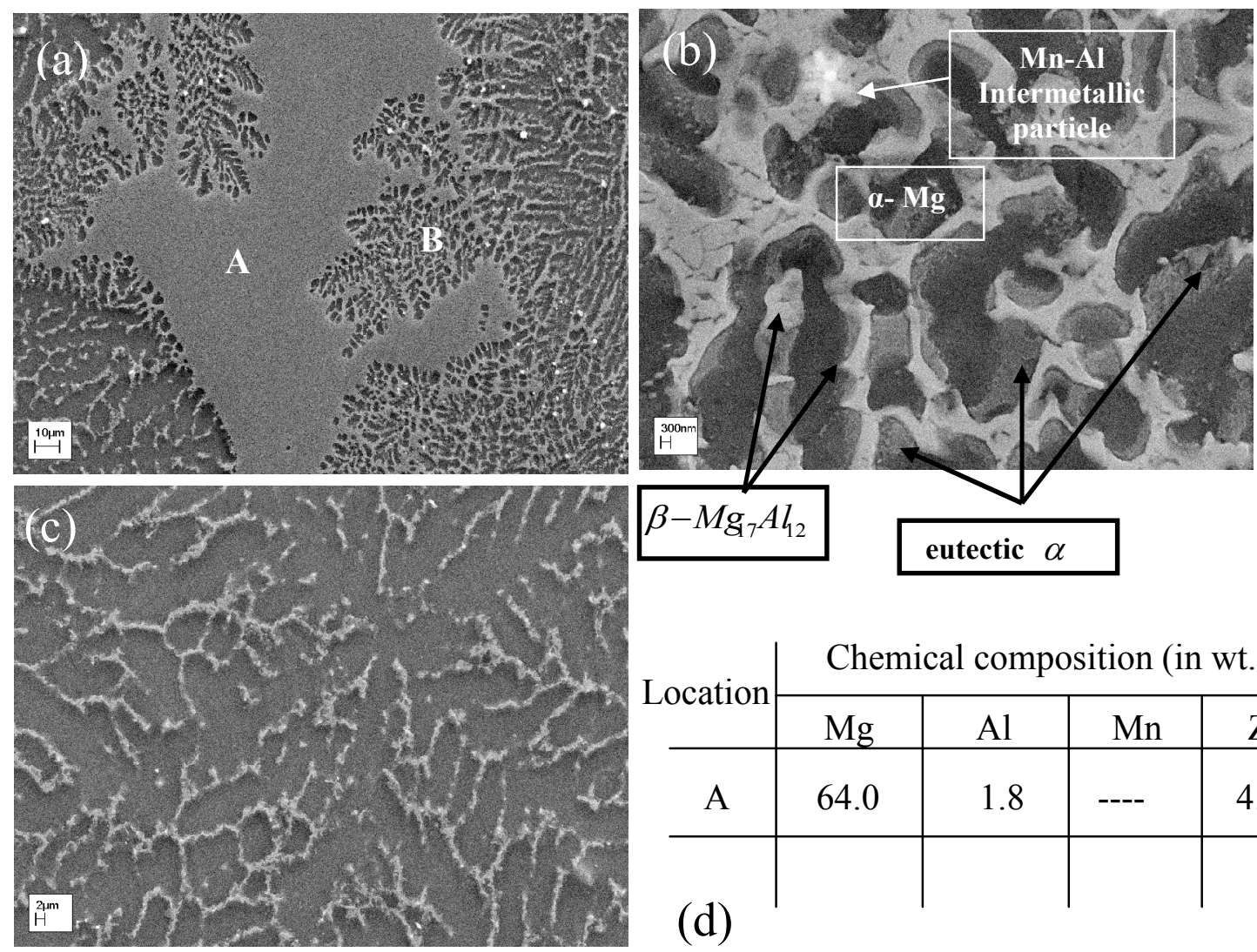

\begin{tabular}{c|c|c|c|c}
\multirow{2}{*}{ Location } & \multicolumn{4}{|c}{ Chemical composition (in wt. \%) } \\
\cline { 2 - 5 } & $\mathrm{Mg}$ & $\mathrm{Al}$ & $\mathrm{Mn}$ & $\mathrm{Zn}$ \\
\hline $\mathrm{A}$ & 64.0 & 1.8 & ---- & 4.3 \\
\hline & & & &
\end{tabular}

(d)

\section{Figure 4.34:}

SEM micrograph showing the, (a) central region in a TRC AZ91D strip, (b) higher magnification of area A, (c) higher magnification of B area and (d) chemical composition of A area which shows that elements is being segregated in central zone.

An SEM micrograph of the middle of MC-TRC AZ91D strip is shown in Figure 4.35.

As expected, in contrast to $\mathrm{TRC}$, only equiaxed grains were found in the middle of $\mathrm{MC}$ -

TRC strip without any centre-line segregation. 


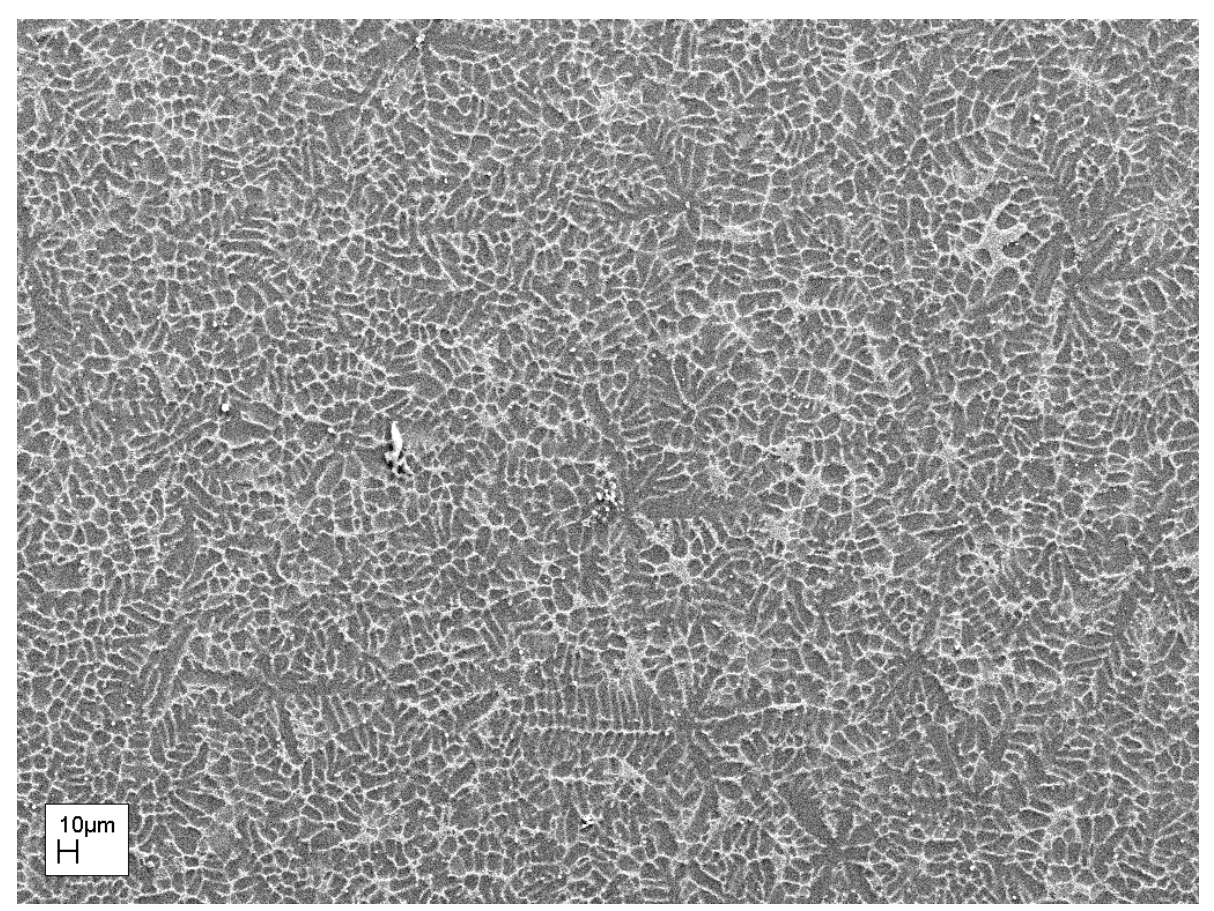

Figure 4.35:

SEM micrograph showing the central region in the magnesium AZ91D MC-TRC strip.

The compositional variation (wt \%) of $\mathrm{Mg}, \mathrm{Al}$ and $\mathrm{Zn}$ through the AZ91D strip thickness from the top surface to the bottom surface were also investigated, as shown in Figure 4.36.
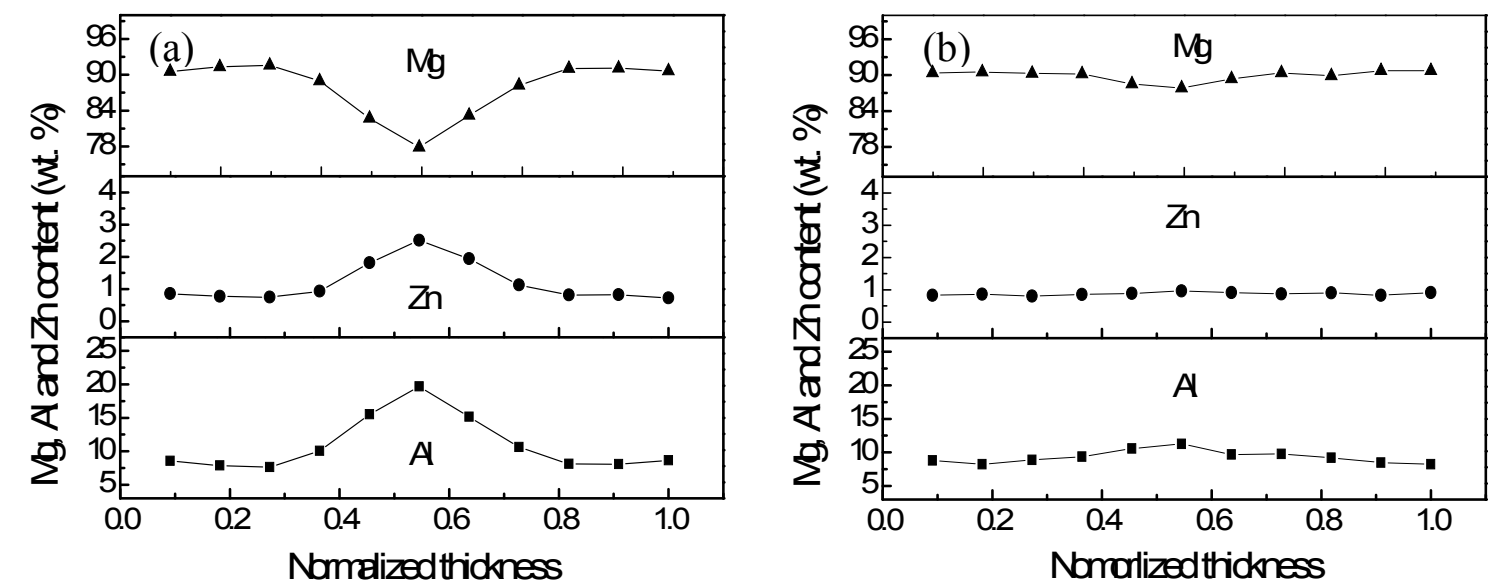

\section{Figure 4.36:}

Chemical composition variation $(\mathrm{Mg}, \mathrm{Al}$ and $\mathrm{Zn}$ ) through thickness of AZ91D alloy strip, (a) nonsheared and (b) sheared at $615^{\circ} \mathrm{C}$ showing the effect of melt shearing. For the sheared samples, the shearing speed and shearing time were $600 \mathrm{rpm}$ and $60 \mathrm{~s}$, respectively. 
As illustrated in Figure 4.36 (a), for the TRC AZ91D strip as distance from the strip surface is initially increased, the $\mathrm{Al}$ and $\mathrm{Zn}$ contents have no obvious variation, however at the central region both $\mathrm{Al}$ and $\mathrm{Zn}$ contents change and increase sharply. The $\mathrm{Al}$ content reaches nearly $20 \%$ and $\mathrm{Zn}$ content is up to $3 \%$. This result suggests chemical segregation in the as-cast strip, which originates from the growth of columnar dendrites and solute rich liquid squeezed out from the interdendritic regions into central areas during deformation process. Moving from the centre to the bottom surface, both $\mathrm{Al}$ and $\mathrm{Zn}$ contents reduce, which is the same tendency as that from the centre to the top.

For the MC-TRC AZ91D strip, as shown in Figure 4.36 (b), it has been noticed that Al, $\mathrm{Mg}$ and $\mathrm{Zn}$ contents have no obvious changes with an increase in the thickness. This result suggests that there is no obvious chemical segregation in the MC-TRC strip. These results verify that the MC-TRC process is effective in preventing the formation of defects such as centre-line segregation.

\subsubsection{Hardness}

The uniformity in mechanical properties across the transverse section of the cast strip is an important factor for the final rolled product. Optical micrographs showing the micro-hardness indenter across the thickness of the TRC and MC-TRC AZ31 strips are presented in Figure 4.37 (a) \& (b). Figure 4.37 (c) \& (d) shows the micro-hardness values across the transverse section of the AZ91D and AZ31 strips produced by the TRC and MC-TRC processes. In the conventional TRC, due to severe centre line segregation the strip exhibits relatively high hardness at the edge and much higher hardness at the centre. Under the effects of melt shearing, the micro-hardness throughout the strip is increased and shows constant hardness across the entire strip. 


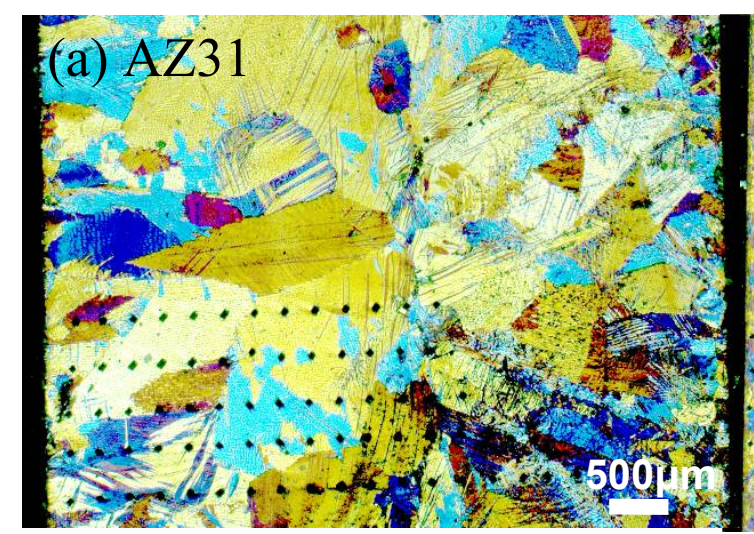

(c)

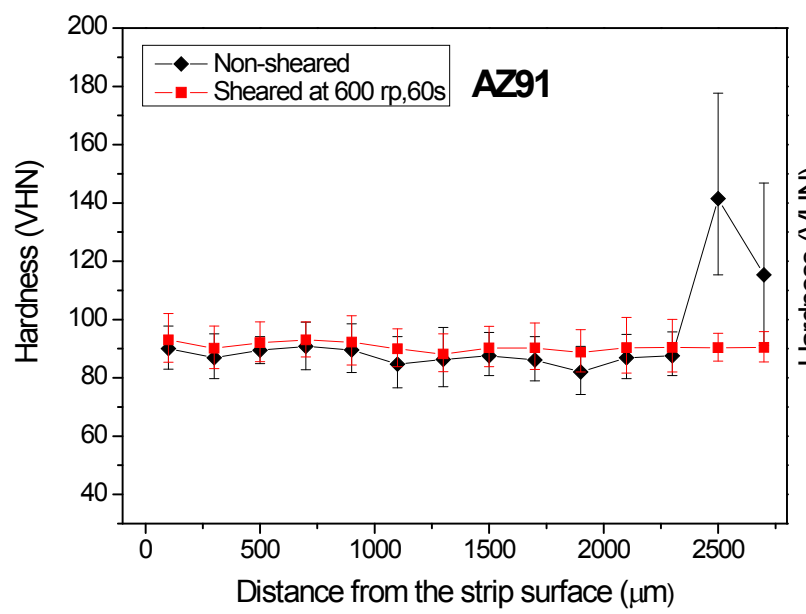

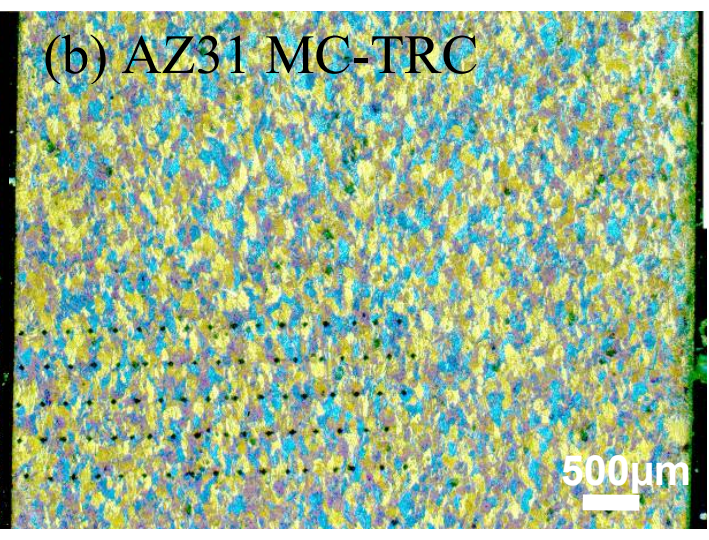

(d)

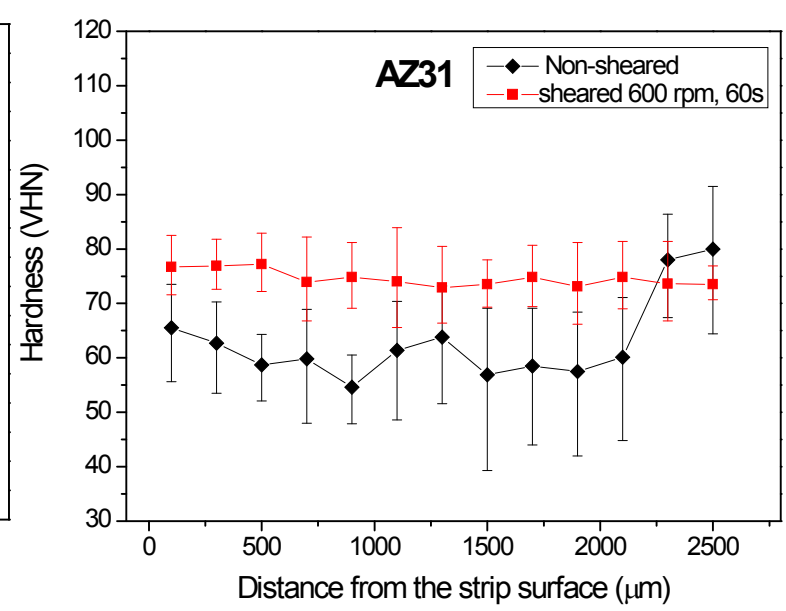

\section{Figure 4.37:}

Micrographs showing the cross-sectional view of the effect of hardness indenters on the samples of AZ31 strips produced by (a) TRC and (b) MC-TRC processes. The change in micro-hardness profile across the (c) AZ91D and (d) AZ31 strips produced by TRC and MC-TRC processes.

It is noteworthy to consider the higher micro-hardness values of AZ91D alloy compared with AZ31 alloy. This is due to a larger amount of aluminium in the AZ91D alloy in comparison with AZ31 alloy.

\subsubsection{Stop-samples}

A stop-sample, is a wedge-shaped piece of solid metal that freezes between the rolls if the caster is instantaneously stopped when the tip is still full of metal. The stop-sample method in a twin roll casting process is a very helpful experimental technique to understand the morphological changes of the final strip during the 
manufacturing process. Photographs of a AZ31 MC-TRC stop-sample are shown in Figure 4.38 in which six zones have been distinguished on the side view (Figure. 4.38 (a)) and front view (Figure 4.38 (b)) with red marks. These zones have been selected based on the alteration in surface quality of the stop-samples at different areas, (Figure 4.38 (b)), and also thickness reduction of the stop-samples during twin roll casting from inside the tundish (zone I) to the final strip (zone VI), (Figure. 4.38 (a)). As it has been shown in Figure 4.38 (a) \& (b), rolling surface marks in zones III, IV, V and VI are in black and distinguishable compared with invisible rolling surface marks in zones I and II. Zone $\mathrm{V}$ is located at the kissing point of the rolls. The only purpose of this zone classification is to compare the microstructure of stop-samples obtained from novel MC-TRC and conventional TRC processes in order to better understand the nucleation mechanism involved with TRC and MC-TRC processes. A schematic diagram of the selected zones is depicted in Figure 4.38 (c).

(a)

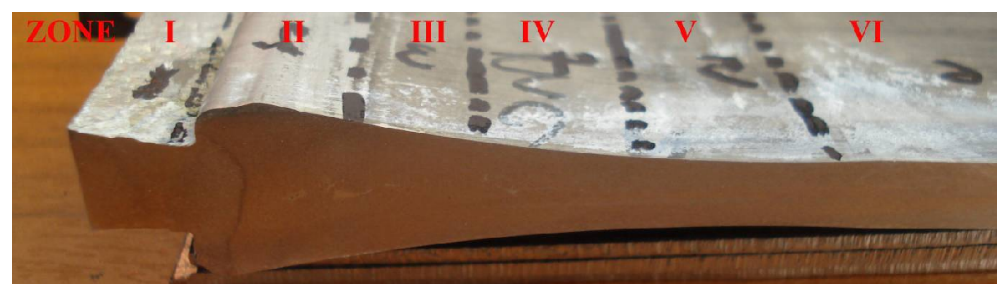

(b)

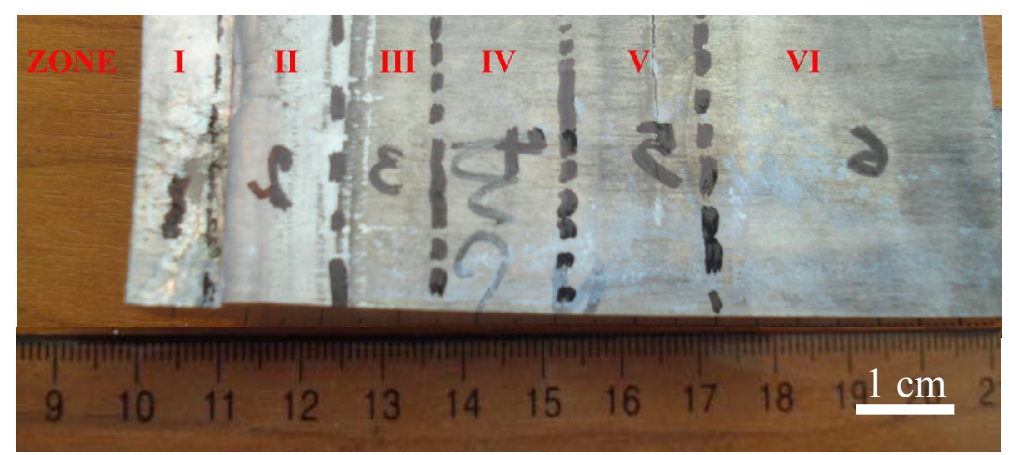

(c)
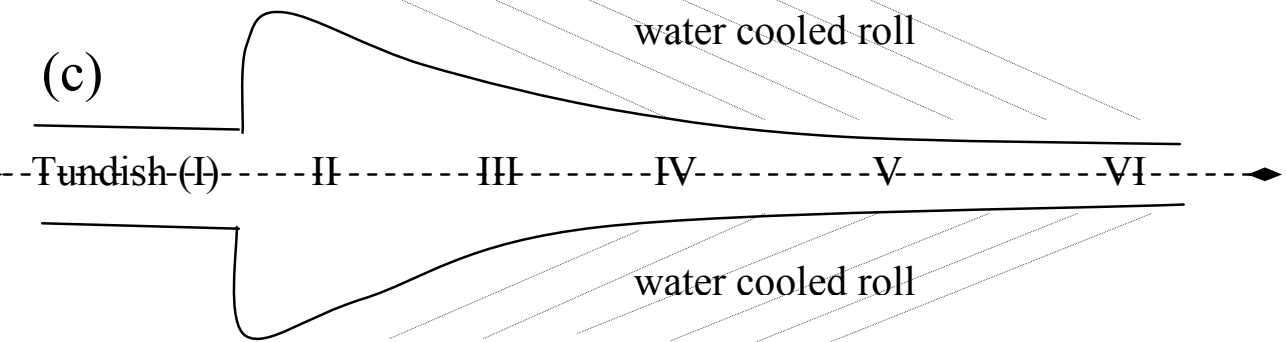

Figure 4.38:

Micrographs showing photographs of an AZ91D TRC stop-sample from the (a) side view and (b) front view of sample. A schematic diagram of the selected zones for stop-sample tests is shown in (c). 
Figure 4.39 shows the microstructural evolution of a stop sample, AZ31 non-sheared and sheared at $645^{\circ} \mathrm{C}$, (Figure 4.39 (a) \& (b)) respectively and AZ91D non-sheared and sheared at $615^{\circ} \mathrm{C}$ (Figure 4.39 (c) \& (d)) respectively. The grain size has been reduced significantly in the sheared melt compared with the non-sheared melt. The grain size inside the tundish in the sheared melt sample compared with the non-sheared melt sample has been reduced notably in both types of alloys. The grain size variations for AZ31 and AZ91D samples as a function of distance from the tundish are shown in Figure 4.40.
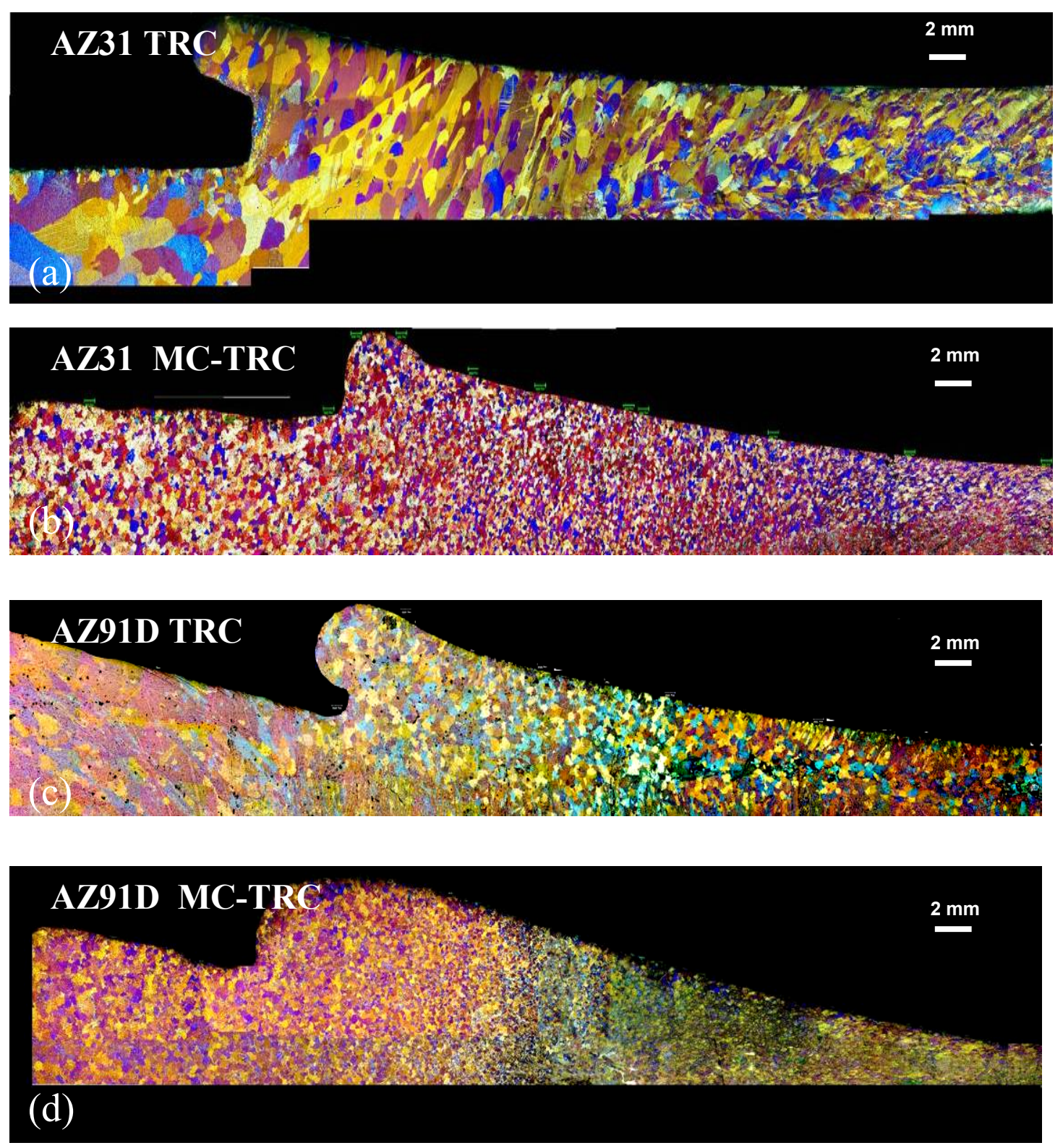

\section{Figure 4.39:}

Optical micrographs of stop-samples (a and b) AZ31 non-sheared and sheared at $645^{\circ} \mathrm{C}$, respectively and (c and d) AZ91D non-sheared and sheared at $615^{\circ} \mathrm{C}$ respectively showing the effect of melt shearing. For the sheared samples, the shearing speed and shearing time were $600 \mathrm{rpm}$ and $60 \mathrm{~s}$, respectively. 
These findings confirm the effect of the MC-TRC process in significant grain refinement of the final $\mathrm{Mg}$ strips which shows that the conditioned $\mathrm{Mg}$ melt at a very low cooling rate in the tundish before impinging to the water-cooled rolls has a very fine ( $\sim 6-7$ times less than the TRC stop-samples) and a uniform grain size variation compared with the large grain size variation of the TRC stop-sample.

(a)

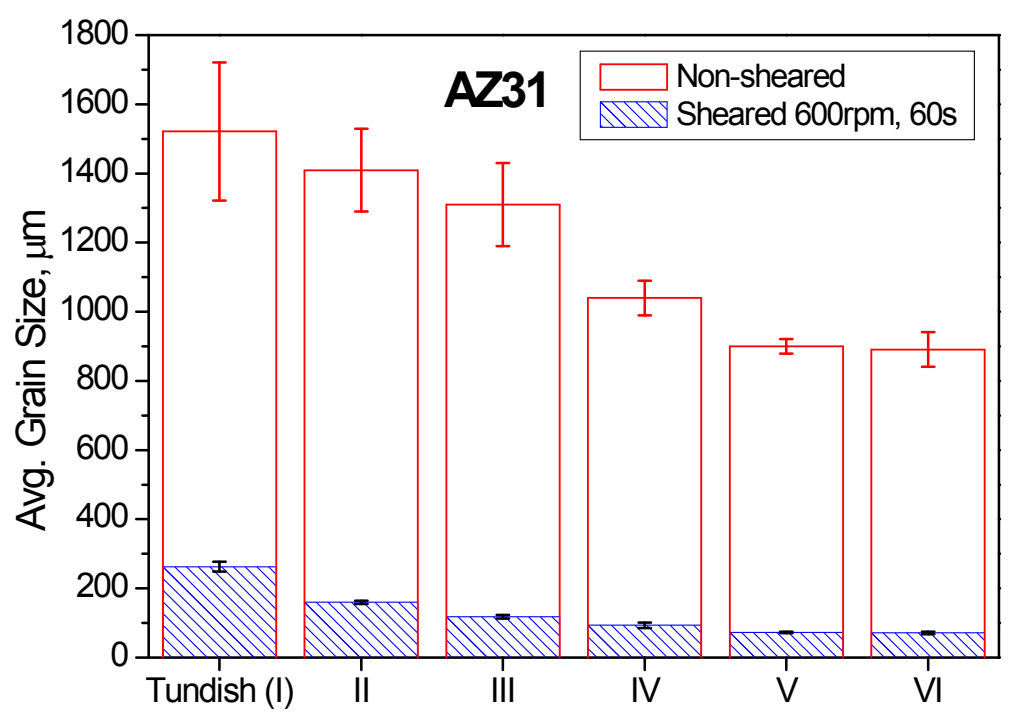

Distance from tundish

(b)

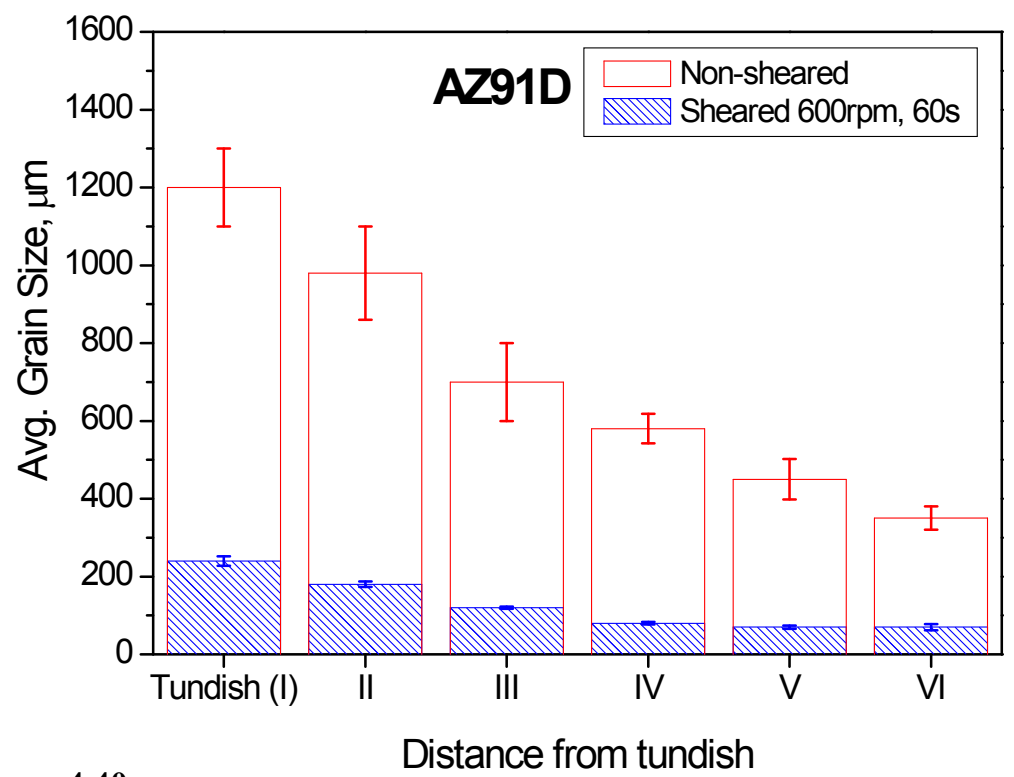

Figure 4.40:

Average grain size variation of (a) AZ31 alloy and (b) AZ91D stop-samples as a function of distance from the tundish through the final strip for non-sheared and sheared melts. 


\section{CHAPTER 5}

\section{RESULTS-2}

\subsection{Microstructure and mechanical properties of TRC and MC-TRC Mg-alloys during down-stream processing}

\subsubsection{Response to homogenization treatment}

The homogenization treatment procedures designed for the AZ91D and AZ31 alloys were applied to the prepared specimens of TRC and MC-TRC AZ91D and AZ31 strips in order to evaluate the microstructural and mechanical properties offered by the TRC and MC-TRC processes under the optimum heat treatment conditions. There are two main parameters involved in evaluating the response of TRC and MC-TRC strips to homogenization treatment, i.e.:

- Holding temperature, i.e. the constant temperature for homogenization,

- Holding time, i.e. the time duration at holding temperature,

\subsubsection{Effect of holding temperature}

AZ31 alloy: Figure 5.1 shows the microstructure of the TRC (Figure 5.1 (a), (c), (e) \& (g)) and MC-TRC (Figure 5.1 (b), (d), (f) \& (h)) AZ31 strips after homogenizing at different temperatures (i.e. $350,370,400$ and $450^{\circ} \mathrm{C}$ ) for 45 minutes. All the fine grains observed, can be presumed as new grains that have been statically recrystallized under the influence of the pre-stress applied by the twin roll casting process and elevated temperature. For the AZ31 MC-TRC samples, by increasing the temperature the newly formed necklace-like recrystallized grains embedded in primary as-cast grains (Figure 5.1 (b)) change into fully recrystallized $(12 \mu \mathrm{m})$ at $400^{\circ} \mathrm{C}$ (Figure 5.1 (f)). By contrast, the AZ31 TRC samples have preserved the as-cast large columnar grains in all 
the temperatures investigated $(356 \mu \mathrm{m})$; however some fine recrystallized grains are formed at temperatures higher than $400^{\circ} \mathrm{C}$. The microstructures of as-cast TRC and MC-TRC AZ31 alloy are shown in Figure 4.30.
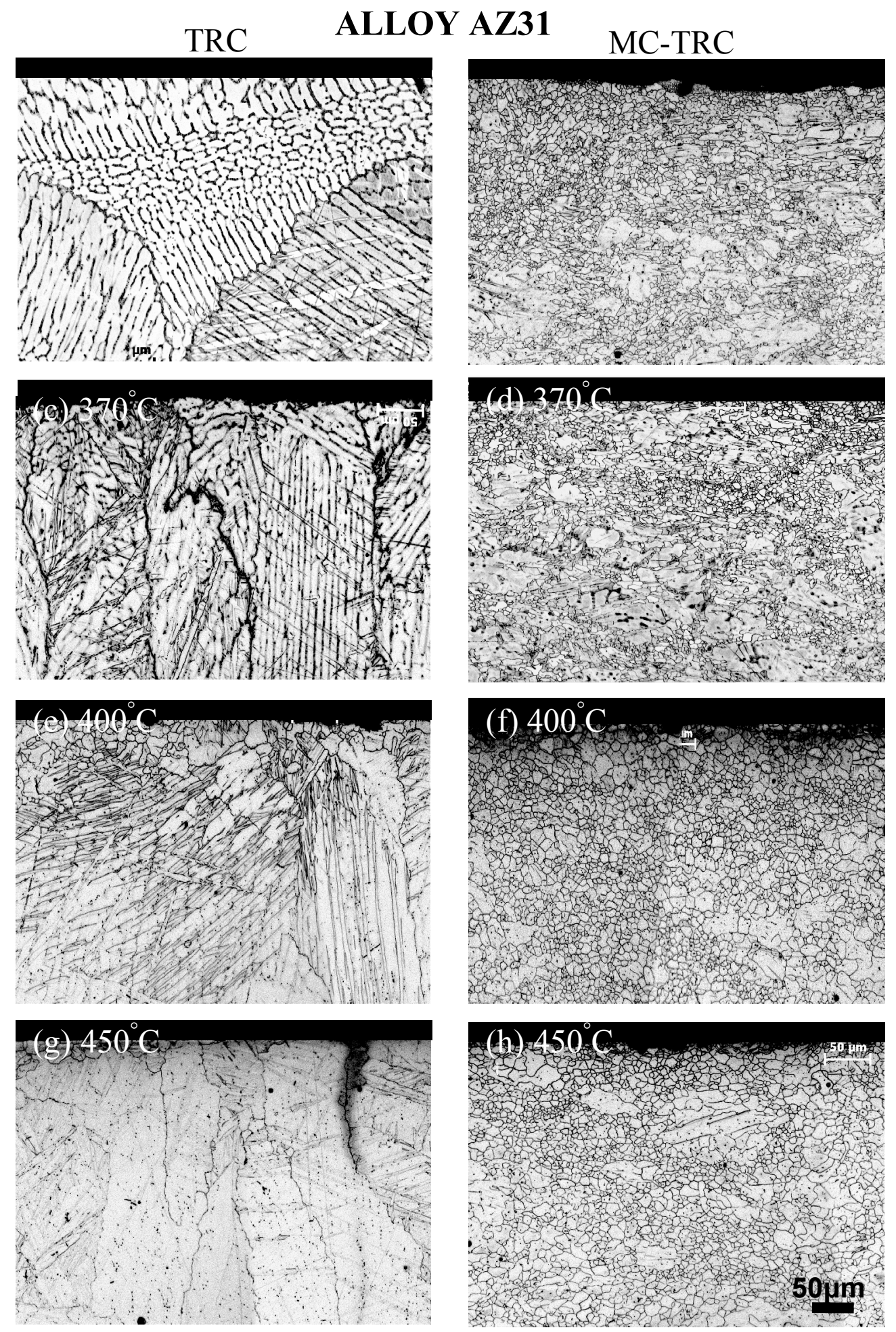

\section{Figure 5.1:}

Optical micrographs showing microstructures of longitudinal sections of homogenized AZ31 alloy at different temperatures for 45 minutes produced by (a, c, e and g) TRC and (b, d, f and h) MC-TRC processes. These micrographs show the effect of different homogenization temperatures at a fixed holding time on the microstructural evolution of AZ31 alloy sheet, (a and b) $350^{\circ} \mathrm{C}$, (c and d) $370^{\circ} \mathrm{C}$, (e and $\mathrm{f}) 400^{\circ} \mathrm{C}$ and $\left(\mathrm{g}\right.$ and $\mathrm{h}$ ) after homogenizing at $450^{\circ} \mathrm{C}$ for 45 minutes. All micrographs shown here were captured at the same magnification. 
AZ91D alloy: Figure 5.2 presents the microstructure of the TRC (Figure 5.2 (a), (c), (e) \& (g)) and MC-TRC (Figure 5.2 (b), (d), (f) \& (h)) AZ91D strips after homogenizing at different temperatures (i.e. $350,370,400$ and $450^{\circ} \mathrm{C}$ ) for 45 minutes. The results obtained for the MC-TRC AZ91D alloy (Figure 5.2), are the same as for the MC-TRC AZ31 alloy (Figure 5.1). The only difference is that the recrystallization rate for the TRC AZ91D alloy is faster than the TRC AZ31 alloy. For the TRC AZ91D alloy homogenized at $400^{\circ} \mathrm{C}$ for 45 minutes the sample is fully recrystallized with fine recrystallized grains $(\sim 14 \mu \mathrm{m})$ as illustrated in Figure $5.2(\mathrm{e})$, but as shown previously the primary elongated as-cast columnar grains for the TRC AZ31 alloy were found not to have changed significantly, as illustrated in Figure 5.1 (e). The microstructures of as-cast TRC and MC-TRC AZ91D alloy are shown in Figures 4.17 and 4.22.

Hence, microstructural observations suggest that a holding temperature of as high as $400^{\circ} \mathrm{C}$ is the optimum homogenization temperature for AZ31 and AZ91D TRC and MC-TRC strips. The holding temperature of $450^{\circ} \mathrm{C}$ was not further considered since higher temperature increases the probability of severe surface oxidation of the samples which in the worst condition without any required protection in the furnace may lead to severe burning of Mg-samples. Also a lower temperature needs less energy and power consumption compared with a very high temperature. 


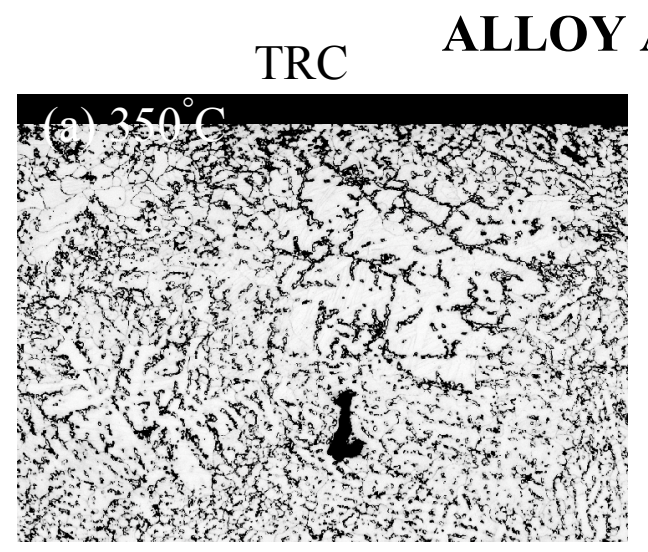

AZ91D

\section{MC-TRC}
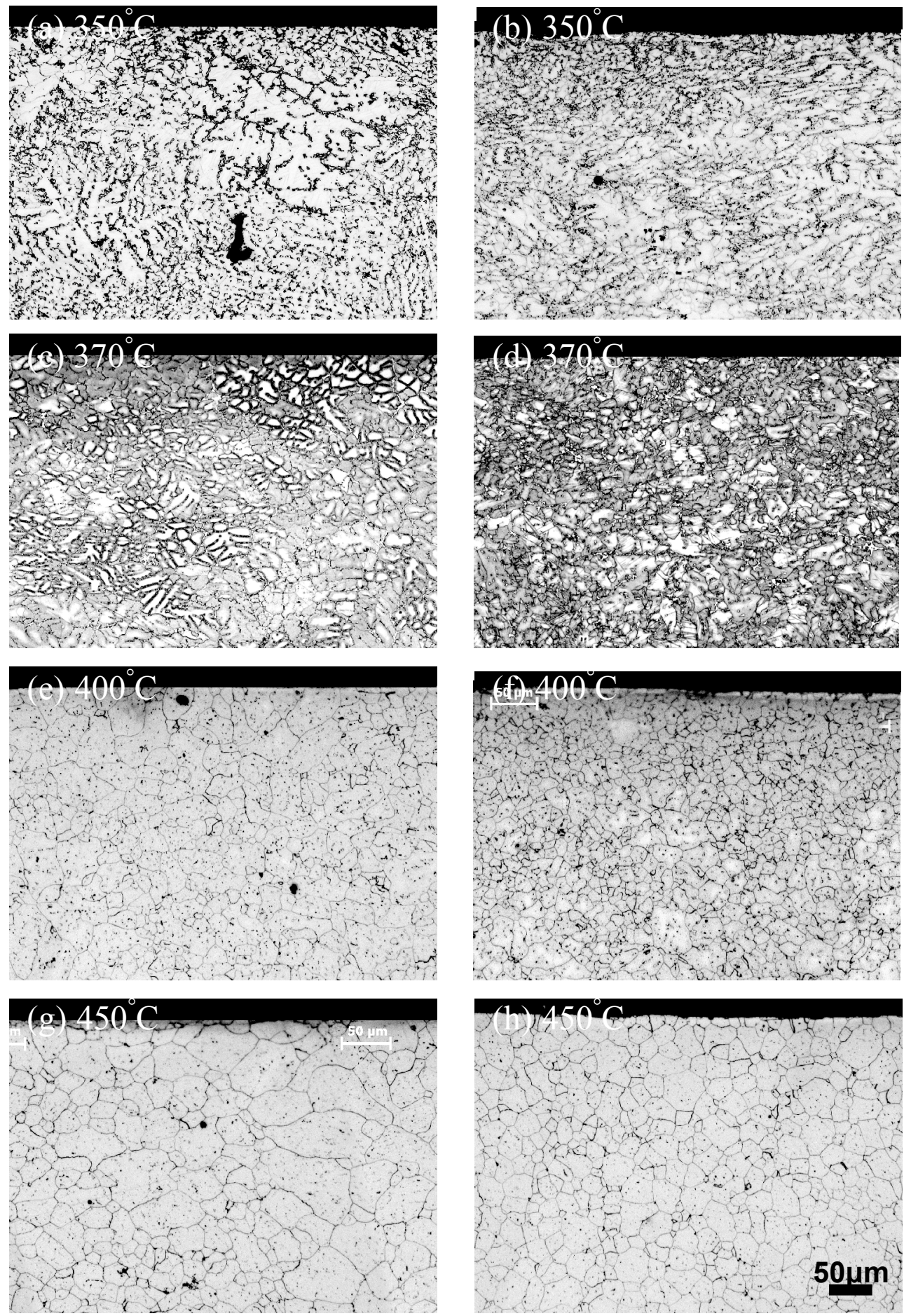

\section{Figure 5.2:}

Optical micrographs showing microstructures of longitudinal sections of homogenized AZ91D alloy at different temperatures for 45 minutes produced by (a, c, e and g) TRC and (b, d, f and h) MC-TRC processes. These micrographs show the effect of different homogenization temperatures at a fixed holding time on microstructural evolution of AZ91D alloy sheet, (a and b) $350^{\circ} \mathrm{C}$, (c and d) $370^{\circ} \mathrm{C}$, (e and $\left.\mathrm{f}\right) 400^{\circ} \mathrm{C}$ and $\left(\mathrm{g}\right.$ and $\mathrm{h}$ ) after homogenizing at $450^{\circ} \mathrm{C}$ for 45 minutes. All micrographs shown here were captured at the same magnification. 


\subsubsection{Effect of holding time}

* AZ31 alloy: The effects of different holding times at $400^{\circ} \mathrm{C}$ on the homogenization response of the TRC and MC-TRC AZ31 alloy strips are shown in Figure 5.3. At a short holding time, i.e. 10 minutes, the recrystallization phenomena has not started, as shown in Figure 5.3 (a) \& (e); however by increasing the holding time to 30 minutes some new recrystallized grains form at the grain boundaries for both TRC and MC-TRC AZ31 strips, as illustrated in Figure 5.3 (b) \& (f). The microstructure of the MC-TRC AZ31 strip homogenized at $400^{\circ} \mathrm{C}$ for 60 minutes was uniform with fully fine equiaxed recrystallized grains as shown in Figure 5.3 (c). The as-cast grains underwent recrystallization to form finer equiaxed grains and the average grain size was $11 \pm 2 \mu \mathrm{m}$. The homogenized TRC strip showed that the large columnar grains with well developed dendrites were preserved as depicted in Figure $5.3(\mathrm{~g})$. A few finer recrystallized grains and some cracks were observed near the surface of the TRC strip where more intensive deformation was applied by the TRC process.

Grains having an average diameter of $\leq 15 \mu \mathrm{m}$ are defined as 'fine' grains produced by recrystallization and the area fraction of fine grains $A_{f}$ is defined as follows:

$$
A_{f}=\frac{\text { Total area of individual fine grains, } \Sigma A_{i}}{\text { Total sampling area, } \Sigma A_{\text {total }}}
$$

It is crucial to measure the grain size based on either the area fraction of fine grains, $A_{f}$ or the average grain diameter due to the in-homogenous nature of the grain distribution resulting from incomplete DRX, [Tan and Tan 2003, Yang and Ghosh 2006]. The quantitative analyses of the homogenized MC-TRC and TRC AZ31 alloy micrographs shown in Figure 5.3 are presented in Figure 5.4. In Figure 5.4 (a)-(c) it is seen that by increasing the holding time from 10 minutes up to 1 hour a narrow distribution of fine grains for MC-TRC AZ31 alloy can be achieved, but a further increase in holding time up to 1.5 hour leads to recrystallized-grain growth, as shown in Figure 5.4 (d). 


\section{ALLOY AZ31}

\section{MC-TRC}
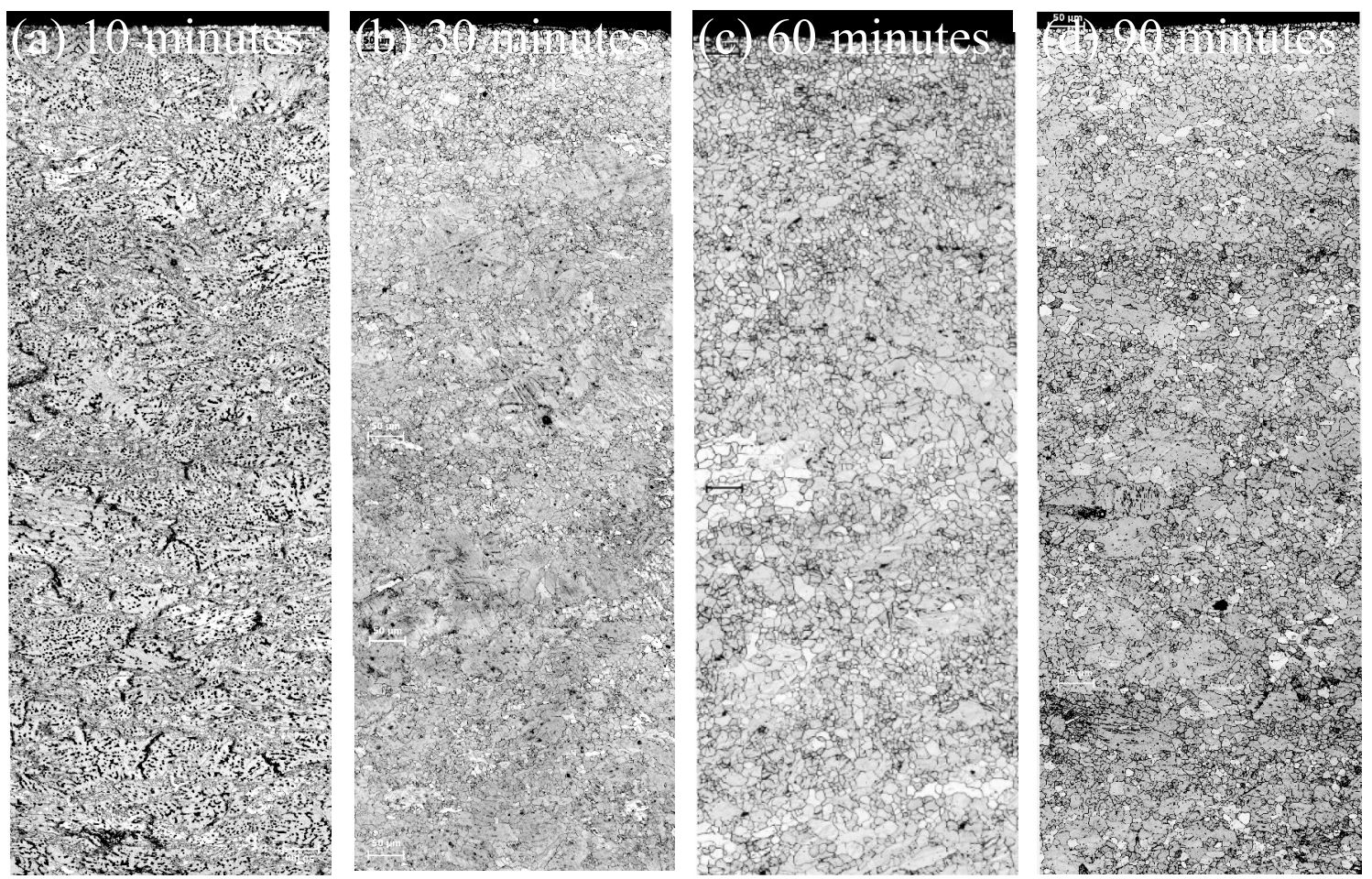

TRC
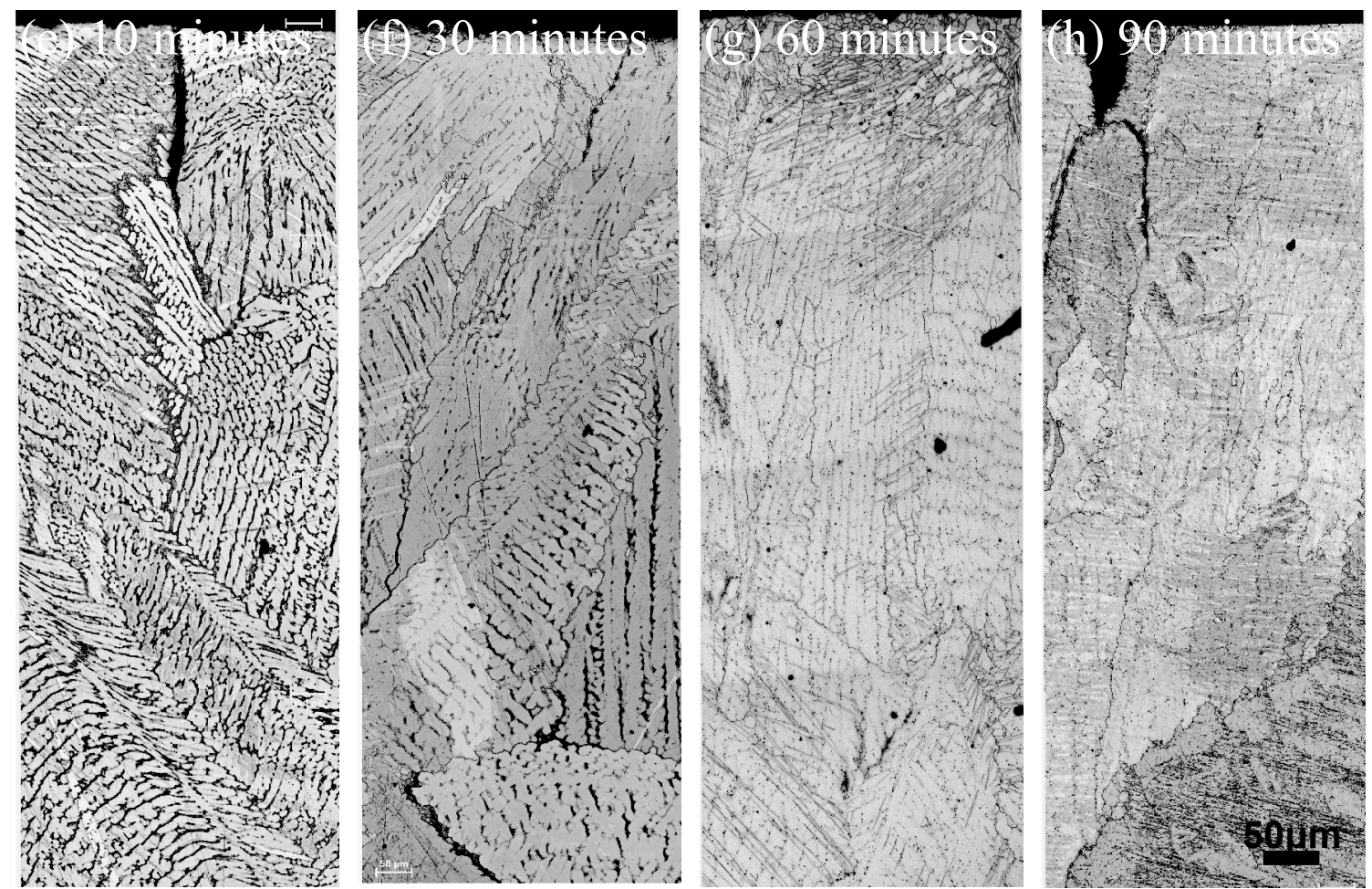

Figure 5.3:

Optical micrographs showing microstructures of longitudinal sections of homogenized AZ31 alloy at $400^{\circ} \mathrm{C}$ for different holding times produced by (a-d) MC-TRC and (e-h) TRC processes. These micrographs show the effect of different homogenization holding times at a fixed holding temperature on microstructural evolution of AZ31 alloy sheet, (a and e) 10minutes, (b and f) 30minutes, (c and g) 60 minutes and $(\mathrm{d}$ and $\mathrm{h})$ after homogenizing at $400^{\circ} \mathrm{C}$ for 90 minutes. All micrographs shown here were captured at the same magnification. 


\section{ALLOY AZ31}

(a)
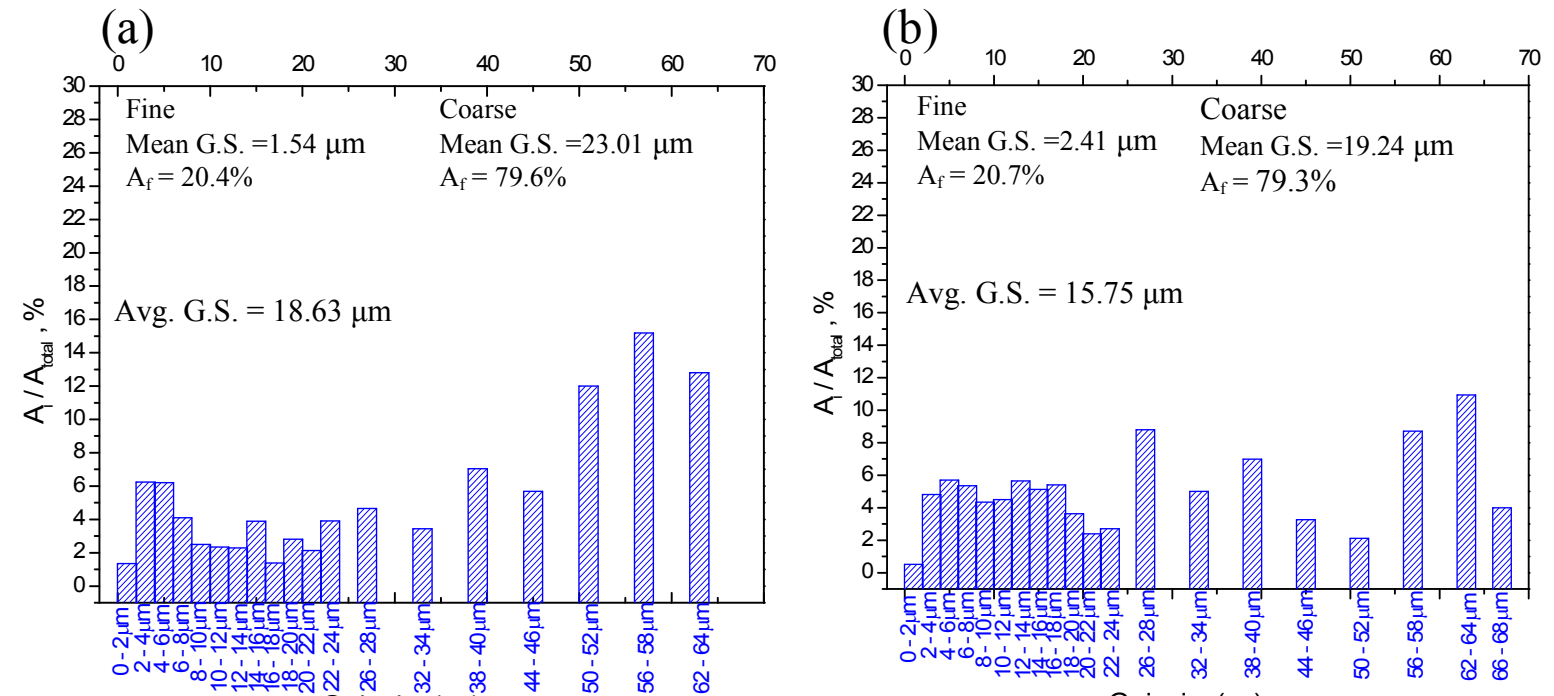

(c)

Grain size $(\mu \mathrm{m})$

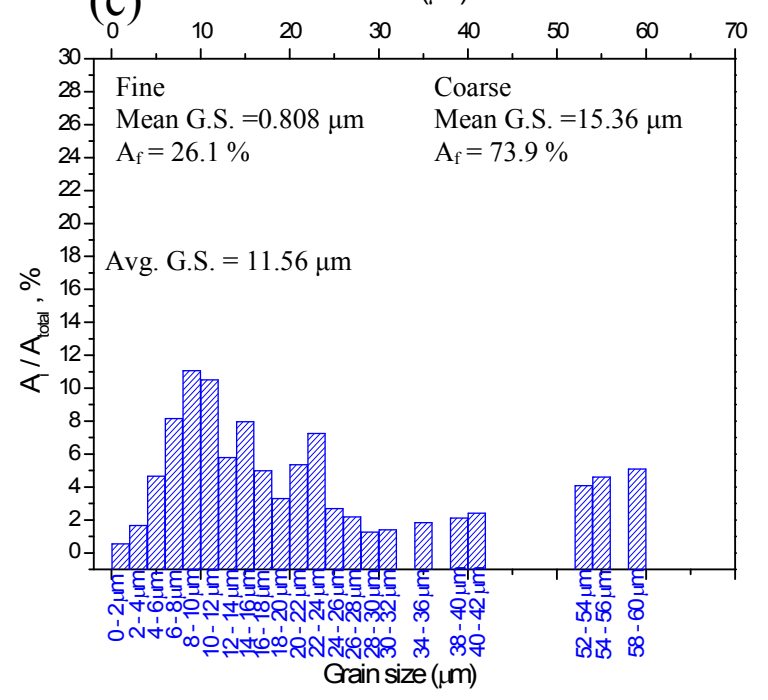

(d)

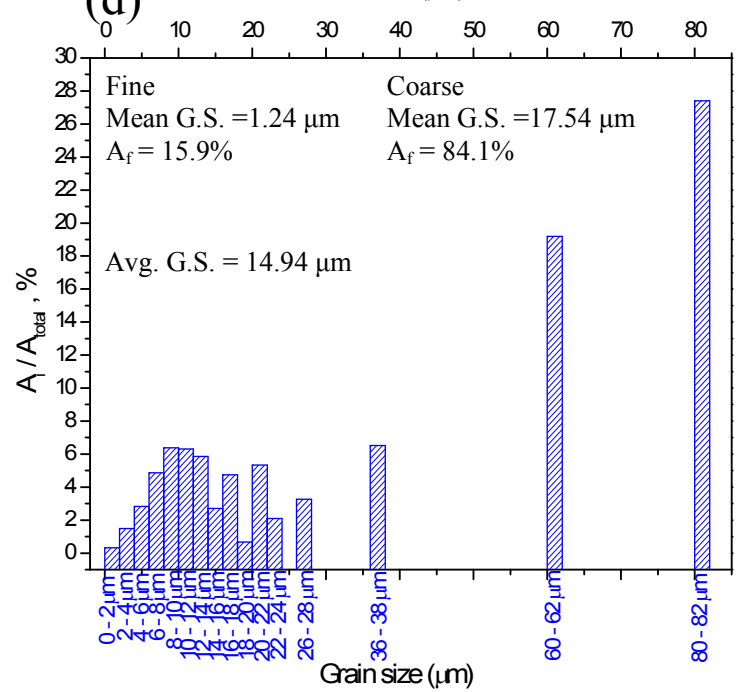

(e)

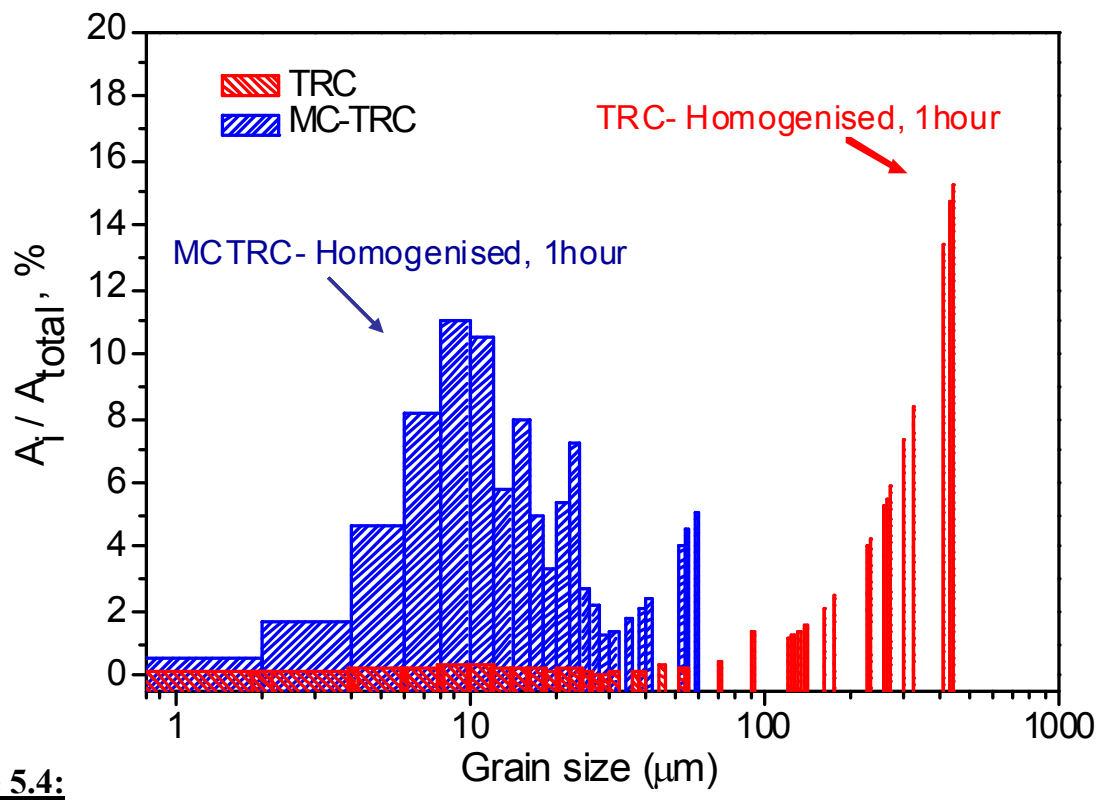

Figure 5.4:

Grain size $(\mu \mathrm{m})$

The grain size distribution of the recrystallized samples after homogenization processes at $400^{\circ} \mathrm{C}$ for different holding times, showing refined grain size and narrow size distribution by melt shearing in the MC-TRC AZ31. (a) 10minutes, (b) 30minutes, (c) 60minutes and (d) 90minutes. Figure (e) shows the difference in size distribution of the recrystallized grains between the TRC and MC-TRC AZ31 homogenized at $400^{\circ} \mathrm{C}$ for 60 minutes. The average recrystallized grain size was reduced from $344.9 \mu \mathrm{m}$ to $11.56 \mu \mathrm{m}$ by the melt shearing. Also the area fraction of fine grains (i.e. less than $15 \mu \mathrm{m}$ ) is about $50.4 \%$ for MC-TRC AZ31 strip while it is less than 2\% for TRC AZ31 strip. 
Based on these findings, the best optimum condition for homogenizing the TRC and MC-TRC AZ31 alloy strips was found to be $400^{\circ} \mathrm{C}$ for 1 hour. The quantitative metallographic results of the homogenized TRC and MC-TRC AZ31 microstructures obtained in the optimum condition are depicted in Figure 5.4 (e). This shows that intensive melt shearing reduces the average recrystallized grain size from $344.9 \mu \mathrm{m}$ to $11.56 \mu \mathrm{m}$ and narrows the grain size distribution, also the area fraction of fine grains (i.e. less than $15 \mu \mathrm{m}$ ) is about $50.4 \%$ for MC-TRC AZ31 strip while it is less than $2 \%$ for TRC AZ31 strip as shown in Figure 5.4 (e).

Figure 5.5 shows the effect of homogenization time at $400^{\circ} \mathrm{C}$ on recrystallized grain size variation (Figure 5.5 (a)), and area fraction of fine grains (Figure 5.5 (b)) of AZ31 strip produced by TRC and MC-TRC processes. Even prolonged annealing for 6 hours did not promote recrystallization for the TRC strip.

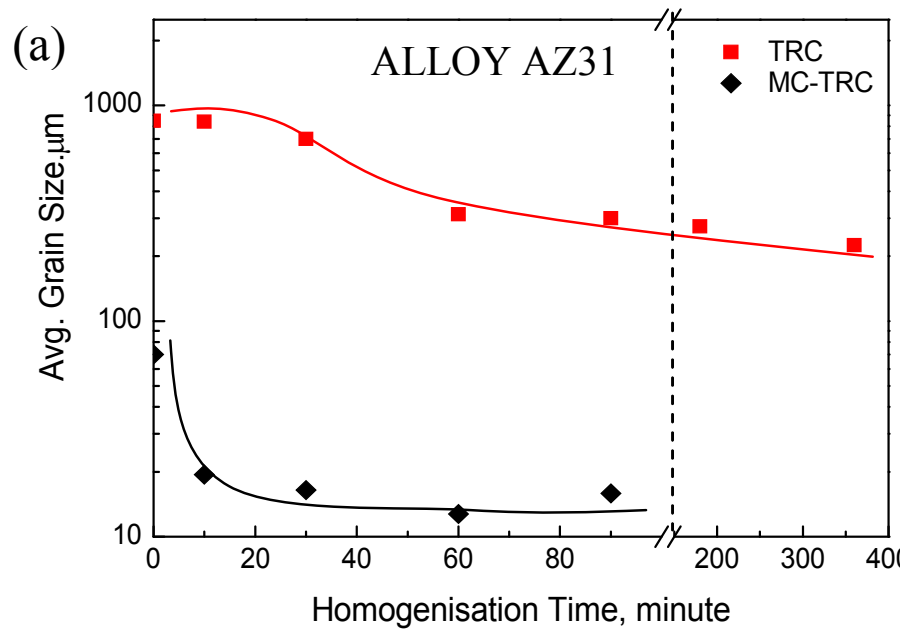

\section{Figure 5.5:}

Quantitative analysis showing the behaviour of AZ31 alloy produced by TRC and MC-TRC manufacturing processes on the effect of homogenization time on: (a) recrystallized grain size

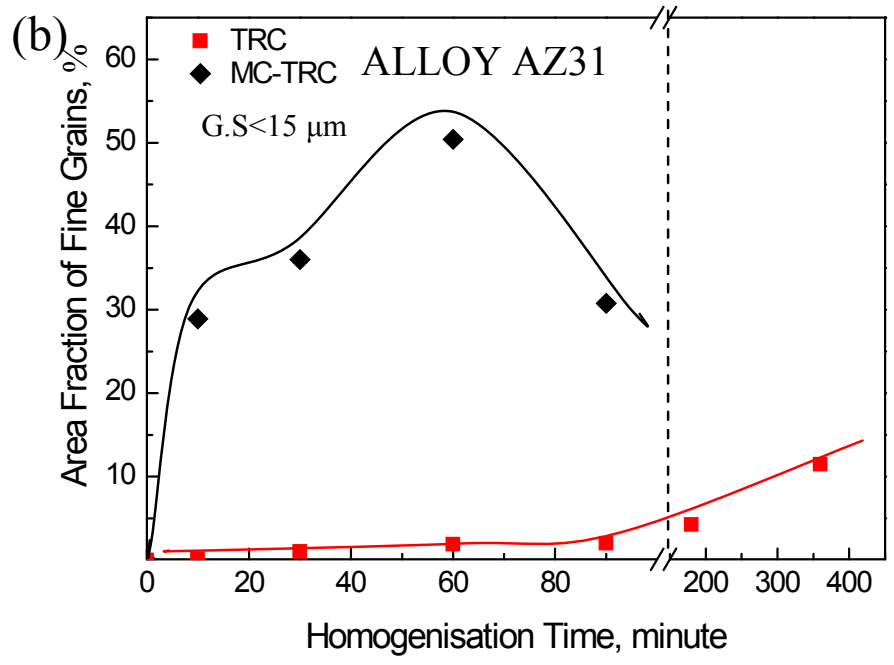
variation, and (b) area fraction of fine grains (i.e. less than $15 \mu \mathrm{m}$ ). The MC-TRC AZ31 homogenized strip illustrates finer and well distributed new recrystallized grains compared with the TRC AZ31 homogenized strip. 
AZ91D alloy: Figure 5.6 shows the effect of different holding times at $400^{\circ} \mathrm{C}$ on the homogenization response of the TRC and MC-TRC AZ91D alloy strips. The microstructural evolution and morphological changes of as-cast grains after the homogenization treatment for both TRC and MC-TRC AZ91D alloy strips are closely parallel to each other. The same as the heat treatment of TRC and MC-TRC AZ31 strips, 1hour holding time at $400^{\circ} \mathrm{C}$ (see Figure 5.3 (c) \& (g)) is found to be the optimum condition for fully homogenizing the TRC and MC-TRC AZ91D strips, as shown in Figure $5.6(\mathrm{c}) \&(\mathrm{~g})$.

The quantitative analysis shown in Figure 5.7 for the TRC and MC-TRC AZ91D strips homogenized at $400^{\circ} \mathrm{C}$ for 1 hour verifies the above findings in similarity of recrystallized grain distribution for both types of AZ91D strip casting processes, i.e. TRC and MC-TRC processes ( $18 \mu \mathrm{m}$ and $16 \mu \mathrm{m}$ respectively).

\subsubsection{Nucleation sites for homogenization process}

The nucleation sites for recrystallized grains in homogenized magnesium alloy strips are depicted in Figure 5.8. Twins, grain boundaries and eutectic (i.e. $\mathrm{Mg}_{17} \mathrm{Al}_{12}$ phase) particles are considered to be the potential sites for nucleating new grains. During deformation, more dislocations accumulate near the in-homogeneities (twins, grain boundaries and eutectic particles) to form deformation zones which lead to nucleation of new strain-free recrystallized grains after homogenization process. 

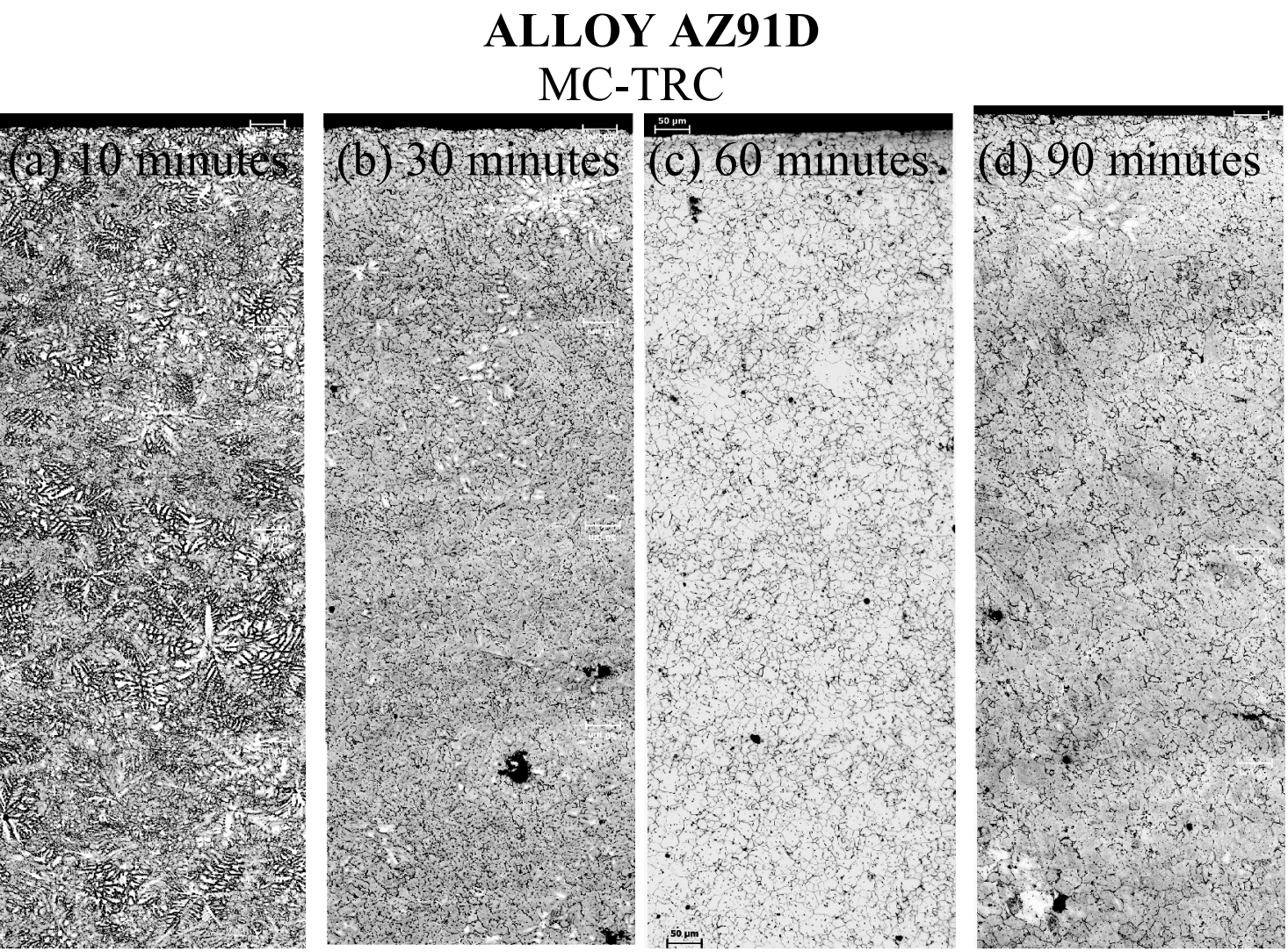

\section{TRC}
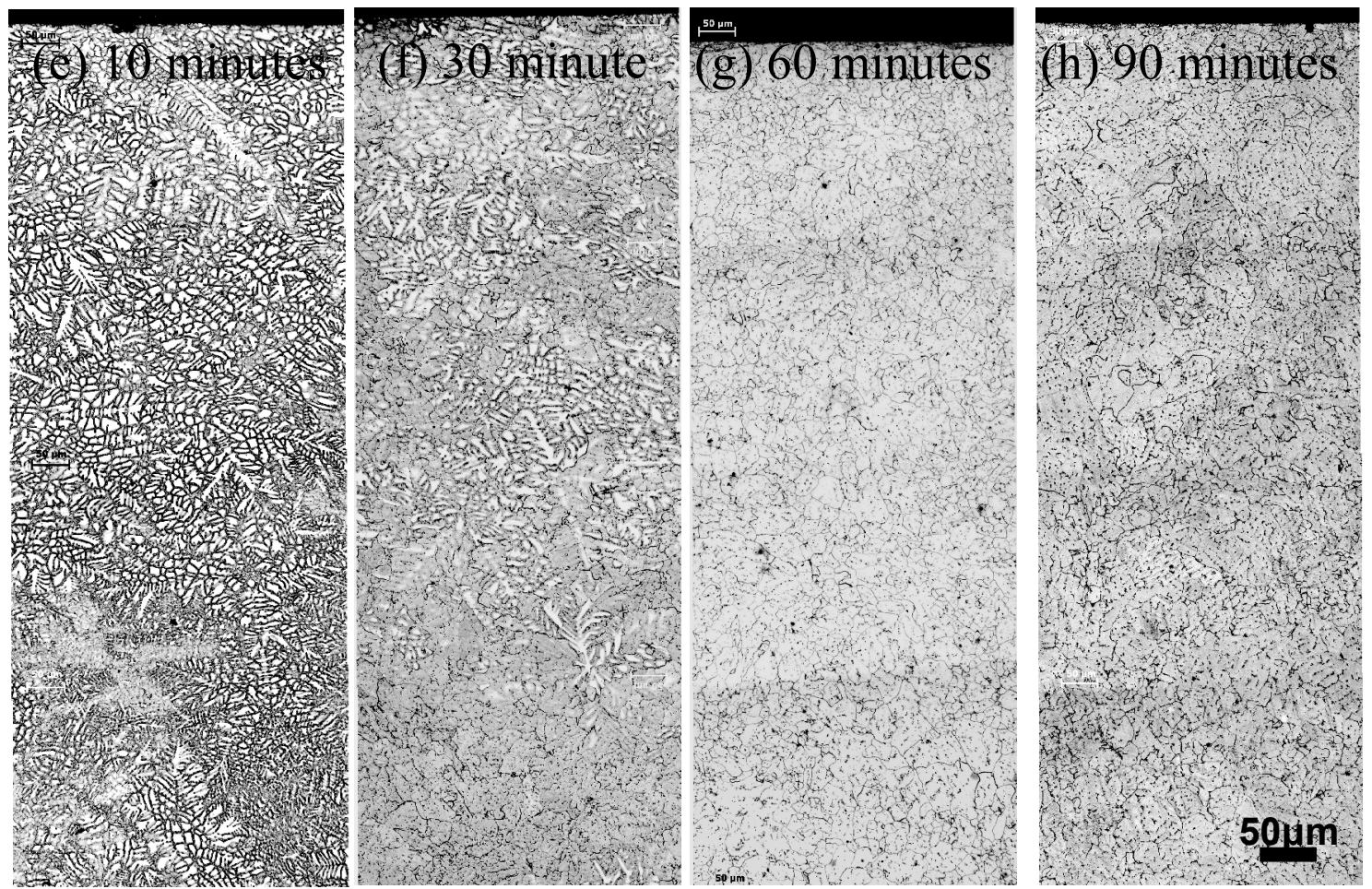

Figure 5.6:

Optical micrographs showing microstructures of longitudinal sections of homogenized AZ91D alloy at $400^{\circ} \mathrm{C}$ for different holding times produced by (a-d) MC-TRC and (e-h) TRC processes. These micrographs show the effect of different homogenization holding times at a fixed holding temperature on the microstructural evolution of AZ91D alloy sheet, (a and e) 10minutes, (b and f) 30minutes, (c and g) 60 minutes and (d and h) after homogenizing at $400^{\circ} \mathrm{C}$ for 90 minutes. All micrographs shown here were captured at the same magnification. 


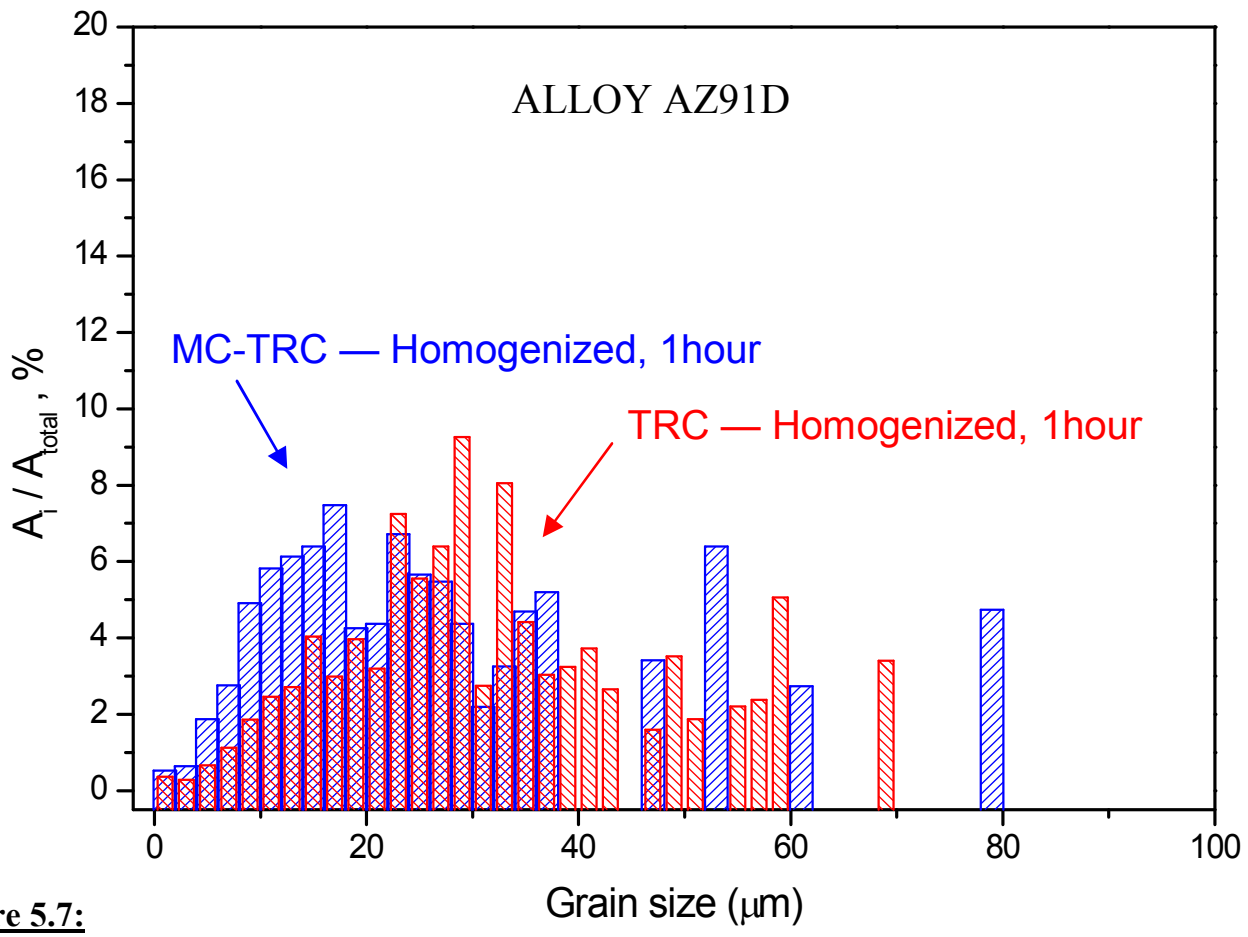

\section{Figure 5.7:}

Grain size $(\mu \mathrm{m})$

The size distribution of the recrystallized grains after a homogenization process at $400^{\circ} \mathrm{C}$ for 60 minutes, showing a similarity of the recrystallized grain distribution for both types of AZ91D strip casting processes, i.e. TRC and MC-TRC processes (18 $\mu \mathrm{m}$ and $16 \mu \mathrm{m}$ respectively).
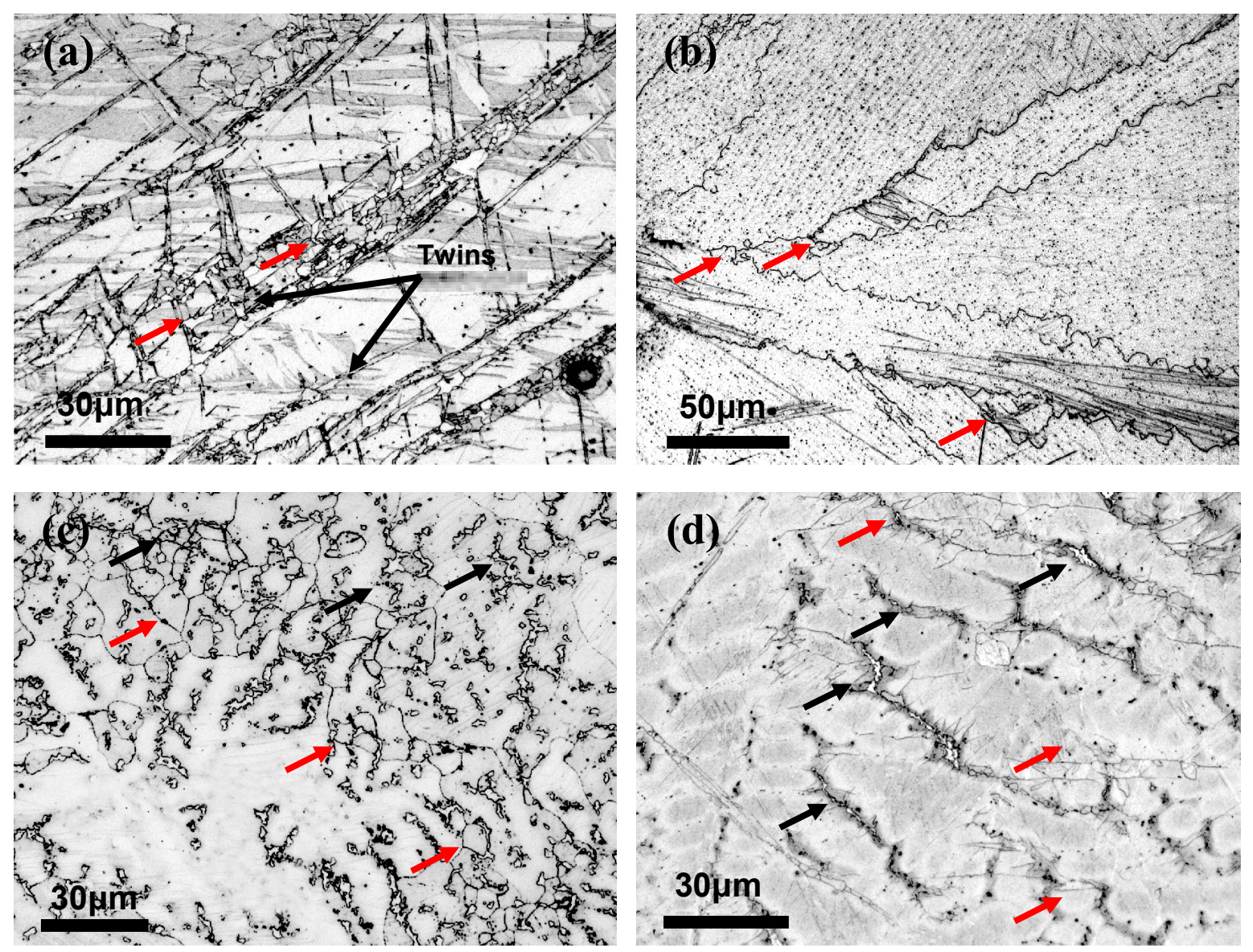

\section{Figure 5.8:}

Micrographs show the nucleation agents of recrystallized grains in homogenized strips of magnesium alloys, (a) Twins, AZ31 alloy, (b) Grain boundaries, AZ31 alloy, (c and d) eutectic particles in AZ91D and AZ31 alloys respectively. The black arrows in (c and d) are indicative of the eutectic particles, i.e. $\mathrm{Mg}_{17} \mathrm{Al}_{12}$ phase. The red arrows are indicative of the new recrystallizaed grains. 


\subsubsection{Response to the hot rolling process}

The hot rolling procedures designed for the AZ91D and AZ31 alloys were applied to the homogenized TRC and MC-TRC AZ91D and AZ31 strips in order to evaluate the microstructural and mechanical properties offered by the TRC and MC-TRC processes under the thermo-mechanical processing conditions. There are two main parameters involved in evaluating the response of TRC and MC-TRC strips to thermo-mechanical processing:

- Strain rate

- Temperature

\subsubsection{Effect of strain rate}

In order to investigate the effect of strain rate on the TRC and MC-TRC strips, simple experiments were carried out at a very high $\left(\sim 314 \mathrm{~mm} . \mathrm{s}^{-1}\right)$, medium $\left(\sim 190 \mathrm{~mm} . \mathrm{s}^{-1}\right)$ and very low $\left(\sim 63 \mathrm{~mm} . \mathrm{s}^{-1}\right)$ rolling speeds at a fixed temperature of $400^{\circ} \mathrm{C}$. Due to economic considerations and limited number of MC-TRC strips available all the trials were performed on the TRC AZ91D strip. The results in Figure 5.9 (a), (b) \& (c) show that the final gauge hot-rolled AZ91D strip (73\% reduction in thickness) at the medium rolling speed (i.e. $190 \mathrm{~mm} \cdot \mathrm{s}^{-1}$ ) is a defect-free sample with an average grain size of $16 \mu \mathrm{m}$ while at a very low rolling speed some severe cracking at an angle of approximately 45 degree to the strip surface occurred. Also at a very high rolling speed, shear zones appear on the surface of the strip which indicates that the rolling force did not spread evenly throughout the strip during the hot-rolling process. Figure 5.9 (d), (e) \& (f) show these microstructural characteristics in more detail. It is of concern to note the existence of centre-line segregation after 9 rolling passes of $15 \%$ reduction per pass. This confirms that the thermomechanical processing is not capable of eliminating the internal 
defect of brittle centre-line segregation of as-cast TRC strips. Based on these findings the medium rolling speed $\left(\sim 190 \mathrm{~mm} \cdot \mathrm{s}^{-1}\right)$ was selected for further investigation of the hotrolling procedure on TRC and MC-TRC AZ31 and AZ91D strips.
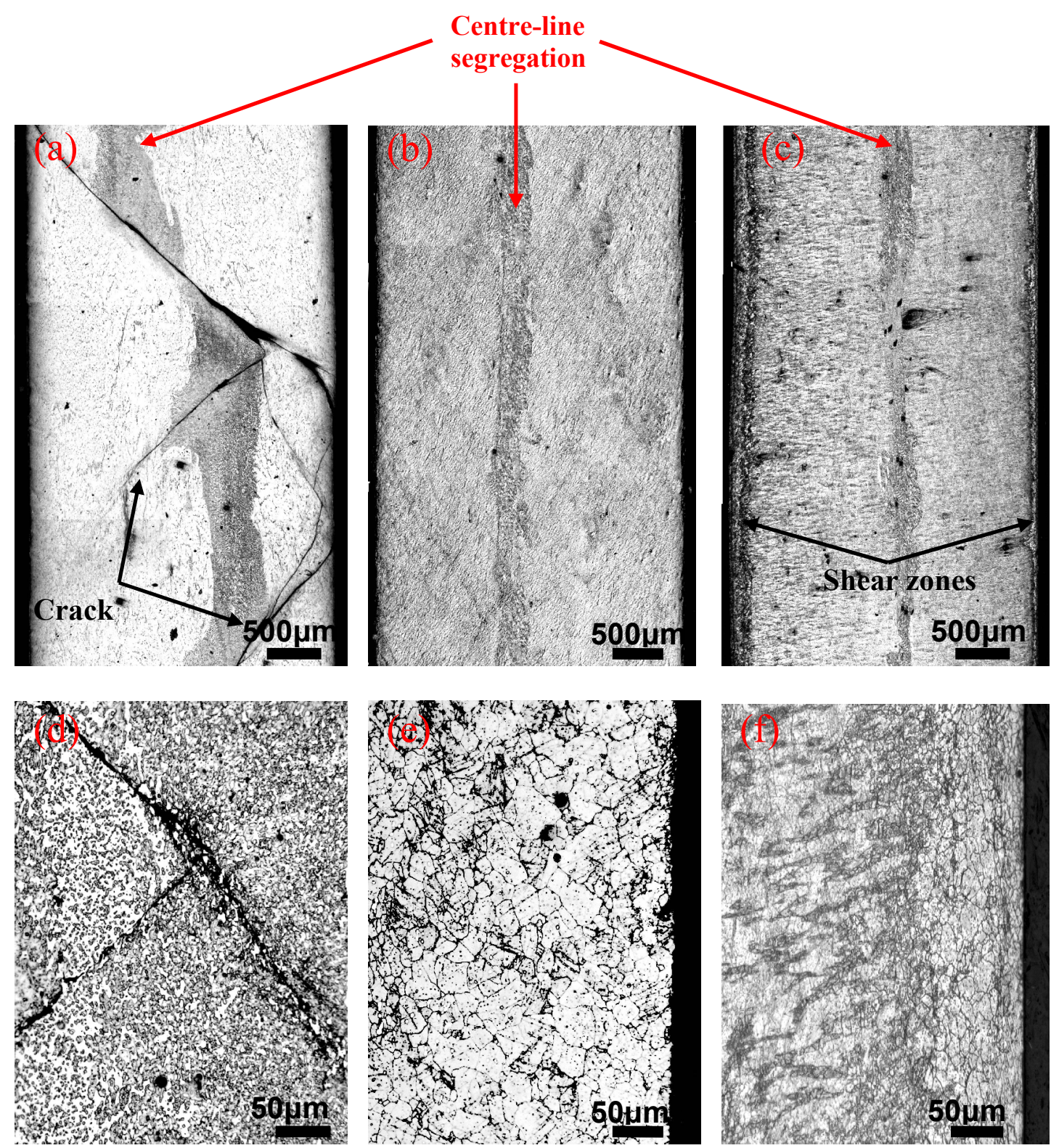

\section{Figure 5.9:}

Optical micrographs showing microstructures of longitudinal sections (LS) of final gauge sheet of TRC AZ91D alloy hot-rolled at $400^{\circ} \mathrm{C}$ for different rolling speeds (a and d) $63 \mathrm{~mm} \cdot \mathrm{s}^{-1}$., (b and e) $190 \mathrm{~mm} . \mathrm{s}^{-1}$ and (c and f) $314 \mathrm{~mm} \cdot \mathrm{s}^{-1}$. The medium rolling speed sample (i.e. $190 \mathrm{~mm} \cdot \mathrm{s}^{-1}$ ) is defect-free with an average grain size of $16 \mu \mathrm{m}$ while at a very low rolling speed some severe cracking at an angle of approximately 45 degree to the strip surface occurred. At a very high rolling speed, shear zones appears on the surface of the strip which indicates that the rolling force did not spread evenly throughout the strip during the hot-rolling process. All micrographs shown here were captured at the same magnification. 


\subsubsection{2. $\quad$ Effect of the hot rolling temperature}

AZ31 alloy: Figure 5.10 illustrates the microstructures of longitudinal sections (LS) of AZ31 alloy strip hot rolled at $400^{\circ} \mathrm{C}$ with a constant rolling speed of $190 \mathrm{~mm} . \mathrm{s}^{-1}$ produced by TRC (Figure 5.10 (a)-(d)) and MC-TRC (Figure 5.10 (e)-(h)) processes as a function of the rolling reduction percentage from the homogenized state up to $59 \%$ thickness reduction during the hot-rolling process. Figure 5.11 shows microstructures of longitudinal sections (LS) of AZ31 alloy strip hot rolled at $400^{\circ} \mathrm{C}$ with a constant rolling speed of $190 \mathrm{~mm} \cdot \mathrm{s}^{-1}$ (Figure 5.11 (a)-(d)) and $370^{\circ} \mathrm{C}$ (Figure 5.11 (e)-(h)) produced by TRC (Figure 5.11 (a), (b), (e) \& (f)) and MC-TRC (Figure 5.11 (c), (d), (e) \& (h)) processes. These micrographs show the effect of percentage rolling reduction and process development on microstructural evolution of AZ31 alloy sheet, after $73 \%$ reduction (Figure 5.11 (a), (c), (e) \& (g)) and after $73 \%$ reduction followed by annealing at $345^{\circ} \mathrm{C}$ for 2 hours (Figure 5.11 (b), (d), (f) \& (h)). Hot-rolling at $370^{\circ} \mathrm{C}$ (Figure 5.11 (e)-(h)) compared with hot-rolling at $400^{\circ} \mathrm{C}$ (Figure 5.11 (a)-(d)) results in the formation of more twins and shear bands at the micro level for both TRC and MC-TRC AZ31 hot-rolled sheets.

The microstructure of as-rolled MC-TRC sheet was comprised of fine and uniform recrystallized grains up to the end of thickness reduction. Whilst the as-rolled conventional TRC sheet had an extremely non-uniform microstructure with fine recrystallized grains surrounded by un-recrystallized large elongated grains. In addition TRC rolled-sheet showed some wide shear bands and obvious cracks and voids. 


\section{AZ31 hot-rolled at $400^{\circ} \mathrm{C}$}
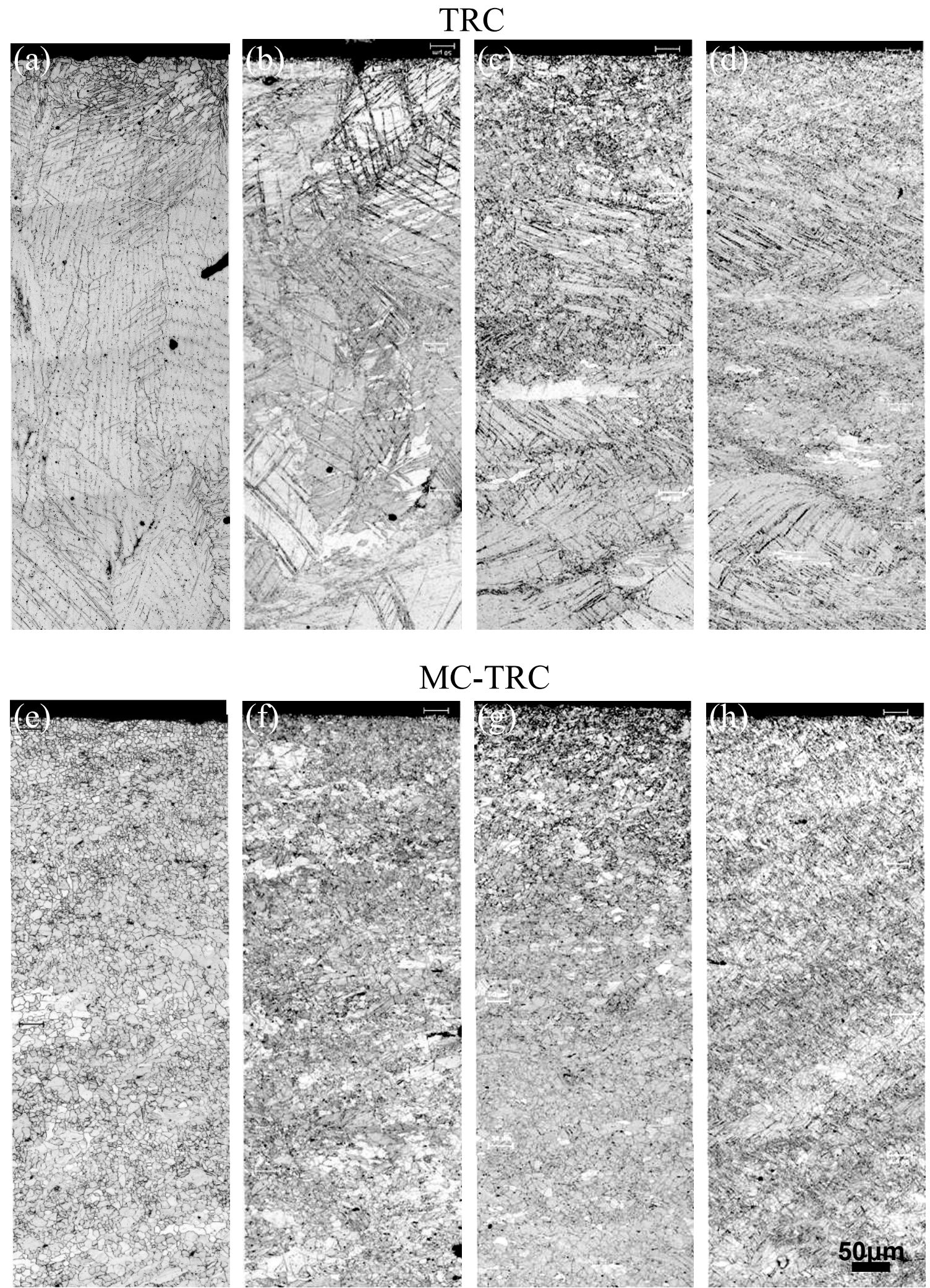

\section{MC-TRC}
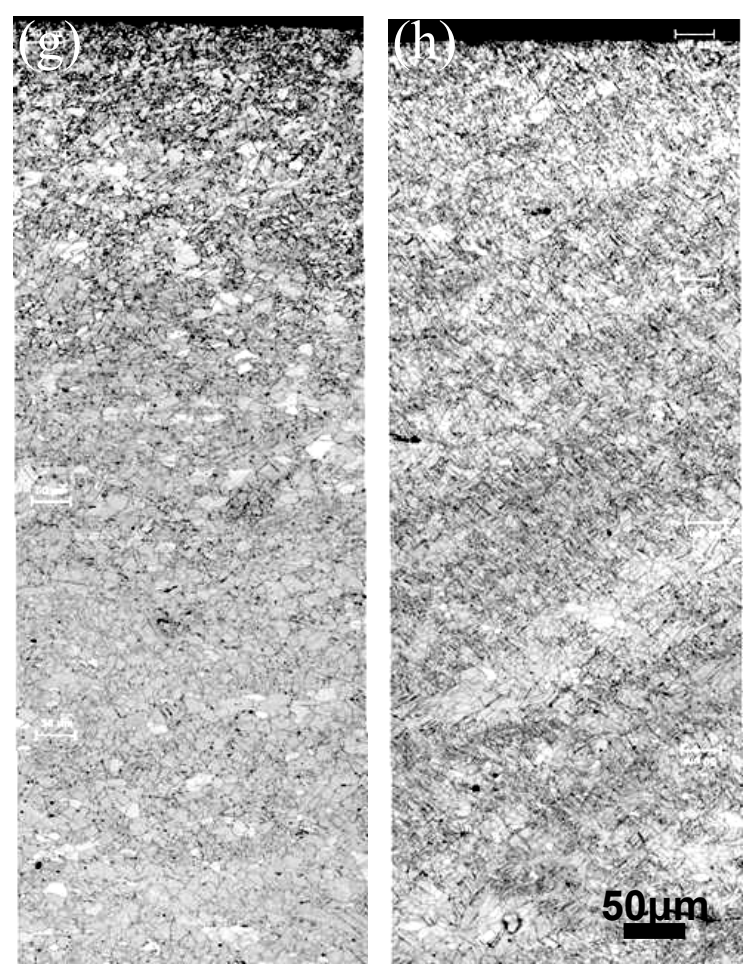

\section{Figure 5.10:}

Optical micrographs showing microstructures of longitudinal sections (LS) of AZ31 alloy strip hot rolled at $400^{\circ} \mathrm{C}$ with a constant rolling speed of $190 \mathrm{~mm} \cdot \mathrm{s}^{-1}$ produced by (a-d) TRC and (e-h) MC-TRC processes. These micrographs show the effect of percentage rolling reduction and process development on microstructural evolution of AZ31 alloy sheet, (a and e) $0 \%$, (b and f) 24\%, (c and g) 41\% and (d and h) $59 \%$. All micrographs shown here were captured at the same magnification. 


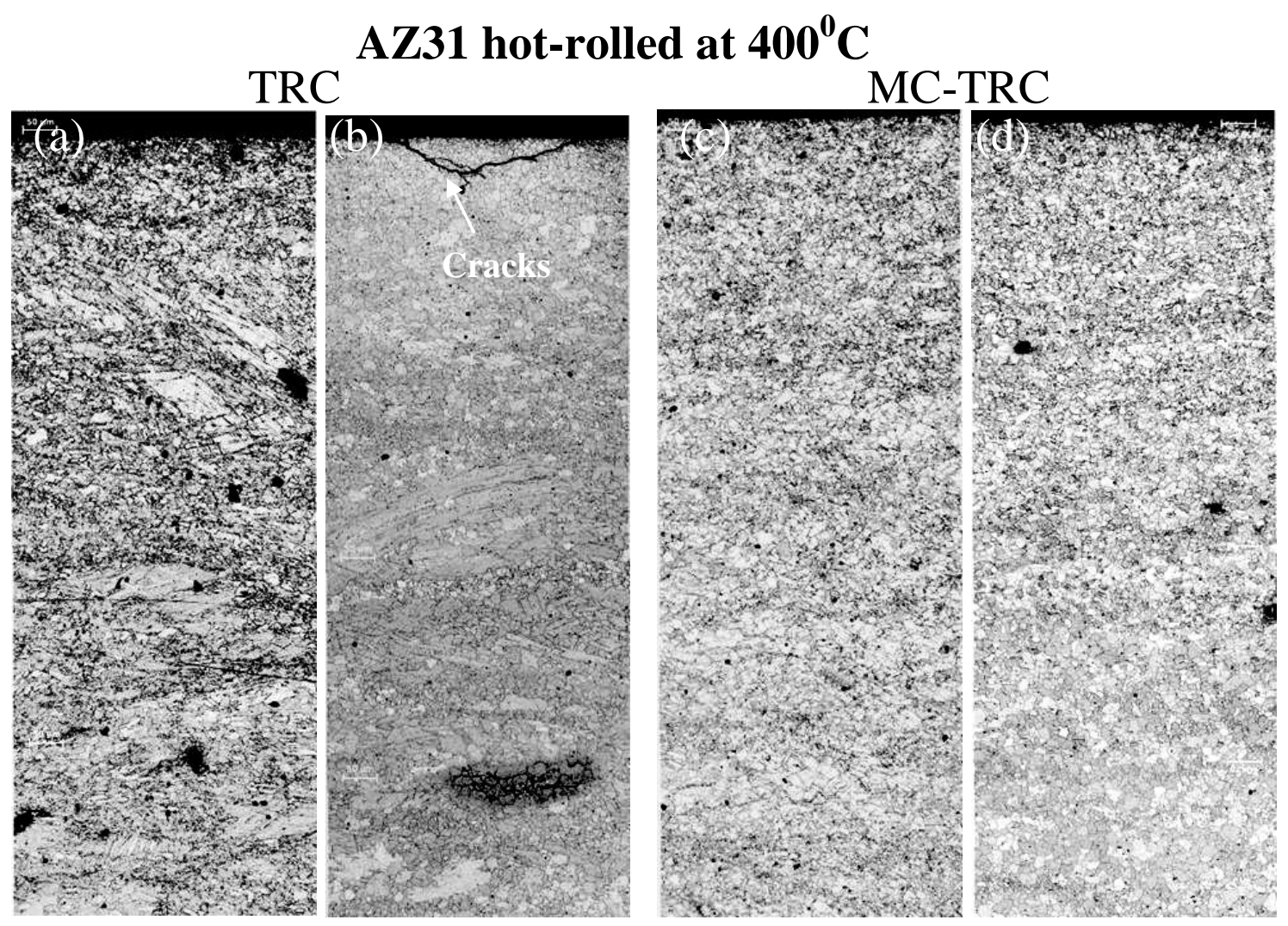

\section{TRC \\ AZ31 hot-rolled at $370^{\circ} \mathrm{C}$}
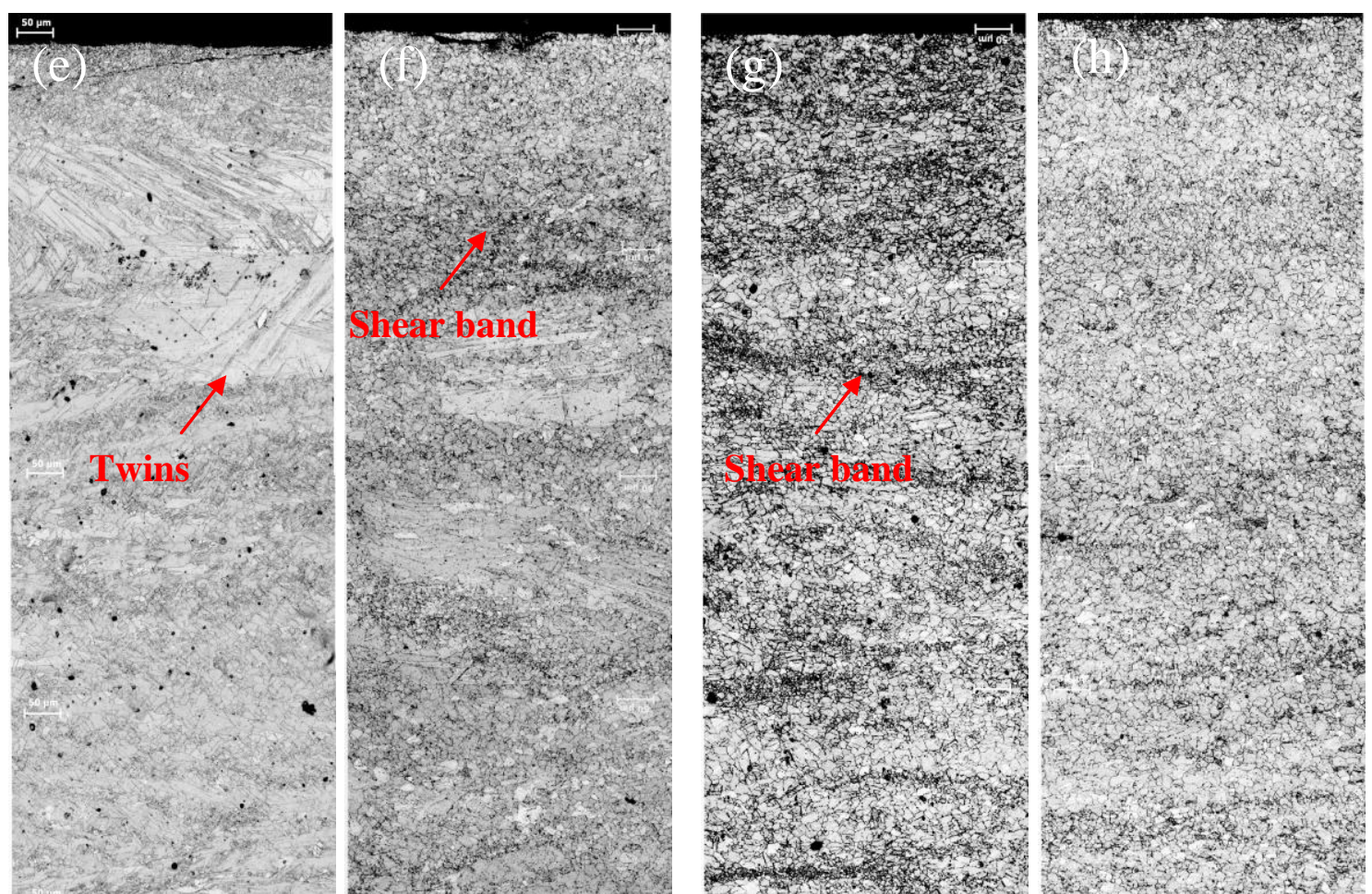

\section{Figure 5.11:}

Optical micrographs showing microstructure of longitudinal sections (LS) of AZ31 alloy strip hot rolled at $400^{\circ} \mathrm{C}(\mathrm{a}-\mathrm{d})$ and $370^{\circ} \mathrm{C}(\mathrm{e}-\mathrm{h})$ produced by TRC (a, b, e and f) and MC-TRC (c, d, e and h) processes. These micrographs show the effect of percentage rolling reduction and process development on microstructural evolution of AZ31 alloy sheet, (a, c, e and g) 73\% and (b, d, f and h) $73 \%$ after annealing at $345^{\circ} \mathrm{C}$ for 2 hours. All micrographs shown here were captured at the same magnification. 
The quantitative analysis, shown in Figure 5.12 (a)-(b) and Figure 5.13 (a)-(b), verifies these findings that the average recrystallized grain size in hot-rolled MC-TRC strip is uniform and relatively insensitive to the rolling reduction which reduces from $12.76 \mu \mathrm{m}$ at $24 \%$ reduction to $8.4 \mu \mathrm{m}$ at $73 \%$ reduction. By contrast, the average recrystallized grain size in hot-rolled TRC strip is non-uniform and strongly dependant upon the amount of deformation applied which reduces from $313.2 \mu \mathrm{m}$ to $32.1 \mu \mathrm{m}$ during the hot-rolling procedure. In addition, the area fraction of fine grains $(\leq 10-15 \mu \mathrm{m})$ in MC-TRC rolled sheet is much higher than in the TRC rolled sheet which confirms the uniformity in grain size variation of MC-TRC rolled sheet.

(a)

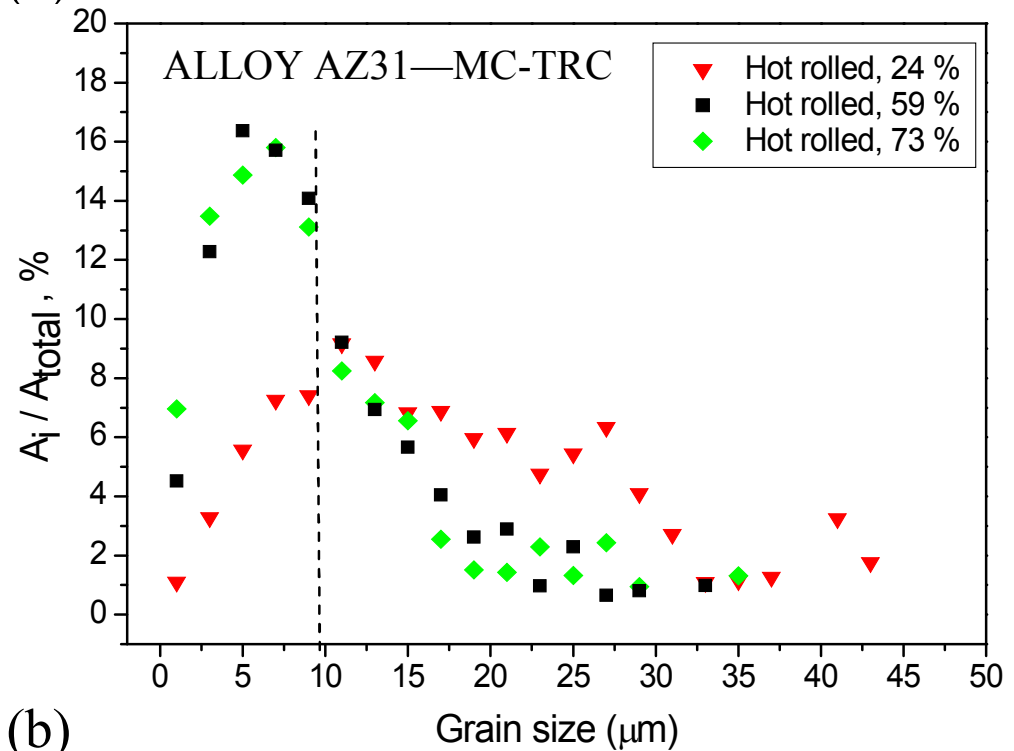

Figure 5.12:

The size distribution of the recrystallized grains of AZ31 alloy strip after different percentages of hot rolling reduction at $400^{\circ} \mathrm{C}$ (a and b), showing (a) refined grain size and narrow size distribution by melt shearing in the MC-TRC, compared with, (b) wide size distribution of coarse grains in the strip produced by conventional TRC process. 

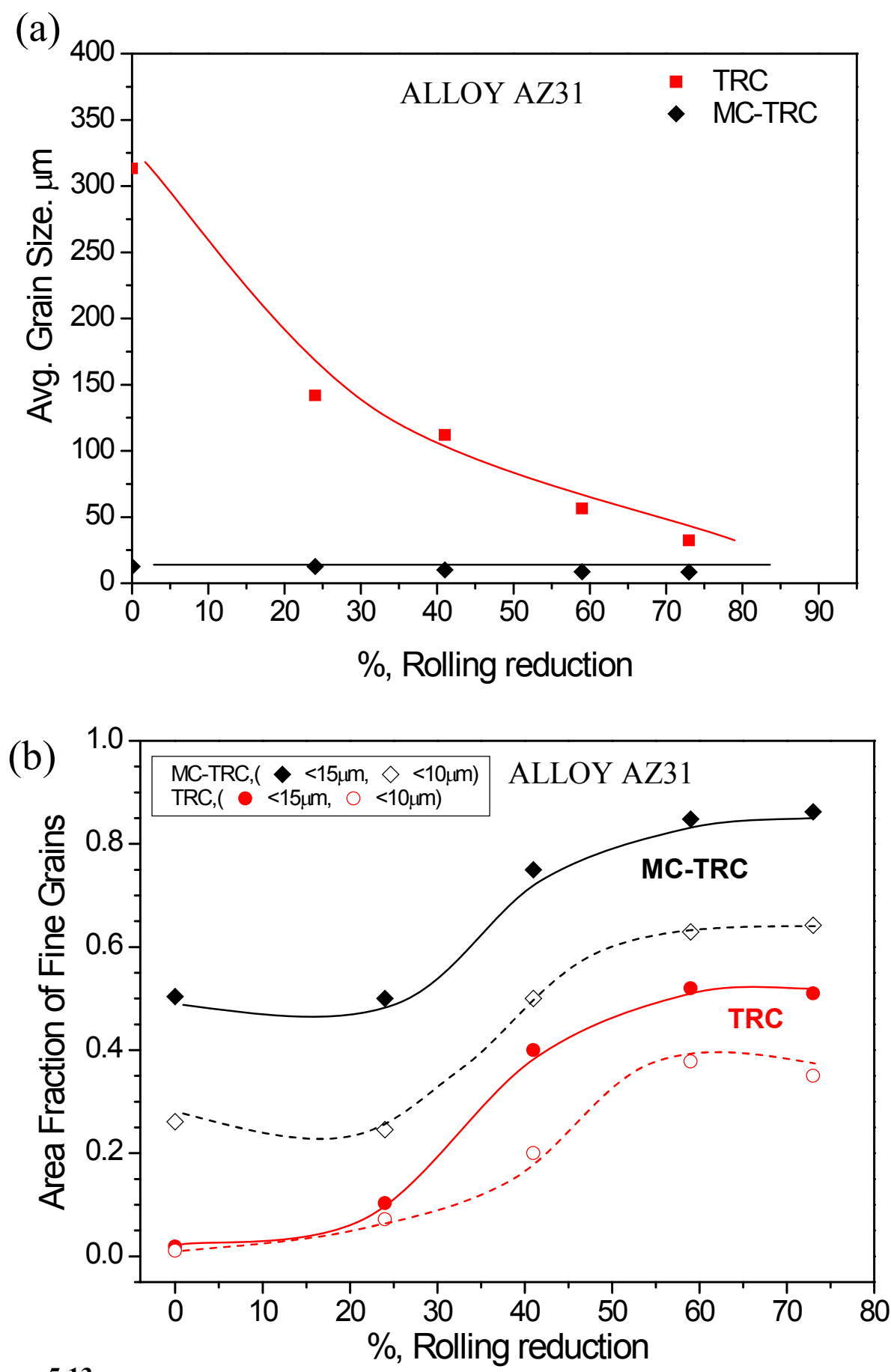

Figure 5.13:

(a) The effect of rolling reduction on the average grain size of AZ31 strip produced by TRC and MC-TRC processes and, (b) the effect of rolling reduction on the area fraction of fine grains (i.e. $<10 \mu \mathrm{m}$ and $<15 \mu \mathrm{m}$ ) of strips produced by TRC and MC-TRC processes, showing a refined grain size and higher area fraction of fine grains in the strip produced by melt shearing in the MC-TRC. It also shows uniformity of recrystallized grain size in the range of $10 \mu \mathrm{m}-15 \mu \mathrm{m}$ from the start of hot-rolling process for MC-TRC strip compared with initial non-uniform grain size of TRC strip.

The quantitative microstructural analysis of Figure 5.11 is given in Figure 5.14. By increasing the hot rolling temperature from $370^{\circ} \mathrm{C}$ to $400^{\circ} \mathrm{C}$ non-uniformity of recrystallized grains decreases and a narrower fine grain size distribution $(<10 \mu \mathrm{m})$ can be 
achieved. In addition, it can be seen from the above analysis that after annealing at $345^{\circ} \mathrm{C}$ for 2 hours for all processing conditions, the peaks of the graphs shifted to the right side which means that the grain size slightly increases after annealing compared with nonannealed hot-rolled sheets, for example the average grain size of MC-TRC AZ31 final gauge sheet hot rolled at $370^{\circ} \mathrm{C}$ and $400^{\circ} \mathrm{C}$ increases after annealing at $345^{\circ} \mathrm{C}$ for 2 hours from $8.4 \mu \mathrm{m}$ to $9.5 \mu \mathrm{m}$ and from $8.7 \mu \mathrm{m}$ to $10 \mu \mathrm{m}$, respectively.

(a) ALLOY AZ31-TRC, $370^{\circ} \mathrm{C}$

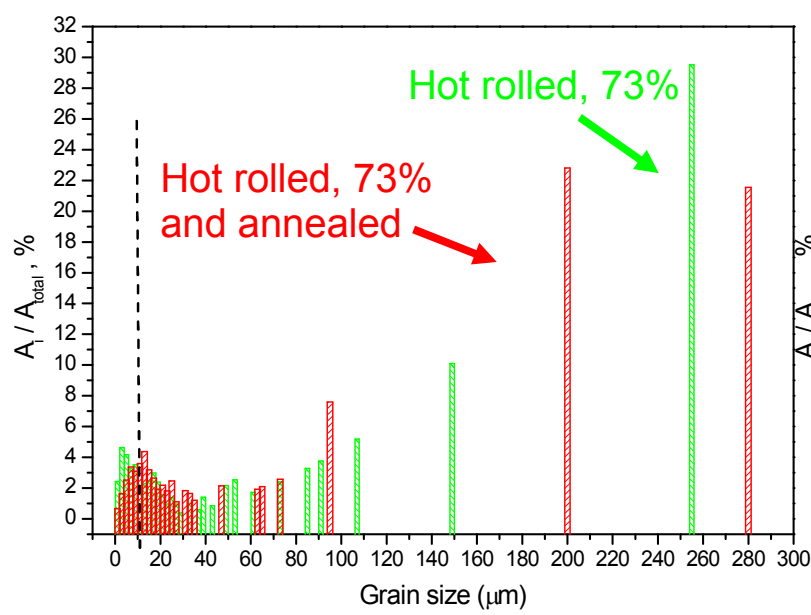

(b) ALLOY AZ31-TRC, $400^{\circ} \mathrm{C}$

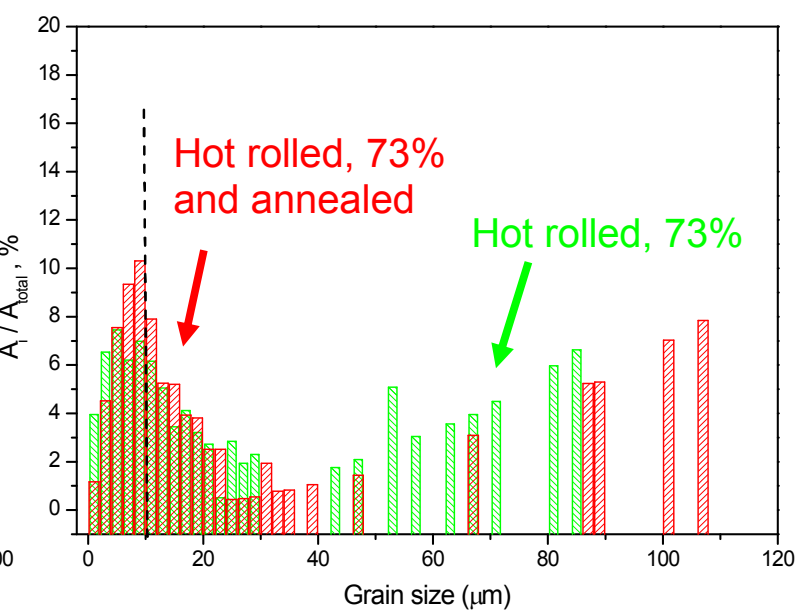

(c) ALLOY AZ31-MCTRC, $370^{\circ} \mathrm{C}$

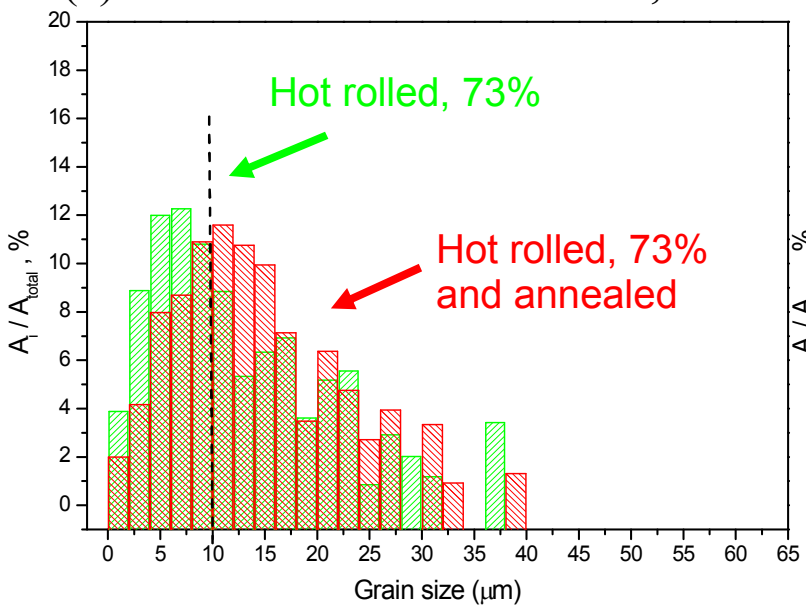

(d) ALLOY AZ31-MCTRC, $400^{\circ} \mathrm{C}$

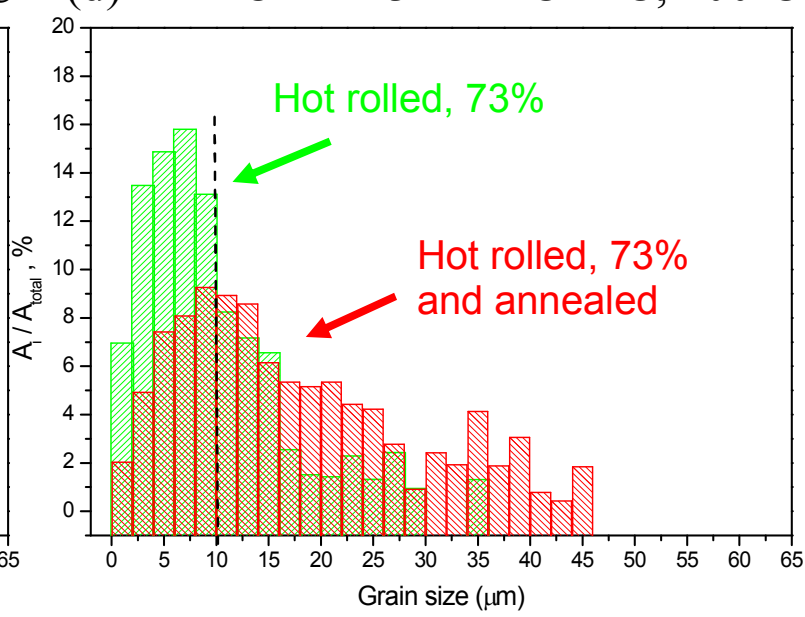

Figure 5.14:

The size distribution of the recrystallized grains of $\mathrm{AZ31}$ alloy strip after $73 \%$ hot rolling reduction at $370^{\circ} \mathrm{C}$ (a and c) and $400^{\circ} \mathrm{C}(\mathrm{b}$ and $\mathrm{d}$ ) produced by TRC (a and b) and MC-TRC (c and d) processes, followed by annealing at $345^{\circ} \mathrm{C}$ for 2 hours, showing a refined grain size and narrow size distribution by melt shearing in the MC-TRC samples, compared with, a wide size distribution of coarse grains in the strip produced by the conventional TRC process. In addition, a more refined and more homogenous recrystallized grain size can be achieved by hot-rolling at $400^{\circ} \mathrm{C}$ compared with hot-rolling at $370^{\circ} \mathrm{C}$. 
Figure 5.15 shows the general microstructure of AZ31 sheet hot-rolled at $400^{\circ} \mathrm{C}$ to a thickness reduction of $24 \%$ (Figure 5.15 (a) \& (b)), 73\% (Figure 5.15 (c) \& (d)) and then annealed at $345^{\circ} \mathrm{C}$ for 2 hours (Figure 5.15 (e) \& (f)), produced by MC-TRC, and TRC processes. These figures show extensive twinning in the $24 \%$ thickness reduction of the TRC sample (Figure 5.15 (b)), although there is nothing in the MC-TRC sample (Figure 5.15 (a)). After annealing, twins in the MC-TRC sample which were formed due to the severe plastic deformation during the rolling process (Figure 5.15 (c)) were mostly removed (Figure 5.15 (e)), while a few of the twins in the TRC sample (Figure 5.15 (d)) remained within the elongated columnar grains (Figure 5.15 (f)). Based on these findings, it can be concluded that the strip produced by MC-TRC process is much more uniform with less defects and twins compared with the TRC sample.

Optical micrographs of morphological changes for crack formation in a conventional AZ31 alloy strip produced by the TRC process are shown in Figure 5.16. This morphological evolution commences from the casting stage (Figure 5.16 (a)), which included large voids along grain boundaries and severe twinning within the elongated columnar grains. The next stage is homogenization at $400^{\circ} \mathrm{C}$ for 60 minutes which can enlarge the size of the as-casted voids due to grain growth and clustering of small voids at high temperature (Figure 5.16 (b)). The last stage is the hot-rolling process in which applying severe shear deformation would change the morphology of voids into cracks with an approximately 45 degree to the rolling direction (Figure 5.16 (c)). The schematic diagram of the crack formation mechanism in TRC AZ31 hot-rolled sheet is shown in Figure 5.16 (d). 

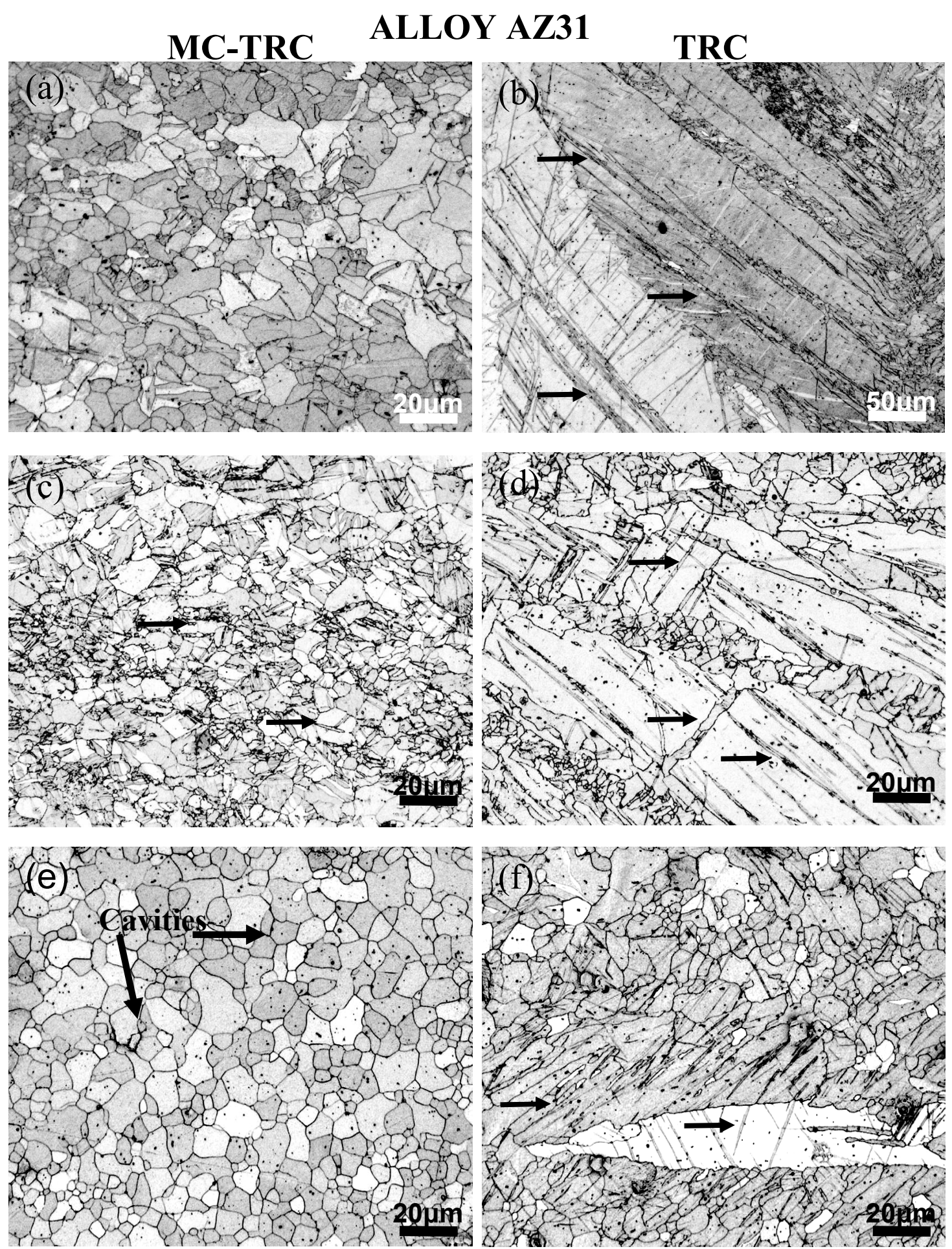

\section{Figure 5.15:}

Micrographs of AZ31 hot-rolled at $400^{\circ} \mathrm{C}$ to a thickness reduction of $24 \%$ (a and b), $73 \%$ (c and d) and then annealed at $345^{\circ} \mathrm{C}$ for 2 hours (e and f), produced by MC-TRC (a, c and e), and TRC (b, d and f) processes. These figures show extensive twinning in the $24 \%$ thickness reduction of TRC sample (b), although there is nothing in the MC-TRC sample (a). Also most of the twins formed in higher thickness reduction in MC-TRC and TRC samples (c and d), still remain after annealing in the TRC sample (f) while there is no severe twinning in the MC-TRC sample (e). The effect of melt conditioning (MC-TRC) on uniformity and distribution of grain sizes are clearly visible. The arrows are indicative of the twin formation due to plastic deformation. 


\section{ALLOY AZ31-TRC}

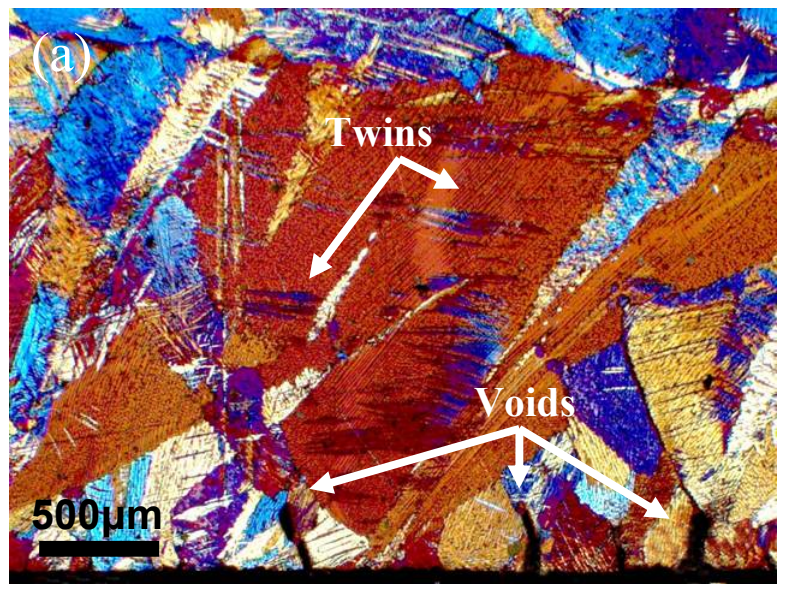

(d)
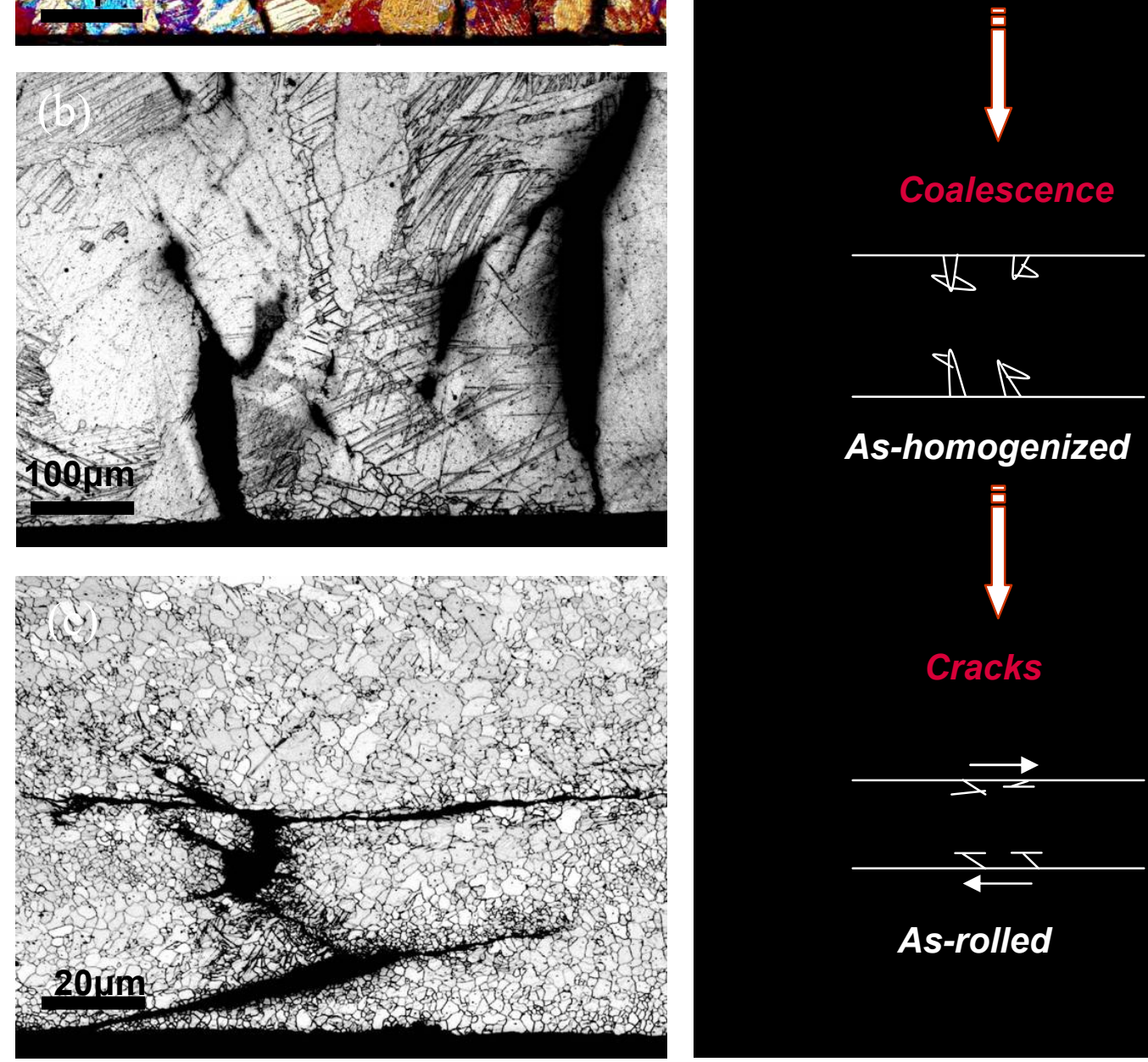

\section{As-homogenized}

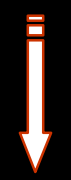

Cracks

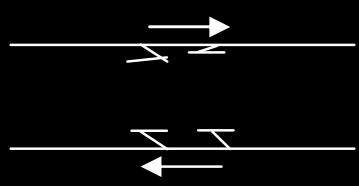

As-rolled

Figure 5.16:

Optical micrographs showing (a) voids and severe twins formed near the surface of a conventional TRC AZ31 alloy strip, (b) void enlargement due to clustering of small voids along grain boundaries in TRC strip after the homogenization process at $400^{\circ} \mathrm{C}$ for 60 minutes, (c) cracks formation with an approximately 45 degree to the rolling direction after severe shear deformation applied by the hot-rolling procedure at $400^{\circ} \mathrm{C}$. The schematic diagram (d) illustrates a mechanism of crack formation in hot-rolled TRC AZ31 alloy which comes from the twin-induced voids in the as-cast TRC strip. 
AZ91D alloy: Figure 5.17 illustrates the microstructures of longitudinal sections (LS) of hot rolled AZ91D alloy strip at $400^{\circ} \mathrm{C}$ with a constant rolling speed of $190 \mathrm{~mm} . \mathrm{s}^{-1}$ produced by TRC (Figure 5.17 (a)-(d)) and MC-TRC (Figure 5.17 (e)-(h)) processes as a function of the percentage rolling reduction from the homogenized state up to $59 \%$ thickness reduction during the hot-rolling process. Figure $\mathbf{5 . 1 8}$ shows the microstructures of longitudinal sections (LS) of final gauge (i.e. 73\% thickness reduction) AZ91D alloy strip hot-rolled at $400^{\circ} \mathrm{C}$ with a constant rolling speed of $190 \mathrm{~mm} . \mathrm{s}^{-1}$ before (Figure 5.18 (a) \& (c)) and after annealing at $345^{\circ} \mathrm{C}$ for 2 hours (Figure 5.18 (b) \& (d)) produced by TRC and MC-TRC processes.

The quantitative analysis, as shown in Figure 5.19, verifies that the MC-TRC AZ91D final gauge hot rolled sheet contains a more uniform recrystallized grain size distribution compared with TRC AZ91D final gauge rolled sheet but the average grain size of the final products for both types of the manufacturing processes (i.e. TRC and MC-TRC processes) are very close to each other (i.e. $13.4 \mu \mathrm{m}$ for MC-TRC vs. $14.2 \mu \mathrm{m}$ for TRC). These results for AZ91D TRC and MC-TRC hot rolled sheets are in absolute contrast with the results obtained for AZ31 TRC and MC-TRC hot-rolled sheets, shown previously, (see Figure $5.10 \& 5.11$ ). The microstructural difference between TRC and MC-TRC final gauge hot-rolled sheets for the AZ31 alloy are more distinguishable compared with TRC and MC-TRC final gauge hot-rolled sheets for the AZ91D alloy. These differences come from the as-cast microstructure of these alloys which were explained thoroughly in Section 4.3.1 \& 4.3.2. 


\section{AZ91D hot-rolled at $400^{\circ} \mathrm{C}$}

\section{TRC}
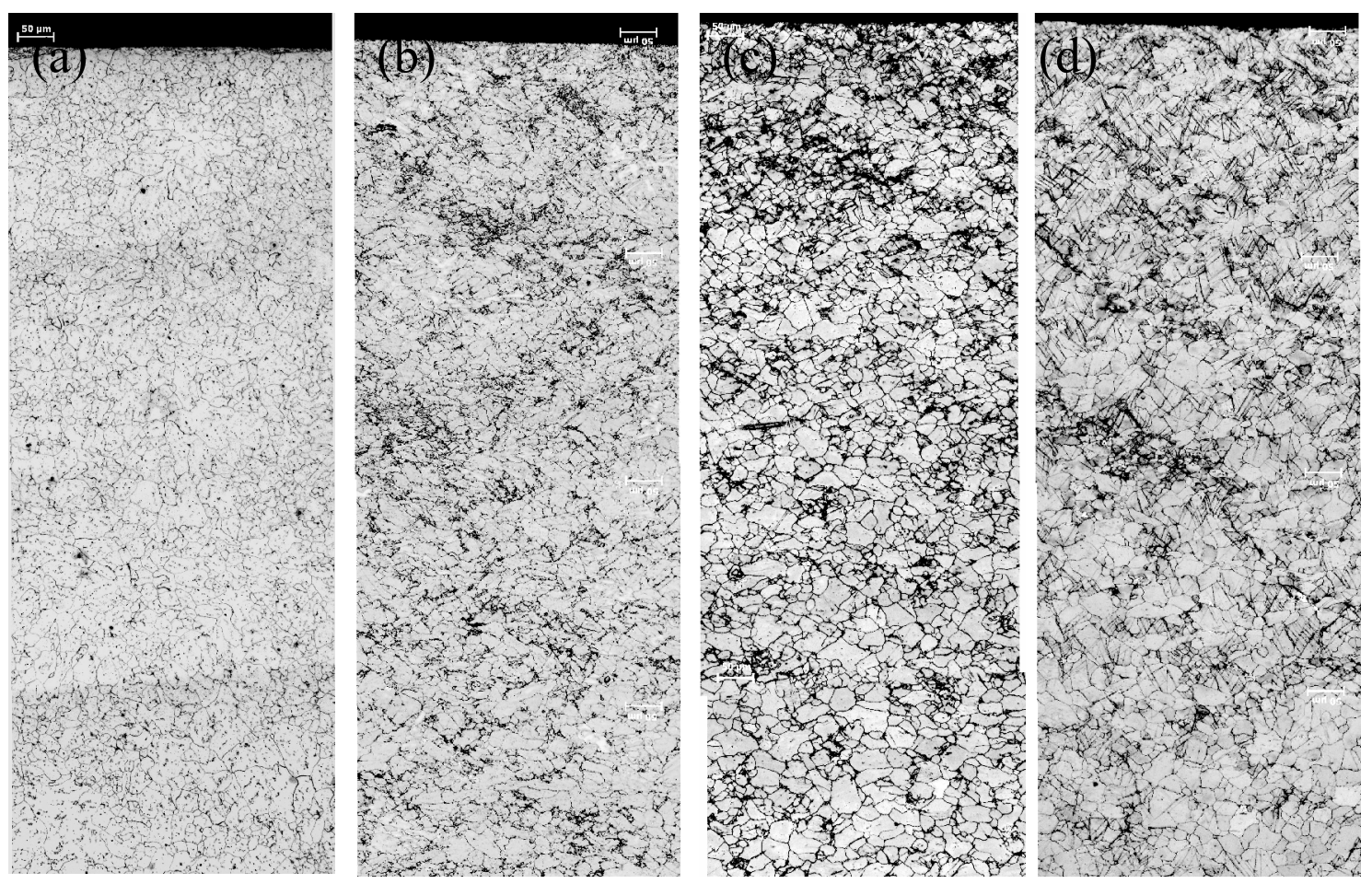

\section{MC-TRC}
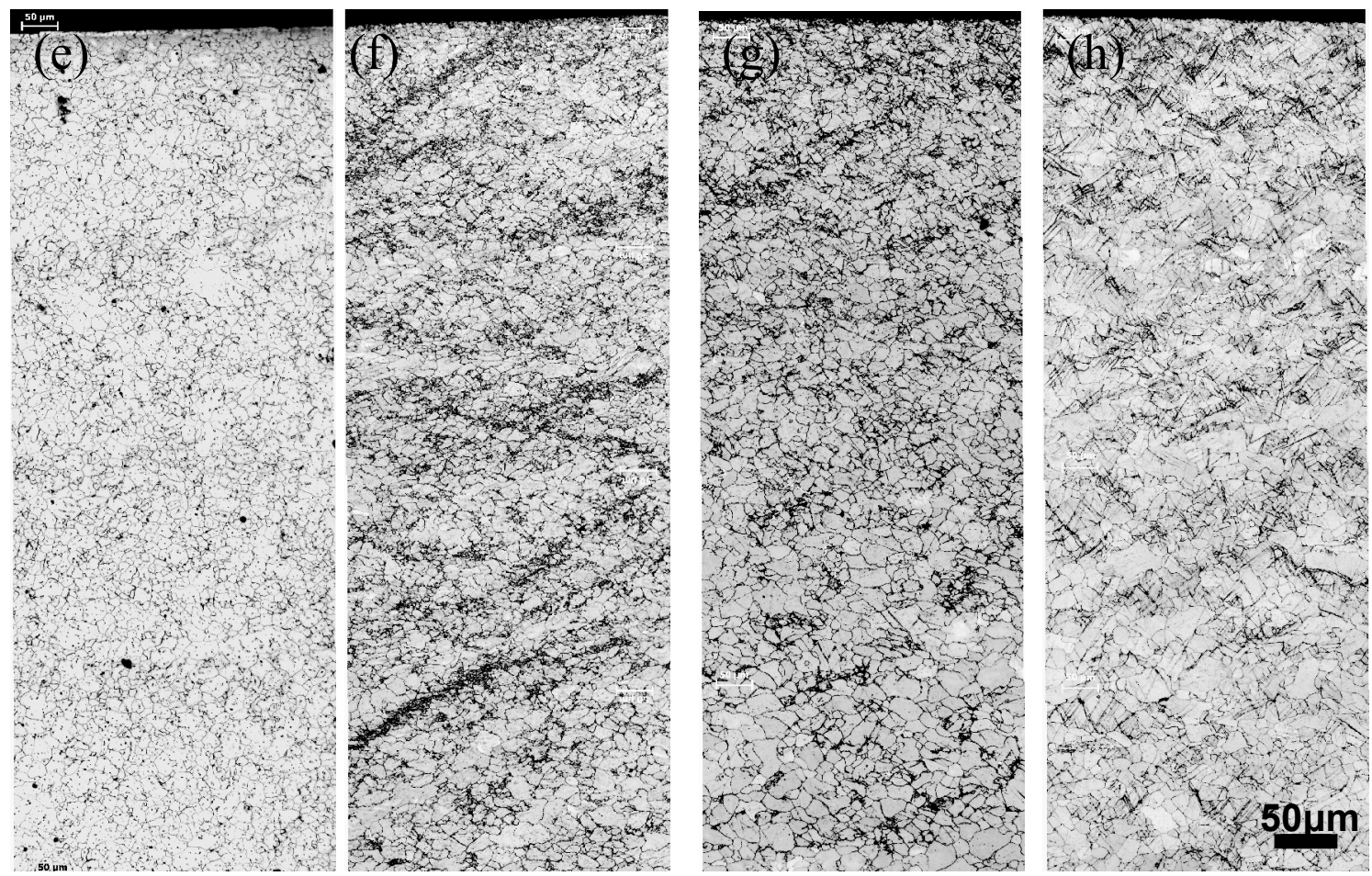

\section{Figure 5.17:}

Optical micrographs showing microstructures of longitudinal sections (LS) of hot rolled AZ91D alloy at $400^{\circ} \mathrm{C}$ with a constant rolling speed of $190 \mathrm{~mm} \cdot \mathrm{s}^{-1}$ produced by (a-d) TRC and (e-h) MC-TRC processes. These micrographs show the effect of percentage rolling reduction and process development on the microstructural evolution of AZ91D alloy sheet, (a and e) $0 \%$, (b and f) 24\%, (c and g) $41 \%$ and (d and h) $59 \%$. All micrographs shown here were captured at the same magnification. 


\section{AZ91D hot-rolled at $400^{\circ} \mathrm{C}$}

TRC

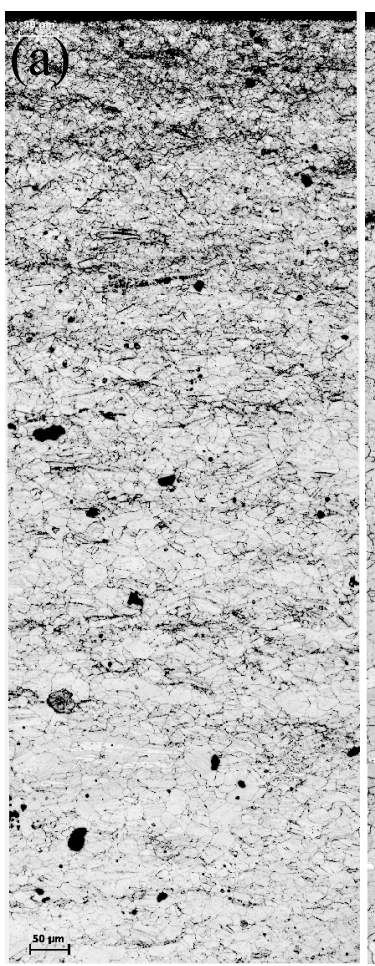

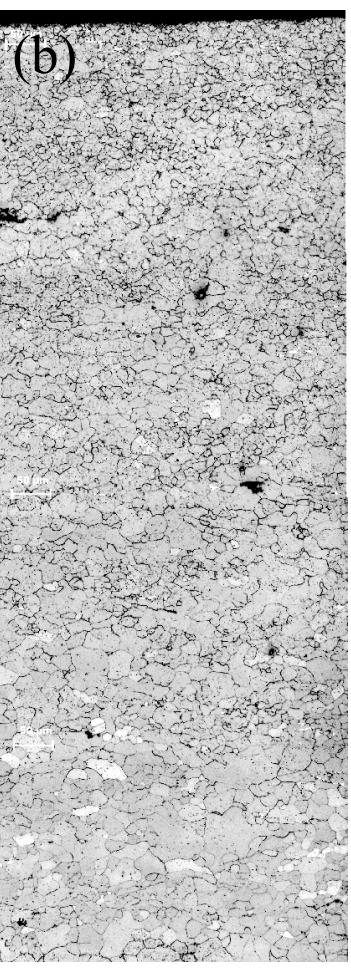

MC-TRC

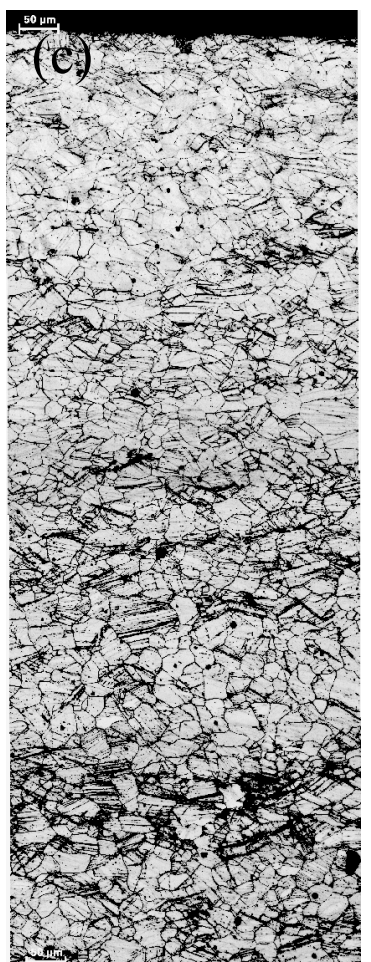

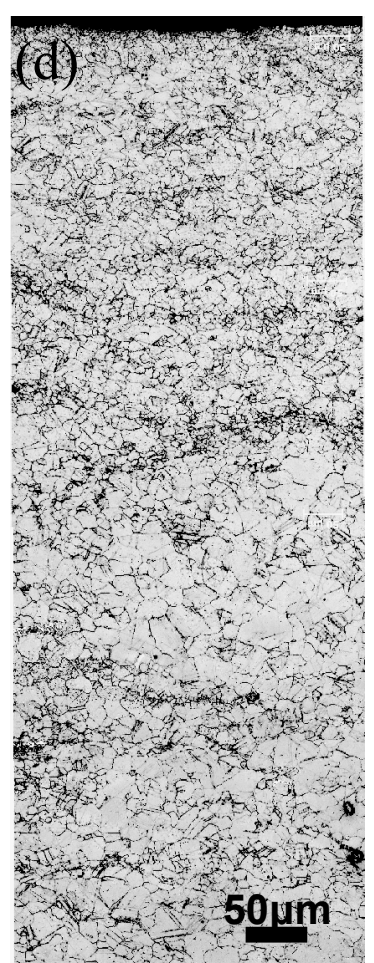

\section{Figure 5.18:}

Optical micrographs showing microstructures of longitudinal sections (LS) of hot rolled AZ91D alloy at $400^{\circ} \mathrm{C}$ with a constant rolling speed of $190 \mathrm{~mm} \cdot \mathrm{s}^{-1}$ produced by TRC (a and b) and MC-TRC ( $\mathrm{c}$ and d) processes. These micrographs show the effect of percentage rolling reduction and process development on microstructural evolution of AZ91D alloy sheet, (a and c) 73\% and (b and d) 73\% after annealing at $345^{\circ} \mathrm{C}$ for 2 hours. All micrographs shown here were captured at the same magnification.

(a)

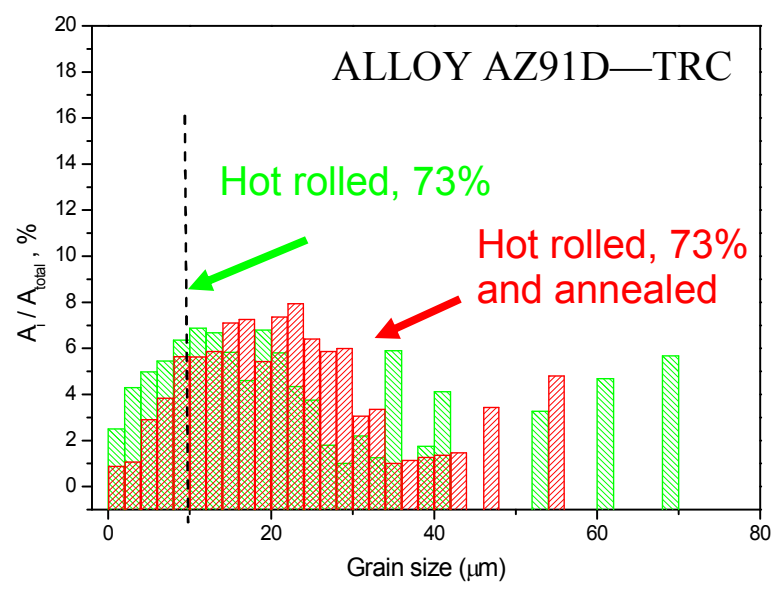

(b)

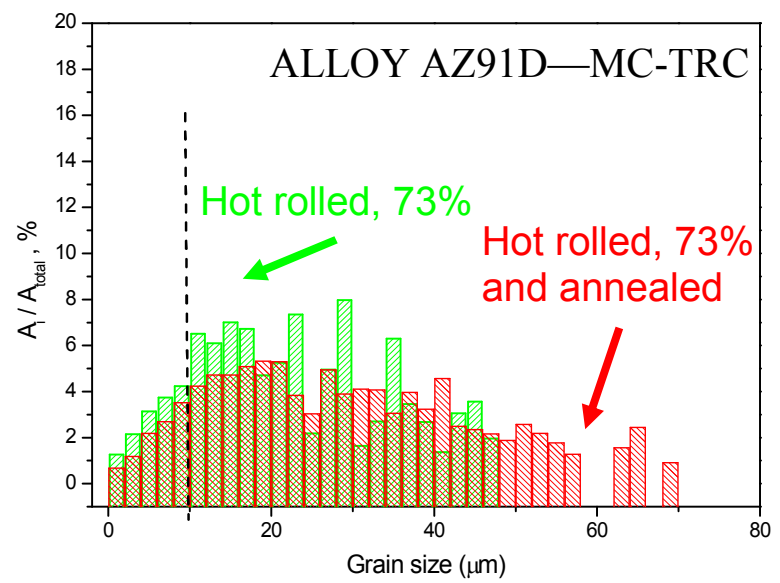

Figure 5.19:

The size distribution of the recrystallized grains of AZ91D alloy strip after 73\% hot rolling reduction at $400^{\circ} \mathrm{C}$ produced by TRC (a) and MC-TRC (b) processes, followed by annealing at $345^{\circ} \mathrm{C}$ for 2 hours, showing a refined grain size and narrow size distribution for both types of hotrolled sheets produced by MC-TRC and TRC processes. The MC-TRC hot-rolled sheet illustrates a more uniform and better grain size distribution after annealing compared with annealed TRC hot-rolled sheet. 


\subsubsection{Mechanical properties of TRC and MC-TRC Mg-alloys during down-stream processing}

\subsubsection{Macro-hardness tests}

In order to investigate the effect of the TRC and novel MC-TRC strip casting processes on the rollability of the final gauge hot-rolled sheets, macro-hardness tests were carried out. The measurements were performed on the surface of the strips in the as-cast state then after homogenization and also during the hot-rolling process and after an annealing treatment on both TRC and MC-TRC AZ31 strips and sheets.

Figure 5.20 shows the work hardening curves of AZ31 strips produced by TRC and MC-TRC processes during the hot-rolling procedure. The hardness value for the as-cast state of MC-TRC strip is higher than for the TRC strip. Also, as the rolling reduction increases, the hardness rises in both types of the strips with a higher increasing rate in the TRC sample than for the MC-TRC sample. This means that the rollability of MC-TRC strip is superior to TRC strip. The homogenized as-cast TRC and MC-TRC strips show hardness values of 53.8 and 60.9 Vickers, while the macro-hardness values of the $73 \%$ hot-rolled TRC and MC-TRC sheets increase to 71.9 and 73.4 Vickers and then after annealing at $345^{\circ} \mathrm{C}$ for 2 hours reduce to 62.3 and 60.7 Vickers, respectively. This graph also shows that the macro-hardness values of TRC and MC-TRC as-cast strips correspond to $8 \%$ and $69 \%$ reduction in area by the hot rolling process, which verifies homogenous and fine grain size in as-cast MC-TRC strip compared with as-cast TRC strip. 


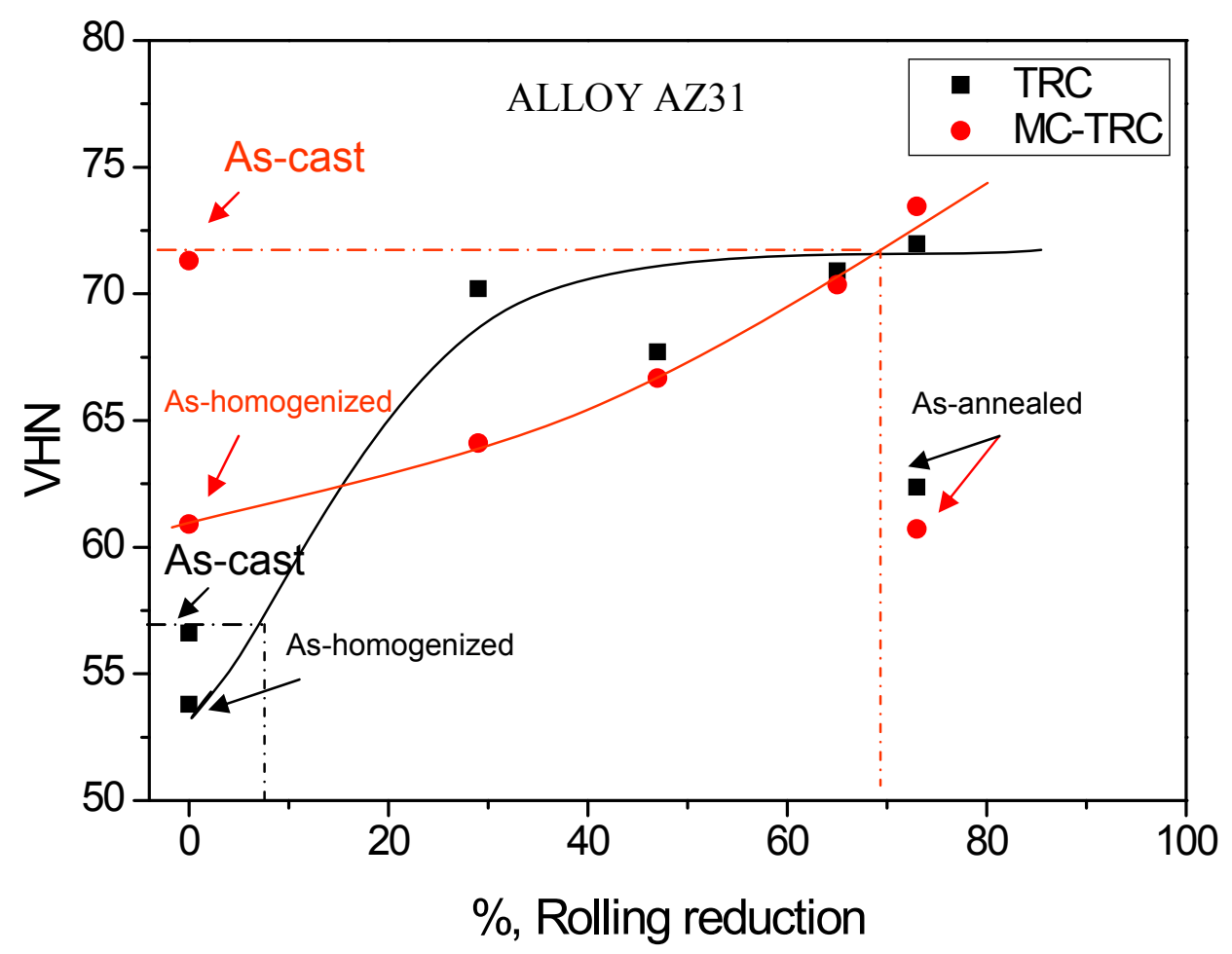

\section{Figure 5.20:}

Macrohardness-value (Vickers hardness) variations of AZ31 strips produced by TRC and MC-TRC processes as a function of percentage rolling reduction, which shows the better rollability and a lower yield strength of the melt conditioned strip compared with conventional twin roll casted strip.

\subsubsection{Tensile properties}

\section{(a) At Room Temperature}

Table 5.1 and 5.2 give the mechanical properties of the AZ31 and AZ91D alloys strips produced by TRC and MC-TRC processes under as-cast and hot-rolled conditions at room temperature. In the as-cast and hot-rolled conditions at room temperature, the MC-TRC process improves the uniform elongation and elongation-to-failure substantially compared with the TRC process. In addition, the MC-TRC process improves the yield strength (YS) and ultimate tensile strength (UTS) for the as-cast AZ31 and AZ91D compared with the TRC process. The results show that the TRC AZ31 hot- 
rolled at $370^{\circ} \mathrm{C}$ has superior mechanical properties compared with TRC AZ31 hot-rolled at $400^{\circ} \mathrm{C}$.

Table 5.1:

Mechanical properties of AZ31 alloy strip produced by TRC and MC-TRC processes tested under different conditions.

\begin{tabular}{|c|c|c|c|c|c|c|}
\hline $\begin{array}{c}\text { Conditions } \\
\text { AZ31 }\end{array}$ & $\begin{array}{l}\text { Tensile test } \\
\text { conditions }\end{array}$ & Process & $\begin{array}{c}\text { Yield } \\
\text { Stress } \\
(\mathrm{MPa}) \\
\end{array}$ & $\begin{array}{c}U T S \\
(M P a)\end{array}$ & $\begin{array}{c}\text { Uniform } \\
\text { Elongation } \\
\text { (\%) }\end{array}$ & $\begin{array}{c}\text { Elongation- } \\
\text { to-failure } \\
(\%)\end{array}$ \\
\hline As-cast & $\mathrm{RT}^{*}$ & $\begin{array}{c}\text { TRC } \\
\text { MC-TRC }\end{array}$ & $\begin{array}{c}163 \pm 26.6 \\
196 \pm 3\end{array}$ & $\begin{array}{c}184 \pm 30.5 \\
254 \pm 5.5\end{array}$ & --- & $\begin{array}{c}1 \pm 0.3 \\
5.4 \pm 0.78\end{array}$ \\
\hline $\begin{array}{l}\text { Hot-rolled at } \\
\qquad 370^{\circ} \mathrm{C}\end{array}$ & $\mathrm{RT}$ & $\begin{array}{c}\text { TRC } \\
\text { MC-TRC }\end{array}$ & $\begin{array}{l}173.5 \pm 1.0 \\
166.6 \pm 4.6\end{array}$ & $\begin{array}{l}241.6 \pm 2.0 \\
234.9 \pm 4.7\end{array}$ & $\begin{array}{c}8.5 \pm 0.67 \\
13.7 \pm 0.14\end{array}$ & $\begin{array}{l}12.4 \pm 0.8 \\
28.4 \pm 0.7\end{array}$ \\
\hline $\begin{array}{l}\text { Hot-rolled } \\
\text { at } 400^{\circ} \mathrm{C}\end{array}$ & RT & $\begin{array}{c}\text { TRC } \\
\text { MC-TRC }\end{array}$ & $\begin{array}{l}181.6 \pm 1.9 \\
177.7 \pm 3.3\end{array}$ & $\begin{array}{l}243.1 \pm 2.7 \\
251.1 \pm 2.1\end{array}$ & $\begin{array}{c}6.1 \pm 0.45 \\
14.6 \pm 0.27\end{array}$ & $\begin{array}{c}9.6 \pm 0.7 \\
27.7 \pm 2.1\end{array}$ \\
\hline
\end{tabular}

* RT means Room Temperature

Table 5.2:

Mechanical properties of AZ91D alloy strip produced by TRC and MC-TRC processes tested under different conditions.

\begin{tabular}{ccccccc}
\hline $\begin{array}{c}\text { Conditions } \\
\text { AZ91D }\end{array}$ & $\begin{array}{c}\text { Tensile test } \\
\text { conditions }\end{array}$ & Process & $\begin{array}{c}\text { Yield } \\
\text { Stress } \\
(\mathbf{M P a})\end{array}$ & $\begin{array}{c}\text { UTS } \\
(\mathbf{M P a})\end{array}$ & $\begin{array}{c}\text { Uniform } \\
\text { Elongation } \\
(\%)\end{array}$ & $\begin{array}{c}\text { Elongation- } \\
\text { to-failure } \\
(\%)\end{array}$ \\
\hline \multirow{2}{*}{ As-cast } & \multirow{2}{*}{$\mathrm{RT}^{*}$} & $\mathrm{TRC}$ & $161 \pm 8$ & $202 \pm 16$ & -- & $0.975 \pm 0.11$ \\
& & MC-TRC & $195 \pm 7$ & $273.5 \pm 4.5$ & -- & $1.41 \pm 0.01$ \\
\hline $\begin{array}{c}\text { Hot-rolled } \\
\text { at } 400^{\circ} \mathrm{C}\end{array}$ & $\mathrm{RT}$ & $\mathrm{TRC}$ & $160.9 \pm 2.2$ & $257.5 \pm 10$ & $6.9 \pm 1.3$ & $10.5 \pm 2.5$ \\
\hline
\end{tabular}

* RT means Room Temperature

A photograph of the AZ31 tensile tests samples is given in Figure $\mathbf{5 . 2 1}$ which shows that the MC-TRC AZ31 samples have broken in the middle of the tensile test specimens associated with the necked area while there is no indication of necking phenomena in the TRC broken sample. 


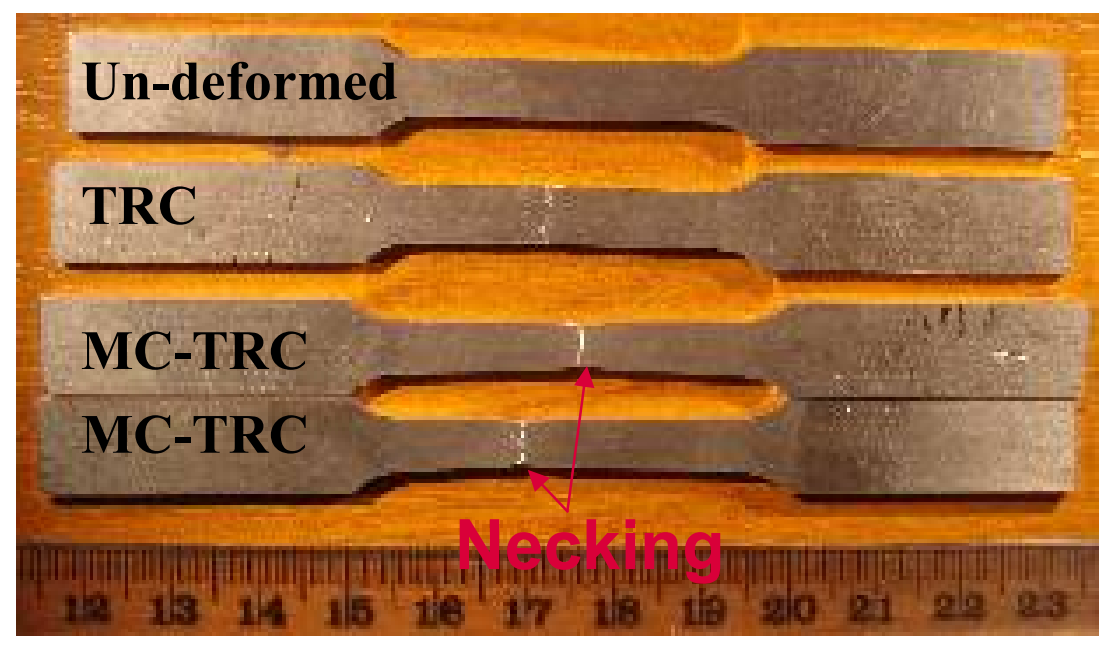

\section{Figure 5.21:}

A photograph of the final gauge hot-rolled AZ31 tensile test samples which shows that the MC-TRC AZ31 samples have broken in the middle of the tensile test specimens associated with the necked area while there is no indication of necking phenomena in the TRC broken sample.

\section{(b) At High Temperature $\left(\sim 350^{\circ} \mathrm{C}\right)$}

In order to examine the response of as-cast TRC and MC-TRC strips to the hot rolling process, high temperature $\left(\sim 350^{\circ} \mathrm{C}\right)$ tensile testing was carried out on both types of as-cast AZ31 and AZ91D strips. Table 5.3 shows the mechanical properties of the AZ31 and AZ91D alloys strips produced by TRC and MC-TRC processes in the as-cast state at elevated temperature.

\section{Table 5.3:}

High temperature mechanical properties of AZ91D and AZ31 alloy strip produced by TRC and MC-TRC processes tested in the as-cast state.

\begin{tabular}{cccccc}
\hline $\begin{array}{c}\text { Conditions } \\
\text { AZ91D }\end{array}$ & $\begin{array}{c}\text { Tensile test } \\
\text { conditions }\end{array}$ & Process & $\begin{array}{c}\text { Yield } \\
\text { Stress } \\
(\mathbf{M P a})\end{array}$ & $\begin{array}{c}\text { UTS } \\
(\mathbf{M P a})\end{array}$ & $\begin{array}{c}\text { Elongation- } \\
\text { to-failure } \\
(\%)\end{array}$ \\
\hline \multirow{2}{*}{ AZ31 } & \multirow{2}{*}{$350^{\circ} \mathrm{C}$} & TRC & $26 \pm 2$ & $37 \pm 6$ & $7.8 \pm 0.3$ \\
As-cast & & MC-TRC & 14.0 & $44 \pm 7$ & $56.6 \pm 0.4$ \\
\hline \multirow{2}{*}{ AZ91D } & \multirow{2}{*}{$350^{\circ} \mathrm{C}$} & TRC & 11 & $46.5 \pm 0.5$ & $43.35 \pm 4.15$ \\
As-cast & & MC-TRC & 8.5 & $38.5 \pm 3.5$ & $118.1 \pm 20.9$ \\
\hline
\end{tabular}




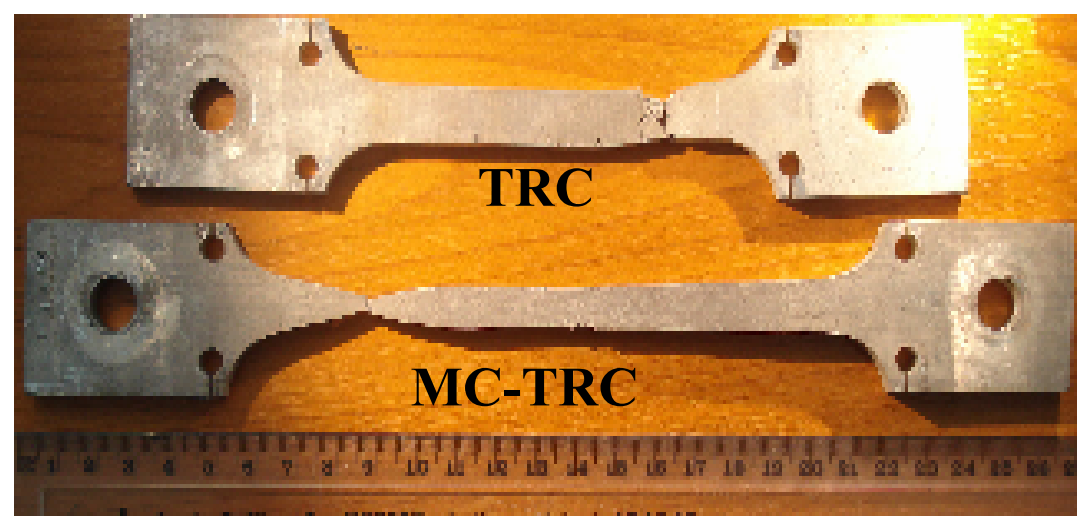

\section{Figure 5.22:}

A photograph of the as-cast TRC and MC-TRC high temperature tensile tests AZ31 samples which shows that the MC-TRC samples have broken in the necked area while there is no indication of necking phenomena in the low-ductility TRC broken sample.

For both AZ31 and AZ91D alloys, the elevated tensile test in the as-cast state shows that the MC-TRC strip has much higher ductility at high temperature compared with the TRC strip, so a higher reduction per pass is applicable to the MC-TRC strip. Furthermore the lower yield strength of the MC-TRC strip hints that a lower force is needed for plastic deformation of the MC-TRC strip during the hot-rolling process which is a vital beneficial saving in consumption of energy and time in industry.

Another interesting result is the higher percentage elongation-to-failure of AZ91D strips compared with AZ31 strips. Figure 5.22 gives a photograph of the broken tensile tests samples of TRC and MC-TRC AZ31 as-cast strips which shows that the MC-TRC sample is more ductile than the TRC sample.

Figure 5.23 shows a schematic of the position of prepared cut specimens ( $A-A$ and $B-B$ cross sections) from the high temperature tensile tests samples. The optical micrographs of A-A and B-B cross sections of the as-cast TRC and MC-TRC AZ31 and AZ91D alloys are illustrated in Figure 5.23 (a)-(h). 


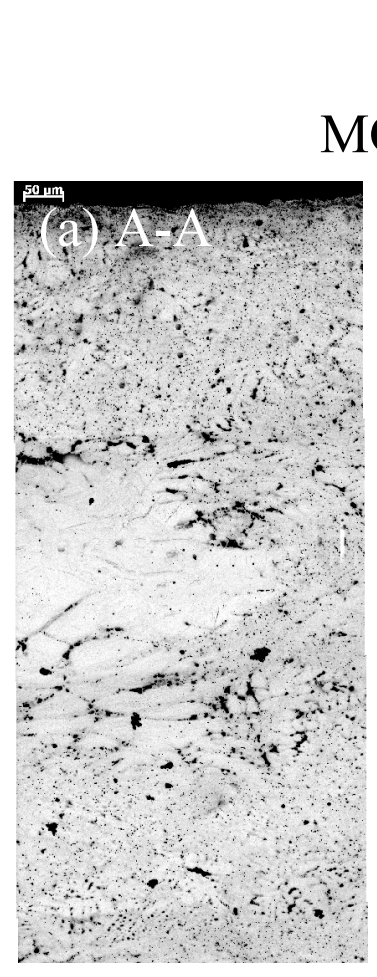

\section{MC-TRC}

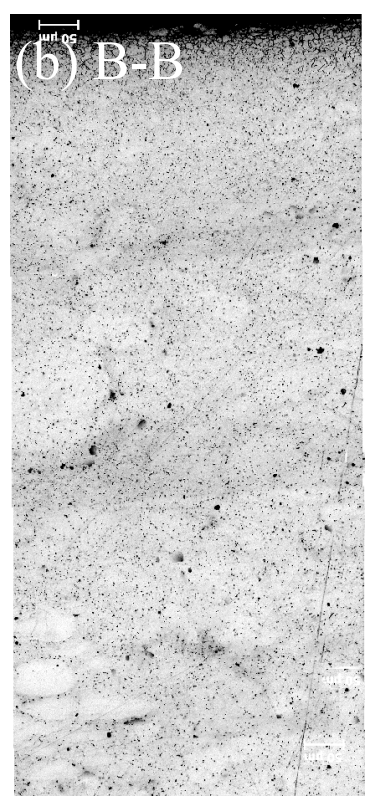

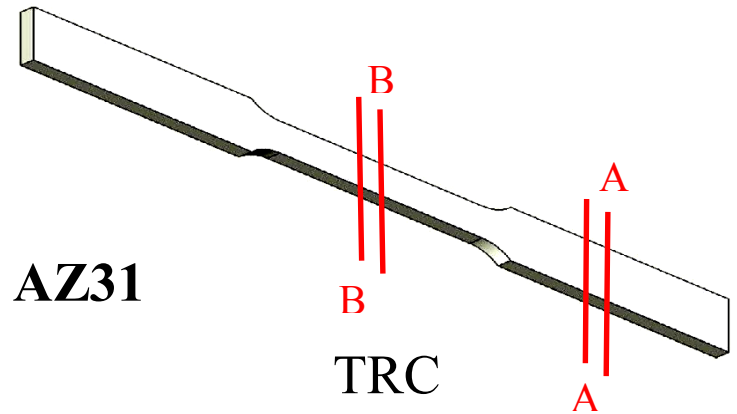
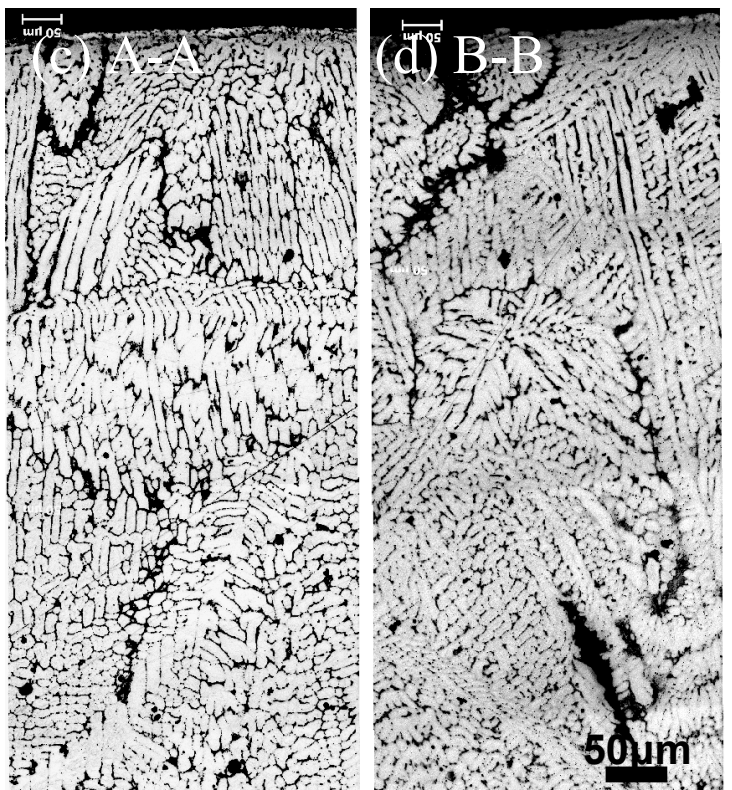

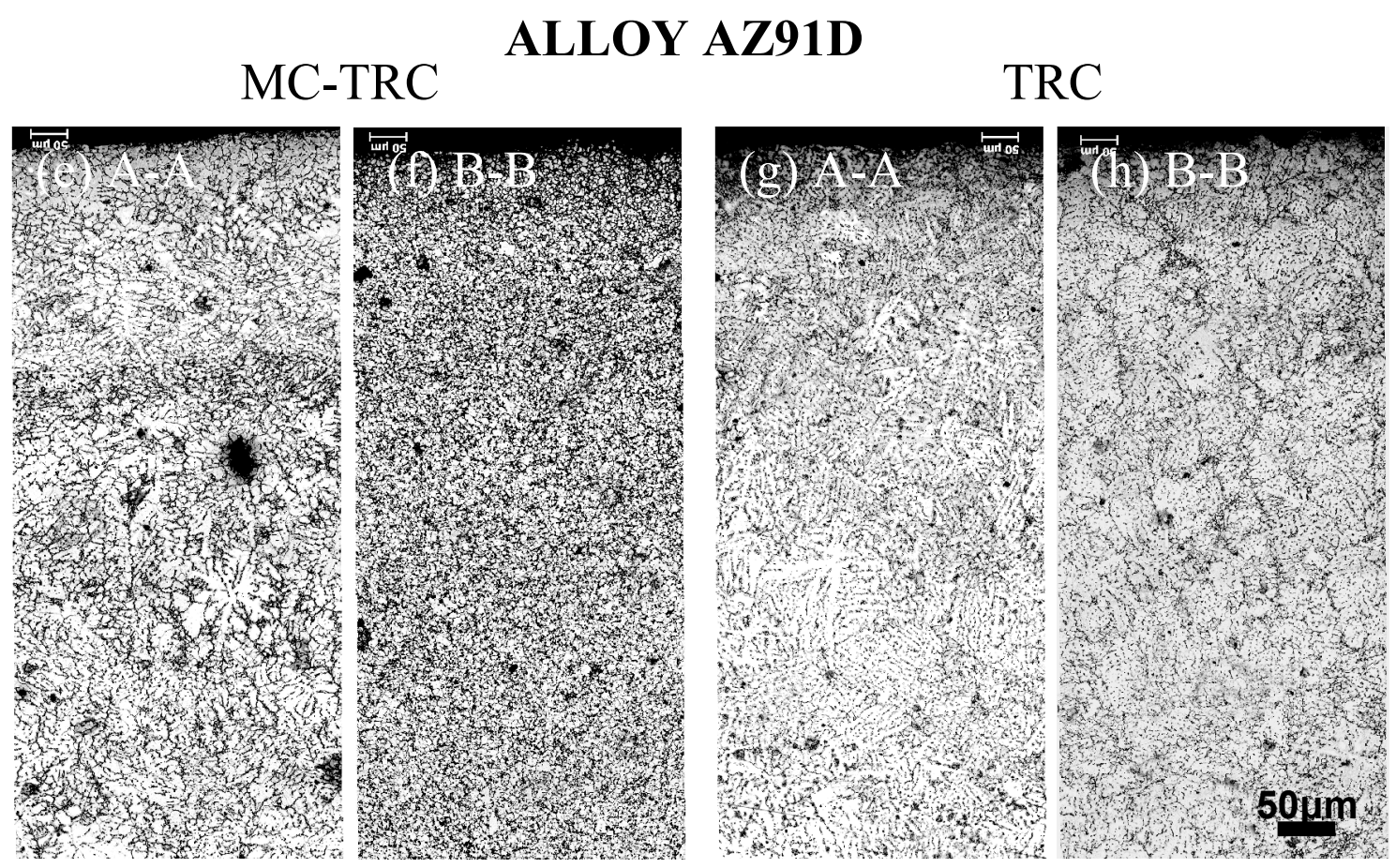

\section{Figure 5.23:}

Optical micrographs showing the shoulder (A-A section) and gauge length (B-B section) microstructures after high temperature tensile tests of, (a-d) AZ31 alloy strip and (e-h) AZ91D alloy strip produced by MC-TRC (a, b, e and f) and TRC (c, d, g and h)processes. This shows that the recrystallization rate of AZ91D strip is higher than AZ31 strip during high temperature tensile tests. 
Higher magnification micrographs of the B-B (gauge length section) section of the TRC and MC-TRC AZ31 and AZ91D samples are shown in Figure 5.24. Figure 5.24 (a) shows that under the conditions of a high temperature tensile test, new recrystallized grains in MC-TRC AZ31 strip nucleate, yet there still are no significant changes in the general as-cast microstructure of AZ31 TRC strip (Figure 5.24 (b)). By contrast, in MC-TRC and TRC AZ91D strip the recrystallization rate is higher than for the AZ31 alloy as a larger number of grains have been recrystallized and a low amount of primary grains still exist (Figure 5.24 (c) \& (d)).

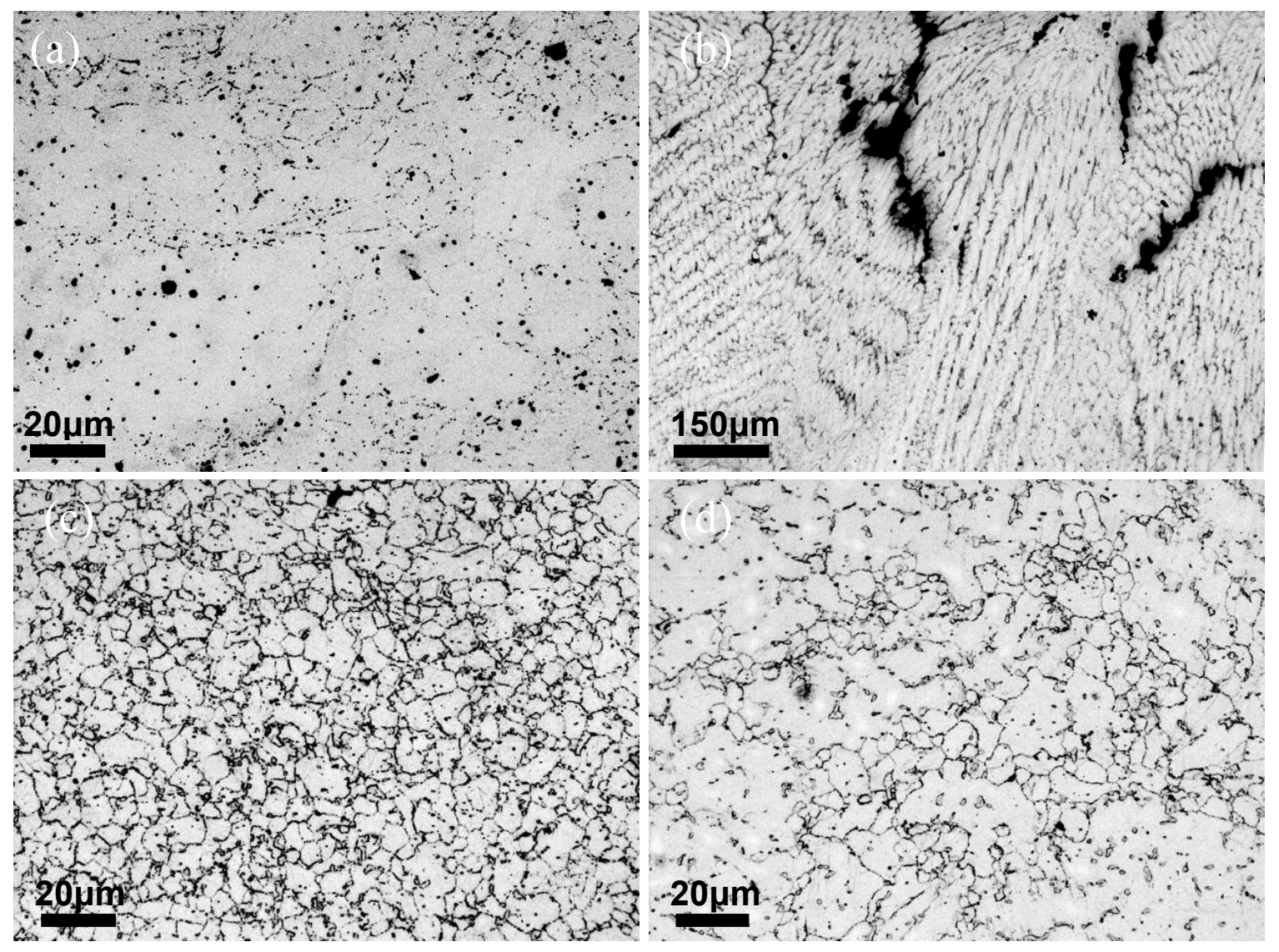

\section{Figure 5.24:}

Detailed micrographs showing at higher magnification the gauge length microstructures after high temperature tensile tests of, (a) AZ31 MC-TRC, (b) AZ31 TRC, (c) AZ91D MC-TRC and (d) AZ91D TRC, as-cast strips. This shows that the recrystallization rate of AZ91D strip is higher than AZ31 strip during high temperature tensile tests, as the number and quantity of $\mathrm{Mg}_{17} \mathrm{Al}_{12}$ particles stimulate recrystallization in the AZ91D alloy is more than that in the AZ31 alloy. 


\section{CHAPTER 6}

\section{DISCUSSION}

\subsection{Solidification behaviour in the MC-TRC of magnesium alloys}

The solidification behaviour in the MC-TRC process is unique, compared with existing casting processes. The solidification in the MC-TRC process basically occurs in two stages. The primary stage takes place in the MCAST unit, where the magnesium alloy melt undergoes a high shear rate and a high intensity of turbulence; the secondary stage refers to the complete solidification of the conditioned melt of magnesium alloy, taking place under the pressure of water cooled rolls with a relatively very high cooling rate. In order to discuss the solidification in the MC-TRC process, first we need to understand the nature of convection or shear provided by the MCAST unit used in this investigation for MC-TRC processing.

\subsubsection{Nucleation under intensive forced convection}

In a conventional casting process i.e. a TRC process, after the initial step of melt pouring, primary solidification begins by heterogeneous nucleation of the chilled liquid at the mould wall (water-cooled rolls) through a mechanism known as 'Big-Bang' by Chalmers, [Chalmers 1963]. The nuclei created on the chilled mould are mainly transferred by the convection caused by rotating water-cooled rolls to the overheated liquid zone and dissolve. Therefore, columnar growth initiates from the chilled zone resulting in the typical coarse cast microstructure. The low survival rate of the nuclei which contribute to the final microstructure, resulting in a coarse and non-uniform microstructure. 
However, a large nucleation rate is a required condition for grain refinement, although it is not adequate on its own. The survival rate of the nuclei is an important factor in the final grain refinement. Subsequently, it can be concluded that a crucial step towards microstructural refinement is to certify that every single nucleus formed during nucleation can survive and contribute to the final microstructure.

The following conditions need to be obtained in order to achieve a $100 \%$ nucleus survival rate:

- Uniform temperature and chemical composition throughout the entire volume of the liquid alloy;

- Well-dispersed heterogeneous nucleation agents;

- Rapid extraction of latent heat to prevent recalescence;

Creating these conditions result in what is known as 'effective nucleation' [Fan and Liu 2005, Ji and Fan 2002], where all nuclei obtained will have a chance to survive and ultimately contribute to the microstructural refinement.

The microstructural refinement of $\mathrm{Mg}$ alloys by the MC-TRC process can be understood from two different levels, macroscopic and microscopic levels.

(I) At the macroscopic level in the MCAST unit, the fluid flow is characterised by a high shear rate, high intensity of turbulence and cyclic variation of the shear rate due to the continuous change of the gap between the screws and the barrel. In the MC-TRC process, this intensive melt shearing of the MCAST unit creates uniform temperature and chemical composition fields throughout the entire volume of the melt and results in a characteristic nucleation and growth phenomena that is different from the conventional TRC process. 
(II) At the microscopic level, non-sheared magnesium alloy melts usually contain clusters of oxide particles and oxide films which are non-uniformly dispersed. The results obtained from Fan and his co-workers experiments [Fan et al. 2009a], Figure 6.1, show that three different morphologies of $\mathrm{MgO}$ are present in the non-sheared magnesium alloy melt:

(i) young oxide film formed during melt handling, such as melt transfer and pouring;

(ii) old oxide film formed on the top of the alloy melt in the crucible during melting;

(iii) oxide skins brought into the alloy melt from the original alloy ingot.

Previous research at BCAST [Fan et al. 2009a] is presented in Figures 6.1 \& 6.2 showing optical and SEM micrographs obtained by a pressurised melt filtration technique. This procedure is carried out initially when the alloy melt is forced to flow through a microporous filter and inclusions and intermetallic particles are collected on the top surface of the filter. Hence, small size and very scarce population numbers of solid particles can not be a barrier to study on inclusions and intermetallic particles in an alloy melt.
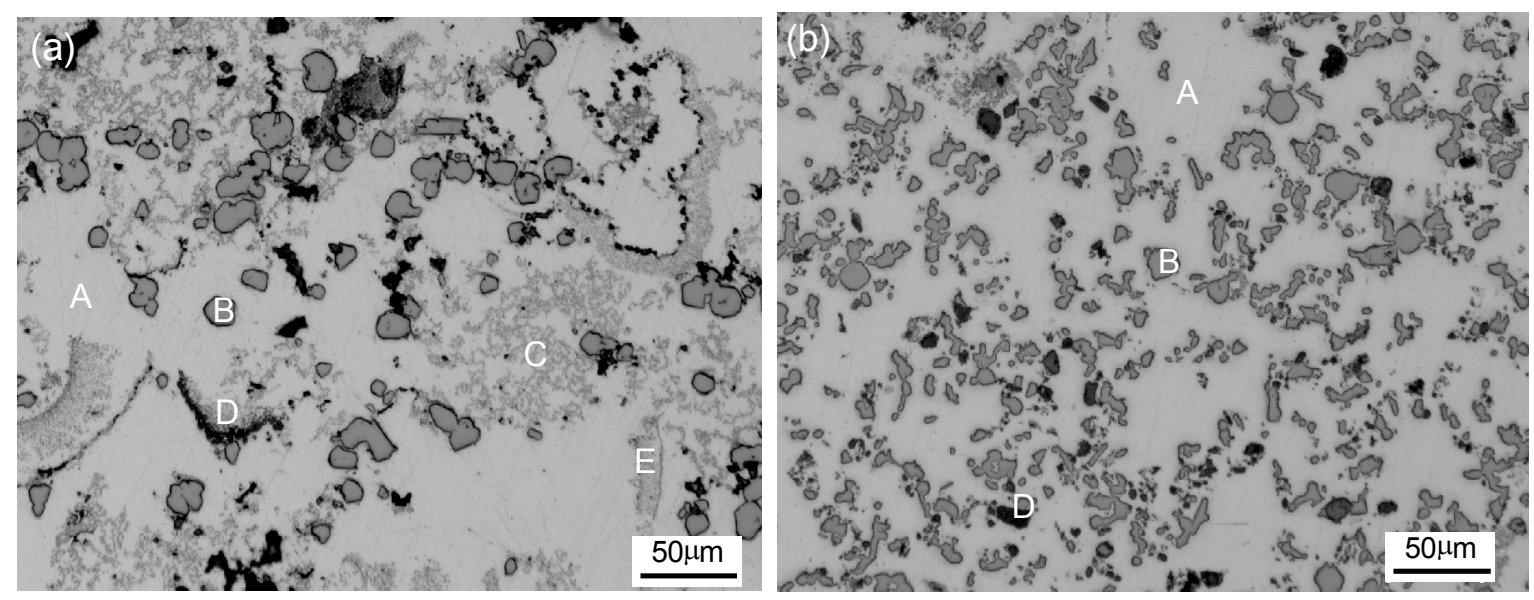

\section{Figure 6.1:}

Optical micrographs showing the morphology of oxide and $\mathrm{Al}_{8} \mathrm{Mn}_{5}$ intermetallic particles from (a) non-sheared and (b) sheared AZ91D alloy melts. For the sheared sample, the shearing temperature, shearing speed and shearing time were $650^{\circ} \mathrm{C}, 800 \mathrm{rpm}$ and $45 \mathrm{~s}$ respectively. The following labels are used in the micrographs: $\mathrm{A}: \alpha-\mathrm{Mg}$ matrix; $\mathrm{B}: \mathrm{Al}_{8} \mathrm{Mn}_{5}$ particle; $\mathrm{C}$ : young $\mathrm{MgO}$ films; $\mathrm{D}$ : old $\mathrm{MgO}$ films; E: MgO skins. [Fan et al. 2009a] 

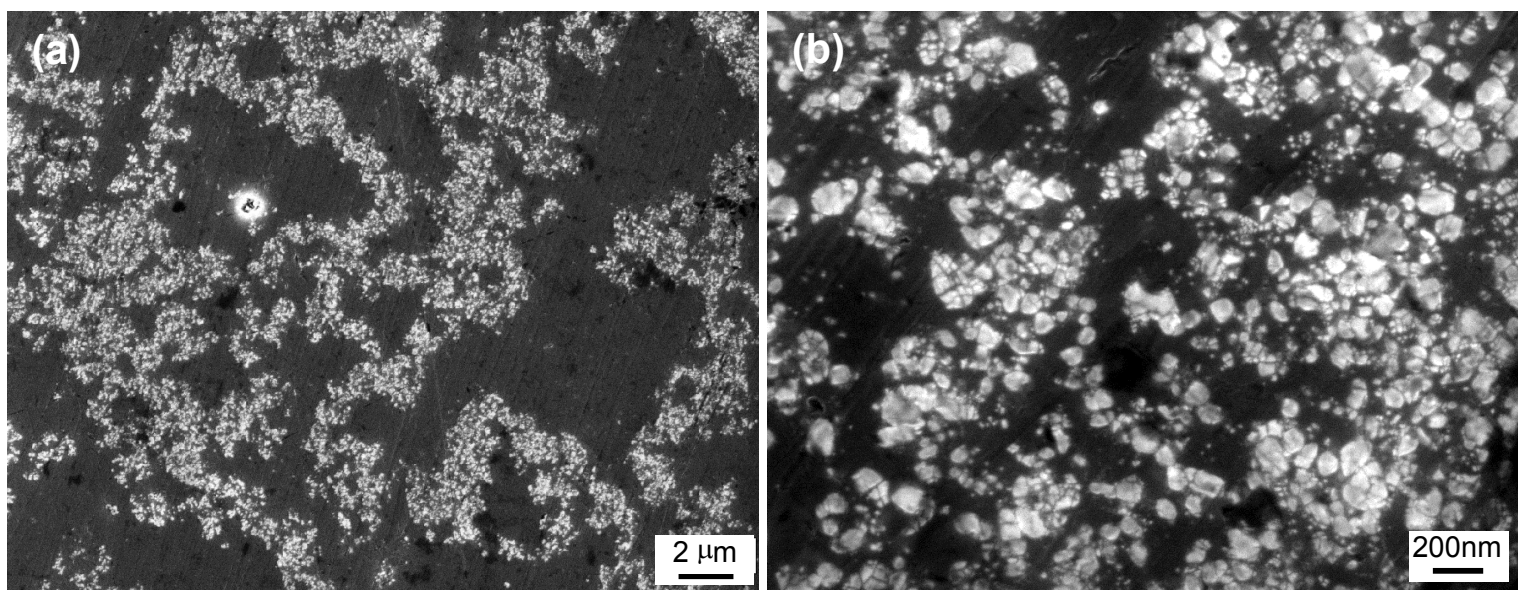

Figure 6.2:

SEM micrograph showing (a) the oxide film from the unsheared melt and (b) the morphology of the $\mathrm{MgO}$ particles of the sheared AZ91D alloy melt. [Fan et al. 2009a]

Figures $6.1 \& 6.2$, give a comparison between the microstructure of the sheared and nonsheared solidified AZ91D alloy. In the alloy melt usually, two types of solid particles are found, oxides and intermetallic compounds. The sheared sample at high magnification obtained by SEM examination showed that both the young oxide films and the oxide skins were broken up and distributed as single particles of $100-200 \mathrm{~nm}$ in size (Figure $6.2(\mathrm{~b})$ ).

Recently, a detailed microstructural and crystallographic analysis by Fan and co-workers [Fan et al. 2009 a], show that both $\mathrm{MgO} / \alpha-\mathrm{Mg}$ and $\mathrm{MgO} / \mathrm{Al}_{8} \mathrm{Mn}_{5}$ interfaces are semicoherent with a small crystallographic misfit, while the $\mathrm{Al}_{8} \mathrm{Mn}_{5} / \alpha-\mathrm{Mg}$ interface is incoherent due to poor crystallographic matching across the interface. An orientation relationship has been observed between the $\mathrm{MgO}$ and $\alpha$-Mg phases. i.e.:

$$
\langle 1-210\rangle_{M g} / /\langle 01-1\rangle_{M g O} \text { and }\{0002\}_{M g}-2^{\circ} \text { from }\{111\}_{M g O}
$$

Fan and co-workers in the BCAST found that $\mathrm{MgO}$ particles can act as potent nucleation sites for both $\mathrm{Al}_{8} \mathrm{Mn}_{5}$ intermetallics and the primary $\alpha-\mathrm{Mg}$ phase, although it is very 
implausible that $\mathrm{Al}_{8} \mathrm{Mn}_{5}$ particles are potent nucleating particles for the primary $\alpha-\mathrm{Mg}$ phase because of the poor crystallographic match, [Fan et al. 2009 a\& b]. However, according to the free-growth model for grain initiation developed by Greer and coworkers [Greer et al. 2000], the presence of potent nucleating particles could not effectively result in grain refinement in the solidified microstructure. For a given alloy system containing completely wetted nucleating particles, this model predicts the free growth undercooling $\Delta T_{f g}$ which is inversely proportional to the nucleating particle size $d$ shown in the equation below:

$$
\Delta T_{f g}=\frac{4 \gamma}{\Delta S_{V} d}
$$

where $\gamma$ is the interfacial energy between the liquid and nucleating solid phases and $\Delta S_{V}$ is the entropy of fusion per unit volume. This model suggests that the larger particles only need a small undercooling to be active for the heterogeneous nucleation, whereas the smaller ones require a larger undercooling. Consequently, grain growth begins from large inoculation particles and small particles will probably be re-melted or be deprived of a contribution to grain refinement. Therefore, it can be concluded that the size distribution of nucleant particles is crucial. Intensive shearing at temperatures near to the liquidus temperature of a magnesium alloy in the MCAST unit can effectively disperse the oxide films and oxide skins into individual $\mathrm{MgO}$ particles of 100-200 $\mathrm{nm}$ in diameter with a narrow size distribution, (see Figure 6.1 (b) \& 6.2 (b)). In case of a narrow size distribution, the chance of contribution of small particles to grain nucleation is higher compared with wide particle size distribution.

In summary, for effective grain refinement of a given alloy the potent nucleating particles need to have sufficient numbers and appropriate size distribution in addition to a 
favourable particle size, [Greer et al. 2000, Quested and Greer 2004]. Intensive melt shearing can successfully provide these conditions for grain nucleation (i.e. primary $\alpha-\mathrm{Mg}$ phase) on refined and well-distributed $\mathrm{MgO}$ particles with a narrow size distribution [Fan et al. 2009a, Xia et al. 2009].

It has been suggested that in real alloy systems, it is possible for solid particles of different chemical natures to co-exist in a liquid magnesium alloy. Solid particles, other than $\mathrm{MgO}$ particles, with the highest potency (smallest crystallographic misfit), appropriate size, size distribution and sufficient numbers may become effective in the competition for heterogeneous nucleation. The justifications discussed do not eliminate the likelihood that other solid particles can be active nucleation sites. Even though there is not any strong experimental evidence provided in these investigations, it can be suggested that for example $\mathrm{Al}_{4} \mathrm{C}_{3}$ (or $\mathrm{Al}_{2} \mathrm{CO}$ ) particles may be responsible for the grain refining of $\mathrm{Mg}-\mathrm{Al}$ alloys in both superheating and carbon inoculation processes, [Fan et al. 2009a, StJohn et al. 2005, Emley 1966, Zhang et al. 2005].

\subsubsection{Solidification behaviour of conditioned magnesium alloy melt}

Based on our experimental results and the equilibrium phase diagram for Mg-Al-Zn-Mn system calculated by [Ohno et al. 2006], the heterogeneous nucleation events during solidification of AZ91D and AZ31 alloys in the MC-TRC process can be clarified. Figure 6.3 shows the calculated vertical section of the equilibrium phase diagram for the Mg-A19-Mn-Zn1 system and a bright-colour hatched area representing the AZ91D alloy system investigated in this study. Based on Figures $6.3 \& \mathbf{2 . 3}$, at a temperature just below $642^{\circ} \mathrm{C}$ (i.e. the equilibrium temperature for formation of $\mathrm{Al}_{8} \mathrm{Mn}_{5}$ phase), the $\mathrm{Al}_{8} \mathrm{Mn}_{5}$ phase is nucleated on the pre-existing $\mathrm{MgO}$ particles, resulting in a population of $\mathrm{Al}_{8} \mathrm{Mn}_{5}$ particles suspended in the alloy melt. This solidification procedure takes place inside the MCAST unit under intensive melt shearing which is referred to as the 'primary solidification stage'. 


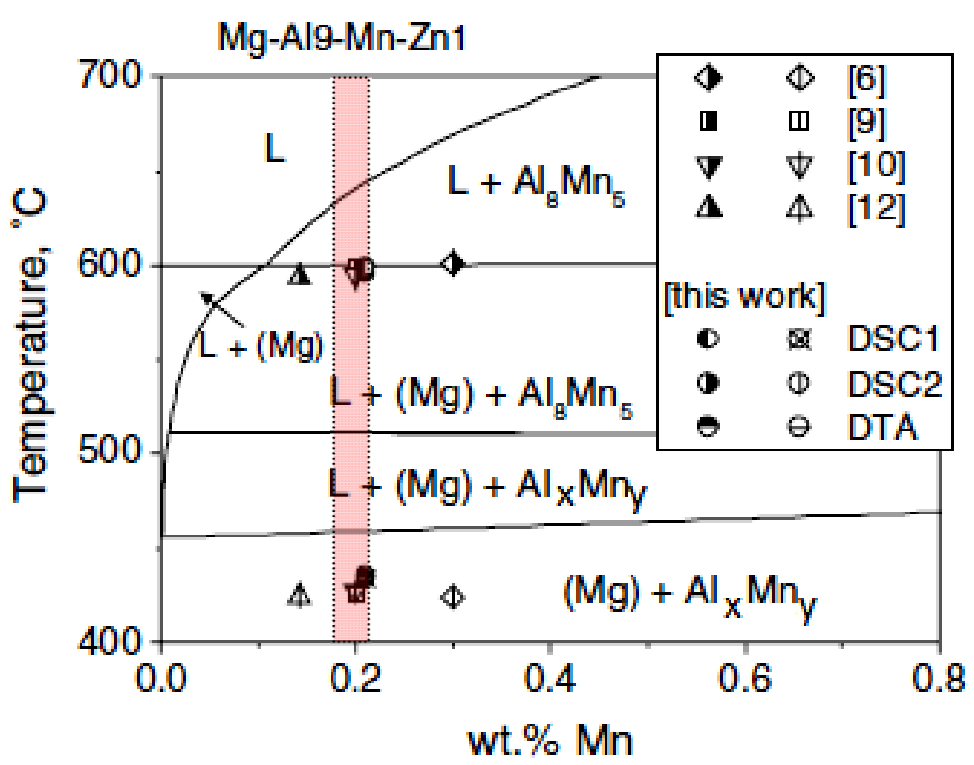

Figure 6.3:

Calculated vertical phase diagram section at a composition of Mg-9 wt.\% Al-Mn-1 wt.\% Zn. The hatched area represents the similar alloy system investigated in this study, i.e. AZ91D alloy. [Ohno et al. 2006]

The next step in the solidification is feeding the conditioned melt into the TRC machine which solidifies the Mg-melt as a strip under a very high cooling rate $\left(2 \times 10^{2} K . s^{-1}-\right.$ $6 \times 10^{2} K . s^{-1}$, [Park et al. 2004, Park et al. 2003, Löchte et al. 2005, Nakaura and Ohori 2005]). With further cooling of the alloy melt to a temperature below $600^{\circ} \mathrm{C}$ for $\mathrm{AZ91D}$ and $632^{\circ} \mathrm{C}$ for AZ31 (i.e. the liquidus temperature for the formation of $\alpha-\mathrm{Mg}$ ), the remaining $\mathrm{MgO}$ particles in the alloy melt trigger the heterogeneous nucleation of the primary $\alpha-\mathrm{Mg}$ phase. This solidification procedure takes place at the kissing point between the melt and the water-cooled rolls of the TRC machine termed the 'secondary solidification stage'.

For the TRC process, as discussed previously, the non-sheared magnesium melt contains $\mathrm{MgO}$ in the form of young oxide films, old oxide films and oxide skins. Each oxide film

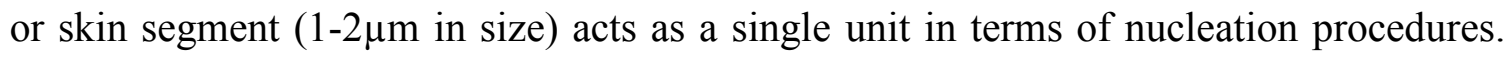
This will considerably reduce the number of potential active nucleating particles in the 
non-sheared alloy melt for the TRC process, giving rise to a coarse grain structure in the as-cast TRC magnesium strip, (see Figure 4.25 (a) \& (b) and 4.28 (a) \& (b)).

As has been demonstrated previously, intensive magnesium alloy melt shearing in the MC-TRC process can disperse the $\mathrm{MgO}$ particles in the oxide films and skins into individual particles with a narrow particle size distribution, [Fan et al. 2009a, Xia et al. 2009]. The individual $\mathrm{MgO}$ particles with a narrow size distribution considerably increase the number of active nucleating particles, resulting in a much finer grain size after solidification due to enhanced heterogeneous nucleation of the primary $\alpha-\operatorname{Mg}$ phase on refined and well-distributed $\mathrm{MgO}$ particles. Due to the loosely packed $\mathrm{MgO}$ particles inside the oxide films and skin segments, dispersion of such oxide particles can be simply accomplished if the shear rate and shearing time are past a critical level. As long as the oxide particles are dispersed, an additional increase in shear rate and shearing time will not result in any further grain refinement, (see Figure 4.21 and Figure 4.22).

The combination of the spreading of the fine size oxide particles with a narrow size distribution, and enhanced effective nucleation offered by the MCAST machine will enhance significantly the heterogeneous nucleation of the primary phase, resulting in a finer and more uniform primary equiaxed dendrites of $\alpha-\mathrm{Mg}$, (see in Figures 4.25 (c) \& (d), Figure 4.28 (c) \& (d) and Figure 4.39 (b) \& (d)).

\subsubsection{Effect of casting parameters on microstructural evolution}

Based on the experimental results in Section 4.1 the effect of casting parameters on microstructural evolution during the twin roll casting process of AZ91D and AZ31 alloys can be clarified. As discussed earlier, the coarse microstructure of Mg alloy strip 
produced by the conventional TRC process are due to the small number of nuclei available and gradually decreasing the melt temperature gradient. At the beginning of solidification, when the initial thin-solidified shell is formed on the roll surface the temperature gradient is very high, which results in fine equiaxed grains termed the chill zone. By increasing the shell thickness on the roll surface as the solidification proceeds, the heat extraction rate and temperature gradient of the melt decrease further, causing the formation of elongated columnar dendrites. By continuous extraction of heat from the melt, the temperature gradient reaches a critical value at which fully equiaxed growth occurs; see Figure 4.2 (a) \& 4.17.

All the TRC casting parameters can affect the shell thickness as the solidification proceeds. By increasing the casting speed and or reducing the roll gap much less shell thickness can be produced which further results in grain refinement of the final magnesium alloy strip due to the increased heat transfer rate from the thin solidifying shell into the water-cooled rolls. Hence, the final grain size of the Mg-alloy strip in the TRC process is directly dependent upon casting parameters and can be altered significantly by changing the shell thickness and heat transfer rate during twin roll casting. Among the casting parameters, the freezing range of an alloy can also change the final microstructure of $\mathrm{Mg}$ alloy strip in the TRC process. In the following section the effect of this parameter will be discussed thoroughly.

\section{Effect of freezing range}

The results of grain size analysis on conventionally twin roll cast AZ31 and AZ91D strips (see Figure 4.39 (a) \& (c), 4.25 (a) \& (b) and Figure 4.28 (a) \& (b)), show the strong effect of solute elements on grain size refinement for these two types of 
magnesium alloys. Since solute elements play a major role in controlling the growth of the nucleated grains and in subsequent nucleation, it can be suggested that the effect of solute elements on grain size is as vital as that of nucleant particles, [Easton and StJohn 1999a and b]. Hunt's CET model was the first numerical model proposed to evaluate the effect of solute elements on grain morphology [Hunt 1984]. This effect has been investigated in various $\mathrm{Mg}$ alloy systems and explained in terms of the growth restriction factor (GRF), [StJohn et al. 2005, Lee et al. 2000, Dahle et al. 2001]:

$$
\sum_{i} m_{i} C_{0, i}\left(k_{i}-1\right)
$$

where $m_{i}$ is the slope of the liquidus line (assumed to be a straight line), $k_{i}$ is the distribution coefficient, and $C_{0, i}$ is the initial concentration of element $i$. The aluminium content as a major element of AZ91D alloy $(\sim 8.71 \%)$ is higher than in the AZ31 alloy $(\sim 3.34 \%)$, resulting in significantly different values of GRF $(\sim 43.3$ for AZ91D and 19.6 for AZ31) calculated from data available in the literature [Lee et al. 2000], (Table. 6.1). As a result of this phenomenon, the grain size in the AZ91D TRC strip is smaller than in the AZ31 TRC strip.

Table 6.1. Slope of the Liquidus Line (m), Equilibrium Distribution Coefficient (k), and Growth Restriction Factor m(k-1) for various alloying elements in magnesium*

\begin{tabular}{lccc}
\hline Element & $m$ & $k$ & $m(k-1)$ \\
\hline $\mathrm{Zn}$ & -6.04 & 0.12 & 5.31 \\
\hline $\mathrm{Al}$ & -6.87 & 0.37 & 4.32 \\
\hline $\mathrm{Mn}$ & 1.49 & 1.10 & 0.15 \\
\hline$*$ The value of GRF is calculated from $C_{o} m(k-1)$, where $C_{o}$ is the composition of the alloy. \\
\hline
\end{tabular}

Constitutional undercooling in a diffusion layer ahead of the advancing solid/liquid interface is generated by adding extra solute elements, which causes grain growth restriction as the diffusion of the solute takes place slowly. Moreover, nucleants in the 
melt are more prone to survive and be activated in the constitutionally undercooled zone; this is why further nucleation takes place in front of the interface, [Lee et al. 2000].

Another interesting phenomena obtained is that the grain size variation in the sheared melts of AZ91D and AZ31 shows no significant difference, which shows that MC-TRC is applicable to a wide range of alloys and is insensitive to the GRF value. 


\subsection{Macro-segregation behaviour in TRC and MC-TRC processes}

Macrosegregation can be defined as the spatial non-uniformity in the chemical composition throughout the cross-section of the casting. The main mechanism behind macrosegregation in conventional casting processes is well understood: a relative movement of the liquid and solid phases during the solidification within the mushy zone occurs in the presence of solute partitioning (microsegregation) which is due to solidification shrinkage, natural convection and deformation of the solid network, [Flemings 1974, Nadella et al. 2008]. Nicolli and co-workers proposed a macrosegregation model caused by volumetric deformation in a coherent mushy zone. Their modelling results for an Al-4 wt pet $\mathrm{Cu}$ alloy indicate that even quite small volumetric strains $(\approx 2$ pct), i.e. deformation of the solid network, can lead to a macrosegregation which is comparable to that resulting from the solidification shrinkage induced melt flow, [Nicolli et al. 2005]. Based on quite large values of volumetric strains reported in a twin roll casting process ( $\approx 30-60$ pct) [Berg 1995, Westengen and Nes 1984] and experimental evidence established elsewhere [Jin et al. 1982, Bayandorian et al. 2009, Lockyere et al. 1996, Monaghan 1993, Park et al. 2009a \& b], the dominating macrosegregation formation mechanism might be the squeezing effect of the rolls (i.e. deformation of the solid network) in the mushy region forcing the remaining liquid, enriched in alloying elements, to be squeezed out towards the centre-line of the strip. The results for the segregation profiles show a severe segregated region in the midsection of a TRC strip, as shown in Figure 4.32 (a) \& (c).

The macro-segregation behaviour of Mg-alloys strips produced by TRC and MC-TRC processes can be analysed in terms of two different approaches:

- Effect of morphology and size of nucleated grains in the mushy zone area;

- Effect of casting parameters; 


\subsubsection{Effect of grain size and its morphology}

The published results on the effect of grain size and its morphology on central line segregation are scarce: Cooper and co-workers observed that the centre line segregation in twin roll cast AA1145 aluminium alloy strip can be minimized or eliminated by adding A13Ti0.2B as an effective grain refiner [Cooper et al. 1994]. In a later study Guo and co-workers investigated the effect of electromagnetic vibration on the segregation behaviour of an as-cast AZ80 magnesium alloy billet, and found that a refined grain size with equiaxed morphology leads to significantly reduced macrosegregation in the billet, [Guo et al. 2006].

However, there are many scientific parameters which control the extent of segregation in the central line of twin roll cast strip. The result of this study suggest that the changed morphology of the grains from columnar to equiaxed dendrites and fine grain sizes achieved by the MC-TRC process through intensive melt shearing plays an important role in the segregation behaviour, as shown in Figures 4.25, 4.28 and 4.32. During solidification, solute is rejected continuously from the solid to the surrounding liquid, causing the liquid to become richer in solutes. In addition, the morphology of the solid in the direction of a solute rejection is important [Kurz and Fisher 1986], as the large number of equiaxed solid grains throughout the MC-TRC strip can reject enriched solute evenly along all their available dendrite axes, while a limited number of elongated columnar grains in the TRC strip will pile-up solute just at the centre line of the strip where columnar tips meet each other, (see Figure 4.33).

Also, as the solidification proceeds the crystal growth increases the volume fraction of solid $\left(f_{s}\right)$ and at a critical value of $f_{s}$ the crystals impinge on one another, [Gourlay and 
Dahle 2007], which is often termed the dendrite coherency solid fraction $\left(f_{s}^{c h}\right)$. This term is a strong function of the size and shape of crystals [Sumitomo et al. 2000, Arnberg et al. 1993, Veldman et al. 2001], which ranges from $\sim 0.15$ for columnar dendrites to $\sim 0.5-0.74$ for equiaxed crystals, [Arnberg et al. 1993, Dahle and StJohn 1998].

In addition, other scientists have shown that under a compressive load, the yield strength of the equiaxed dendritic mushy zone is much lower than the columnar dendritic mushy zone area [Dahle and StJohn 1998], which results in lower local applied forces on the intergranular liquid and easier deformation of the equiaxed grains by grain rearrangement through sliding and rolling [Tzimas and Zavaliangos 1999, Martin et al. 1997] compared with columnar grains which are deformed plastically since the rearrangement of columnar grains is constrained due to their morphology and the uneven enriched solute in intergranular spaces, [Martin et al. 1997].

Based on these explanations and a modified Carman-Kozney model [Bear 1972] [ $k \propto d_{m}^{2}$ where $k$ is the permeability parameter and $d_{m}$ is the average grain size] which was introduced in (equation 2.4) Section 2.3.2.2 of Chapter 2, during deformation of the mushy zone since the permeability of the remaining liquid between the fine equiaxed grains is much lower than for the coarse columnar dendrites, the separation and movement of liquid from the solid into the central line of the strip would be more difficult in the MC-TRC mushy zone which leads to a diminishing of the central line macrosegregation in the MC-TRC strip in comparison with the severe segregation in the central line of the TRC strip, (see Figure 4.34, 4.35 and 4.36). 
As seen from Figure 4.37, the microhardness values for the AZ91D and AZ31 strip are higher at the centre than the surface when the strip is cast by the conventional TRC process. This suggests that the brittle and hard $\mathrm{Mg}_{17} \mathrm{Al}_{12}-\beta$ and $\mathrm{Al}_{\mathrm{x}} \mathrm{Mn}_{\mathrm{y}}$ phases which are aluminium enriched phases [Jung et al. 2007, Kawalla et al. 2008] segregated in the centre of the strip while there are no changes in microhardness values throughout the as-cast strip in the MC-TRC strip, which reconfirms the elimination of centreline macrosegregation in the MC-TRC as-cast strip.

\subsubsection{Effect of casting parameters}

Referring to Section 2.3.1, the TRC simulation results for Al alloys show that casting parameters can alter the amount of external pressure on the mushy zone and also the shape and geometry of the sump area. In this study in Section 4.1, after carrying out practical experiments we found that the percentage of centre-line segregation in the TRC AZ91D strip is dependant upon the casting parameters, such as roll speed and roll setback. Unfortunately, the laboratory-scale TRC machine used in this study was not equipped with pressure measurement devices, hence some conclusions made in this study are based on microstructural observations obtained from Mg-strips at different casting parameters.

The simulation results of TRC process found elsewhere for Al-8 wt pct $\mathrm{Cu}$, [Bradbury 1994] can suggest that in Al-alloy with a very low roll speed and a very high tip setback, a very high roll separating force is present. The centre-line segregation can usually be reduced or removed by increasing the roll separating force, [Thomas 2003]. Experimental work illustrated in this study shows that at very high tip setback and very low roll speed 
and roll gap, a low amount of centre-line segregation and high amount of surface segregation appear which verifies Bradbury's simulation results, (see Figure 4.4, 4.10 (b)). However, Based on this explanation, the position and shape of the mushy zone area was considered to be a key issue the same as the applied pressure. Hence, more detailed scientific simulation work by computer needs to be carried out on interactions between the applied pressure and the geometry of the sump shape in order to fully understand the formation of centre-line segregation in the TRC process for Mg-alloys.

\subsubsection{Hot-tear formation}

When grains begin to impinge and touch one another but are still surrounded by a continuous liquid film, hot tears or hot cracks in the intergranular macro-segregation can be formed, i.e. at the dendrite coherency point $\left(f_{s}^{c h}\right)$, [Campbell 2003]. For finer grains, due to the higher $f_{s}^{c h}$ more strain can be accommodated by easy slip along the lubricated boundaries without the risk of cracking, also due to the existence of many boundaries the strain is more widely distributed compared with coarser grains. Additionally, on a progressive level if fine cracks created at the grain boundaries of finer grains reach the next grain that commonly have a different orientation, this may prevent crack propagation. In contrast, for the case of large elongated columnar grains the boundaries at the right angle to the stress direction e.g. right angle to the two rotating rolls, can provide conditions for easy initiation of a tear along such favourably oriented grain boundaries, [Campbell 2003]. 
During the TRC process, a very complex field of stresses are applied to the solidifying metal in between the two rolls such as compression, tension and shear forces which can develop the formation of hot tears at grain boundaries. In summary, a finer grain size and reduced temperature gradients will help to reduce the strain that is trying to open up the individual grain boundaries, i.e. similar to the conditions in the MC-TRC process.

It is generally accepted that hot cracking is more severe if the grain morphology is not equiaxed (see Figure 4.31 (a) \& (c)), and that a finer structure (see Figure 4.31 (b) \& (d)) allows a higher casting speed before hot tears appear, [Nadella et al. 2008 and McCartney 1989]. Hence the MC-TRC process can produce strip with a higher surface quality associated with a higher casting rate compared with the conventional twin roll casting process. 


\subsection{Down-stream processing of magnesium alloy strip}

\subsubsection{Microstructural evolution at the homogenization stage}

Generally, the stored energy during twin roll strip casting is significantly high (in our study $\sim 42 \%$ ); hence nucleation of new recrystallized grains during heat treatment at the homogenization stage is expected. Recrystallization will originate at inhomogeneities in the deformed microstructure i.e.:

- Grain boundaries,

- Twins

- Second phase particles, [Humphreys and Hatherly 2004].

The formation of new grains start from prior grain boundaries, twins and eutectic phases in magnesium alloy samples, see Figure 5.8.

\section{$\underline{\text { Grain boundaries }}$}

In many cases, as shown in Figure 5.8 (b), grain boundary bulging designated straininduced grain boundary migration (SIBM) [Humphreys and Hatherly 2004], acts as a precursor for the formation of 'conventional' recrystallized grains, as has been observed in other investigations on magnesium alloys [Tan and Tan 2003, Galiyev et al. 2001, Ion et al. 1982, Yang and Ghosh 2006, Robson et al. 2009].

\section{Twins}

Recently, it has been found that twins and twin intersections in deformed magnesium alloys at high temperatures are suitable sites for nucleating new substructures and recrystallized grains, [Myshlyaev et al. 2002, Yang and Ghosh 2006, Essadiqi et al. 2009, Liu and Ghosh 2005, Sitdikov and Kaibyshev 2001]. The recovering procedure of twins and twin 
intersections due to dislocation-twin boundary interactions may be the reason for nucleating the new strain-free recrystallized grains, [Myshlyaev et al. 2002], (see Figure $5.8(a))$

\section{$\underline{\text { Second phase particles }}$}

The effect of large particles in promoting recrystallization through the mechanism of particle-stimulated nucleation (PSN) is well recognized and will only be possible if dislocations accumulate near the large particles $(>1 \mu \mathrm{m}$ diameter $)$ during deformation to form deformation zones [Humphreys and Hatherly 2004]. It has been shown that dislocation pile-ups occurred against $\beta-\mathrm{Mg}_{17} \mathrm{Al}_{12}$ particles and grain boundaries in stressed $\mathrm{AZ91}$ and AM50 magnesium alloys, [Wang et al. 2003a \& b, Kadiri et al. 2006]. Hence, $\beta-\mathrm{Mg}_{17} \mathrm{Al}_{12}$ particles are potent nucleation sites for recrystallized grains in AZ91D and AZ31 magnesium alloys. Recently, the effect of particles on recrystallization in magnesium alloys have been studied [Robson et al. 2009, Bae et al. 2009, Bohlen et al. 2007, Ball and Prangnell 1994, Mabuchi et al. 1996] but as yet there are few studies on the effect of $\beta-\mathrm{Mg}_{17} \mathrm{Al}_{12}$ eutectic particles on the recrystallization behaviour of Mg-Al-Zn alloys, [Li et al. 2007a]. The coarse and non-deformable $\beta-\mathrm{Mg}_{17} \mathrm{Al}_{12}$ eutectic particles $(\sim 1-20 \mu \mathrm{m}$ in size $)$ would be expected to be effective as initiators of PSN in deformed AZ91D and AZ31 alloys produced by a twin roll casting process, (see Figure 5.8 (c) \& (d)).

In this study, homogenized specimens showed broad evidence of SIBM. It is worth mentioning that examples of SIBM were observed more often than examples of new grains that could be associated with coarse particles or twins, and this is therefore thought to be the dominant mechanism that leads to the nucleation and growth of new grains during homogenization of twin roll cast strips. 
If the grain boundaries are preferred nucleation sites, therefore a given number of nuclei in a fine-grained material i.e. MC-TRC strip (see Figures 6.4 (a)), will lead to more homogenous recrystallization than the same number in a coarse-grained material i.e. TRC strip (see Figures 6.4 (b)). Also the number of available nucleation sites is greater for a fine-grained material compared with a coarse-grained material, [Humphreys and Hatherly 2004].

On a larger scale, it is also found that the main cause of inhomogeneous recrystallized grains in TRC samples compared with homogenous and fine recrystallized grains in MC-TRC samples are because of the larger-scale heterogeneity and large elongated columnar grains of as-cast TRC samples compared with the homogenous and fine grains of as-cast MC-TRC samples. Based on the explanations described above, Figure 5.5 (a) and (b) show much faster recrystallization rate ( $\sim 6$ times) in the MC-TRC strip with finer, more homogeneous and a narrow size distribution of recrystallized grains $(\sim 11.56 \mu \mathrm{m}, 50.4 \%$ less than $15 \mu \mathrm{m})$ which is due to the initial small grained strip produced by the MC-TRC process $(\sim 74 \mu \mathrm{m})$. By contrast, the initial large grain size $(\sim 616 \mu \mathrm{m})$ in the TRC strip can lead to a slower recrystallization rate with larger and nonhomogenous recrystallized grains $(\sim 344.9 \mu \mathrm{m}, 2 \%$ less than $15 \mu \mathrm{m}$ in size $)$.

(a)
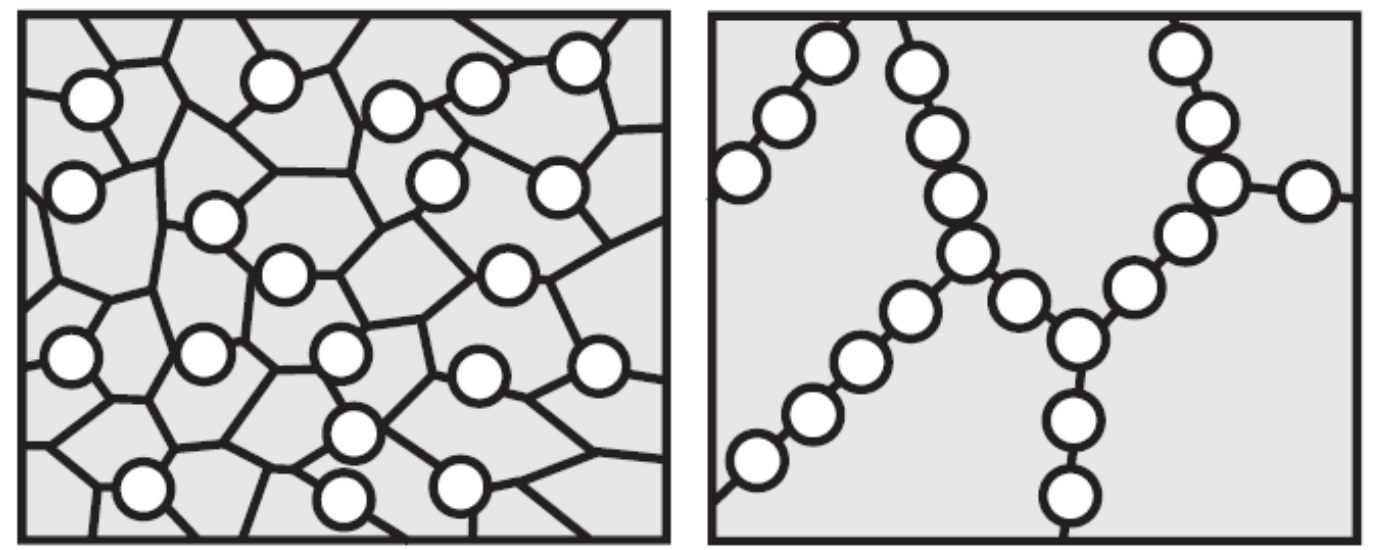

Figure 6.4:

Schematic representation of the effect of the initial grain size on the heterogeneity of nucleation, (a) small initial grain size, (b) large initial grain size. 


\subsubsection{Microstructural evolution at the hot rolling stage}

According to the laws of recrystallization, the recrystallized grain size depends on the amount of stored energy through deformation, the starting grain size and deformation temperature, [Humphreys and Hatherly 2004]. Additionally, the stored energy of a metal deformed to low strains $(\varepsilon<0.5)$ is likely to increase with a decrease in the initial grain size, [Bever et al. 1973]. By increasing the stored energy in the material, smaller and more homogenous new recrystallized grains can be formed. In general, a higher stored energy, a smaller starting grain size combined with a very low deformation temperature can provide the optimum conditions for very fine and homogeneous recrystallized grains in the microstructure of a deformed material. Hence a more homogenous and fine recrystallized grain size is expected to be obtained during hot deformation of the initial fine-grained homogenized MC-TRC strip compared with the coarse-grained homogenized TRC strip, (see Figure 5.10 and Figure 5.11).

During a hot-rolling process, again new recrystallized grains form. The mechanism for dynamic recrystallization can be understood based on some theories proposed elsewhere. Cross-slip or climb of the non-basal dislocations which are predominantly activated near highly-stressed grain boundaries could result in the formation of subgrains, [Galiyev et al. 2001, Ion et al. 1982]. Subsequently absorption of lattice dislocations i.e. the RDX mechanism [Ion et al. 1982, DelValle et al. 2003], or subgrain boundary migration [Galiyev et al. 2001] i.e. the SIBM mechanism, can result in new recrystallized grains formation.

Humphreys and Hatherly, claim that if dynamic recrystallization results in a very small grain size $(\sim<10 \mu \mathrm{m})$, then subsequent deformation may occur by the mechanism of grain boundary sliding (GBS), [Humphreys and Hatherly 2004]. In this study, the possibility of a 
GBS mechanism associated with new grain formation mechanisms described above, are much higher in the hot-rolling stage of MC-TRC strip compared with the TRC specimens (see Figure 5.10, 5.11, 5.12 and 5.13), since more homogenous and fine grains can be achieved by utilizing the MC-TRC process compared with the TRC process. In addition, the existence of cavities around thicker grain boundaries of the equiaxed grains distributed homogeneously in the MC-TRC hot-rolled strip, provides evidence for a grain boundary sliding (GBS) mechanism in the microstructural evolution of MC-TRC hotrolled strip (see Figure 5.15), [Mohri et al. 2000, Wei et al. 2003]. These results indicate that grain boundaries were high-angle boundaries and grain boundary sliding (GBS) occurred significantly in the MC-TRC hot-rolled strip (Figure 5.15 (e)), while there is no evidence of GBS for the inhomogeneous microstructure of TRC hot-rolled strip (Fig. 5.15 (f)).

During high temperature deformation of $\mathrm{Mg}$ alloy strips, a lack of a sufficient number of slip systems in magnesium alloys leads to the activation of non-basal slip systems or twinning mechanisms where their occurrence depends on the grain size [Barnett 2007]. Recently, it has been demonstrated that as the grain size increases twinning becomes more wide-spread, [Barnett 2007, Jain et al. 2008]. This is due to the effect of the Hall-Petch relationship, i.e. $\left[\tau_{\text {twining }} \propto d^{-1 / 2}\right]$, which relates the twinning stress $\left(\tau_{\text {twining }}\right)$ needed for twin nucleation to the grain size (d), [Meyers et al. 2001]. Hence in our study as the grain size obtained by down-stream processing of the MC-TRC strip is much smaller than in the TRC samples, the onset of a twinning mode will be postponed in the MC-TRC strip. Twin formation is postponed up to a high thickness reduction for the MC-TRC strip while there is severe twinning in the TRC rolled strip, (see Figure 5.15). 
It has been shown that networks of twins created after rolling of magnesium alloy strips may play an important role during annealing owing to the relaxation of accumulated energy, [Jäger et al. 2006]. Based on our study, 2 hours of annealing at $345^{\circ} \mathrm{C}$ is enough to fully recrystallize the microstructure of the homogenous fine grained MC-TRC rolled sheet (see 5.11 (d) \& (h), Figure 5.15 (e)), which results in a more uniform microstructure with triple junctions at angles of about $120^{\circ}$. In other words, small twins in the MC-TRC rolled sheet need less time compared with large twins in TRC rolled sheet to recover at high temperature, (see 5.11 (b) \& (f), 5.15 (f)). These show that the MC-TRC rolled sheet would be much quicker in responding to the annealing treatment than the TRC rolled sheet.

\subsection{Mechanical properties of TRC and MC-TRC Mg alloys}

\subsubsection{Mechanical properties at room temperature}

The mechanical properties of AZ31 and AZ91D alloys investigated in this study resulting from $\mathrm{TRC}$ and $\mathrm{MC}-\mathrm{TRC}$ in the hot-rolled state and at room temperature are presented in Table 6.2 and compared with those obtained by other casting processes obtained from the relevant literature. 
Table 6.2. Mechanical properties at room temperature of all the magnesium alloys investigated in this study obtained from TRC and MC-TRC processes in the hot-rolled state and after homogenization and annealing processes compared with other studies. References are cited in the Table.

\begin{tabular}{|c|c|c|c|c|c|}
\hline Materials & $\begin{array}{l}\text { Processing } \\
\text { condition }\end{array}$ & $\mathrm{YS}, \mathrm{MPa}$ & UTS, MPa & $\begin{array}{l}\% \text { Elongation- } \\
\text { to-failure }\end{array}$ & Reference \\
\hline \multicolumn{6}{|c|}{ Twin roll casting (TRC) and continuous casting (CC) } \\
\hline \multirow{7}{*}{ AZ31 } & \multirow{6}{*}{$\mathrm{TRC}+\mathrm{HR}^{1}$} & 236 & 284 & 15.3 & [Park et al. 2004] \\
\hline & & 170 & 240 & 17 & [Thyssenkrupp 2009] \\
\hline & & 120 & 240 & 18 & [Kawalla et al.2008] \\
\hline & & 293 & 310 & 6.5 & $\begin{array}{l}\text { [Nakaura and Ohori } \\
\text { 2005] }\end{array}$ \\
\hline & & $\begin{array}{l}195-210 \\
250-265\end{array}$ & $\begin{array}{l}280-295 \\
305-310\end{array}$ & $\begin{array}{l}18-21 \\
13-15\end{array}$ & [Jung et al. 2007] \\
\hline & & 213 & 288 & 21 & \multirow{2}{*}{$\begin{array}{l}\text { [Liang and cowley } \\
\text { 2004] }\end{array}$} \\
\hline & $\mathrm{CC}+\mathrm{HR}$ & 202 & 266 & 17 & \\
\hline AZ41M & TRC+HR & 218 & 330 & 12.3 & [Kang et al. 2008] \\
\hline \multirow{2}{*}{ AZ91D } & \multirow{2}{*}{$\mathrm{TRC}+\mathrm{HR}$} & 167 & 264 & 6.2 & \multirow{2}{*}{ [Park et al. 2003] } \\
\hline & & 197 & 246 & 1.5 & \\
\hline \multicolumn{6}{|c|}{ Liquid or solid state processing } \\
\hline \multirow{7}{*}{ AZ31 } & $\begin{array}{l}\text { Extrud+HR } \\
\text { at } 723 \mathrm{~K} \\
\text { at } 618 \mathrm{~K}\end{array}$ & $\begin{array}{l}167 \\
110\end{array}$ & $\begin{array}{l}241 \\
---\end{array}$ & $\begin{array}{l}20 \\
16\end{array}$ & $\begin{array}{l}\text { [Chino and Mabuchi } \\
\text { 2009] } \\
\text { [Chino et al. 2009] }\end{array}$ \\
\hline & $\begin{array}{l}\mathrm{EMV}^{* *} \\
+0.01 \mathrm{Ti}^{* *}\end{array}$ & $\begin{array}{l}65 \\
68 \\
\end{array}$ & $\begin{array}{l}-- \\
---\end{array}$ & $\begin{array}{l}18.5 \\
21.5\end{array}$ & [Wang et al. 2007b] \\
\hline & $\mathrm{ARB}^{*}$ & 236 & 315 & 19.6 & [Zhan et al. 2007] \\
\hline & $\begin{array}{l}\text { DSR }^{*} \\
\text { at } 573 \mathrm{~K} \\
\text { at } 523 \mathrm{~K} \\
\text { at } 473 \mathrm{~K} \\
\end{array}$ & $\begin{array}{l}241 \\
237 \\
242 \\
\end{array}$ & $\begin{array}{l}289 \\
290 \\
295\end{array}$ & $\begin{array}{l}13.6 \\
17.3 \\
18.5\end{array}$ & [Watanabe et al. 2007] \\
\hline & $\begin{array}{l}\text { Cross-roll hot } \\
\text { rolling at } \\
618 \mathrm{~K}^{*}\end{array}$ & 110 & --- & 24 & [Chino et al. 2009] \\
\hline & ECAP $^{* *}$ & 217 & 282 & 30 & [Lin et al. 2005] \\
\hline & $\begin{array}{l}\text { ECAP+anne- } \\
\text { aling at } 573 \mathrm{~K} \\
\text { for } 24 \mathrm{hrs}{ }^{* *}\end{array}$ & 130 & 255 & 45 & [Mukai et al. 2001] \\
\hline $\mathrm{Mg}-0.9 \mathrm{Al}$ & $\mathrm{ECAP}^{* *}$ & 150 & 240 & 15 & $\begin{array}{l}\text { [Yamashita et al. } \\
\text { 2001] }\end{array}$ \\
\hline \multicolumn{6}{|c|}{ This study } \\
\hline \multirow{4}{*}{ AZ31 } & \multirow{2}{*}{$\mathrm{TRC}+\mathrm{HR}$} & 173.5 & 241.6 & 12.4 & This study \\
\hline & & 181.6 & 243.1 & 6.1 & This study \\
\hline & \multirow{2}{*}{$\mathrm{MC}-\mathrm{TRC}+\mathrm{HR}$} & 166.6 & 234.9 & 28.4 & This study \\
\hline & & 177.7 & 251.1 & 27.7 & This study \\
\hline \multirow{2}{*}{ AZ91D } & TRC+HR & 160.9 & 257.5 & 10.5 & This study \\
\hline & MC-TRC+HR & 169.4 & 282.3 & 15.9 & This study \\
\hline
\end{tabular}

1 HR: Hot Rolled

* Final sheet

** Primary feedstock 
The improved mechanical properties of the MC-TRC hot-rolled Mg-sheet compared with the TRC hot-rolled Mg-sheet and also other casting processes can be explained in terms of two effects:

- Grain size and morphology

- Defect formation

\section{$>$ Grain size and morphology}

The mechanical properties of magnesium alloy final gauge sheet produced by a twin roll casting process are affected by number of factors such as the grain size and morphology. The grain size is significant in mechanical properties as presented in the well known Hall-Petch equation:

$\sigma_{y}=\sigma_{0}+k_{y} d^{-1 / 2}$

where $\sigma_{y}$ is the tensile yield strength of a polycrystal, $\sigma_{0}$ is the yield stress of a single crystal, $d$ is the average grain diameter and $k_{y}$ is a material constant, [Martin 1996]. This equation illustrates that for a smaller grain size the tensile yield strength of polycrystals is higher. Consequently, the grain size and the morphology of a microstructure essentially affects the mechanical strength although other aspects such as ductility can greatly contribute to properties of castings.

Recently, other researchers have shown that fine-grained ECAE-processed AZ31 magnesium alloys give a large tensile ductility at room temperature which can confirm our findings, [Koike et al. 2003, Mukai et al. 2001]. However based on their results, they have suggested that the large tensile ductility at room temperature for fine-grained magnesium 
alloy is attributed to the activation of non-basal dislocation slip systems, [Koike et al. 2003]. Activation of non-basal dislocation slip systems due to grain-refining of $\mathrm{Mg}$ alloys can be another possible reason for the large ductility obtained for the MC-TRC samples in comparison with the TRC samples. On the other hand, the larger number of grain boundaries in the fine-grained MC-TRC sheet may play an important role in deformation at room temperature compared with the in-homogenous distributed large grain size variation of the TRC sheet.

\section{$\underline{\text { Defect formation }}$}

The most important aspect in promoting reliability of a casting is the control of defects such as cracks, voids and centre-line segregation. These defects are mostly minimised by precise control of the processing techniques. The intensive melt shearing in the MC-TRC process can minimise or eliminate the centre-line segregation, as illustrated in Figure 4.25 (c) \& (d) and Figure 4.28 (c) \& (d). The centre-line segregation of the as-cast TRC strip can not be eliminated through down-stream processing where these brittle un-wanted defects in the final gauge TRC sheet can reduce considerably the mechanical properties of the final product compared with the defect-free final gauge MC-TRC sheet.

By increasing the grain size, twinning becomes more wide-spread and the occurrence of significant twinning during down-stream hot-working can cause premature fracture and form voids and cracks, [Ion et al. 1982, Del valle et al. 2003, Barnett 2007, Barnett et al. 2009]. Recently, it has been discovered that in the twinned grains, the voids either engage a region that seems to have been occupied by a twin or, in some cases, can be seen forming in the twin interior, [Barnett 2007]. 
The strain-induced in the TRC process combined with a large grain size variation through the thickness of as-cast TRC strip could provide the required conditions for void and crack formation along the 'contraction' twins $[\{1011\}-\{10 \overline{1} 2\}$ double twinning (Barnett 2007)] within the elongated grains (Figure 4.30 (c) \& (e) and Figure 5.16 (a)). This is in contrast with the as-cast MC-TRC strip where the fine grains in the strip may suppress twinning, resulting in diminishing voids and cracks along the grain boundaries of the fine grains (Figure 4.30 (d) \& (f)).

In the experiments of this study, prolonged homogenization and subsequent hot rolling did not remove the initial cracks from the as-cast TRC strip. During the homogenization stage, clustering of small voids along grain boundaries in the TRC strip results in enlargement of the voids, (see Figure 5.16 (b)). Subsequently, due to severe shear deformation applied during the hot-rolling stage, the morphology of voids change into cracks at approximately 45 degree to the rolling direction, (see Figure 5.16 (c)). By increasing the homogenization temperature larger voids can coalesce which in the final gauge sheet can change into severe elongated cracks which results in a significant reduction of the mechanical properties of final product especially its ductility.

The explanations given above, could help us to explain the improved mechanical properties of the MC-TRC defect-free rolled sheet at room temperature compared with the TRC rolled sheet where the MC-TRC sheet has uniform and well-distributed fine recrystallized grains without any cracks and voids from the casting stage at or near the surface of the strip. 
ECAP process, as cited in Table 6.2, is the only reported solid state manufacturing process which can compete in mechanical properties, particularly elongation to failure, with MC-TRC followed by a hot-rolling process. However the cost-effectiveness, eco-friendliness and reliability combined with much reduced production steps brought into industry by the MC-TRC process show superiorities of this novel technology over the new ECAP manufacturing process in the magnesium sheet production industry.

The mechanical behaviour of MC-TRC processed magnesium alloy hot-rolled sheets have been reported to demonstrate improvements over conventional continuous casting (CC) products, as cited in Table 6.2. The improvements of mechanical properties over $\mathrm{CC}$ products has been attributed to the rapid rates of solidification in the TRC process which gives marked differences in grain structure, dendrite arm spacing, micro- and macro-segregation, porosity, distribution and size of primary constituents. These features will significantly influence the mechanical behaviour of TRC magnesium alloy hot-rolled sheets.

\subsubsection{Mechanical properties at elevated temperature}

More homogenous and well distributed nucleating agents, such as grain boundaries, twins and particles found in the MC-TRC process could be responsible for the higher recrystallization rate compared with the TRC process, (see Figure 5.23 and Figure 5.24). It has been recognized that enhanced dynamic recovery and recrystallization play a significant role in reducing the flow stress and raising the ductility to improve industrial processing at elevated temperatures, [Myshlyaev et al. 2002, 
Tan and Tan 2003, Galiyev et al. 2001]. This can lead to a higher ductility and lower flow stress of as-cast MC-TRC strips compared with TRC strip, as illustrated in Table 5.3.

A larger quantity of $\mathrm{Mg}_{17} \mathrm{Al}_{12}$ in the $\mathrm{AZ91}$ alloy in comparison with the $\mathrm{AZ31}$ alloy [Avedesian and Baker 1999] leads to more nucleating agents for recrystallization, as a result of a particle-stimulated nucleation mechanism (see Figure 5.24 (a) \& (c)). This causes a lower flow stress and higher ductility of the AZ91D alloy strip compared with the AZ31 alloy strip at high temperature with no soak time.

\subsubsection{Work hardening rate}

When crystals yield, as a result of interactions of dislocations and their accumulation in the material, work hardening occurs [Ashby and Jones 2005]. By increasing the amount of the applied strain during the hot-rolling stage, more dislocations will be created, which leads to a high degree of work hardening in both types of strips produced i.e., TRC and MC-TRC, (see Figure 5.20). Twin-induced hardening in magnesium alloys has been widely reported and attributed to the hardening due to dislocation-twin interactions, [Agnew et al. 2001, Barnett et al. 2004, Koike et al. 2003]. In addition based on the Hall-Petch mechanism, a fine grain size is considered to be a possible source of strengthening, [Ashby and Jones 2005, Barnett et al. 2004]. Hence, twins and grain size are two important factors which compete with each other to control the work hardening rate in deformed magnesium alloys.

In the as-cast state, the MC-TRC strip shows a higher hardness-value due to the finer grain size and narrow grain size distribution in comparison with the TRC strip. Subsequently by increasing the strain $(\sim 24 \%)$ more twins in the large grained TRC 
rolled strip (see Figure 5.15 (b)) could form which leads to a rapid increase in the work hardening rate compared with fine grained MC-TRC rolled strip, (see Figure 5.15 (a)). By further deformation $(\sim 73 \%)$, more twins could be detected in the MC-TRC rolled strip (see Figure 5.15 (c)) which results in overlapping of hardness-values in both types of strips produced. This shows that the rollability of the MC-TRC Mg strip is much higher in comparison with the TRC Mg strip and can be deformed much easier to the final thickness end product. 


\section{CHAPTER 7}

\section{CONCLUSIONS}

1) The twin roll casting (TRC) process for magnesium alloy strip production has been optimised against general surface quality and internal microstructure in terms of fine and uniform grain size, uniform chemical composition and free from casting defects. The optimised TRC processing condition includes: superheat for pouring $=15 \mathrm{~K}$; tip setback=38-43 mm; roll gap $=3 \mathrm{~mm}$ and roll speed $=22 \mathrm{~mm} \cdot \mathrm{s}^{-1}$.

2) The MCAST process for melt conditioning with intensive shearing has been successfully combined with the TRC process to form a novel melt conditioned twin roll casting (MC-TRC) process for the production of high quality magnesium alloy strip. The MC-TRC process has also been optimised based on the optimised TRC processing conditions.

3) The as-cast TRC magnesium alloy strip exhibits coarse and non-uniform microstructure with severe central line segregation and other casting defects even under the optimised TRC processing conditions.

4) The as-cast MC-TRC magnesium alloy strip exhibits a fine and uniform microstructure with much reduced/eliminated centre line segregation and other cast defects due to enhanced heterogeneous nucleation provided by the MCAST process, which can effectively disperse the usual oxide films in the alloy melt into well dispersed fine oxide particles.

5) The MC-TRC strip exhibits about 3 times higher elongation and lower yield strength at high temperature $\left(350^{\circ} \mathrm{C}\right)$ than the corresponding TRC strip indicating that the 
MC-TRC strip will have much improved deformability during down stream rolling process.

6) The homogenization process for the as-cast TRC and MC-TRC magnesium alloy strips has been optimised against a fine and uniform microstructure achieved through recrystallization. The specified optimised condition includes: holding temperature $=400{ }^{\circ} \mathrm{C}$ and holding time $=1$ hour.

7) Grain boundaries, twin boundaries and second phase particles are potential sites for recrystallization during the homogenization process.

8) The MC-TRC magnesium alloy strips exhibit much faster recrystallization rate than the TRC magnesium alloy strips. This is due to the much finer grain size and well dispersed secondary phase in the MC-TRC strips compared with the TRC strips.

9) The hot rolling process for TRC and MC-TRC magnesium alloy strips has been optimised against the surface quality and microstructural evolution of the rolled magnesium sheet. The production of a very fine and uniform grain size by the MC-TRC process effectively inhibits deformation twining in $\mathrm{Mg}$ alloy strip during further down-stream processing with up to $24 \%$ thickness reduction via hot-rolling process.

10) The hot rolled MC-TRC magnesium alloy sheet has high tensile strength and much improved elongation compared with the sheet from the TRC strip due to the finer and more uniform microstructure. Further the mechanical properties obtained by the MC-TRC process are also superior to other data collected from other studies focused on the TRC process and also liquid or solid state deformation processing available now for magnesium sheet production. The advantage of having higher elongation is that the sheet can be formed into more complex components. 


\section{CHAPTER 8}

\section{SUGGESTIONS FOR FURTHER WORK}

The main focus of this study was optimisation of the MC-TRC process in order to improve the microstructure and mechanical properties of AZ91D and AZ31 magnesium alloys. However, this investigation only provides primary information in order to head start further detailed investigations on both the technological development and scientific understanding. This chapter explains the main research directions recognized as a direct result of the study presented in this thesis which are as follows:

1) Process development: Additional technological development is essential to asses the technology in an industrial production environment in order to comprehend the full potential of the MC-TRC process in magnesium strip production. The research along this direction should be on a new design for attaching safely the MCAST unit to the TRC machine to produce magnesium strips in a continuous manner with minimum Mg-burning during casting as possible, which requires reliability of the temperature control system during casting.

2) MC-TRC of other Mg-alloys: To this point, the MC-TRC process has only been applied to AZ31 and AZ91D alloys. This investigation suggests that the advantages of the MC-TRC process acknowledged for AZ91D and AZ31 alloys ought to be equally applicable to other Mg-based alloys. To appreciate the full potential of the MC-TRC process, additional processing investigations must be focused on other castand wrought- Mg alloys e.g. AZ31 with calcium added (e.g. 1-5 wt.\%) to increase the grain refining effect of the MC-TRC process and also prevent from melt burning during magnesium strip casting, or the AJ62 Mg-based alloy. 
3) Mg-alloys particularly created for the MC-TRC process: The present commercially-obtainable Mg-alloys were developed decades ago to suit the casting methods of the time. The freezing ranges of the current Mg-alloys are not suitable for the twin roll casing process as the probability of the formation of internal defects such as centre line segregation increases for alloys with a high freezing range. Hence, special alloys should be developed to exploit the full advantages of the MC-TRC process.

4) Simulation of TRC and MC-TRC processes by computer: Experimental difficulties prevent detection or measurement of the temperature and pressure distribution in TRC and MC-TRC processes, which therefore require a numerical simulation method. In addition, the effect of intensive melt shearing by the MCAST unit on the final microstructure and prediction of the final grain size of as-cast TRC or MC-TRC strips via complex numerical methods can be carried out based on Greer's model for measurement of the final grain size and Hunt's model for prediction of the morphology of the final solidified as-cast grains, i.e. columnar or equiaxed grains.

5) Down-stream processing development: The MC-TRC process can produce $\mathrm{Mg}$ strips with a high quality compared with the TRC process on which further downstream processing needs to be carried out in-line to produce final gauge thin $\mathrm{Mg}$ alloy sheet. In this study, the effects of a conventional hot-rolling process on TRC and MC-TRC magnesium alloys have been investigated, however the effect of other new solid state deformation processes for $\mathrm{Mg}$ sheet production e.g. ARB (accumulative roll bonding) or DSR (differential Speed hot-rolling) or cross-roll hot rolling can be an interesting subject to study. Based on the data collected from the literature, these 
new processes have shown considerably increased mechanical properties for $\mathrm{Mg}$ alloys compared with a conventional hot-rolling process.

6) Rolling textures of the MC-TRC Mg alloys: The development of a preferred orientation or texture is a natural consequence of hot and cold rolling. The particular type of rolling texture depends mainly on the crystal structure but the starting as-cast microstructure, texture and degree of hot-rolling are also important variables. The hot-rolled microstructure and texture are important as they can influence the recrystallization texture upon annealing and the mechanical behaviour of the final gauge $\mathrm{Mg}$-sheets produced by TRC and MC-TRC processes.

7) Corrosion resistance of the MC-TRC Mg-alloys: The MC-TRC process aims at low micro-porosity, high corrosion resistance, improved tensile strength, a refined microstructure and extended life. The aim of this activity is to improve the corrosion behaviour and properties of MC-TRC and TRC Mg-alloys and propose an appropriate surface protection technology, thus offering a feasible answer to industry targeting the corrosion concerns of Mg-alloys. 


\section{REFERENCES}

[Agnew et al. 2001], S. R. Agnew, M. H. Yoo, C. N. Tomé; Acta Materialia, Volume 49, Issue 20, December 2001, pp. 4277-4289

[Ares and Schvezov 2000], A. E. Ares, C. E. Schvezov; Metallurgical and Materials Transactions A, Volume 31, Issue 6, June 2000, pp. 1611-1625

[Arnberg et al. 1993], L. Arnberg, G. Chai, L. Bäckerud; Materials Science and Engineering A, Volume 173, Issue 1-2, December 1993, pp. 101-103

[Ashby and Jones 2005], M. F. Ashby, D. R. H. Jones; 'Engineering Materials 1: an introduction to properties, application and design', $3^{\text {rd }}$ edition, Oxford: Butterworth-Heinemann; 2005, pp. 99-140 [Avedesian and Baker 1999], M. M. Avedesian, H. Baker; 'Magnesium and Magnesium Alloys', ASM International, Materials Park, OH, USA, 1999, pp. 73, 90, 230

[Bae et al. 2009], G. T. Bae, J. H. Bae, D. H. Kang, H. Lee, N. J. Kim; Metals and Materials Internatinal, Volume 15, Issue 1, February 2009, pp. 1-5

[Bagshaw et al. 1986], M. J. Bagshaw, J. D. Hunt, R. M. Jordan; in: Proceedings of the $3^{\text {rd }}$ Conference on modelling and control of casting and welding processes, Metallurgical Soc of AIME, Warrendale, Santa Barbara, CA, USA, 1986, pp. 135-148

[Bagshaw et al. 1988], M. J. Bagshaw, J. D. Hunt, R. M. Jordan; Mathematical and Computer Modelling, Volume 10, Issue 10, 1988, pp. 797

[Ball and Prangnell 1994], E. A. Ball, P. B. Prangnell; Scripta Metallurgica et Materialia, Volume 31, Issue 2, July 1994, pp. 111-116

[Barber and Bush 2007], B. Barber, A. W. Bush; in: Proceedings of the $5^{\text {th }}$ Decennial International Conference on solidification processing, Sheffield, UK, 2007, pp. 420-423

[Barnett 2007], M. R. Barnett; Materials Science and Engineering A, Volume 464, Issue 1-2, August 2007, pp.8-16

[Barnett et al. 2004], M. R. Barnett, Z. Keshavarz, A. G. Beer, D. Atwell; Acta Materialia, Volume 52, Issue 17, October 2004, pp. 5093-5103

[Barnett et al. 2009], M. R. Barnett, N. Stanford, P. Cizek, A. Beer, Z. Xuebin, Z. Keshavarz; JOM, Volume 61, Issue 8, August 2009, pp. 19-24

[Bayandorian et al. 2009], I. Bayandorian, Z. Bian, M. Xia, H. Zhang, G. M. Scamans, Z. Fan; in: TMS 2009 Annual Meeting and Exhibition, Magnesium technology, San Francisco, CA, USA, 2009, pp. 363-368 
[BCAST], Brunel Centre for Advanced Solidification Technology, Brunel University, Uxbridge, UK

[Bear 1972], J. Bear; 'Dynamics of Fluid in Porous Media', Dover Publications, New York; 1972, pp. 764

[Beck et al. 1950], P. A. Beck, P. R. Sperry, H. Hu; Journal of Applied Physics, Volume 21, Issue 5, May 1950, pp. 420-425

[Bercovici 1985], S. J. Bercovici; in: Light Metals: Proceedings of the Technical Sessions at the $114^{\text {th }}$ Annual Meeting of the Metallurgical Society of AIME, Warrendale, New York, NY, USA, 1985, pp. 1285-1299

[Berg et al. 1995], B. S. Berg, V. Hansen, P. T. Zagierski, M. L. Nedreberg, A. Olsen, J. GjØnnes; Journal of Materials Processing Technology, Volume 53, Issue 1-2, August 1995, pp. 65-74

[Bessemer 1865], H. Bessemer; 'Improvement in the manufacture of iron and steel', 1865, US Patent No. 49,053

[Bever et al. 1973], M. B. Bever, D. L. Holt, A. L. Titchener; Progress in Materials Science, Volume 17, Issue C, 1973, pp. 5-177

[Bian et al. 2009], Z. Bian, I. Bayandorian, Z. Fan; Materials Science and Technology, Volume 25, Issue 5, May 2009, pp. 599-606

[Birol 2009], Y. Birol; Journal of Materials Processing Technology, Volume 209, Issue 1, January 2009, pp. 506-510

[Bohlen et al. 2007], J. Bohlen, M.R. Nürnberg, J.W. Senn, D. Letzig, S. R. Agnew; Acta Materialia, Volume 55, Issue 6, April 2007, pp. 2101-2112

[Bradbury 1994], P. Bradbury; 'A mathematical model for the twin roll casting process', D. Phil. Thesis, University of Oxford, Department of Materials, December 1994

[Bradbury and Hunt 1995], P. J. Bradbury, J.D. Hunt; in: Proceedings of the $7^{\text {th }}$ Conference on Modelling of casting, welding and advanced solidification processes, TMS, 1995, London, UK, pp. 739-746

[Brooks 1982], C. H. Brooks; 'Heat Treatment, Structure and Properties of Nonferrous Alloys', 1st Edition, ASM, New York, 1982

[Byrne et al. 2007], C. J. Byrne, A. M. Kueck, S. P. Baker, P. H. Steen; Materials Science and Engineering A, Volume 459, Issue 1-2, June 2007, pp. 172-181

[Campbell 2003], J. Campbell; 'Castings', $2^{\text {nd }}$ edition, Elsevier/Butterworth-Heinemann, Oxford, UK, 2003, pp. 200-300

[Carslaw and Jaeger 2004], H. S. Carslaw, J. C. Jaeger; 'Conduction of heat in solids', $2^{\text {nd }}$ edition, Clarendon Press, Oxford, UK, 2004, pp. 286-287

[Chalmers 1963], B. Chalmers; Journal of Australian Institute of Metals, Volume 8, 1963, pp. 225263 
[Chapman and Wilson 1962], J. A. Chapman, D. V. Wilson; Journal of the Institute of Metals,

Volume 91, 1962, pp. 39-40

[Chen and Tsao 1999], C. P. Chen, C. -Y. A. Tsao; Materials Science and Technology, Volume 15, Issue 9, September 1999, pp. 981-985

[Chino and Mabuchi 2009], Y. Chino, M. Mabuchi; Scripta Materialia, Volume 60, Issue 6, March 2009, pp. 447-450

[Chino et al. 2006], Y. Chino, K. Sassa, A. Kamiya, M. Mabuchi; Materials Science and Engineering A, Volume 441, Issue 1-2, December 2006, pp. 349-359

[Chino et al. 2009], Y. Chino, K. Sassa, M. Mabuchi; Journal of Materials Science, Volume 44, Issue 7, April 2009, pp. 1821-1827

[Cook et al. 1995], R. Cook, P. G. Grocock, P. M. Thomas, D. V. Edmonds, J. D. Hunt; Journal of Materials Processing Technology, Volume 55, Issue 2, November 1995, pp. 76-84

[Cooper et al. 1994], P. S. Cooper, P. Fisher; in: Light Metals: Proceedings of the Technical Sessions at the $123^{\text {rd }}$ Annual Meeting of the Metallurgical Society of AIME, Warrendale, San Francisco, CA, USA, 1994, pp. 977-984

[Czerwinski and Zielinska-Lipiec 2003], F. Czerwinski, A. Zielinska-Lipiec; Acta Materialia, Volume 51, Issue 11, June 2003, pp. 3319-3332

[Dahle and StJohn 1998], A. K. Dahle, D. H. StJohn; Acta Materialia, Volume 47, Issue 1, December 1998, pp. 31-41

[Dahle et al. 2001], A .K. Dahle, Y. C. Lee, M. D. Nave, P. L. Schaffer, D. H. StJohn; Journal of Light Metals, Volume 1, Issue 1, February 2001, pp. 61-72

[Das and Fan 2003], A. Das, Z. Fan; Materials Science and Technology, Volume 19, Issue 5, May 2003, pp. 573-580

[Das et al 2002], A. Das, S. Ji, Z. Fan; Acta Materialia, Volume 50, Issue 18, October 2002, pp. $4571-4585$

[Del Valle et al. 2003], J. A. Del Valle, M.T. Pérez-Prado, O.A. Ruano; Materials Science and Engineering A, Volume 355, Issue 1-2, August 2003, pp. 68-78

[Del Valle et al. 2005], J. A. Del Valle, M.T. Pérez-Prado, O.A. Ruano; Materials Science and Engineering A, Volume 410-411, November 2005, pp. 353-357

[Dieter 1986], G. E. Dieter; 'Mechanical metallurgy', $3^{\text {rd }}$ edition, McGraw-Hill 1986, pp. 590-620

[Doherty et al. 1984], R. D. Doherty, H-I. Lee, E. A. Feest; Materials Science and Engineering, Volume 65, Issue 1, July 1984, pp. 181-189

[Duygulu et al. 2009a], O. Duygulu, S. Ucuncuoglu, G. Oktay, D. S. Temur, O. Yucel, A. A. Kaya; in: TMS 2009 Annual Meeting and Exhibition, Magnesium technology, San Francisco, CA, USA, 2009, pp. 385-390 
[Duygulu et al. 2009b], O. Duygulu, S. Ucuncuoglu, G. Oktay, D. S. Temur, O. Yucel, A. A. Kaya; in: TMS 2009 Annual Meeting and Exhibition, Magnesium technology, San Francisco, CA, USA, 2009, pp. 379-384

[Easton and StJohn 1999a], M. Easton, D. StJohn; Metallurgical and Materials Transactions A, Volume 30, Issue 6, 1999, pp. 1613-1623

[Easton and StJohn 1999b], M. Easton, D. StJohn; Metallurgical and Materials Transactions A, Volume 30, Issue 6, 1999, pp. 1625-1633

[Edmonds et al. 1991], D. V. Edmonds, J. D. Hunt, D. J. Monaghan, X. Yang, M. Yun, D. J. Browne, R. Cook, P. M. Thomas; in: Proceeding of the International Symposium on Extraction, Refining and Fabrication of Light Metals, Pergammon Press, New York, NY, 1991, pp. 257-271

[Emley 1966], E. F. Emley; 'Principles of Magnesium Technology', London, Pergamon Press; 1966. pp. 126-156, 206-223

[Emley 1976], E. F. Emley; International Metallurgical Review, Volume 21, June 1976, pp. 75-115

[Engl 2005], B. Engle; in: Proceedings of the $62^{\text {nd }}$ Annual World Magnesium Conference, IMA, Berlin, Germany, 2005, pp. 27-34

[Esaki et al. 2006], H. Esaki, Y. Watanabe, K. Ueda, H. Uto, K. Shibue; Keikinzoku / Journal of Japan Institute of Light Metals. Volume 56, Issue 5, May 2006, pp. 266-270

[Espedal and Roder 1993], A. B. Espedal, R. Roder; in: Australian-Asian-Pacific Course and Conference on Aluminium Cast House Technology: Theory \& Practice, TMS, Warrendale, Melbourne, Australia, 1993, pp. 303-319

[Essadiqi et al. 2009], E. Essadiqi, M. T. Shehata, A. Javaid, C. Galvani, G. Shen, S. Yue, R. Verma; JOM, volume 61, Issue 8, August 2009, pp. 25-28

[Fan 2002], Z. Fan; International Materials Reviews, Volume 47, Issue 2, 2002, pp. 49-85

[Fan and Liu 2005], Z. Fan, G. Liu; Acta Materialia, Volume 53, Issue 16, September 2005, pp. $4345-4357$

[Fan et al. 1999], Z. Fan, M. J. Bevis, S. Ji; 'Method and apparatus for producing semisolid metal slurries and shaped components', 1999, Patent: PCT/WO 01/21343 A1

[Fan et al. 2000], Z. Fan, S. Ji, M. J. Bevis; 'Process and Apparatus for making alloy casting', 2000, Patent: PCT/GB 01/03596

[Fan et al. 2001], Z. Fan, S. Ji, J. Zhang; Materials Science and Technology, Volume 17, Issue 7, July 2001, pp. 837-842

[Fan et al. 2006], Z. Fan, G. Liu, Y. Wang; Journal of Materials Science, Volume 41, Issue 12, June 2006, pp. 3631-3644

[Fan et al. 2009a], Z. Fan, Y. Wang, M. Xia, S. Arumuganathar; Acta Materialia, Volume 57, Issue 16, September 2009, pp. 4891-4901 
[Fan et al. 2009b], Z. Fan, M. Xia, H. Zhang, G. Liu, J. B. Patel, Z. Bian, I. Bayandorian, Y. Wang, H. T. Li, G. M. Scamans; International Journal of Cast Metals Research, Volume 22, Issue 1-4, 2009, pp. 103-107

[Ferry 2006], M. Ferry; 'Direct strip casting of metals and alloys', 1st edition, Woodhead publishing limited, Cambridge, 2006

[Figueiredo et al. 2007], R. B. Figueiredo, P. R. Cetlin, T. G. Langdon; Acta Materialia, Volume 55, Issue 14, August 2007, pp. 4769-4779

[Finke et al. 2000], S. Finke, M. Suéry, C. L. Wei; in: Proceedings of the $6^{\text {th }}$ International Conference on semi-solid processing of alloys and composites, S2P 2000, Turin, Italy, pp. 169-174

[Flemings 1974], M. C. Flemings; ‘Solidification processing', McGraw-Hill; 1974, pp. 214-262

[Flemings 1991], M. C. Flemings; Metallurgical Transactions, Volume 22A, Issue 5, May 1991, pp. 957-981

[Flemings et al. 1976], M. C. Flemings, R. G. Reik, K. P. Young; Materials Science and Engineering, Volume 25, Issue C, September 1976, pp. 103-117

[Forbord et al. 2006], B. Forbord, B. Andersson, F. Ingvaldsen, O. Austevik, J.A. Horst, I. Skauvik; Materials Science and Engineering A, Volume 415, Issue 1-2, January 2006, pp. 12-20

[Galiyev et al. 2001], A. Galiyev, R. Kaibyshev, G. Gottstein; Acta Materialia, Volume 49, Issue 7, April 2001, pp. 1199-1207

[Gäumann et al. 1997], M. Gäumann, R. Trivedi, W. Kurz; Materials Science and Engineering A, Volume 226-228, June 1997, pp. 763-769

[Gourlay and Dahle 2007], C. M. Gourlay, A. K. Dahle; Nature, Volume 445, Issue 7123, January 2007, pp. 70-73

[Greenfield 1972], P. Greenfield; 'Magnesium', Mills and Boon Limited, London, 1972, pp. 11

[Greer et al. 2000], A.L. Greer, A. M. Bunn, A. Tronche, P. V. Evans, D. J. Bristow; Acta Materialia, Volume 48, Issue 11, June 2000, pp. 2823-2835

[Guo et al. 2005], S. Guo, Q. Le, Z. Zhao, Z. Wang, J. Cui; Materials Science and Engineering A, Volume 404, Issue 1-2, September 2005, pp. 323-329

[Guo et al. 2006], S. Guo, Q. Le, Y. Han, Z. Zhao, J. Cui; Metallurgical and Materials Transactions A, Volume 37, Issue 12, December 2006, pp. 3715-3724

[Haga et al. 2006], T. Haga, H. Watari, S. Kumai; Journal of Achievements and Manufacturing Engineering, Volume 15, Issue 1-2, 2006, pp. 186-192

[Haghayeghi et al. 2008], R. Haghayeghi, Y. Liu, Z. Fan; Solid state phenomena, Volume 141143, 2008, pp. 403-408

[Hall et al. 2000], K. Hall, H. Kaufmann, A. Mundl; in: Proceedings of the $6^{\text {th }}$ International Conference on semi-solid processing of alloys and composites, S2P 2000, Turin, Italy, 2000, pp. $23-28$ 
[Hellawell 1996], A. Hellawell; in: Proceedings of the $4^{\text {th }}$ International Conference on semi-solid processing of alloys and composites, S2P 1996,, Sheffield, UK, 1996, pp. 60-65

[Hitchcock et al. 2007], M. Hitchcock, Y. Wang, Z. Fan; Acta Materialia, Volume 55, Issue 5, March 2007, pp. 1589-1598

[Huang et al. 2009], X. Huang, K. Suzuki, A. Watazu, I. Shigematsu, N. Saito; Journal of Alloys and Compounds, Volume 470, Issue 1-2, February 2009, pp. 263-268

[Humphreys and Hatherly 2004], F. J. Humphreys, M. Hatherly; 'Recrystallization and related annealing phenomena', $2^{\text {nd }}$ edition, Boston: Elsevier; 2004

[Hunt 1984], J. D. Hunt, Materials Science and Engineering, Volume 65, Issue 1, July 1984, pp. $75-83$

[Ion et al. 1982], S. E. Ion, F. J. Humphreys, S. H. White; Acta Metallurgica, Volume 30, Issue 10, October 1982, pp. 1909-1919

[Iricibar and Jin 1984], R. Iricibar, I. Jin; in: Light Metals: Proceedings of Technical Sessions at the $113^{\text {th }}$ Annual Meeting of AIME, Warrendale, TMS, Los Angeles, CA, USA, 1984, pp. 1129-1144

[Jackman et al. 2005], J. A. Jackman, J. Wood, E. Essadiqi, J. Lo, M. Sahoo, S. Xu, J. Thomson, W. Liu; Materials Science Forum, Volume 488-489, 2005, pp. 21-24

[Jäger et al. 2006], A. Jäger, P. Lukáč, V. Gärtnerová, J. Haloda, M. Dopita; Materials Science and Engineering A, Volume 432, Issue 1-2, September 2006, pp. 20-25

[Jain et al. 2008], A. Jain, O. Duygulu, D. W. Brown, C. N. Tom, S. R. Agnew; Materials Science and Engineering A, Volume 486, Issue 1-2, July 2008, pp. 545-555

[Jarry et al. 1996], P. Jarry, D. Toitot, P. -Y. Menet; in: Light Metals: Proceedings of Sessions at the $125^{\text {th }}$ TMS Annual Meeting, Warrendale, Anaheim, CA, USA, 1996, pp. 905-911

[Ji and Fan 2000], S. Ji, Z. Fan; in: Proceedings of the $6^{\text {th }}$ International Conference on semi-solid processing of alloys and composites, S2P 2000, Turin, Italy, 2000, pp. 723-728

[Ji and Fan 2002], S. Ji, Z. Fan; Metallurgical and Materials Transactions A, Volume 33, Issue 11, November 2002, pp. 3511-3520

[Ji et al. 2001], S. Ji, Z. Fan, M. J. Bevis; Materials Science and Engineering A, Volume 299, Issue 1-2, February 2001, pp. 210-217

[Ji et al. 2002], S. Ji, Z. Fan, X. Fang, S. H. Song; in: Proceedings of the $7^{\text {th }}$ International Conference on semi-solid processing of alloys and composites, S2P 2002, Tsukuba, Japan, 2002, pp. 683-688

[Jin et al. 1982], I. Jin, L. R. Morris, J. D. Hunt; Journal of Metals, Volume 34, Issue 6, June 1982, pp. 70-74

[Joly and Mehrabian 1976], P. A. Joly, R. Mehrabian; Journal of Materials Science, Volume 11, Issue 8, August 1976, pp. 1393-1418 
[Ju et al. 2005], D. -Y. Ju, H. -Y. Zhao, X. -D. Hu, K. Ohori, M. Tougo; Materials Science Forum, Volume 488-489, 2005, pp. 439-444

[Jung et al. 2007], I. -H. Jung, W. Bang, I. J. Kim, H. -J. Sung, W. -J. Park, D. Choo, S. Ahn; in: TMS 2007 Annual Meeting and Exhibition, Magnesium technology, Orlando, FL, USA, 2007, pp. 8588

[Kadiri et al. 2006], H. E. Kadiri, Y. Xue, M. F. Horstemeyer, J. B. Jordan, P. T. Wang; Acta Materialia, Volume 54, Issue 19, November 2006, pp. 5061-5076

[Kang et al. 2008], S. B. Kang, H. Chen, H. W. Kim, J. H. Cho; in: TMS 2008 Annual Meeting and Exhibition, Magnesium technology, New Orleans, LA, USA, 2008, pp. 147-151

[Kawalla et al. 2008], R. Kawalla, M. Oswald, C. Schmidt, M. Ulmann, H. -P. Vogt, N. D. Cuong; in: TMS 2008 Annual Meeting and Exhibition, Magnesium technology, New Orleans, LA, USA, 2008, pp. 177-182

[Kenney et al. 1988], M. P. Kenney, J. A. Courtois, R. D. Evans, G. M. Farrior, C. P. Kyonka, A. A. Koch, K. P. Young; 'Metals Handbook', $9^{\text {th }}$ edition, Metals Park, OH, ASM International, Volume 15, 1988, pp. 327-338

[Kim and Grugel 1992], S. Kim, R. N. Grugel; Metallurgical Transactions A, Volume 23, Issue 6, June 1992, pp. 1807-1815

[Kirkwood 1994], D. H. Kirkwood; International Materials Reviews, Volume 39, Issue 5, 1994, pp. 173-189

[Koike et al. 2003], J. Koike, T. Kobayashi, T. Mukai, H. Watanabe, M. Suzuki, K. Maruyama, K. Higashi, Acta Materialia, Volume 51, Issue 7, April 2003, pp. 2055-2065

[Kurz and Fisher 1986], W. Kurz, D. J. Fisher; 'Fundamentals of Solidification', $2^{\text {nd }}$ edition, Trans. Tech. Publications Ltd., Aedermannsdorf, 1986, Appendix 8, pp. 214-216

[Kurz et al. 2001], W. Kurz, C. Bezençon, M.Gäumann; Science and Technology of Advanced Materials, Volume 2, Issue 1, March 2001, pp. 185-191

[Lee and Huang 2004], C. J. Lee, J.C. Huang; Acta Materialia, Volume 52, Issue 10, June 2004, pp. 3111-3122

[Lee et al. 2000], Y. C. Lee, A. K. Dahle, D. H. StJohn; Metallurgical and Materials Transactions A, Volume 31, Issue 11, 2000, pp. 2895-2906

[Lee et al. 2005], J. G. Lee, S. S. Park, S. B. Lee, H. -T. Chung, N. J. Kim; Scripta Materialia, Volume 53, Issue 6, September 2005, pp. 693-697

[Lee et al. 2006], J. G. Lee, H. Lee, Y. S. Oh, S. Lee, N. J. Kim; Intermetallics, Volume 14, Issue 8-9, August 2006, pp. 987-993

[Li et al. 2007a], Z. Li, J. Dong, X. Q. Zeng, C. Lu, W. J. Ding; Materials Science and Engineering A, Volume 466, Issue 1-2, September 2007, pp.134-139 
[Li et al. 2007b], M. Li, T. Tamura, K. Miwa; Acta Materialia, Volume 55, Issue 14, August 2007, pp. $4635-4643$

[Liang and Cowley 2004], D. Liang, C. B. Cowley; JOM, Volume 56, Issue 5, May 2004, pp. $26-28$

[Liang et al. 2006], D. D. Liang, W. Borbidge, D. R. East, R. V. Allen; 'Twin roll casting of magnesium and magnesium alloys', 2006, US Patent No. 7,028,749 B2

[Lin et al. 2004], Y. Lin, K. M. McHugh, Y. Zhou, E. J. Lavernia; Metallurgical and Materials Transactions A, Volume 35, Issue 11, November 2004, pp. 3595-3603

[Lin et al. 2005], H. K. Lin, J. C. Huang, T. G. Langdon; Materials Science and Engineering A, Volume 402, Issue 1-2, August 2005, pp. 250-257

[Liu and Ghosh 2005], Y. Liu, A. K. Ghosh; in: TMS 2005 Annual Meeting and Exhibition, Magnesium technology, San Francisco, CA, USA, 2005, pp. 139-144

[Löchte et al. 2005], L. Löchte, H. Westengen, J. Rødseth; in: TMS 2005 Annual Meeting and Exhibition, Magnesium technology, San Francisco, CA, USA, 2005, pp. 247-252

[Lockyer et al. 1996], S. A. Lockyer, M. Yun, J. D. Hunt, D. V. Edmonds; Materials Characterization, Volume 37, Issue 5, November 1996, pp. 301-310

[Mabuchi et al. 1996], M. Mabuchi, K. Kubota, K. Higashi; Journal of Materials Science, Volume 31, Issue 6, 1996, pp.1529-1535

[Mabuchi et al. 1999], M. Mabuchi, K. Ameyama, H. Iwasaki, K. Higashi; Acta Materialia, Volume 47, Issue 7, May 1999, pp. 2047-2057

[Martin 1996], J. W. Martin; 'Materials for Engineering', The Institute of Materials, London, UK, 1996

[Martin et al. 1997], C. L. Martin, D. Favier, M. Suéry; International Journal of Plasticity, Volume 13, Issue 3, 1997, pp. 215-235

[Matsubara et al. 2003], K. Matsubara, Y. Miyahara, Z. Horita, T.G. Langdon; Acta Materialia, Volume 51, Issue 11, June 2003, pp. 3073-3084

[McCartney 1989], D. G. McCartney; International Materials Reviews, Volume 34, Issue 5, 1989, pp. $247-260$

[McHugh et al. 2004], K. M. McHugh, J. -P. Delplanque, S. B. Johnson, E. J. Lavernia, Y. Zhou, Y. Lin; Materials Science and Engineering A, Volume 383, Issue 1 SPEC.ISS, October 2004, pp. 96106

[McHugh et al. 2008], K. M. McHugh, Y. Lin, Y. Zhou, S. B. Johnson, J. -P. Delplanque, E. J. Lavernia; Materials Science and Engineering A, Volume 477, Issue 1-2, March 2008, pp. 26-34

[Mehrabian and Flemings 1972], R. Mehrabian, M. C. Flemings; AFS Transactions, Volume 80, 1972, pp. $173-182$ 
[Menet et al. 1997], P. -Y. Menet, R. Cayol, J. Moriceau; in: Light Metals: Proceedings of Sessions TMS Annual Meeting, Warrendale, Orlando, FL, USA, 1997, pp. 753-756

[Merchant et al. 1989], H. D. Merchant, T. Z. Kattamis, J. G. Morris; in: Continuous Casting of Non-Ferrous Metals and Alloys, TMS, Chicago, USA, 1989, pp. 1-66

[Meyers et al. 2001], M. A. Meyers, O. Vöhringer, V. A. Lubarda; Acta Materialia, Volume 49, Issue 19, November 2001; pp. 4025-4039

[Mizutani et al. 2005], Y. Mizutani, T. Tamura, K. Miwa; Materials Science and Engineering A; Volume 413-414, December 2005, pp. 205-210

[Mohri et al. 2000], T. Mohri, M. Mabuchi, M. Nakamura, T. Asahina, H. Iwasaki, T. Aizawa, K. Higashi; Materials Science and Engineering A, Volume 290, Issue 1, October 2000, pp. 139-144

[Monaghan 1993], D. J. Monaghan; 'Twin roll cast aluminium alloys', D. Phil. Thesis, University of Oxford, Department of Materials, 1993

[Monaghan et al. 1993], D. J. Monaghan, M. B. Henderson, J. D. Hunt and D. V. Edmonds; Materials Science and Engineering A, Volume 173, Issue 1-2, December 1993, pp. 251-254

[Mordike and Lukáč 2006], B. L. Mordike, P. Lukáč; In: H. E. Friedrich, B. L. Mordike (eds.) Magnesium Technology, Metallurgy, Design Data, Applications, Berlin, Springer-Verlag, 2006, pp. 63-108

[Morris 1982], L. R. Morris; in: Proceedings of the International Conference on Solidification and Casting of Metals, London, UK, 1982, pp. 218

[Mukai et al. 2001], T. Mukai, M. Yamanoi, H. Watanabe, K. Higashi; Scripta Materialia, Volume 45, Issue 1, July 2001, pp. 89-94

[Myshlyaev et al. 2002], M. M. Myshlyaev, H. J. McQueen, A. Mwembela, E. Konopleva; Materials Science and Engineering A, Volume 337, Issue 1-2, November 2002, pp. 121-133

[Nadella et al. 2008], R. Nadella, D. G. Eskin, Q. Du, L. Katgerman; Progress in Materials Science, Volume 53, Issue 3, March 2008, pp. 421-480

[Nakaura and Ohori 2005], Y. Nakaura, K. Ohori; Materials Science Forum, Volume 488-489, 2005, pp. 419-426

[Narasimhan 1979], M. C. Narasimhan, 1979, US Patent 4142571

[Nicolli et al. 2005], L. C. Nicolli, A. Mo, M. M'Hamdi; Metallurgical and Materials Transactions A, Volume 36, Issue 2, February 2005, pp. 433-442

[Ohno et al. 2006], M. Ohno, D. Mirkovic, R. Schmid-Fetzer; Acta Materialia, Volume 54, Issue 15, September 2006, pp. 3883-3891

[Park et al. 2002], S. S. Park, Y. S. Park, N.J. Kim; Metals and Materials International, Volume 8, Issue 6, December 2002, pp. 551-554

[Park et al. 2003], S. S. Park, J. G. Lee, Y. S. Park, N. J. Kim; Materials Science Forum, Volume 419-422, Issue II, 2003, pp. 599-604 
[Park et al. 2004], S.S. Park, J. G. Lee, H. C. Lee, N. J. Kim; in: TMS 2004 Annual Meeting and Exhibition, Magnesium technology, Charlotte, NC, USA, 2004, pp. 107-112

[Park et al. 2005], S. S. Park, D. H. Kang, G. T. Bae, N. J. Kim; Materials Science Forum, Volume 488-489, 2005, pp. 431-434

[Park et al. 2009a], J. P. Park, M. G. Kim, U. S. Yoon, W. J. Kim; Journal of Materials Science, Volume 44, Issue 1, January 2009, pp. 47-54

[Park et al. 2009b], S. S. Park, W. -J. Park, C. H. Kim, B. S. You, N. J. Kim; JOM, Volume 61, Issue 8, August 2009, pp. 14-18

[Pérez-prado et al. 2004], M. T. Pérez-Prado, J. A. Del Valle, O. A. Ruano; Scripta Materialia, Volume 51, Issue 11, November 2004, pp. 1093-1097

[Polmear 2006], I. J. Polmear; 'Light Alloys: from traditional alloys to nanocrystals', 4th edition, Elsevier/Butterworth-Heinemann, Oxford, 2006

[Porter and Easterling 1992], D. A. Porter, K. E. Easterling; 'Phase transformations in metals and alloys', $2^{\text {nd }}$ edition, Chapman and Hall, London, 1992, pp. 139, 185

[Qin and Fan 2000], R. S. Qin, Z. Fan; in: TMS 2000 Annual Meeting and Exhibition, Magnesium technology, Turin, Italy, 2000, pp. 819-824

[Quested and Greer 2004], T. E. Quested, A. L. Greer; Acta Materialia, Volume 52, Issue 13, August 2004, pp. 3859-3868

[Quested and Greer 2005], T. E. Quested, A. L. Greer; Acta Materialia, Volume 53, Issue 17, October 2005, pp. 4643-4653

[Robson et al. 2009], J. D. Robson, D. T. Henry, B. Davis; Acta Materialia, Volume 57, Issue 9, May 2009, pp. 2739-2747

[Sahai and Saxena 2002], Y. Sahai, A. Saxena; in: Light Metals: Proceedings of Sessions TMS Annual Meeting, Warrendale, Seattle, WA, USA, 2002, pp. 643-650

[Saito et al. 1999], Y. Saito, H. Utsunomiya, N. Tsuji, T. Sakai; Acta Materialia, Volume 47, Issue 2, 1999, pp. 579-583

[Sarioğlu and Thevoz 2003], K. Sarioğlu, P. Thevoz; in: Light Metals: Proceedings of the Technical Sessions presented by the TMS Aluminium Committee at the $132^{\text {nd }}$ TMS Annual Meetings, San Diego, CA, USA, 2003, pp. 747-751

[Shibata et al. 2006], H. Shibata, S. Itoyama, Y. Kishimoto, S. Takeuchi, H. Sekiguchi; ISIJ International, Volume 46, Issue 6, 2006, pp. 921-930

[Sitdikov and Kaibyshev 2001], O. Sitdikov, R. Kaibyshev; Materials Transactions, Volume 42, Issue 9, 2001, pp. 1928-1937

[Spencer et al. 1972], D. B. Spencer, R. Mehrabian, M. C. Flemings; Metallurgical Transactions, Volume 3, Issue 7, June 1972, pp. 1925-1932 
[Spittle 2006], J. A. Spittle; International Materials Reviews, Volume 51, Issue 4, August 2006, pp. 247-269

[Stefanescu 2008], D. M. Stefanescu; 'Science and engineering of casting solidification', $2^{\text {nd }}$ edition, 2008, Springer, pp. 144-160

[StJohn et al. 2005], D. H. StJohn, M. Qian, M.A. Easton, P. Cao, Z. Hildebrand; Metallurgical and Materials Transaction A, Volume 36, Issue 7, July 2005, pp. 1669-1679

[Sumitomo et al. 2000], T. Sumitomo, D. H. StJohn, T. Steinberg; Materials Sciene and Engineering A, Volume 289, Issue 1, September 2000, pp. 18-29

[Sun et al. 2006], N. Sun, B. R. Patterson, J. P. Suni, E. A. Simielli, H. Weiland, L. F. Allard; Materials Science and Engineering A, Volume 416, Issue 1-2, January 2006, pp. 232-239

[Takatani et al. 2000], H. Takatani, Ch. -A. Gandin, M. Rappaz; Acta Materialia, Volume 48, Issue 3, February 2000, pp. 675-688

[Tan and Tan 2003], J. C. Tan, M.J. Tan; Materials Science and Engineering A, Volume 339, Issue 1-2, January 2003, pp. 81-89

[Thomas 2003], P. Thomas; in: 'Solidification and casting', B. Cantor, K. O’Reilly (eds.), Institute of physics publishing, 2003, pp. 26-47

[Tsuji et al. 2003], N. Tsuji, Y. Saito, S. -H. Lee, Y. Minamino; Advanced Engineering Materials, Volume 5, Issue 5, May 2003, pp. 338-344

[Thyssenkrupp 2009], Thyssenkrupp MgF; http://thyssenkruppmgf.com/de/anwendungen/ index.jsp, December 2009

[Tzimas and Zavaliangos 1999], E. Tzimas, A. Zavaliangos; Acta Materialia, Volume 47, Issue 2, 1999, pp. 517-528

[Valer et al. 1998], J. Valer, F. Saint-Antonin, P. Menses, M. Suéry; in: Proceedings of the $5^{\text {th }}$ International Conference on semi-solid processing of alloys and composites, S2P 1998, Colorado, USA, 1998, pp. 3-10

[Valiev et al. 1991], R. Z. Valiev, N. A. Krasilnikov, N. K. Tsenev; Materials Science and Engineering A, Volume 137, Issue C, May 1991, pp. 35-40

[Veldman et al. 2001], N. L. M. Veldman, A. K. Dahle, D. H. StJohn, L. Arnberg; Metallurgical and Materials Transactions A, Volume 32, Issue 1, 2001, pp. 147-155

[Vogel et al. 1979], A. Vogel, R. D. Doherty, B. Cantor; in: 'Solidification of Casting of Metals', The Metals Society, London, 1979, pp. 518-525

[Wang et al. 2003a], R. M. Wang, A. Eliezer, E. M. Gutman; Materials Science and Engineering A, Volume 344, Issue 1-2, March 2003, pp. 279-287

[Wang et al. 2003b], R. M. Wang, A. Eliezer, E. M. Gutman; Materials Science and Engineering A, Volume 355, Issue 1-2, August 2003, pp. 201-207 
[Wang et al. 2006], Y. Wang, G. Liu, Z. Fan; Acta Materialia, Volume 54, Issue 3, February 2006, pp. 689-699

[Wang et al. 2007a], Y. Wang, G. Liu, F. Wang, Z. Fan; in: Proceedings of the $5^{\text {th }}$ Decennial International Conference on solidification processing, Sheffield, UK, 2007, pp. 600-605

[Wang et al. 2007b], Y. Wang, X. Zeng, W. Ding, A. A. Luo, A. K. Sachdev; Metallurgical and Materials Transactions A, Volume 38, Issue 6, June 2007, pp. 1358-1366

[Watanabe et al. 2007], H. Watanabe, T. Mukai, K. Ishikawa; Journal of Materials Processing Technology, Volume 182, Issue 1-3, February 2007, pp. 644-647

[Watari et al. 2004], H. Watari, K. Davey, M. T. Rasgado, T. Haga, S. Izawa; Journal of Materials Processing Technology, Volume 155-156, Issue 1-3, November 2004, pp. 1662-1667

[Watari et al. 2007], H. Watari, T. Haga, N. Koga, K. Davey; Journal of Materials Processing Technology, Volume 192-193, October 2007, pp. 300-305

[Wechsler 2003], R. Wechsler; Scandinavian Journal of Metallurgy, Volume 32, Issue 1, February 2003, pp. 58-63

[Wei et al. 2003], Y. H. Wei, Q. D. Wang, Y. P. Zhu, H. T. Zhou, W. J. Ding, Y. Chino, M. Mabuchi; Materials Science and Engineering A, Volume 360, Issue 1-2, November 2003, pp. 107-115 [Westengen and Nes 1984], H. Westengen, K. Nes; in: Light Metals: Proceedings of the Technical Sessions at the $113^{\text {th }}$ Annual Meeting of the Metallurgical Society of AIME, Warrendale, Los Angeles, CA, USA, 1984, pp. 1111-1127

[Xia and Tausig 1998], K. Xia, G. Tausig; Materials Science and Engineering A, Volume 246, Issue1-2, May 1998, pp. 1-10

[Xia et al. 2009], M. Xia, Y. Wang, H. Li, S. Arumuganathar, Y. Zuo, G. M. Scamans, Z. Fan; in: TMS 2009 Annual Meeting and Exhibition, Magnesium technology, San Francisco, CA, USA, 2009, pp. $135-140$

[Yamashita et al. 2001], A. Yamashita, Z. Horita, T. G. Langdon; Materials Science and Engineering A, Volume 300, Issue 1-2, February 2001, pp. 142-147

[Yang and Ghosh 2006], Q. Yang, A.K. Ghosh; Acta Materialia, Volume 54, Issue 19, November 2006, pp. 5147-5158

[Yang et al. 2005], C. Yang, P. Ding, D. Zhang, F. Pan; Materials Science Forum, Volume 488489, 2005, pp. 427-430

[Yun et al. 2000], M. Yun, S. Lockyer, J. D. Hunt; Materials Science and Engineering A, Volume 280, Issue 1, March 2000, pp.116-123

[Yurko et al. 1999], J. A. Yurko, X. P. Niu, I. Pinwill; Journal of Materials Science Letters, Volume 18, Issue 22, November 1999, pp. 1869-1870

[Zapuskalov 2003], N. Zapuskalov; ISIJ International, Volume 43, Issue 8, 2003, pp. 1115-1127 
[Zeng et al. 2009], J. Zeng, R. Koitzsch, H. Pfeifer, B. Friedrich; Journal of Materials Processing Technology, Volume 209, Issue 5, March 2009, pp. 2321-2328

[Zhan et al. 2007], M. Y. Zhan, Y. Y. Li, W. P. Chen, W. D. Chen; Journal of Materials Science, Volume 42, Issue 22, November 2007, pp. 9256-9261

[Zhang et al. 2005], M. X. Zhang, P. M. Kelly, M. Qian, J. A. Taylor; Acta Materialia, Volume 53, Issue 11, June 2005, pp. 3261-3270 